\title{
Interrogative words and content questions in Tundra Nenets
}

\author{
Nikolett Mus \\ A $\mathrm{PhD}$ dissertation submitted for the degree of Doctor of Philosophy of the \\ University of Szeged \\ University of Szeged \\ Doctoral School in Linguistics \\ Uralic Studies PhD Programme
}

Supervisor: Beáta Wagner-Nagy, Prof. Dr.

Szeged, 2015 
This page intentionally left blank 


\section{Acknowledgements}

The story of this dissertation began at the University of Szeged in 2001, when I missed a Finnish course, which was obligatory at the first year of Hungarian studies. Instead of Finnish I had to choose any other "related" language such as Udmurt, Mordvin or Nenets. At that time, I was reading a series of books written by Margit Sandemo. A really exciting part of this series is set in Siberia among Enets characters. I did not think the difference could be great between Nenets and Enets, therefore I decided to attend the Nenets language course held by Erika Körtvély. The course aroused my interest towards Samoyed linguistics and turned my attention to Samoyed syntax which was a less described field of study at that time. I owe special thanks to Erika who became my advisor later. I feel very fortunate to have had such a great teacher.

I definitely have to thank to my supervisor, Beáta Wagner-Nagy, for taking on my research. She accompanied the developement of this dissertation and her comments were useful in writing. I hope that our work will continue in the future. In addition, I thank to my opponents for the first, departmental, defence, Anna Gazdik and Valentin Gusev, who provided extremely helpful reviews about the previous version of this work. I also owe thanks to my boss, Marianne Bakró-Nagy, as well as, to my colleagues at the Research Institute for Linguistics, Hungarian Academy of Sciences. I am grateful to Mária Sipos, Zsuzsa Duray, Csilla Horváth and Zsuzsa Várnai for having read various parts of this work and proposing changes and corrections.

I am grateful to Veronika Hegedüs, who read this dissertation and corrected my English. Without her comments this study would be much less.

Furthermore, I would like to thank Evdokija Lampay and Elena Evay for providing data on Tundra Nenets negation and for filling in my questionnaire whose parts have also been used for this dissertation. In addition, I would like to thank Oksana Dobzhanskaya for her intercession.

I am also thankful to Tom Blauwendraat for helping me in writing the PERL script.

For the funding of my study I thank the Eötvös Scholarship of the Hungarian State.

My dissertation could not have been realised without Barbara Egedi, who has constantly helped, inspired and encouraged me. She provided me with valuable feedback in all aspects of my work. Our late-night discussions illuminated me and helped me to answer thousands of questions. In the course of our work she became my best friend. I cannot be grateful enough for her support and for all of those cunning plans we made together.

I also would like to thank friends, especially Bori Németh, Eszter Simon and Dávid Takács. Many other people have contributed to the dissertation in its current state, to all of whom I would like to express my gratitude.

Finally, I would like to express my deepest gratitude to my family: to my mom who supports me in every conceivable way and who encouraged me not to give up anything. I am also grateful to my sister who always believed in me more than I have. I am very glad for having her. Finally, thanks go to my brother-in-law, János, for being the member of this family. This dissertation is dedicated to my family. 


\section{Contents}

Acknowledgements $\quad$ iii

List of abbreviations $\quad$ vi

1. Introduction 1

2. The Tundra Nenets language 5

2.1. Demography and ethnography 6

2.2. Writing system, transcription, glossing conventions 12

2.3. The main typological features of Tundra Nenets 14

2.4. Previous research on (Tundra) Nenets and Samoyedic languages 26

3. Data, sources and methodology 31

3.1. Preliminary considerations $\quad 31$

3.2. Sampling frame $\quad 33$

3.2.1. Recorded texts $\quad 35$

3.2.2. Imagined texts 36

3.2.2.1. Phrasebooks 36

$\begin{array}{ll}\text { 3.2.2.2. Methodological handbooks } & 37\end{array}$

3.2.2.3. Reading books 38

3.2.2.4. Textbooks 39

3.3. Data collection strategies $\quad 41$

4. The subject of the study 43

4.1. Speech act distinctions $\quad 44$

4.2. The subtypes of interrogative clauses $\quad 47$

4.3. Content questions $\quad 52$

4.4. Defining the analysed constructions in Tundra Nenets 59

4.5. Previous research on Tundra Nenets (content) questions 64

4.6. Research questions $\quad 69$

5. The lexico-semantics of interrogative words $\quad 70$

5.1. Non-selective interrogative words $\quad 71$

5.1.1. Possessor $\quad 74$

5.1.2. Comitative and instrument 74

$\begin{array}{ll}\text { 5.1.3. Beneficiary and goal } & 76\end{array}$

$\begin{array}{ll}\text { 5.1.4. Non-human versus selection/quality } & 77\end{array}$

$\begin{array}{ll}\text { 5.1.5. Non-human versus reason } & 79\end{array}$

$\begin{array}{ll}\text { 5.2. Selective interrogative words } & 79\end{array}$

5.2.1. The non-restricted selective interrogative word 80

5.2.2. The restricted selective interrogative word 81

5.3. The qualitative interrogative word $\quad 82$

5.4. The interrogative size specification $\quad 83$

$\begin{array}{ll}\text { 5.5. The quantitative interrogative word } & 84\end{array}$

5.5.1. The interrogative category of rank 85

5.5.2. The subspecification of interrogative time category 85

$\begin{array}{ll}\text { 5.6. The interrogative place specification } & 86\end{array}$

5.7. The interrogative time specification $\quad 88$

5.8. The interrogative manner specification $\quad 89$

5.9. Other semantic categories $\quad 89$

6. The parts-of-speech categories of interrogative words 91

6.1. The interrogative pronouns 93

6.1.1. Interrogative pronouns as constituents of the main clause 94

6.1.2. Interrogative pronouns as complements of phrases 103 
6.1.3. The attributive use of the non-human interrogative pronoun 105

6.1.4. The adverbial use of the non-human interrogative pronoun 107

6.2. The interrogative determiners 109

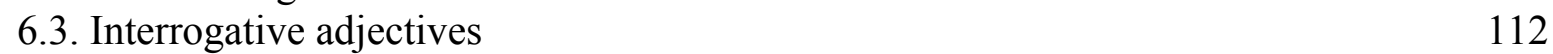

$\begin{array}{ll}\text { 6.4. Interrogative quantifiers } & 115\end{array}$

$\begin{array}{ll}\text { 6.5. Interrogative adverbs } & 118\end{array}$

$\begin{array}{lr}\text { 6.5.1. Sentential interrogative adverbs } & 119\end{array}$

$\begin{array}{lr}\text { 6.5.2. The predicational interrogative adverb } & 122\end{array}$

7. The syntactic position of interrogative phrases $\quad 126$

$\begin{array}{lr}\text { 7.1. Intransitive content questions } & 132\end{array}$

7.1.1. Existential content questions 146

$\begin{array}{ll}\text { 7.1.2. Predicative possession expressed by content questions } & 149\end{array}$

7.2. Transitive content questions 153

7.3. Content questions with nonverbal predicates 169

7.3.1. Content questions with nominal predicates: equative and inclusive constructions

174

7.3.2. Predicative possession with definite possessed item expressed by content questions

7.3.3. Content questions with adjectival predicates 182

$\begin{array}{lr}\text { 7.3.4. Content questions with quantifier predicates } & 183\end{array}$

$\begin{array}{ll}\text { 7.3.5. Locative predicates expressed by content questions } & 184\end{array}$

$\begin{array}{ll}\text { 7.3.6. Temporary possession expressed by content questions } & 188\end{array}$

$\begin{array}{ll}\text { 7.3.7. Content questions with temporal predicates } & 188\end{array}$

7.3.8. Content questions with manner predicates 189

8. Conclusions 191

$\begin{array}{ll}\text { List of references } & 194\end{array}$ 


\section{List of abbreviations}

\section{Abbreviations used in the glosses}

$\begin{array}{llll}1 & \text { first person } & \text { IMPF } & \text { imperfect } \\ 2 & \text { second person } & \text { IND } & \text { indicative mood } \\ 3 & \text { third person } & \text { INDF } & \text { indefinite } \\ \text { ABL } & \text { ablative } & \text { INST } & \text { instrumental } \\ \text { ACC } & \text { accusative } & \text { INT } & \text { interrogative mood } \\ \text { ADJ } & \text { adjective } & \text { LIM } & \text { limitative } \\ \text { AN } & \text { action nominal } & \text { LOC } & \text { locative } \\ \text { AOR } & \text { aorist } & \text { NOM } & \text { nominative } \\ \text { BEN } & \text { benefactive } & \text { NARR } & \text { narrative } \\ \text { CAR } & \text { caritive } & \text { NEG.AUX } & \text { negative auxiliary } \\ \text { CNG } & \text { connegative } & \text { NEG.EX } & \text { negative existential verb } \\ \text { CO } & \text { linking element } & \text { NOM } & \text { nominative } \\ \text { COM } & \text { comitative } & \text { OBJ } & \text { objective conjugation } \\ \text { COMP } & \text { comparative } & \text { OBL } & \text { oblique } \\ \text { CONT } & \text { continuative } & \text { ORD } & \text { ordinal number } \\ \text { CVB } & \text { converb } & \text { PCP } & \text { participle } \\ \text { DAT } & \text { dative } & \text { PL } & \text { plural } \\ \text { DEF } & \text { definite } & \text { PROB } & \text { probabilitive } \\ \text { DIM } & \text { diminutive } & \text { PROS } & \text { prosecutive } \\ \text { DU } & \text { dual } & \text { PST } & \text { past } \\ \text { EMP } & \text { emphatic clitic } & \text { PX } & \text { possessive suffix } \\ \text { ESS } & \text { essive } & \text { REFL } & \text { reflexive } \\ \text { FREQ } & \text { frequentative } & \text { SEL } & \text { selective } \\ \text { FUT } & \text { future } & \text { SG } & \text { singular } \\ \text { GEN } & \text { genitive } & \text { SUP } & \text { supine } \\ \text { GER } & \text { gerund } & \text { TR } & \text { transitive } \\ \text { HAB } & \text { habitual } & \text { VX } & \text { verbal agreement suffix } \\ \text { HORT } & \text { hortative } & & \\ & & & \end{array}$

\section{Abbreviations used in the text}

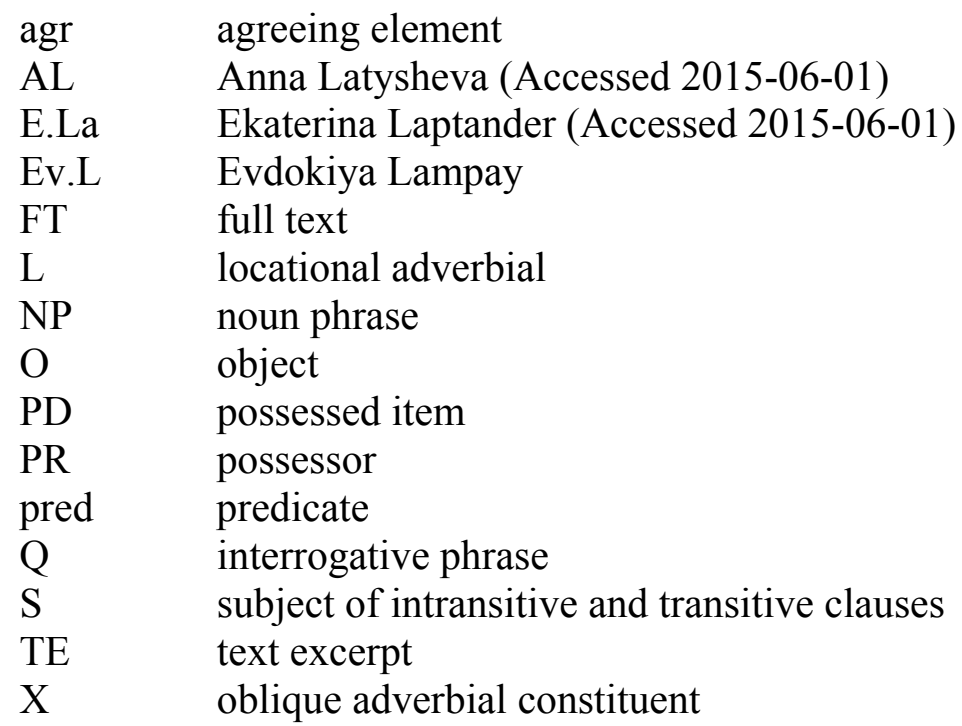


$\mathrm{V} \quad$ finite verb

VT Valentina Taleeva (Accessed 2015-06-01) 


\section{Introduction}

The aim of this study is to provide a description of Tundra Nenets (Northern Samoyedic, Uralic) content questions. Tundra Nenets is an indigenous, endangered, minority language spoken in the Russian Federation. The language belongs to the Northern Samoyedic group of the Uralic language family. Although a significant number of linguistic description of Tundra Nenets may, at first sight, appear, the language can be considered as a poorly documented and described language compared with the other Samoyedic or Finno-Ugric languages. This is particularly true for the syntax of Tundra Nenets, since there are two grammars available which focus on the description and analysis of the Tundra Nenets clauses (see Tereshchenko 1973 and Nikolaeva 2014). Despite the fact that these grammars describe the basic grammar of the main clause-types found in Tundra Nenets, comprehensive analyses of content questions are not provided. In addition, there are grammar books (e.g. Kupriyanova et al. 1957, Almazova 1961) used in primary schools, which do not satisfy the criteria for modern linguistic descriptions. These sources in question, furthermore, may provide the results of analyses based on historical data since the investigations summarised were carried out at least 50 years ago. In summary, my main aim is to remedy the deficiencies in the literature in respect of content questions in Tundra Nenets.

Content questions are treated here as single wh-interrogatives, i.e. content questions which have only a single interrogative word. Traditionally, content questions are described as questions which (i) require a specific answer other than 'Yes/No' and (ii) contain an interrogative phrase (cf. Dryer 2013a). The set of the interrogative words seems to be universal in the known languages, or at least there is a set of elements that is used in content questions for substituting unknown information. Studies on interrogatives usually discuss inherent properties of interrogative words that may vary from language to language. For instance, it is language-specific, which semantic gaps are encoded by interrogative words (see e.g. Cysouw 2004; 2005; Mackenzie 2008). Additionally, the way in which the available semantic categories are encoded in a language may also significantly differ across languages. A further aspect of interrogative words usually discussed (e.g. Siemund 2001; Schachter \& Shopen 2007; Velupillai 2010) is the grammatical categories of the interrogative words, i.e. what parts-of-speech categories they belong to. The presence or absence of a given category in a given language cannot be pressupposed. Another typical criterion discussed concerning content questions is the syntactic position of the interrogative words (see e.g. Greenberg 
1966; Siemund 2001; König \& Siemund 2007; Dryer 2013a). These language-specific distinctions above raise the following questions as regards Tundra Nenets interrogatives:

(i) What meanings are encoded in the set of Tundra Nenets interrogative words? How are the available semantic categories encoded in Tundra Nenets? Which lexemes are simplex and which are compound (or phrases) within the synchronic structure of the language? What parts are compound lexemes made from? Which categories use the same lexemes?

(ii) Which word classes do Tundra Nenets interrogative words belong to? Do the interrogative words form a grammatically homogenous set? What kind of inflectional categories are there available for the interrogative words? What is the distribution of the different interrogative words? What kind of syntactic functions can be filled by interrogative words in Tundra Nenets?

(iii) What is the position of interrogative words in Tundra Nenets? Is there a dedicated syntactic position available for interrogative phrases? In addition, is there only one available syntactic position for Tundra Nenets interrogatives or are there several? In other words, does Tundra Nenets allow interrogative phrases to occur in various structural positions? Do the interrogative phrases appear in positions other than the expected ones only under special circumstances? What are these special circumstances?

Although, there are proposals which attempt to answer the questions in (ii) and/or some of those in (iii), the questions in (i) have not been addressed at all.

In the literature (see e.g. Kupriyanova et al. 1957; Hajdú 1968; Tereshchenko 1973; Salminen 1998; Burkova et al. 2010; Nikolaeva 2014; etc.), Tundra Nenets interrogative words are either categorized as pronouns, even though not every element of the set shares the same grammatical properties, or the categories of interrogative pronouns, adjectives, quantifiers, determiners, adverbs and verbs are identified but the descriptions do not provide analyses of the semantic, morphological and/or distributional differences among these interrogative elements. In addition, Tundra Nenets is said to be a so-called in situ language, which does not have a special position for its interrogative words (see e.g. Salminen 1998). However, some descriptions (e.g. Tereshchenko 1973; Nikolaeva 2014) propose more than one available syntactic position for Tundra Nenets interrogative words. The present study aims at answering the questions raised in (i)-(iii) above. 
The research has been carried out on a closed data set representing the written version of the Tundra Nenets language. The data set originates from published sources, which were compiled on the basis of pre-specified criteria (for a detailed description see Chapter 3). One of these criteria concerns the historical aspect of the data. Namely, texts collected before the 1960s are excluded from the set. This arbitrary decision has to be made in order to ensure the historical uniformity of the data. The available texts after the 1960s constitute more than 600,000 tokens. This amount of data is considered sufficient for the purpose of describing the content questions.

A number of grammatical features discussed in the present dissertation may also be characteristics of other (Northern) Samoyedic, Finno-Ugric, Turkic, etc. languages. In addition, a comparative analysis of the expression of content interrogatives may bring new perspectives on interrogatives and provide valuable insight for linguists working on questions. This analysis would provide new perspectives for the languages spoken in Siberia, e.g. Forest Nenets, Enets, Nganasan, Selkup, Khanty, Mansi, Dolgan, Ket, etc., in particular. However, the structure of content interrogatives is not/barely described in the languages in question. Furthermore, not many annotated corpora exist for the target languages. Therefore, this investigation and comparison may be beyond the scope of the present study. In addition, content questions are discussed in many other Uralic languages spoken in countries other than Russia, e.g. Hungarian, Finnish, Estonian. Nevertheless, the methodology of comparison of these languages and Tundra Nenets does not appear to have any basis in fact. To conclude, the analysis of this dissertation holds only for Tundra Nenets, consequently other Uralic, Turkic, Yeniseic, etc., languages will not be affected.

The dissertation is organized as follows. Chapter 2 provides a description of the demography and ethnography of Tundra Nenets, as well as, of its writing system, transcription, glossing conventions. Furthermore, the chapter gives a general overview of the syntactic and morphosyntactic features of Tundra Nenets that are relevant for the present study. Finally, Chapter 2 reviews the literature on (Tundra) Nenets and Samoyedic languages in general. Chapter 3 concentrates on the primary data and the corpus. In addition, certain considerations and data collection strategies are discussed. Chapter 4 is an overview of the general literature on interrogatives from a typological point of view. The analysed constructions are introduced, and several research questions are formulated. At the same time, the chapter excludes those constructions which do not have relevancy of the study: polar and alternative interrogatives, echo questions, relative and indefinite pro-forms, compound clauses, negated clauses, multiple interrogatives, interrogative mood marker and interrogative 
verb. As the study is based on written sources, interrogative intonation cannot be examined either. Chapter 5 provides the lexico-semantic categorization of Tundra Nenets interrogative words. Chapter 6 discusses the grammatical properties of Tundra Nenets interrogative words. Chapter 7 examines the syntactic position of interrogative phrases in intransitive, transitive and nonverbal questions. Chapter 8 sums up the findings of this thesis. 


\section{The Tundra Nenets language}

The chapter both provides an orientation to previous literature concerning the ethnolinguistic situation of the Tundra Nenets language and summarizes certain grammatical characteristics of the language. This so-called guidance is necessary to clarify certain theoretical questions found in the literature, and to fill the missing information gaps relating to the current status of the language.

The chapter contains the following Sections. $\$ 2.1$ introduces the genetic affiliation of Tundra Nenets and discusses some difficulties concerning its position within the (Northern) Samoyedic branch of the Uralic language family. Within the frame of this genetic classification, the closest linguistic relatives of Tundra Nenets and their relation to each other will also be dicussed. Afterwards, the traditional areas of habitation and the dialectal division of Tundra Nenets will be presented, which is affected by the geographical location of the speakers. This subsection includes a brief account of the demographic and ethnographic situation existing in the traditional territories of Tundra Nenets speakers with respect to the presence of other (non-Uralic) indigenous minorities. Additionally, the current sociolinguistical and demographical situation of the Tundra Nenets language will also be considered. $\$ 2.2$ deals with literacy and writing system of Tundra Nenets. Although there were intentions to create a standard literary language of (Tundra) Nenets already in the early 1930s, the standardisation processes have not been finished until today. While one may expect a standard written language used for schoolbooks, this language is not unified and it may differ in certain types of printed registers. The goal of this subsection is to discuss the decisions made in this dissertation in order to present the examples of the Tundra Nenets language. Additionally, the glossing conventions used will be briefly introduced. $\$ 2.3$ provides an overview of some basic typological characteristics of Tundra Nenets, such as the typical grammatical features of nouns, adjectives, adverbs and verbs. In addition, the internal structure of the phrases and the correlation between the basic word order and the order of minor elements will also be discussed. The description here is not concerned either with the phonological or with the phonetic characteristics of the language because these are of little relevance for the present study. The typological description in $\$ 2.3$ does not aim at giving a comprehensive grammatical description or at discussing all grammatic features that may be characteristic for Tundra Nenets. Note that only those phenomena will be introduced here that have relevance for the present discussion. Finally, $\$ 2.4$ presents an overwiev of previous research on (Tundra) Nenets and Samoyedic languages including the current research trends. 


\subsection{Demography and ethnography}

Tundra Nenets is an endangered Northern Samoyedic (Uralic) language. The Samoyedic languages are considered to be one of the two branches of the Uralic language family. Traditionally, the Samoyedic branch is further devided into two sub-branches: Northern and Southern Samoyedic. This traditional classification is illustrated in Figure 1.

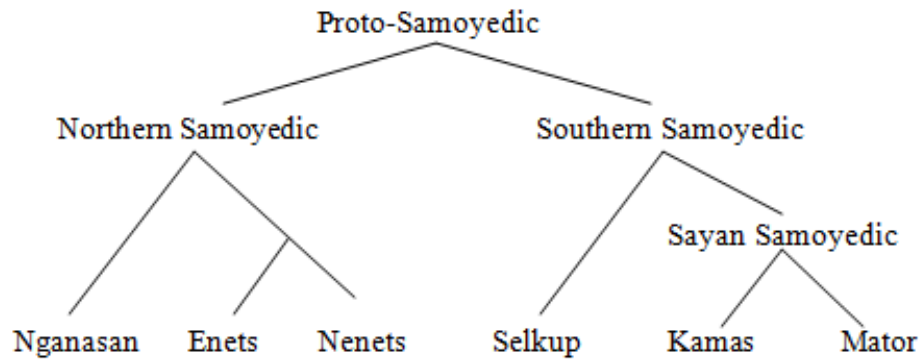

Figure 1. The traditional classification of Samoyedic languages (source: Hajdú 1966: 14)

This classification has been challenged in recent years as it is more likely an area-based division of the Samoyedic languages influenced by secondary language contacts (see Helimski 1982 a.o.). A new taxonomy is provided, for example, by Janhunen (1998: 459), illustrated in Figure 2.

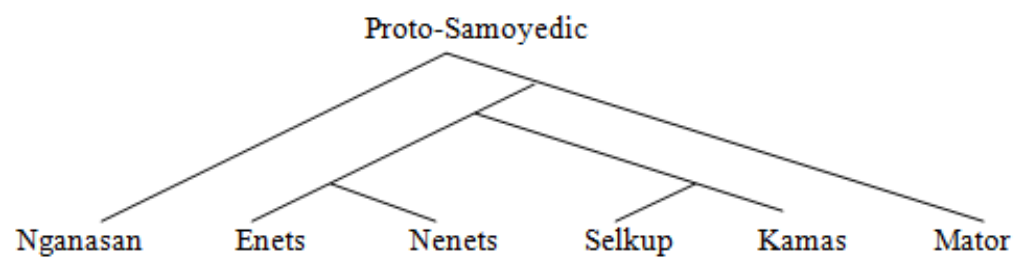

Figure 2. Janhunen's classification of Samoyedic languages (1998)

(source: Janhunen 1998: 459)

Janhunen (1998) assumes two endpoints of the Samoyedic languages, Nganasan and Mator, and situates the remaining Samoyedic languages as a continuum between these two endpoints (for the detailed discussion of this topic see e.g. Janhunen 1998: 458-459 and Wagner-Nagy 2011: 1-4). 
A somewhat different taxonomy provided by Helimski (2005) assumes secondary contacts among the Samoyedic languages caused by migrations after the dissolution of the primary language units. Figure 3 demonstrates this classification:

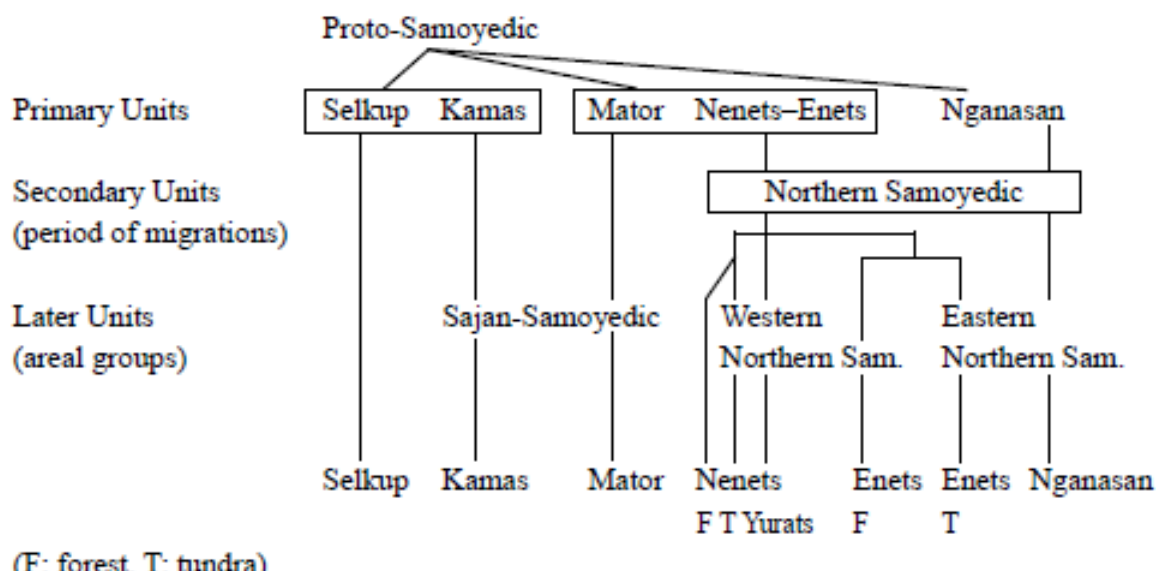

Figure 3. Helimski's classification of Samoyedic languages (2005)

(source: Wagner-Nagy 2011:2)

These new taxonomies illustrated in Figure 2 and 3 do not question the position of the (Tundra) Nenets language within the Samoyedic group and do not modify the relation of (Tundra) Nenets to its closest relatives. As the internal classification of Samoyedic languages within the language family and the (secondary) areal contacts do not have any relevance for the present study, the traditional classification will be followed here. Thus, (Tundra) Nenets together with Enets and Nganasan are treated here as being Northern Samoyedic languages.

The Samoyedic languages are traditionally devided into further dialectal groups and (sub)dialects (cf. Tereshchenko 1993: 326-343; Wagner-Nagy 2011: 6-9). Tundra and Forest Nenets languages are usually considered in the literature as being the two so-called dialectal groups of the Nenets language. Nevertheless, these language groups show significant differences as regards their phonological and lexical properties, as well as, their grammatical structures (for further details, see e.g. Hajdú 1968: 17-20). Due to the many significant differences between these two groups it makes sense to consider them as separate languages (see, for instance, the grammars of Tundra Nenets provided by Tereshchenko 1956, Hajdú 1968; Salminen 1998; etc., additionally the Forest Nenets grammatical descriptions of, for example, Verbov 1973; Sammallahti 1974; Popova 1978; a.o.).

The traditional territory where the Tundra Nenets language is spoken is located in the North-Eastern part of Europe and in the North-Western part of Siberia. Speakers live in three 
major administrative districts, in so-called Okrugs, of the Russian Federation. These are the Nenets District, the Yamal Nenets District and the Taymyr Municipal District. Additionally, a few more groups of speakers can sporadically be found in the Khanty-Mansi Autonomous District, in the Komi Republic, and in the Murmansk region. Map 1 shows the regions of the Russian Federation in which the Tundra Nenets language is spoken.

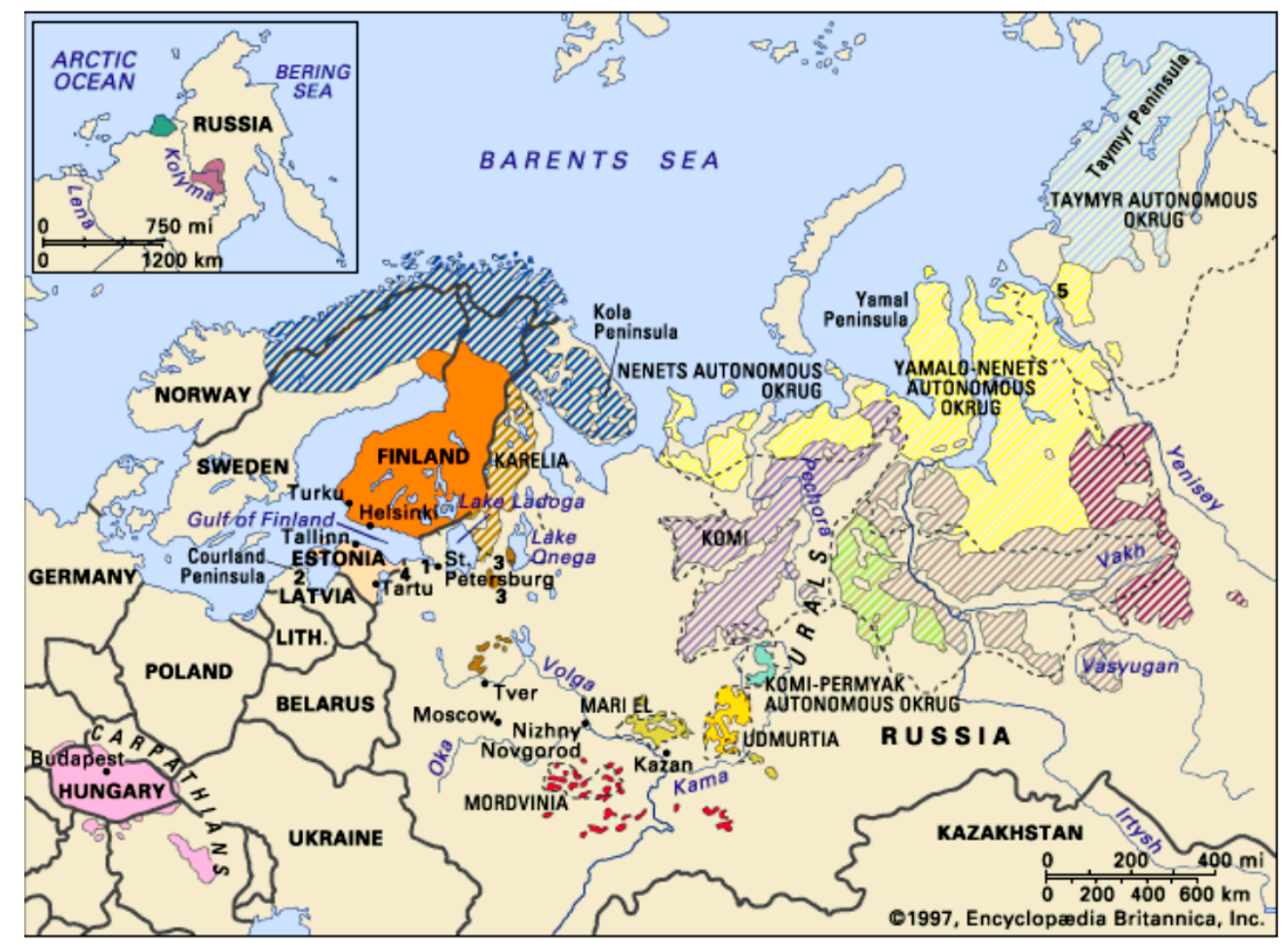

Map 1. The (Tundra) Nenets-speaking area of the Russian Federation (source: Encyclopaedia Britannica)

Despite the fact that Tundra Nenets is considered to be one of the many endangered indigenous languages in the Russian Federation, this language has still the largest number of speakers within the Northern Samoyedic language group. Table 1 illustrates the demographical changes and the number of speakers of Nenets in the past five decades.

Table 1. The demography and the number of Nenets speakers

\begin{tabular}{lccccc}
\hline Year & $\mathbf{1 9 7 0}$ & $\mathbf{1 9 7 9}$ & $\mathbf{1 9 8 9}$ & $\mathbf{2 0 0 2}$ & $\mathbf{2 0 1 0}$ \\
\hline Demography & 28,487 & 27,294 & 34,190 & 41,302 & 44,640 \\
Speakers & 23,844 & 22,081 & 26,730 & 31,311 & 21,926 \\
Rate & $83,7 \%$ & $80,9 \%$ & $78,18 \%$ & $75,8 \%$ & $49,11 \%$ \\
\hline \multicolumn{5}{c}{ (based on Dudeck 2013: 132) }
\end{tabular}


According to the latest population Census of the Russian Federation (2010) there are 21,926 Nenets speakers, which is about $50 \%$ of the total number of the 43,777 people who identified themselves as Nenets. The census, however, does not differentiate between Tundra and Forest Nenets languages. Volzhanina (2007: 143-154) provides data about the number of Forest Nenets speakers. This was less than 2,000 people in 2002. Consequently, it can be estimated that there are less than 20,000 people who speak Tundra Nenets as their mother tongue.

As evidenced by Table 1, there is an increase in the number of people who regard themselves as Nenets in the past two decades. As Dudeck (2013: 131) states, this tendency is caused by the "affirmative measures taken by the state" (Dudeck 2013: 131). Besides, it is also frequent that people name their heritage language as their mother tongue, even though they do not speak the given language anymore (cf. Pakendorf 2010: 714).

The official state language of the Russian Federation is the Russian language, which is predominantly used in the domain of everyday life and education of Tundra Nenets people. Besides the Russian language, other indigenous minorities with their own languages can be found in the traditional territories of Tundra Nenets. These minority languages may influence and may be influenced by the Tundra Nenets language. A map illustrating the ethnic and the linguistic diversity of the traditional Tundra Nenets territories in Siberia is provided under (2) below.

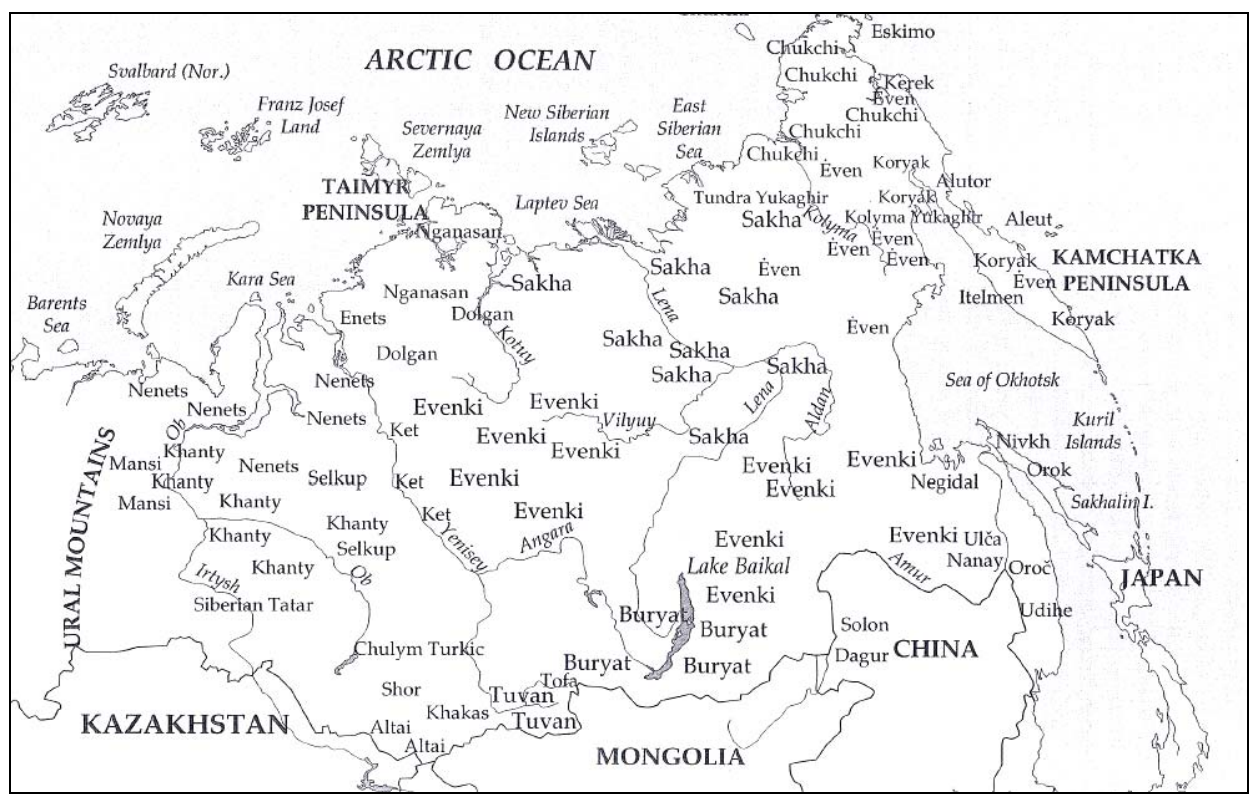

Map 2. The ethnic and linguistic diversity of Siberia

(source: Pakendorf 2010: 717) 
As is illustrated in Map 2, Khanty, Mansi and Selkup speakers can be found in the Yamal Nenets District, while Nganasan, Tundra and Forest Enets, Dolgan (Turkic), Ket (Yeniseic) and Evenki (Northern Tungusic) speakers live in the Taymyr Peninsula.

Additionally, a relatively large number of Komi speakers live in the European part of the Tundra Nenets territories, in the Nenets District. On the basis of the 2010 Census of the Russian Federation, 9\% (3 623 people) of the population in the Nenets District declared themselves as Komi. In this district, the ratio of Nenets speakers is $18.6 \%$ (7 504), while the actual number of Russian speakers is 26,648 (66.1\%). In addition, 2,524 (6.3\%) individuals claimed themselves to be of other ethnic origin. Regarding the relatively rich ethnic and linguistic diversity in the traditional habitat of Tundra Nenets, one can hardly find a Tundra Nenets, who is not a bi- or multilingual speaker.

The Tundra Nenets language itself also consists of three main dialectal groups, namely, the Western, the Central and the Eastern groups. Within them, one can distinguish further (sub)dialects (cf. Hajdú 1968: 17; Salminen 1998: 516). Table 2 represents these dialectal groups and the dialects of Tundra Nenets (cf. Tereshchenko 1993: 326-343).

Table 2. The Tundra Nenets dialectal groups and dialects

\begin{tabular}{l|l}
\hline Dialectal groups & Dialects \\
\hline \multirow{3}{*}{ Western } & Kolguyev \\
& Kanin \\
& Timan \\
& Malaya Zeml'a \\
\hline Central & Bol'shaya Zeml'a \\
\hline & Ob/Ural \\
& Yamal \\
Eastern & Taz \\
& Nadym \\
& Taymyr \\
\hline
\end{tabular}

As Salminen (1998: 516) notes, the dialectal variation is remarkable especially between the Western and the Central-Eastern dialectal groups, as "the Urals tend to divide morphological and lexical variants so that it is often justified to talk about specifically European vs. Siberian features of Tundra Nenets" (Salminen 1998: 516). The geographical position of Tundra Nenets speakers correlates with the dialectal classification of the language. Consequently, the Western dialect is mainly spoken in the Nenets District, while speakers of the Central dialect can tipically be found in the Yamal Nenets District. Finally, the Eastern dialect is mostly spoken in the Taymyr Municipal District. 
The structural differences among these dialectal groups and dialects have primarily been examined at the level of phonology and phonetics (e.g. Hajdú 1968: 21-22; Salminen 1998: 516). One of the most conspicuous phonological differences among the dialects of Tundra Nenets is the lack of the velar nasal $(\eta-)$ in the word initial position in some of the Western dialects, i.e. in Kolguyev, Kanin and Timan subdialects (cf. Hajdú 1968: 21). This difference is illustrated in $\left(1 \mathrm{a}-\mathrm{c}^{1}\right)$ :

(1)a. Western dialect, Kanin Subdialect ${ }^{2}$

$$
\begin{array}{lll}
\text { mań } & a c ̌ k i-n & o k a . \\
\text { 1SG } & \text { child-PX.PL.1SG } & \text { many.VX.3SG }
\end{array}
$$

'There are a lot of children of mine. ${ }^{3}$ [AL, 2002]

b. Central Dialect, Bol'shaya Zeml'a Subdialect

$$
\begin{array}{lll}
\text { mań } & \text { yaćeki-n } & \text { yoka-P. } \\
\text { 1SG } & \text { child-PX.PL.1SG } & \text { many-VX.3PL }
\end{array}
$$

'There are a lot of children of mine.' [VT, 2002]

c. Eastern dialect, $\mathrm{Ob} / \mathrm{Ural}$ Subdialect

$$
\begin{array}{lll}
\text { mań } & \text { yaćeke-ḿi } & \text { yoka. } \\
\text { 1SG } & \text { child-PX.1SG } & \text { many.VX.3SG }
\end{array}
$$

'There are a lot of children of mine.' [E.La, 2002]

This phonological phenomenon in the Western dialect leads to a change in the basic syllable structure of words, as Tundra Nenets fundamentally does not allow vowels in word initial position (cf. Salminen 1998: 519). Further lexical differences are provided e.g. by Tereshchenko (1956).

Additionally, more dialectal variations were identified, among others, by Jalava (2012). However, a systematic comparison of the grammatical structures of Tundra Nenets dialects has not been published yet.

The traditional indigenous Tundra Nenets lifestyles involve nomadic reindeer herding and hunting by wandering along the tundra. The traditional lives changed in many ways in the

\footnotetext{
${ }^{1}$ The Tundra Nenets examples and data are transcribed here on the basis of Hajdú (1968). Nevertheless, some minor changes were to be done in the system of Hajdú (1968). For the details of the writing system and the transcription of Tundra Nenets see $§ 2.2$.

${ }^{2}$ The dialectal classification of the example sentences will hereinafter be indicated, if it is appropriate for the discussion.

${ }^{3}$ Unless otherwise stated, the interlinear glossess and translations of Tundra Nenets examples are provided by me. For a detailed descripton of glossing conventions see $\$ 2.2$.
} 
past decades, as more and more people settled down into villages and cities, therefore, the reindeer herding decreased in the Tundra Nenets communities (for a detailed description about the interaction between the "modernized" nomadic reindeer herding culture and its environment see e.g. Stammler 2005). The tendency to settle down and start a new lifestyle (instead of traditional "tundra life") which decreases the possibility of passing the language onto the next generation, is especially typical of the younger/youngest generation (cf. Dudeck 2013: 135; Laptander 2013: 183). The sociolinguistic situation of the territory basically changed in the recent decades (for more information about the current situation of Tundra Nenets societies in the North, see e.g. Liarskaya 2009; 2010; Ziker 2010; Kasten \& de Graaf 2013; Volzhanina 2013).

To summarize the facts, Tundra Nenets is definitely an endangered Northern Samoyedic language, spoken by fewer and fewer speakers each year. The speakers live on a relatively large territory in the Northern part of the Russian Federation, together with other indigenous minorities in the area. The Russian language and culture has a great influence on the Tundra Nenets speaking community. The traditional reindeer herding culture seems to be replaced by a modern lifestyle that involves the settlement of the originally nomadic peoples. However, there are also sporadic groups that succesfully adapted to the new circumstances in the $21 \mathrm{st}$ century. They have the possibility to continue their traditional life and use their mother language.

\subsection{Writing system, transcription, glossing conventions}

(Tundra) Nenets literacy does not have a long history and tradition. The intention to create unified literary languages and writing systems of the indigenous people of Western Siberia arose only in the late 1920s and early 1930s, when these Northern cultures have undergone a significant change (cf. Touluze 1999: 53). ${ }^{4}$ These social changes were primarily caused by the transformations in the Russian political system, the emergence of the Soviet system. The new leadership aimed to treat (and to solve) the "problem" of the indigenous minorities of the North in a new, different way (e.g. by forced settlements, unification, political education). One of the most efficient devices to achieve this goal was the development of a new educational program introducing boarding schools. However, this new educational system

\footnotetext{
${ }^{4}$ There are sources, texts, translations of Tundra Nenets already from the 17th century. However, these texts were created without the intention of creating a unified writing system (for more information about Tundra Nenets literacy see e.g. Burkova et al. 2010: 186-189).
} 
required the existence of writing systems and literary languages of the Northern minority languages. As Touluze (1999: 68) notes, this literary development focused on choosing a graphical system and a prestige dialect recognized as the norm (for further details about the development of the written culture in Western Siberia see e.g. Touluze 1999; etc.). In the case of the Nenets language, this prestige dialect was the "dialect" spoken in the tundra (close to the Yamal subdialect of the Tundra Nenets language; cf. Toulouze 1999: 75). Despite these attempts originating from external needs, neither a unified literary language, nor a unified writing system has been created yet. As a real reference dialect for Tundra Nenets has not been chosen and the language has not been unified, the text variants representing different dialectal variations and/or edited by different authors often have their own coding systems.

In addition, the writing system of Tundra Nenets is based on the Cyrillic alphabet, which is not totally appropriate to encode the phonemic system of the language. For instance, the length of vowels is not marked in texts written in Cyrillic script at all. Furthermore, in some Tundra Nenets sources the glottal stop (?) is not marked by any Cyrillic character. Considering the fact that the glottal stop in Tundra Nenets functions as the marker of the plural number and the genitive case in the nominal domain, furthermore, it marks the 3rd person plural in the verbal agreement, and it serves as a distinctive feature in certain plural paradigms, these sources lack significant grammatical information.

Additionally, the Latin based linguistic transcriptions used in grammatical descriptions (e.g. Hajdú 1968; Salminen 1993; 1998; Staroverov 2006; Kavitskaya \& Staroverov 2008; etc.) are not unified either. They show differences mainly in the interpretation of the Tundra Nenets vowel system. As the present study does not aim at discussing phonological features of Tundra Nenets, a simple transliteration based on Hajdú (1968) will be used here. However, the length of vowels will not be indicated in the examples because the original Cyrillic texts lack to mark it.

The Tundra Nenets examples are glossed and translated by me, with the exception of those which originate from Nikolaeva (2003; 2005b), Salminen (1998) and Dalrymple \& Nikolaeva (2011). The glossing conventions and abbreviations used in the present dissertation are based on the Leipzig Glossing Rules ${ }^{5}$ with some minor additions.

\footnotetext{
${ }^{5}$ Available at: http://www.eva.mpg.de/lingua/pdf/LGR08.02.05.pdf (Accessed 2015-06-01).
} 


\subsection{The main typological features of Tundra Nenets}

Tundra Nenets is a typical SOV language in which the order of the minor elements relative to each other correlates with the order of the major constituents. Consequently, the adjective precedes the noun it modifies, as well as, the possessor precedes the possessed noun, etc.

The major word classes distinguished in Tundra Nenets are nouns, adjectives (and numerals), adverbs and verbs. Additionally, other parts-of-speech categories, such as pronouns, determiners, etc. can also be found in the language.

The category of nouns is specified for three numbers: singular, dual and plural; seven cases: nominative, accusative, genitive, dative, locative, ablative and prosecutive; and possessive and predestinative declensions (cf. Salminen 1998: 537-539). Tundra Nenets, being an agglutinative language, expresses these categories mostly by suffixes attached to the nouns. The examples in $(2 \mathrm{a}-\mathrm{c})$ demonstrate the singular, plural and accusative case marked forms of the word $t i$ 'reindeer'. The category of singular number and nominative case is expressed by a zero morpheme in Tundra Nenets. In the following Chapters, these categories will not be glossed and marked separately unless their marking is relevant for the discussion.

(2)a. $t i$

reindeer.SG.NOM

b. $t i-$ ?

reindeer-PL.NOM

c. $t i-m$ ?

reindeer-SG.ACC

(Hajdú 1968: 41)

Additionally, there are some fusional processes available in the language (see e.g. Hajdú 1968: 38). The accusative plural forms of some nouns are, for instance, indicated by changing the final wovel of the noun (see $3 a-b)$.

(3)a. xale

fish.SG.NOM

b. xali

fish.PL.ACC

(Hajdú 1968: 38) 
The possessive relation in Tundra Nenets possessive phrases may be marked on the head of the phrase (on the possessed item), on the dependent (on the possessor), or on both of them. The possessor always precedes the possessed item. Head marking through possessive suffixes is available for possessive phrases with pronominal possessor (see 4). In this case, the presence of the pronominal possessor is optional. The brackets in the examples indicate the optionality of the elements in the phrases.

\author{
(4)(pidar) te-r \\ (2SG) reindeer-PX.2SG \\ 'your reindeer' (Nikolaeva 2005b: 223)
}

The pronominal possessor, if it is overt in the phrase, can be either preceded (see 5a) or followed by a determiner (see $5 b$ ).

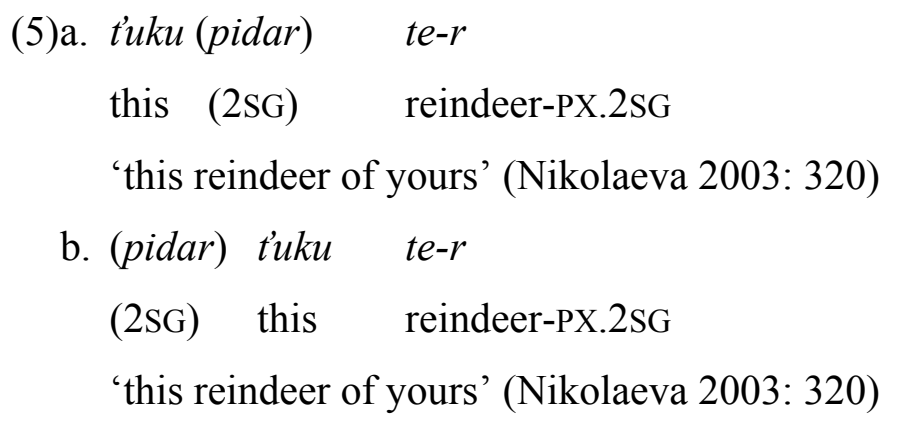

Unlike pronominal possessors, lexical ones always appear in genitive case and normally they do not require agreement on the head noun. Thus, the possessive relation is marked only on the dependent (cf. Nikolaeva 2005a: 223; see 6).

$$
\begin{aligned}
& \text { (6)Wata-P } \quad t i \\
& \text { Wata-GEN reindeer } \\
& \text { (the) reindeer of Wata' (Nikolaeva 2005b: 223) }
\end{aligned}
$$

Nevertheless, the possessive relation can also be marked both on the lexical possessor (in genitive) and on the possessed item (that takes a possessive suffix; see 7). 
$\begin{array}{ll}\text { (7) Wata-P } & \text { te-da } \\ \text { Wata-GEN } & \text { reindeer-PX.3SG } \\ \text { '(the) reindeer of Wata' (Nikolaeva 2005b: 227) }\end{array}$

As Nikolaeva (2005a) states, the two lexical possessors have different structural positions. The one that does not trigger agreement on the head (the so-called regular possessor illustrated in (6) can only occur after a determiner (see 8 below). In this type of possessive phrase, agreement via possessive suffixes on the possessed item is not possible (cf. Nikolaeva 2005a: 228).

$\begin{array}{cccc}\text { (8)tuku } & \text { Wata-P } & t i & / \\ \text { this } & \text { Wata-GEN } & \text { reindeer } & \text { (reindeer-PX.3SG) } \\ \text { 'this reindeer of Wata' } & \text { (Nikolaeva 2005b: 228) }\end{array}$

In contrast, the possessor triggering agreement on the head, the peripheral possessor (illustrated in 7 above), can only be situated before a determiner (see 9). In this construction, the possessed item is obligatorily marked by possessive suffixes:

$$
\begin{array}{clll}
\text { (9)Wata-P tuku } & \text { te-da } & (* t i) \\
\text { Wata-GEN this } & \text { reindeer-PX.3SG } & \text { (reindeer) } \\
\text { 'this reindeer of Wata' (Nikolaeva 2003: 320) }
\end{array}
$$

The insertion of an adjective between the possessor and the possessed item is possible with either types of lexical possessors (see 10a-b).

$$
\begin{aligned}
& \text { (10) a. Wata-? serako ti } \\
& \text { Wata-GEN white reindeer } \\
& \text { '(the) white reindeer of Wata' (Nikolaeva 2005b: 227) } \\
& \text { b. Wata-? serako(-da) te-da } \\
& \text { Wata-GEN white(-PX.3SG) reindeer-PX.3SG } \\
& \text { '(the) white reindeer of Wata' (Nikolaeva 2005b: 227) }
\end{aligned}
$$


As example (10b) illustrates it, the attributive adjective can also take possessive agreement markers. For further details about the agreement in person between attributive adjective and head noun see the discussion of example (19).

In nominal phrases, the nouns can be modified by determiners. The determiners in Tundra Nenets precede the head nouns and agree with them in number as in (11a), but person and case agreement is not available for them see (11b) (cf. Nikolaeva 2003: 316).

\author{
(11) a. tiki-? xid'a-? \\ that-PL dish-PL \\ 'those dishes' (Okotetto 1998: 135) \\ b. tiki kinoteatra-n? \\ that cinema-DAT \\ 'to that cinema' (Nenyang 2005: 73)
}

As illustrated in examples (8) and (9) above, the determiner can either precede or follow the possessor (both pronominal and lexical possessors). Additionally, the determiner can precede the adjectival modifier in the phrase see (12):

$$
\begin{aligned}
& \text { (12) tiki yarka xabt } \\
& \text { that big reindeer.ox } \\
& \text { 'that big reindeer ox' (Barmich 2008b: 50) }
\end{aligned}
$$

Finally, a noun can be a complement in a postpositional phrase. The postpositional phrase is also head-final in Tundra Nenets and the dependent noun appears in genitive case as in (13):

$$
\begin{aligned}
& \text { (13) tol'-? ḿud } \\
& \text { table-GEN in.ABL } \\
& \text { 'from a/the table' (Okotetto 1998: 75) }
\end{aligned}
$$

Nouns (and noun phrases) typically function as arguments of verbs in the clauses. Case marking of nouns indicates their syntactic functions. In (14), the constituent in nominative (ne 'woman') functions as the subject of the clause, while the constituent marked by accusative case (mal'cam? 'malitsa') is the direct object in the clause. 
(14) ńe mal'ća-m? sedibi.

woman malitsa-ACC sew.VX.3SG

'A/The woman sews a/the malitsa.' (Nenyang 2005: 14)

The nouns (or noun phrases) can be predicates in nonverbal clauses by taking verbal endings, the so-called subjective conjugation suffixes, in every person and number without an overt copula (see 15).
(15) $m a n ́ n t i ?$
lekara-dm?.
$1 \mathrm{SG}$ reindeer.PL doctor-VX.1SG
'I am a/the vet.' (Nenyang 2005: 93)

In these clauses, the predicate noun always occupies the clause final position as in (15) above. In addition to the agreement markers, the past tense marker is also attached to the predicate noun without using a copula (see 16).

\author{
(16) mań jor-ta-dam-ź. \\ 1SG fish-PCP.IMPF-VX.1SG-PST \\ 'I was a/the fisher.' (Kupriyanova et al. 1957: 202)
}

The nouns functioning as predicates can only take the agreement and the past tense markers. If any additional grammatical meaning (such as future tense, aspect, mood, etc.) is expressed, a copulative verb appears in the clause as in (17).

(17) mań l'etčika-dm? $\eta c e-\eta k u-d m$ ?
1SG pilot-VX.1SG be-FUT-VX.1SG
'I will be a/the pilot.' (Almazova 1961: 61)

To sum it up, nouns in Tundra Nenets can function as any constituents of the main clause by taking case or agreement markers. Additionally, they can be modified by adjectives and by other nouns in possessive phrases. They can also be the complements of postpositional and 
possessive phrases $^{6}$ and they can be the predicates of clauses by taking agreement and past tense markers.

Unlike nouns, adjectives in Tundra Nenets can only fulfil attributive and predicative functions. As it was illustrated by the structures above, phrases in Tundra Nenets are headfinal. The attributive adjective precedes its head noun and can agree with it in number, case and person (cf. Nikolaeva 2003: 322). Certain agreement types are optional and some of them are only available for certain dialects of Tundra Nenets. Agreement in number is always available in noun phrases, but it is the most typical in the Western dialects (cf. Nikolaeva 2003: 322; see 18).

$$
\begin{aligned}
& \text { (18) } \operatorname{serako(-P)~te-?~} \\
& \text { white(-PL) reindeer-PL } \\
& \text { 'white reindeer (pl)' (Nikolaeva 2003: 324) }
\end{aligned}
$$

Similarly, person agreement between the head noun and the attributive adjective via possessive suffixes is optional. As Nikolaeva (2003: 322) notes, it is possible in possessive phrases in which the relation between the possessor and the possessed item is inalienable. As in example (19) below the reindeer represents an inalienable possessed item, its adjectival modifier can show agreement in person.

$$
\begin{aligned}
& \text { (19) } \operatorname{serako(-r)\quad te-r} \\
& \text { white(-PX.2SG) reindeer-PX.2SG } \\
& \text { 'your white reindeer' (Nikolaeva 2003: 324) }
\end{aligned}
$$

As Nikolaeva (2005a: 226) observed, the agreement feature in person is available only for the Eastern dialects of Tundra Nenets.

Finally, internal case agreement can also take place. Agreement in case can appear only in combination with other agreement features (cf. Nikolaeva 2003: 324). If the head noun is marked for more than one agreement feature (e.g. for number and case), then the adjective can also take these agreement markers (see 20a). Similarly to person agreement, agreement in case is not obligatory in noun phrases either. In this case, the adjectival modifier can only be

\footnotetext{
${ }^{6}$ For further attributive use of nouns see e.g. Nikolaeva (2003).
} 
marked for number, even if the head noun takes both a number and a case marker in the phrase, as in (20b).

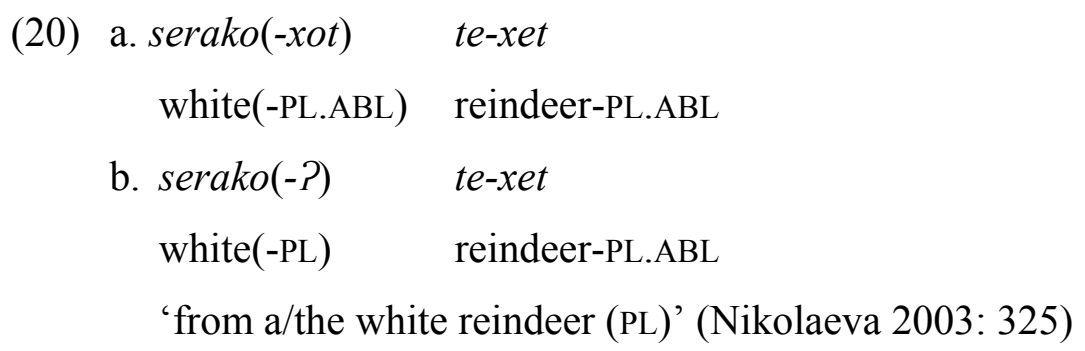

As these features are all optional, the modifying adjective can appear in the phrase without showing any agreement with its head noun.

The (cardinal and ordinal) numerals in Tundra Nenets do not constitute a different word class from adjectives, thus the agreement rules discussed above also apply for them (cf. Nikolaeva 2003: 321). Similarly to adjectives, agreement in number, person and case is optional in the case of numerals, too. In example (21), for instance, the attributive numeral can agree with the head noun in person.

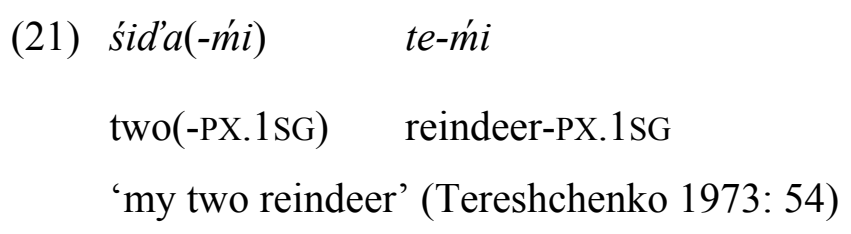

As example (21) illustrates, nouns quantified by numerals are in singular, but nouns can take a dual marker with the numeral sid'a meaning 'two' (see 22).

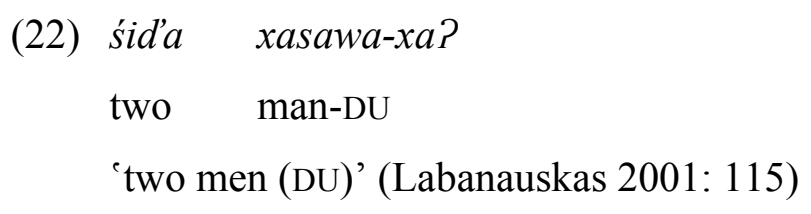

A characteristic property of numeral modifiers is that, when combined with other adjectives numerals usually precede the adjectives in the noun phrase (see 23). 
(23) ńaxar? yarka ma?
three big tent
'three big tents' (Pushkareva \& Khomich 2001: 338)

Like nouns, adjectives (including the subclass of numerals) can function as the predicate of the clause on their own. ${ }^{7}$ The predicative adjective/numeral can appear without an overt copula in every person and number both in present and past tense (see $24 a-b$ ).

(24) a. mań $\begin{gathered}\text { yarka-dm?. } \\ 1 \mathrm{SG} \quad \text { big-VX.1SG } \\ \text { 'I am an/the adult.' (Almazova 1961: 51) } \\ \text { b. mań } \quad \text { yarka-dam-ź. } \\ 1 \mathrm{SG} \quad \text { big-VX.1SG-PST } \\ \text { 'I was an/the adult.' (Kupriyanova et al. 1957: 223) }\end{gathered}$

As with the predicative nouns, a linking copula is used to encode any other grammatical meaning (e.g. future tense, aspect, etc.) (see 25):

(25) mań yarka-dm? yce-ygu-dm?

$1 \mathrm{SG} \quad$ big-VX.1SG be-FUT-VX.1SG

'I will be an/the adult.' (Yangasova 2001: 123)

Adverbs in Tundra Nenets cannot be marked for any grammatical features (person, number, case, etc.), with the exception of the locational/directional adverbs. This subcategory of adverbs can take the locative case markers (dative, locative, ablative and prosecutive).

According to Salminen (1998: 540), there is a set of locative case markers different from those attached to nouns that can appear on adverbs. The uninflected form of this subcategory of adverbs cannot appear on its own. Consequently, the stems of adverbs can rather be

\footnotetext{
${ }^{7}$ Certain adjectival meanings are expressed by verbs in Tundra Nenets. These forms, however, exhibit the same grammatical properties as verbs, and these predicates cannot be considered to be nonverbal predicates:
(i) ńe yaćeki-d śado?
woman child-PX.2sG be.beautiful.vX.3SG
'Is your daughter beautiful?' [Ev.L: 2012]


considered as roots appearing only in the local forms. The examples in (26a-d) illustrate the paradigm of the adverbial root t $u$ - 'up', which cannot be used without these locative suffixes.

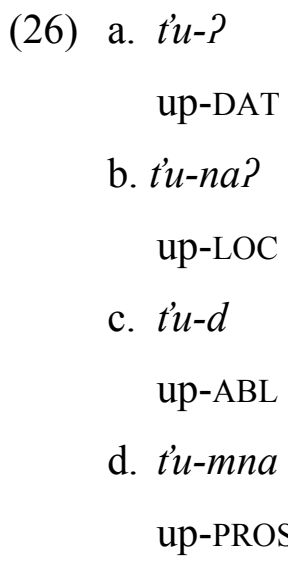

(Hajdú 1968: 54)

The markers that can appear on verbs are tense, mood and agreement. In the tense paradigm, there is a so-called aorist tense, which expresses present or immediate past tense, depending on the given verb. Furthermore, an inflectional suffix is used to indicate preterite tense, while, future is expressed with derivational morphemes. The mood system in Tundra Nenets is not clarified in the literature. While Hajdú (1968: 62-65) distinguishes 10 modal categories and markers, Salminen (1998: 530) differentiates 16 moods in the language. This question will not delt with here, as it has no relevance for the present discussion. The grammatical features of verbs are indicated by suffixes similarly to nominal grammatical categories (see $27 \mathrm{a}-\mathrm{c}$ ). The aorist tense in Tundra Nenets has no overt marker so it will not be glossed in the examples.

(27) a. $n u-d m$

stand-AOR.VX.1SG

'I stand'

b. nu-dam-ć

stand-VX.1SG-PST

'I stood'

c. $n u-x a-d m$

stand-HORT-VX.1SG

'let me stand' (Salminen 1998: 530-531) 
Intransitive verbs obligatorily agree with their subject in person and number in the clauses expressed by conjugational suffixes attached to the verb (see $28 \mathrm{a}-\mathrm{b}$ ). This verbal conjugation type is traditionally called subjective conjugation (see e.g. Hajdú 1968; Salminen 1998).

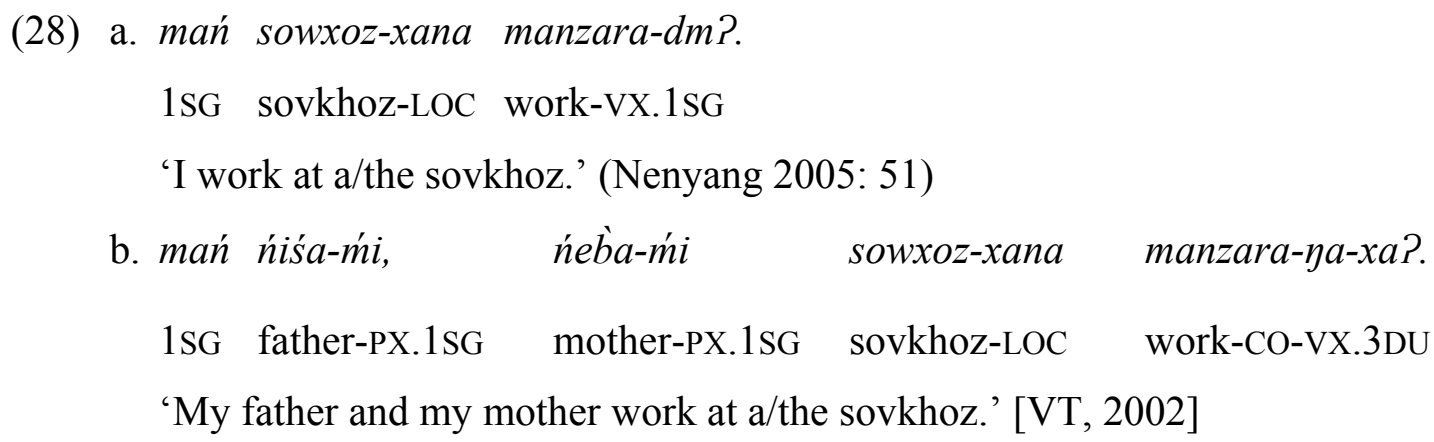

The subject can be omitted, if it is a discourse-old, topical element ${ }^{8}$ (cf. Dalrymple \& Nikolaeva 2011: 133), in which case the verb encodes its person and number through the agreement suffix (see 29b).
a. What are you doing?
b. manzara-da??
work-VX.2PL

'Are you working?' (Okotetto 1998: 125)

A transitive verb in Tundra Nenets agrees either with the subject only or both with the subject and the object. Agreement with the object is only in number. If a transitive verb agrees only with its subject, it takes the so-called subjective conjugational suffix. If the verb agrees both with the subject and with the object, it is conjugated in the so-called objective conjugation.

According to Dalrymple \& Nikolaeva (2011: 131-137), object agreement appears on the verb if the object has a topical role in the discourse. Example (30b) can be understood as an answer to the question in (30a). ${ }^{9}$

\footnotetext{
${ }^{8}$ The term topic is defined here on the basis of Dixon (2010: 235) as a discourse category. Topic is "an argument which occurs in a succession of clauses in a discourse and binds them together" (cf. Dixon 2010a: 340). It is interpreted here as an old, given, known element of the clause.

${ }^{9}$ Dalrymple \& Nikolaeva (2011: 132) provide further contexts in which the clause with the object that does not trigger agreement in $(30 \mathrm{~b})$ can appear. These contexts narrow the focus either to the predicate (What did the man $d o$ ?), or to the object element (What did a/the man kill?). In these contexts, the object cannot appear with object agreement on the verb, therefore it cannot be interpreted as being a topical element. I cite here the most neutral context provided by Dalrymple \& Nikolaeva (2011: 132) for illustrating the difference between these two types of objects in Tundra Nenets.
} 
(30) a. What happened?

b. xasawa ti-m xada.

man reindeer-ACC kill.vX.3SG

'A/the man killed a/the reindeer.' (Dalrymple \& Nikolaeva 2011: 132)

In this case, the object cannot be considered the topic of the clause and it does not control agreement on the predicate verb. In contrast, in (31b) the predicate verb agrees with its object because it has a topical role indicated by the context in (31a).

(31) a. What did a/the man do to the/a reindeer?

b. xasawa ti-m xada-da.

man reindeer-ACC kill-VX.OBJ.3SG

'A/the man killed a/the reindeer.' (Dalrymple \& Nikolaeva 2011: 132)

Similarly to topical subjects, topical objects can also be covert in the clause. If a topical object is omitted, the transitive verb always shows agreement with it (cf. Dalrymple \& Nikolaeva 2011: 132), as in the example in (32).

(32) xada-da.

kill-VX.OBJ.3sG

'He killed it' (Dalrymple \& Nikolaeva 2011: 132)

The agreement of the verbal predicate with the topical object is only available with 3rd person objects. 1st and 2nd person objects never trigger agreement on the verb (see 33).

\begin{tabular}{|c|c|c|c|}
\hline (33) mań & sit & tańa? & toewra-ygu-dm? \\
\hline $1 \mathrm{SG}$ & 2SG.ACC & there.DAT & take-FUT-VX.1SG \\
\hline
\end{tabular}

As the previous examples already illustrate, the predicate appears in sentence final position. Auxiliaries also follow the main verb by occupying the clause final position in the clause (see 34). 
(34) mań to-wa-n xarwa-dm?.
1SG come-AN-DAT want-VX.1SG
'I want to come.' (Labanauskas 2001: 60)

The only exception is the negative auxiliary used in standard clausal negation (and in certain subtypes of non-standard negation) that precedes the negated main verb, thereby changing the expected VAux order (see 35).

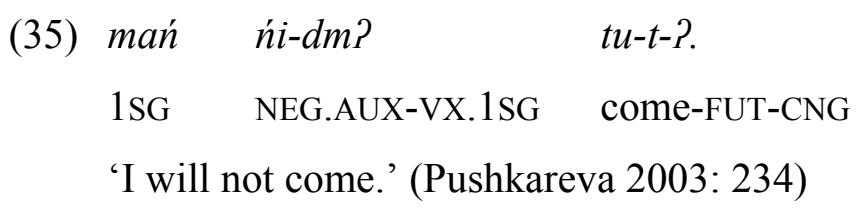

As was already mentioned, Tundra Nenets has an SOV basic word order, consequently the subject (be it pronominal or lexical) occupies the sentence initial position. ${ }^{10}$ However, it can be preceded, for instance, by a temporal adverbial (see 36).

(36) t'uku jal'a-? mańa? teatra-n? xanta-wa?.
this day-GEN 1PL theatre-DAT go-VX.1PL
'Today we are going to the theatre.' (Nenyang 2005: 73)

According to Salminen (1998: 543), the most typical word order of Tundra Nenets (transitive) clauses is the following:

(37) $\mathrm{X}^{11}$ Time $\mathrm{S} \quad \mathrm{X}_{\mathrm{L}} \quad \mathrm{O} \mathrm{X}_{\text {Manner }} \mathrm{V}$

In his description, Salminen (1998: 543) assumes an $\mathrm{SX}_{\mathrm{L}} \mathrm{OV}$ basic word order in which the temporal adverbial may precede the subject, occupying a clause initial position. In contrast, Dalrymple \& Nikolaeva (2011: 136) note that the possible order of subject (S), object (O), oblique phrase $(\mathrm{X})$ and verb in transitive clauses can be either an SXOV or an SOXV, illustrated in $(38 \mathrm{a}-\mathrm{b})$, where the spatial adverbial can optionally precede or follow the object in the clause. Verbal agreement with the object is possible with both word orders.

\footnotetext{
${ }^{10}$ The example in (14) above also illustrates that the basic word order of Tundra Nenets is SOV.

${ }^{11} \mathrm{X}$ stands for any oblique phrase functioning as an adverbial modifier or adjunct of the verbal predicate.
} 
(38)

a. ńiśa-da pedara-xana weńeko-m lada / lada-da.
father-PX.3SG forest-LOC dog-ACC hit.VX.3SG hit.VX.OBJ.3SG

'His father hit a/the dog in the forest.'

b. ńiśa-da weńeko-m pedara-xana lada / lada-da.

father-PX.3SG dog-ACC forest-LOC hit.VX.3SG hit-vX.OBJ.3SG

'His father hit a/the dog in the forest.' (Dalrymple \& Nikolaeva 2011: 136)

Moreover, Nikolaeva (2014: 214) provides a typical order of constituents, which is illustrated in (39) below:

(39) time adjunct - subject - place adjunct - indirect object - direct object - manner adverb - verb

Although this order is frequent in declaratives - as Nikolaeva (2014: 214) states - the constituents can appear in relatively free order in the clause. Nevertheless, the clause finality of the verb seems to be a rigid syntactic rule. It is only a right-dislocated element that may follow the finite verb. On the basis of the literature, we can conclude, that the order of the clausal element is free, but there is a preferred order in which the constituents usually appear. We will return to the word order patterns in Tundra Nenets in Chapter 7.

\subsection{Previous research on (Tundra) Nenets and Samoyedic languages}

There is no generally accepted periodization of the history of Samoyedic linguistics. This is not suprising, since as Helimski (2001) states:

"Until approximately the turn of the 20th century Samoyedology remained a Cinderella among the branches of Uralic studies, suffering from both a scarcity of available materials and poorly developed methodology." (Helimski 2001: 175)

Although recordings of Samoyedic languages were taken by scholars (e.g. Peter Mundy, Richard James, Philip Johann Strahlenberg, Daniel Gottlieb Messerschmidt, etc.; for a more detailed description of the history of Samoyedic philology see e.g. Hajdú 1968: 10-16; Helimski 2001) already from the 17th and 18th centuries, these early sources containing word 
lists and preliminary grammatical notes of certain Samoyedic languages (see e.g. the polyglot dictionary of Pallas 1787; 1789) cannot be considered to be systematic linguistic descriptions. It shall be mentioned, however, that these materials contain data about Samoyedic languages which are already distinct today (e.g. Grigorij Spassky collected materials from Koibal and Motor speakers). Comparative methods (mainly in combination with regular field trips) were primarily used during the early documentation and description of these languages. Thus we see that during this period it was the (historical) relation of the Samoyedic languages with the other group of Uralic language family, the Finno-Ugric branch, that were intended to be described. These initiatives, however, resulted in the development of the first grammars and grammatical descriptions of the then undescribed Samoyedic languages (amongst the other indigenous languages of the Russian tundra) in the middle of the 19th century by Matthias Alexander Castrén. The works of Castrén are usually considered to be the beginning of Samoyedic philology.

At the beginning of the 20th century, the systhematic studies of Samoyedic languages started, and organized expeditions to the North were undertaken in order to document and describe the Samoyedic languages. The collected materials of Toivo Lehtisalo (e.g. 1947; 1956) provide the possibility to analyse the Nenets language. Nowadays, these data can be regarded as historical data and many properties of language change can be captured in it. Lehtisalo republished the materials of Castrén among folklore compilations and dictionaries (see Lehtisalo 1960).

In the 20th century, the standardization of indigenous languages in the Northern part of Russia became necessary, and as a result, a writing system and a literary language of Nenets (together with the Selkup writing system and literary language) were also created. The linguist who contributed to these processes was Georgiy Prokofyev. Prokofyev wrote and published his research results on the Nenets language (see e.g. Prokofyev 1936) and also participated in the development of the educational system. Prokofyev published the first schoolbooks and textbooks of Nenets. As was mentioned in $\$ 2.1$, the Tundra Nenets language was considered a dialect of the Nenets language for a long time. Therefore, the grammatical descriptions providing information about the Nenets language in the 20th century discussed mainly Tundra Nenets as the most representative dialect of the Nenets language. This, however, had some important consequences. The most serious one is that the other so-called dialect(al group) of the Nenets language, Forest Nenets, remained poorly described and documented. Considering the fact that this language is seriously endangered today with about 2000 speakers, this cannot be compensated or made up for. Among the students of Prokofyev 
(e.g. Grigoriy Verbov; ${ }^{12}$ Anton Pyrerka ${ }^{13}$ ) Natalija Tereshchenko became the most prominent scholar of Samoyedic languages at the end of the 20th century.

The grammars published by Tereshchenko (e.g. Tereshchenko 1947; 1956) focus mainly on the morphological and syntactic properties of Nenets, and on the dialectal differences of the Nenets language. Tereshchenko published a description of the syntax of Samoyedic languages (see Tereshchenko 1973), which has remained the only comprehensive syntactic study of Samoyedic languages to date. She also produced a Russian-Nenets dictionary (see Tereshchenko 1965). In addition to Tereshchenko's works, other grammars were published in this period (e.g. Kupriyanova et al. 1957; Almazova 1961, etc.; for a more detailed description of the history of Samoyedic philology in the 20th century see e.g. Helimski 2001). These descriptions were accompanied by regular fieldworks and consulting native speakers. In this period, two chrestomathies were published about Tundra Nenets by Hungarian researchers, Gyula Décsy (see Décsy 1966) and Péter Hajdú (see Hajdú 1968). There is also a short grammar of Forest Nenets provided by Pekka Sammallahti (see Sammallahti 1974). By the end of the 20th century the phonological and the morphological system of (Tundra) Nenets had been described. Additionally, the only syntactic study (Tereshchenko 1973) has discussed the grammatic behaviour of some (major) syntactic units and formulated several syntactic rules. Considering that the patterns and processes described in these grammars were resulted in examinations of data which may be deemed to be historical ones, their conclusions regarding the grammatic system of the language may differ from that in the present-day (Tundra) Nenets language in several important respects.

At the end of the 20th century, the comparative historical research of Samoyedic languages also emerged. One of the most significant researchers of this topic was Tibor Mikola (e.g. Mikola 1988; 2004). In addition, Helimski and Janhunen have also questioned some points of the traditional Samoyedic historical linguistics (see e.g. Janhunen 1998; Helimski 2005). Nowadays, new results concerning Samoyedic etymologies are provided by Aikio (see e.g. Aikio 2002; 2006).

In recent years, Samoyedic studies mostly focus on typological characteristics (especially on syntactic structures) of the Samoyedic languages. Furthermore, there are projects that attempt to describe and document these languages. However, several syntactic questions of the (Tundra) Nenets language have remained unanswered, even though there are studies that

\footnotetext{
${ }^{12}$ Grigoriy Verbov published Forest Nenets materials (see e.g. Verbov 1973).

${ }^{13}$ Anton Pyrerka was the first Nenets intellectual who participated in the constitution of a Nenets literary language.
} 
aimed at the clarification of some questions. The most significant results of (Tundra) Nenets syntax (among other languages, e.g. Northern Khanty and Yukaghir) are provided by Irina Nikolaeva, whose works are related to the analysis of phrase structures and object agreement constructions, as well as, the information structure of the language (e.g. Nikolaeva 2001; 2003; 2005a; 2005b; 2011; 2012; 2014). There is also a documentation project called Siberian Languages $^{14}$ undertaken by Nikolaeva. This project provides multimedia collections of several endangered languages. In 2014, Nikolaeva published her comprehensive grammar of Tundra Nenets, which aims in particular at describing the syntax of Tundra Nenets. This syntactic analysis of the Tundra Nenets language is the only grammar which examine clauses and structures using modern methods of linguistic description.

Further syntactic analysis concerning intransitive constructions in Tundra Nenets is provided by Olesya Khanina (see Khanina 2007). Additionally, there are finished and ongoing research projects that focus on certain characteristics of Samoyedic and/or Uralic languages from a typological point of wiev (e.g. Typology of Negation in Ob-Ugric and Samoyedic Languages $^{15}$ and see e.g. Wagner-Nagy 2011; Miestamo et al. in Press). These projects also focus on the documentation of the (Tundra) Nenets language (see furthermore the Documentation of Enets and Forest Nenets ${ }^{16}$ project). There are also studies that describe the (Tundra) Nenets phonological/phonetic structure in a modern theoretical framework (see e.g. Staroverov 2006; Kavitskaya \& Staroverov 2008). Additionally, descriptive studies of the Tundra Nenets language (like Körtvély (2005) about verbal morphology and Jalava (2012) about the modal system) can also be found. In recent years, some grammar and grammatical descriptions were also published (see e.g. Salminen 1998; Burkova et al. 2010).

Finally, sociolinguistical research also emerged in recent years (e.g. Laptander 2013; furthermore the project called $O R H E L I A^{17}$ ). These studies mainly focus on the conditions and the present situation of the language (see Volzhanina 2007; furthermore the volume edited by Kasten \& de Graaf 2013; the MinorEuRus ${ }^{18}$ project) and are usually combined with socio-

\footnotetext{
${ }_{14}^{14}$ Available online at: <http://larkpie.net/siberianlanguages/> (Accessed 2015-06-01).

${ }_{16}^{15}$ Available online at: < http://www.univie.ac.at/negation/index-en.html $>$ (Accessed 2015-06-01).

16 Available online at: <https://www.etis.ee/portaal/projektiAndmed.aspx?VID=a5268f5f-fa76-4fdd-9974b3513e9f3a38\&LastNameFirstLetter=K\&PersonVID=173\&lang=en\&FromUrl0=isikud.aspx\&FromUrl1=isikuP rojektid.aspx $>$ (Accessed 2015-06-01).

17 Oral History of Elders in Arctic. Available online at: $<$ http://www.arcticcentre.org/InEnglish/RESEARCH/Sustainable-Development--Research-Group/Anthropologyresearch-team/Oral-History-of-Empires-by-Elders-in-the-Arctic----ORHELIA > (Accessed 2015-06-01).

${ }^{18}$ Empowerment and revitalization trends among the linguistic minorities in the European Union and the Russian Federation. Available online at: $<\mathrm{http}$ ///blogs.helsinki.fi/minor-eurus/> (Accessed 2015-06-01).
} 
anthropological research (see e.g. the work of Florian Stammler, Stephan Dudeck at the Arctic Centre).

There is further research on Nenets and Samoyedic that this short introduction cannot go into. For a more detailed bibliography, see e.g. Burkova et al. (2010: 199-221) and Helimski (2001). 


\section{Data, sources and methodology}

As was already mentioned, the results discussed in the present study are based on a corpus consisting of published and electronically accessible written texts. I use the term "corpus" here for a repository of collected and structured electronic texts. The selected texts were used for extracting language data of interrogative words and content questions. This chapter discusses certain data collection strategies that were taken to be relevant within the frame of the present analysis. Throughout the text collection process the main aim was to select texts provided by as many authors as possible from different social classes, age, sex and dialects. However, the availability of Tundra Nenets sources is limited and in many cases certain characteristics of the texts cannot be validated and/or controlled for. Therefore, certain factors had to be considered during the selection of the Tundra Nenets texts/sources. In $\$ 3.1$ these considerations will be presented. $§ 3.2$ discusses the methodological aspects and background of corpus creation. In this section, the available and used text types and their typical characteristics will also be dealt with. Additionally, those decisions will be discussed that were made when sampling the language. Finally, the methods and the data will be presented. In addition, the limits of the present corpus-based study will also be considered.

\subsection{Preliminary considerations}

The methods of designing a corpus and collecting data were developed here with the intention of creating a text-compilation that contains reliable, natural, and representative data (cf. Himmelmann 1998: 165). There are many factors, however, that one has to consider with respect to the Tundra Nenets language when collecting texts and text excerpts, that is "segments of discourse extracted from a larger complete text" (Biber \& Conrad 2009: 5). These factors discussed below in (i-viii) can influence the criteria of reliability, naturalness, and representativeness as established by Himmelmann (1998: 165).

(i) There are some audio recordings of the Tundra Nenets language available. However, the vast majority of these recordings can be regarded as elicited data and translations from Russian into Tundra Nenets. Although there are also naturally produced recorded texts, these give few analysable constructions. 
Therefore, these audio corpora or collections of spoken material do not provide sufficient data without additional sources.

(ii) Electronically searchable and/or annotated corpora are also available. These corpora were designed from written sources. Similarly to the previous group, they contain a very limited amount of tokens and do not provide a representative sample of the Tundra Nenets language.

(iii) Although several fieldtrips to Tundra Nenets territories have been undertaken in recent years, the collected texts are either not available for the research community, or the texts were published in printed form.

(iv) There is a relatively large amount of printed written texts collected during fieldtrips. As mentioned in $\S 2.1$, Tundra Nenets is spoken in territories of the Russian Federation where different types of bi-or multilingual situations can be found. On the one hand, Russan is the dominant language both politically and economically, so almost every Tundra Nenets speaker speaks Russian as his/her mother tongue, too. On the other hand, there are also speakers of other minority languages in these districts (and in most cases these languages are also endangered), which can also influence the language use. Consequently, the language competence of Tundra Nenets speakers may vary significantly. Therefore, texts were mainly collected from speakers who can be characterized as being “old, fluent speakers" of the community (see Grinevald \& Bert 2011: 49).

(v) The texts in printed sources were collected especially with ethnographical intention and the sociolinguistical parameters of consultants (such as age, sex, occupation, etc.) may not be balanced.

(vi) The printed texts may be republished versions of earlier compilations so the texts may not provide synchronically valid data or the synchronicity of the data cannot be verified.

(vii) The representativity of text varieties associated with speakers of different dialectal groups may also not be balanced.

(viii) In addition to printed texts that were collected during fieldworks, there are also sources published with educational purposes. Certain linguistic parameters of the informants who produced these texts cannot be verified. As a consequence, the use of these registers has its own limits. 
As the available acoustic corpora did not provide sufficient data of content questions, I excluded these sources from my research. ${ }^{19}$ However, this decision has its consequences. One of the most important consequences is that the suprasegmental features (such as emphasis, intonation) of content questions will not be discussed and examined in this dissertation.

The data of the present research originate from written and electronically available sources, which dominantly represent the written version of the Tundra Nenets language. As Hundt (2008: 169) notes (amongst others), written language usually differs in some properties from spoken language. One of the most usually described and discussed differences between written and spoken language is that written language is often more complex structurally. This means that more complex phrases, e.g. extremely complex noun phrases, are usually employed by written registers (cf. Biber \& Conrad 2009: 262). Nevertheless, certain written text types can have essentially the same linguistic characteristics as spoken registers (see Schneider 2003: 53). In what follows, I will discuss those aspects of texts that were identified by designing the corpus.

\subsection{Sampling frame}

The goal of the text selection was to design a corpus that contains a relatively representative amount of tokens and is appropriate for answering linguistically relevant questions. As I used data from written sources, which are usually described as a secondary coding of a language (in contrast to speech), I classified the sources on the basis of their proximity to speech. In this categorization the criteria discussed by Schneider (2002: 71-74) were used (see 40a-c).

(40) a. identity of speaker(s) and writer(s)

b. temporal distance between speech and record

c. reality of speech event

As Schneider (2002: 72) notes, a text can be constructed either by the speaker or by another participant of the given speech situation. This factor, the identity of the speaker and the writer, specifies - among other parameters - the situational characteristics of a given text (cf. Biber

\footnotetext{
${ }^{19}$ I do not consider the audio recording of the Russian-Nenets Audio Phrasebook to be an acoustic corpus, althogh the data were recorded in audio forms as well. However, the data were elicited, therefore they do not represent a naturally produced language.
} 
\& Conrad 2009: 40). In contrast, the temporal relation between the speech event and its recording in (40b) defines the so-called production circumstances of texts (cf. Biber \& Conrad 2009: 40; Schneider 2002: 72). Finally, a speech event coded in a written text can be based on a real situation in a given time and place or it can represent a text produced in an imagined situation. On the basis of these criteria, the following text-types were selected for designing a corpus of Tundra Nenets (see Table 3).

Table 3. The Tundra Nenets primary sources

\begin{tabular}{ccccc}
\hline $\begin{array}{c}\text { Category of } \\
\text { texts }\end{array}$ & Type of sources & $\begin{array}{c}\text { Speaker-writer } \\
\text { identity }\end{array}$ & $\begin{array}{c}\text { Temporal } \\
\text { distance } \\
\text { speech-record }\end{array}$ & $\begin{array}{c}\text { Reality of speech } \\
\text { event }\end{array}$ \\
\hline recorded & Folklore compilations & different & immediate & $\begin{array}{c}\text { real, } \\
\text { unique }\end{array}$ \\
\hline imagined & Phrasebooks & $\begin{array}{c}\text { identical/ } \\
\text { different }\end{array}$ & immediate & $\begin{array}{c}\text { hypothetic, } \\
\text { unique }\end{array}$ \\
\hline imagined & $\begin{array}{c}\text { Methodological } \\
\text { handbooks }\end{array}$ & identical & immediate & $\begin{array}{c}\text { hypothetic, } \\
\text { unique }\end{array}$ \\
\hline imagined & Reading books & identical & immediate & $\begin{array}{c}\text { hypothetic, } \\
\text { unspecified }\end{array}$ \\
\hline imagined & Textbooks & identical & immediate & $\begin{array}{c}\text { hypothetic, } \\
\text { unspecified }\end{array}$ \\
\hline
\end{tabular}

Additionally, I also considered some aspects of texts on the basis of Atkins et al. (1992) (see $41 \mathrm{a}-\mathrm{d})$.

(41) a. recording date

b. dialect

c. text type

d. genre

As already mentioned above, decades may pass between the date of recording and publishing. Consequently, texts may provide synchronically invalid data. Therefore, I excluded those data sets that were collected in fieldworks undertaken before the 1960s.

There are sources (e.g. schoolbooks) which were not collected but produced by a speaker of the community. These sources do not contain information about the time of their production. In these cases, I supposed that the date of publishing is the approximate date of the text production. The dialectal origin of the sources is only relevant in the case of the folklore compilations, because the other text types were recorded (written down) in the standard variant of Tundra Nenets language. Finally, I classified the types of texts in order to 
characterize the homogenity of the corpus (for further information on the types of subregisters and genre characteristics of texts in general see Biber \& Conrad 2009: 32). The following sections discuss the principal features of collected texts.

\subsubsection{Recorded texts}

The Tundra Nenets folklore text compilations can be characterized as recorded texts as these texts are direct written recordings of a real speech event, in real time and real place in a real situation (cf. Hundt 2008: 169). On the basis of Schneider's (2002: 72) classification, these types of written texts are the closest to spoken texts. Table 4 illustrates those folklore compilations that were used for collecting data. In Table 4 the full texts are abbreviated by FT.

Table 4. The Tundra Nenets folklore compilations

\begin{tabular}{|c|c|c|c|c|c|c|c|}
\hline Compiler/Editor & $\begin{array}{l}\text { Date of } \\
\text { publishing }\end{array}$ & $\begin{array}{l}\text { Date of } \\
\text { recording }\end{array}$ & $\begin{array}{l}\text { Speaker- } \\
\text { writer } \\
\text { identity }\end{array}$ & $\begin{array}{l}\text { Dialectal } \\
\text { classification }\end{array}$ & Genre & $\begin{array}{l}\text { Text } \\
\text { type }\end{array}$ & $\begin{array}{l}\text { Number } \\
\text { of token }\end{array}$ \\
\hline Labanauskas & 1995 & $1973-1993$ & different & Eastern & narrative & FT & 23,768 \\
\hline Labanauskas $^{\mathrm{a}}$ & 2001 & $1965-1990$ & different & Eastern & narrative & FT & 19,391 \\
\hline Lar \& Pushkareva & 2001 & 1984-1997 & different & Eastern & narrative & FT & 253,665 \\
\hline Pushkareva & 2003 & 1987 & different & Eastern & narrative & $\mathrm{FT}$ & 8,972 \\
\hline $\begin{array}{l}\text { Pushkareva \& } \\
\text { Khomich }^{\text {b }}\end{array}$ & 2001 & $1965-1980$ & different & $\begin{array}{l}\text { Eastern } \\
\text { Western } \\
\text { Central }\end{array}$ & narrative & FT & 22,564 \\
\hline Yangasova & 2001 & no data & different & Eastern & narrative & FT & 50,555 \\
\hline Total & & & & & & & 378,915 \\
\hline
\end{tabular}

The folklore compilations were collected and recorded by ethnographers and/or linguists whose primary goal was to present and preserve not only the language but also the culture of the given community. The recording process (writing down) was usually simultaneous. In addition, certain texts may also have been transcribed later from a mechanical recording with the help of the consultants. The sources provided additional information about the recording circumstances and sociological information about the consultants, such as age, gender and social status, etc., so the dates of recording were also presented. As mentioned, exclusively those texts were chosen that were collected in a fieldwork undertaken after the mid-1960s. In the course of the fieldworks, the texts were produced by a member of the community in real and unique speech events in which the speaker was not identical with the writer. The 
published volumes usually provide basic information about the location of the fieldwork, therefore these data can be used for determining the dialectal characteristics of the texts. The selected texts in Table 4 mainly originated from the Eastern dialectal group. These folklore texts are solely those text types in the corpus that preserved dialectal characteristics of the language. The folklore text compilations contain narrative mythical texts, lakhanako, syudbabts, yarabts, etc., and songs produced by the consultants. From these, only the narrative texts were chosen, while the songs and poems were excluded. These narrative folklore texts contain specialized subregisters (e.g. conversations) from which the full texts (FT) were kept instead of selecting text excerpts (TE). As Table 4 illustrates, the subcorpus containing folklore texts (either narrative texts or conversations) consists of 378,915 words.

\subsubsection{Imagined texts}

The so-called imagined texts were also created by speakers of the community, however, they differ from recorded texts in the sense that they were never spoken but were originally created in writing (cf. Schneider 2002: 72-73). The imagined texts are devided here into two subgroups. The first subgroup contains texts originally created to be spoken, such as phrasebooks and methodological handbooks for teachers, while the second group consists of texts prepared to be written, those are reading books and textbooks. Both of these subcategories represent the written standard of the Tundra Nenets language, so they show some differences in comparison with the previously discussed folklore texts. As the exact date of recording could not be determined, this information can only be hypothesized. As already mentioned, these texts were written in the standard language, therefore they cannot be categorized dialectally.

\subsubsection{Phrasebooks}

The phrasebooks aim at providing utterances that can be used in a normal, daily, real conversation. Therefore, these texts are relatively close to natural speech, but they are only simulations of a hyphothetical and ideal speech event. They are characterized here as imagined texts. As these texts are not real recordings of an originally spoken language use, the recording is supposed to be immediate with respect to the hypothetical speech situation. Table 5 lists the used phrasebooks. In Table 5, text excerpts are abbreviated by TE. 
Table 5. The Tundra Nenets phrasebooks

\begin{tabular}{llllll}
\hline Compiler/Editor & $\begin{array}{l}\text { Date of } \\
\text { publishing }\end{array}$ & $\begin{array}{l}\text { Speaker-writer } \\
\text { identity }\end{array}$ & Genre & Text type & $\begin{array}{l}\text { Number of } \\
\text { token }\end{array}$ \\
\hline Khanzerova et al. & 2012 & equal & conversation & TE & 926 \\
Nenyang & 2005 & equal & conversation & TE & 5,171 \\
$\begin{array}{l}\text { Russian-Nenets Audio } \\
\text { Phrasebook }\end{array}$ & 2002 & different & conversation & TE & 4,491 \\
Vanuyto & 2012 & equal & conversation & TE & 4,098 \\
\hline Total & & & & $\mathbf{1 4 , 6 8 6}$ \\
\hline
\end{tabular}

The speaker, the writer and the participants of the (imagined) conversations are (usually) identical. (S)he is the member of the speech community. The only one example that was selected for the corpus is the Russian-Nenets Audio Phrasebook that provided utterances by speakers from different dialectal groups: Valentina Taleeva (henceforth VT; the speaker of the Central Dialect), Ekaterina Laptander (hereinafter E.La, who provides texts from the Eastern Dialect) and Anna Latysheva (henceforth AL, she comes from a speech community that uses the Western Dialect). With the exception of this register these sources contained information neither about the speaker/informant nor about the location and time of the recording. However, it can be supposed that the texts were created at or near the date of publishing, and were not recorded many decades before they were published. The phrasebooks contained solely short conversations (usually question-answer pairs) structured along different themes. These dialogues were not full texts but text excerpts (TE). The corpus contain 14,686 words that originate from phrasebooks.

\subsubsection{Methodological handbooks}

Like the phrasebooks, the so-called methodological handbooks contain short and imagined conversations. The main distinction between phrasebooks and methodological handbooks is that the latter were written for educational purposes. These conversations are used in primary education to develop the communicative skills of children. These sources usually contain an introduction either in Tundra Nenets or in Russian and some instructions for the teachers. Only the thematic parts of the methodological handbooks, consisting of conversations, were selected into the corpus (see Table 6). 
Table 6. The Tundra Nenets methodological handbooks

\begin{tabular}{llllll}
\hline Compiler/Editor & Date of publishing & $\begin{array}{l}\text { Speaker-writer } \\
\text { identity }\end{array}$ & Genre & Text type & Number of token \\
\hline Nenyang & 2007 & equal & conversation & TE & 3,034 \\
Okotetto & 1998 & equal & conversation & TE & 16,566 \\
\hline Total & & & & & $\mathbf{1 9 , 6 0 0}$ \\
\hline
\end{tabular}

In the imagined speech situation, the speaker and the hearer of the hyphothetical discourse were the same person, who was the editor/writer of the book. However, the methodological handbooks for teachers supposed a speech situation in which the participants were the teacher (who was asking questions) on the one hand and the students/children (who were answering the questions) on the other hand. Consequently, these sources were created for real communicative situations. Therefore, the conversations were recorded as if they were spoken. It was only supposed that each of the texts was recorded immediately at the time of the speech event. Similarly to phrasebooks, the speaker, the circumstances of the recording, and the temporal distance between the speech and recording could only be presumed. These conversations were regarded as text excerpts rather than full texts. The corpus contain 19,600 number of words chosen from these methodological handbooks.

\subsubsection{Reading books}

The reading books contain texts originating from the folklore of several cultures (usually) other than Tundra Nenets (e.g. Nganasan, Chukchi, Khanty, etc.). These texts are usually translations into Tundra Nenets by members of the community. Thus, they represent the written standard of Tundra Nenets. The texts were intentionally prepared to be written for educational purposes, developing the reading abilities of children and providing cultural information. As such, they do not aim to represent a real discourse situation. Table 7 shows the Tundra Nenets reading books used here. 
Table 7. The Tundra Nenets reading books

\begin{tabular}{lccccc}
\hline \multicolumn{1}{c}{ Compiler/Editor } & Date of publishing & $\begin{array}{c}\text { Speaker-writer } \\
\text { identity }\end{array}$ & Genre & Text type & Number of token \\
\hline Barmich & $2008 \mathrm{a}$ & equal & narrative & FT & 6,882 \\
Barmich & $2008 \mathrm{~b}$ & equal & narrative & FT & 9,403 \\
Orlova et al. & 1996 & equal & narrative & FT & 13,711 \\
Pushkareva et al. & 1994 & different & narrative & FT & 40,570 \\
Samoylova \& Barmich & 2008 & equal & narrative & FT & 5,944 \\
Samoylova \& Barmich & 2010 & equal & narrative & FT & 16,046 \\
Susoy & 1990 & different & narrative & FT & 33,036 \\
Tereshchenko \& Susoy & 1995 & different & narrative & FT & 17,749 \\
\hline Total & & & & & $\mathbf{1 4 3 , 3 4 1}$ \\
\hline
\end{tabular}

Similarly to the previously presented folklore texts, the compiler/editor and the writer/translator of the texts may be a different person. However, in most of the cases, the speaker and the writer were the same person. The temporal distance between speech and recording was presumably immediate and the speech event was hypothetical. The place and the location of the "recording" and the dialectal classification of these texts could not be specified. The reading books contained full texts that may include some conversations too. The corpus contains 143,341 words that originated from the register type of reading books.

\subsubsection{Textbooks}

Like the reading books, the textbooks were also prepared for educational use. Therefore, they represent the written standard of the Tundra Nenets language. Additionally, textbooks contain questions, instructions concerning the given theme illustrated by the texts. Furthermore, there are also grammatical descriptions and comments on certain characteristics of the Tundra Nenets language. Both the narrative texts and the discussions were built into the corpus. The selected textbooks are introduced in Table 8.

Table 8. The Tundra Nenets textbooks

\begin{tabular}{llllll}
\hline Compiler/Editor & Date of publishing & $\begin{array}{l}\text { Speaker-writer } \\
\text { identity }\end{array}$ & Genre & Text type & Number of token \\
\hline Barmich & 2007 & no data & mixed & mixed & 41,549 \\
Barmich \& Nyaruy & 2007 & no data & mixed & mixed & 14,941 \\
Barmich \& Nyaruy & 2008 & no data & mixed & mixed & 10,836 \\
Barmich \& Nyaruy & 2009 & no data & mixed & mixed & 12,838 \\
\hline Total & & & & & $\mathbf{8 0 , 1 6 4}$ \\
\hline
\end{tabular}

The compiler/editor of textbooks was usually a member of the speech community, or a language specialist supported by the community. However, the circumstances of the creation, 
such as the identity of the speaker and the writer, the recording place, time and dialect, etc., could not be detected. As these sources consisted of two special types of subregisters, i.e. narrative full texts and text excerpts representing conversations, they did not represent a homogenous subpart of the corpus with respect to their genre and type features. The word number of textbooks is 80164 in the corpus.

Consequently, text types introduced above under 3.2.1-3.2.2 were selected for the corpus. A figure illustrating the frame of the designed Tundra Nenets corpus is provided below in Figure (4).
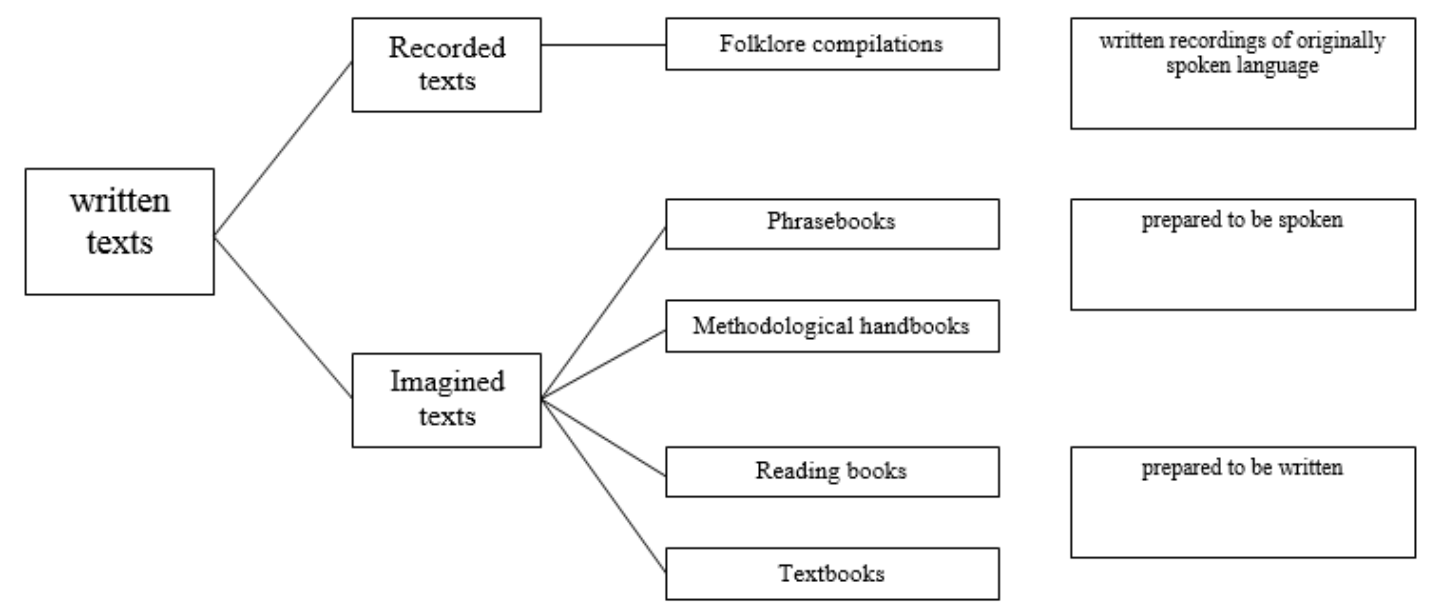

Figure 4. The sampling frame of Tundra Nenets text compilation

In what follows, I will give some additional characterictics of the corpus by using the classificational criteria discussed by Atkins et al. (1992: 13-14):

(i) The data originated from narratives and conversations representing three categories of texts: recorded texts, imagined texts prepared to be spoken and imagined texts prepared to be written. I aimed at sampling the language through a relatively balanced text compilation. However, certain text categories were underrepresented due to their limited availability.

(ii) These text categories are full texts and text excerpts providing synchronic data.

(iii) The corpus is a monolingual (Tundra Nenets) one, but the sources contained Russian translations not built in the corpus.

(iv) The printed texts were scanned and saved in machine-readable forms with an OCR (Optical character recognition) program. This format allows to make simple 
searches (e.g. occurrences of words or word forms), but complex information cannot be extracted from the corpus as it does not contain any explicit additional information (such as parts-of-speech tagging, etc.).

(v) The texts were converted from Cyrillic into Latin automatically by a PERL script written for this purpose.

This corpus has its own limits; for instance, it is not appropriate for analyzing dialectal differences or measuring sociolectal features because these additional pieces of information were largely missing from the sources.

\subsection{Data collection strategies}

The data (content questions) were collected manually from the corpus so collecting every occurrence (every token) of certain interrogative words was not aimed at. Rather, the types of possible occurrences of grammatical structures were gathered. The interrogative clauses were analyzed and grouped into three clause types: intransitive, transitive and nonverbal clauses. On the basis of Dixon (2010: 228-229), intransitive clauses are defined here as clauses which have a single core argument, that is the intransitive subject. Additionally, transitive clauses are clauses with two core arguments, i.e. a transitive subject and a transitive object (cf. Dixon 2010a: 228-229). Finally, nonverbal clauses are treated here as clauses in which a nonverbal element functions as the predicate (cf. Payne 1997; Dryer 2007b). Table 9 below illustrates the occurrences and numbers of these question types in the corpus.

Table 9. The analyzed Tundra Nenets content questions

\begin{tabular}{cccc}
\hline Intransitive clauses & Transitive clauses & Nonverbal clauses & Total \\
\hline 595 & 392 & 507 & 1,494 \\
\hline
\end{tabular}

These occurrences, however, are not representative of the frequency of interrogative words. On the one hand, not every token was selected from the corpus, as mentioned above. On the other hand, the interrogative words can also be used in clause types that will not be analyzed in the present dissertation (e.g. interrogative clauses with negative predicates, or multiple interrogatives; for further details of the subject of this study see Chapter 4). Consequently, I excluded those occurrences that have no relevance for the present study. Afterwards, I determined the constituents of the content questions in order to analyze the grammatical 
characteritics of interrogative words. The grammatical features will be discussed in Chapter 6 . Finally, I examined the syntactic structure of questions in order to define the position of the interrogative words within the clause (the results will be discussed in Chapter 7).

This study based on a written corpus has its own limits. One of its limits is that it is only possible to examine and identify functions and occurrences of a given interrogative word or phrase if it occurs in the corpus. Hence, to exclude grammatical properties that do not occur in the texts is not possible. Therefore, the present dissertation will discuss only those parameters of Tundra Nenets interrogative words and clauses that can be demonstrated by the data extracting from the corpus. 


\section{The subject of the study}

The aim of this chapter is to classify aspects which will be used in the analysis of Tundra Nenets content questions. This chapter describes the terminology and theoretical framework behind this study.

The present work aims at providing a cross-linguistically valid and comparable description of content questions in Tundra Nenets, therefore mainly typological results and approaches will be discussed here. Throughout the analysis, a neutral and widely accepted terminology will be used. Since the main aim of the present discussion is to describe the content questions in Tundra Nenets, the theoretical framework followed here is the so-called basic linguistic theory elaborated by Dixon (2010a; 2010b; 2012). The basic linguistic theory is widely employed in language description, because it provides a flexible and analytic framework in terms of which the grammar of any language can be described. This theory is not a formal one, however, it has been influenced by certain formal theories, e.g. by generative grammar. Within the frame of basic linguistic theory, the language is analysed as a system in its own right via data collected with a minimum of preconceptions about the language.

The present chapter is organized as follows. $\$ 4.1$ discusses typical clause types available in languages on the basis of the speech acts the clauses are associated with. Additionally, structural/grammatical correlations between speech act types and clauses performing these speech acts will be described. $\$ 4.2$ deals with cross-linguistic types of interrogative constructions. Typical strategies used across languages for differentiating between interrogative types will be defined. $\S 4.3$ discusses certain aspects of content interrogatives with respect to the availability of interrogative substitutes. Semantic categories, lexical forms, parts-of-speech categories, and the syntactic functions of the interrogative words will be considered here. Afterwards, a cross-linguistic classification of content question types on the basis of the possible syntactic positions occupied by the interrogative words will be provided. $\S 4.4$, identifies the set of those relevant constructions and elements that will be examined in the following chapters. $\S 4.5$ reviews the literature and approaches to Tundra Nenets content questions and interrogative words. Finally, §4.6. formulates numerous research questions that will be answered later in this thesis. 


\subsection{Speech act distinctions}

There are several approaches that categorize clause types in the known languages. As Dryer (2007b: 224) notes, "there are at least four senses in which one can talk about clause or sentence types in a language". These classifications result in dichotomies within clauses illustrated in $(42 \mathrm{a}-\mathrm{d})$ :

(42) a. main and subordinate clauses

b. active and passive clauses, etc.

c. clauses with a verbal or a nonverbal predicate

d. declarative, imperative, interrogative sentences

Further approaches may be distinguished from the four aforementioned ones, which may lead to more (sub)types of clauses. The classification in $(42 a-d)$ is, however, considered here sufficient to illustrate the basic differences between the interpretations.

Within the frame of the categorization in (42a), a subordinate (or dependent) clause, which can be a complement clause, an adverbial clause, or a relative clause, is interpreted as a constituent of the main clause (cf. Velupillai 2012: 315-316). As this categorization is not relevant for the present discussion, I will not deal with it here in detail (for a typological description of independent clause types see e.g. Noonan 2007; Velupillai 2012: 316).

Similarly, clause types in (42b) will not be analysed here, therefore they will not be a topic of concern (for a detailed description of this topic see e.g. Foley 2007).

A clause defined by the criterion in (42c) may contain verbal or nonverbal elements functioning as predicates (cf. Dryer 2007b: 224). Verbal predicates can be intransitive, transitive and ditransitive ${ }^{20}$ (cf. Dryer 2007b: 250). Besides, there are several clause types cross-linguistically (such as equative, inclusive, etc.) in which a nonverbal element is employed for expressing the predicate (for a detailed description see e.g. Payne 1997; Dryer 2007b). This classification provides the basis of the analysis of Tundra Nenets interrogative structures in Chapter 7, in which I will return to this categorization.

\footnotetext{
${ }^{20}$ The term ditransitive predicate is defined on the basis of Dixon (2010: 229) in the following way. Ditransitive predicates are constructions with three core, i.e. obligatory, arguments. These construction-types are often called as extended transitive constructions (see Dixon 2010a: 229).
} 
Finally, the so-called illocutionary acts, i.e. speech acts performed by the speaker in a utterance result in a further differentiation of clauses (see 42d). Usually, three basic sentence types, declaratives, imperatives and interrogatives, are employed by the languages for expressing various speech acts (cf. Sadock \& Zwicky 1985; König \& Siemund 2007; Velupillai 2012). Examples in (43 a-c) represent these basic sentence types in English:

(43) a. John is taking out the garbage.

b. Take out the garbage, John.

c. Is John taking out the garbage? (König \& Siemund 2007: 277) (declarative clause)

(imperative clause)

(interrogative clause)

In addition to these three types, there are also minor categories, such as exclamations illustrated in (see 44) (for further subtypes see Sadock \& Zwicky 1985: 162-165).

(44) That's so tacky! (exclamative clause)

(Sadock \& Zwicky 1985: 162)

While the three main clause types are traditionally differentiated across languages and seem to be universal, the minor types can rather be understood as subcategories of the three main ones (cf. Velupillai 2012: 345).

Declarative sentences (illustrated in 43a) are normally used for speech acts as describing, asserting, claiming, stating, accusing, criticizing, promising, guaranteeing, etc. (cf. König \& Siemund 2007: 285; Velupillai 2012: 346). As König \& Siemund (2007: 284-285) claim, affirmative declaratives form the most frequent sentence type, and are typically unmarked in the languages (for languages that mark the affirmative declarative sentences see e.g. Sadock \& Zwicky 1985: 165-166; König \& Siemund 2007: 284; Velupillai 2012: 346). Therefore, the other two main types of sentences (imperatives and interrogatives) are usually interpreted as derived forms of affirmative declaratives ${ }^{21}$ (cf. König \& Siemund 2007: 285), but it does not necessarily mean that they are not marked. Instead, declarative affirmatives can be characterized by the absence of those formal properties that are available for the other two categories (cf. König \& Siemund 2007: 286). The word order represented by affirmative

\footnotetext{
${ }^{21}$ Imperatives and interrogatives can only be regarded as results of some operations made on declaratives in languages, in which affirmative declaratives are unmarked (cf. Sadock \& Zwicky 1985: 165-166 and König \& Siemund 2007: 285).
} 
declaratives is usually regarded as the basic word order of a language (cf. König \& Siemund 2007: 285) and this clause type has the least restricted distribution relative to the other types of clauses (cf. Velupillai 2012: 346). Within declaratives, affirmative and negative declaratives are traditionally differentiated (cf. Velupillai 2012: 346-347; see 43a and 45, respectively).

(45) John is not taking out the garbage. (negative declarative clause)

Negative affirmatives, in contrast, are usually marked constructions that change the truth value of a proposition (for a detailed description of standard clausal negation from a typological point of view see Miestamo 2005).

Imperatives (see e.g. 43b) typically convey commands, orders, requests, suggestions, instructions, warnings, etc. (cf. Sadock \& Zwicky 1985: 170; Velupillai 2012: 359). There is a broad and a narrow interpretation of imperatives (cf. König \& Siemund 2007: 303). In the narrow sense, imperatives are restricted to second person subjects. The extended definition includes commands, requests, etc. addressed to first and third persons, which are traditionally called hortative and optative clauses (cf. König \& Siemund 2007: 303). Imperatives are usually marked constructions, most typically by morphological marking (e.g. affixes or bare verb stems; cf. König \& Siemund 2007: 303). These clauses can also be either positive or negative (also called as prohibitive; cf. Velupillai 2012: 359; see 46 below and 43b above).

(46) Don't take out the garbage, John! (negative imperative clause)

The third type of sentences found nearly universally in languages is the interrogative one. Interrogative sentences are typically used for requesting information (cf. Sadock \& Zwicky 1985: 178; König \& Siemund 2007: 290-291; Velupillai 2012: 352). Similarly to the other two types of clauses, interrogatives can be devided into subtypes. These categories will be discussed in $\S 4.2$ in detail, so I will give examples there.

In sum, the three basic types of clauses discussed above are the ones tipically differentiated in languages. As Huddleston (1994: 412) notes, if a language distinguishes these categories of sentences, the categories will show syntactic differences.

Although these basic sentence types have a default interpretation (associated with a typical speech act), they can also be used with a distinct communicative function in a discourse (c.f. König \& Siemund 2007: 283). For instance, the example in (47) performs the speech act of a 
request, which is typically associated with imperative clauses but formally the clause is an interrogative clause.

(47) Could you please close the window?

(interrogative clause, request)

(König \& Siemund 2007: 283)

As König \& Siemund (2007: 284) note, these inferences depend on contextual factors, so the utterance in (47) requires a physical reaction (closing the window) rather than an oral one ('Yes'). In what follows, the various subtypes of interrogative clauses will be dicussed.

\subsection{The subtypes of interrogative clauses}

As mentioned in $\S 4.1$, interrogatives are one of the main clause types and they are typically used for requesting information (cf. König \& Siemund 2007: 291; Velupillai 2012: 346).$^{22}$ In addition, other speech acts can be associated with them as well. A typical example is illustrated in (47) above, in which the interrogative asks for an action and not for information. This speech act, i.e. requesting an action, is usually associated with imperative clauses (for a detailed description about speech acts that are available for interrogatives other than asking for an information see Huddleston 1994). At the same time, clause types other than interrogatives can also be used as questions (cf. Siemund 2001: 1011; see 48).

(48) He has come today? (declarative clause, question)

(Siemund 2001: 1011)

In example (48), a declarative clause is used for expressing a speech act typically characteristic of interrogative clauses. Nevertheless, the default interpretation of interrogatives is associated with requesting information, asking a question.

\footnotetext{
22 The terms "question" and "interrogative" are often interpreted interchangeably in the literature. According to Huddleston (1994: 412-414), however, the former defines a set of answers, while the latter is used for a clause type. In my dissertation, I will follow this distribution and use the term "question" for Tundra Nenets clauses which require unknown information and contain an interrogative phrase.
} 
There are many aspects of interrogatives that may result in interrogative subcategories. As Haan (2001: 12) notes, there are nine interrogative types typically discussed and differentiated in the literature (see 49):

(49) a. Polar questions

b. Alternative questions

c. Content questions

d. Tag-questions

e. Declarative questions

f. Echo-questions

g. Elliptic questions

h. Rhetorical questions

i. Embedded questions

In this study, the types in (49a-i) will not be distinguished and discussed in detail, but a simpler classification will be followed. Interrogatives will therefore be differentiated here on the basis of the typical answer they require. Depending on the answer claimed, one can distinugish three major types of interrogative clauses, illustrated above in (49a-c). These are polar questions (or Yes/No questions; see 50a), alternative questions (see 50b) and content questions (also called constituent, information, question-word questions, or wh-questions on the basis of the typical English interrogative word forms; see 50c; cf. Sadock \& Zwicky 1985: 179; Siemund 2001: 1010).
(50) a. Does a platypus lay eggs?
(polar question)
b. Is a platypus a mammal or a bird?
(alternative question)
c. What is a platypus?
(content question)

(Siemund 2001: 1011)

The use of a more simple classification here is because the types of interrogatives illustrated above in $(49 \mathrm{a}-\mathrm{i})$ partially overlap as far as, for instance, a polar or a content question can be echoed for expressing surprise or incorrect understanding/hearing of the preceding utterance (cf. Haan 2001: 16; see 51a-b). 

(51) a. She is a genius? (polar echo question)
b. She is a what? (content echo question)

(Huddleston 1994: 427)

Unlike non-echoed polar and content questions, echo questions do not ask for new information, but they are typically used to ask for repetition or clarification of a given part of the preceding information (cf. Huddleston 1994: 432). Typically, the structure of echo questions differs from their non-echoed counterparts see (52a-b) and compare with $(51 \mathrm{a}-\mathrm{b})$.
(52) a. Is she a genius? (polar question)
b. What is she? (content question)

In what follows, prototypical characteristics of the three basic interrogative types will be discussed. According to Sadock \& Zwicky (1985: 178-179), polar questions (see e.g. 50a and 51a) are (nearly) universal across languages. These questions request the hearer to decide whether a given proposition is true or false, therefore the minimal answer to this type can be a simple 'yes' or 'no' (cf. Sadock \& Zwicky 1985: 178; König \& Siemund 2007: 291; Velupillai 2012: 352). The typical strategies for marking polar questions across languages are provided under (53a-h) below (cf. Siemund 2001: 1011; Dryer 2005: 470; König \& Siemund 2007: 292; Miestamo 2007: 303, Velupillai 2012: 652-356; Dryer 2013b: 1).
(53) a. interrogative intonation
b. interrogative particles
c. interrogative tags
d. interrogative verb morphology
e. interrogative auxiliary verb
f. disjunctive-negative structures
g. interrogative word order
h. absence of declarative morphemes

The techniques in $(53 \mathrm{a}-\mathrm{h})$ will not be illustrated here because they are not relevant for the purpose of the discussion. However, a short explanation of the typical strategies and crosslinguistic observations will be provided. For the techniques employed by the Tundra Nenets language with examples see $\S 4.5$. 
In many languages, it is only the intonation that differentiates the declarative clauses from the polar interrogatives. The most typical case is that declaratives have a falling intonation, while interrogatives have a rising intonation. Nevertheless, the opposite can also be found in some languages, e.g. in Fanti (Niger-Congo, Kwa; cf. König \& Siemund 2007: 292). Furthermore, some languages, such as Russian, Finnish, Estonian, etc., mark their polar questions by an interrogative particle that typically appears in the clause final position. As König \& Siemund (2007: 295) note, the position of the interrogative particle correlates with the basic word order of languages: verb-final languages usually situate the interrogative particle in the clause-final position, while verb-initial languages are more likely to have clause-initial interrogative particles (cf. König \& Siemund 2007: 295). In some languages (e.g. in English), an interrogative tag - that is closely related to interrogative particles - is used in polar questions. The clause to which the interrogative tag is attached is formally a declarative clause (which is either affirmative or negative). The polarity of the two elements, i.e. the clause and the tag, is different in most languages employing interrogative tags. It means that the clause is affirmative, while the tag is negative, or it is the other way around. In addition, the combination of positive clause and positive tag is also quite frequent across languages (cf. König \& Siemund 2007: 296-297). In this case, however, the tag usually occurs at the sentence final position regardless of the basic word order of the language. Furthermore, there are languages, e.g. Tundra Nenets, in which inflectional suffixes - different from those used in declarative clauses - are attached to the verb for marking polar questions (cf. König \& Siemund 2007: 299). Moreover, interrogative (auxiliary) verbs can also be used for expressing polar questions (this strategy is employed by Tundra Nenets as well, cf. Miestamo 2007: 303). In the so-called disjunctive-negative structures (or A-not-A constructions), the affirmative predicate is followed by its negative counterpart for expressing a polar question (this technique is found e.g. in Mandarin Chinese; cf. König \& Siemund 2007: 297). The strategy of marking polar questions by changing the order of the clause constituents is typically available for (and seems to be restricted to) Indo-European languages. The most typical word order change is that the verb appears in the clause initial position (cf. König \& Siemund 2007: 299). Finally, the absence of a special interrogative marker can also be a technique of differentiating polar questions. In these languages (e.g. in Dinka, NiloSaharan, Eastern Sudanic), however, it is the declarative clause that is marked by a special marker. According to Velupillai (2012: 354), this strategy is, however, very rare.

Another type of interrogatives that typically occurs across languages is the alternative question. This type requires the hearer to make a choise between two (or more) entities. As it 
has a lot in common with polar questions structurally, it is usually discussed as a subcategory of polar questions (cf. König \& Siemund 2007: 291). ${ }^{23}$ However, alternative questions cannot be answered by a simple 'yes' or 'no'. In addition, the semantics of alternative questions is similar to that of content questions in the sense that both of these question types specify the field in which the expected answers can be found (cf. Sadock \& Zwicky 1985: 185). The alternative questions, though, allow for an answer, which is provided by the question itself. Furthermore, this question type does not contain any interrogative word/phrase. Despite the significant similarities, consequently, it makes sense to consider alternative questions to be separate type of interrogatives.

Finally, content questions are the third subcategory of interrogatives (see e.g. 50c and 52b). According to Sadock \& Zwicky (1985: 179), this type is close to being nearly universal across languages. It is typically used in a discourse when the speaker misses an element of a given statement and assumes that the hearer knows this required information. Consequently, the speaker requests the hearer to share this piece of missing information with him. Various strategies employed by polar questions (illustrated in $53 \mathrm{a}-\mathrm{h}$ ) are also available for content questions (cf. König \& Siemund 2007: 299). The most typical distinction is the presence of a specific interrogative substitute, an interrogative word (also called question word or interrogative proform), that indicates the missing information. As the interrogative word (or phrase) specifies the missing information, the required answer cannot be 'Yes' or 'No' (cf. König \& Siemund 2007: 291; Dryer 2013a: 1). Content questions can be described as being interrogatives which:

(i) contain an interrogative word (phrase) and

(ii) require a specific answer (other than $\mathrm{Yes} / \mathrm{No}$ ).

$\S 4.3$ defines interrogative words and discusses some aspects of categorizing interrogative words.

\footnotetext{
${ }^{23}$ There are also categorizations, which consider polar questions as subpart of the alternative questions (cf. e.g. Karttunen 1977: 391).
} 


\subsection{Content questions}

As already mentioned, the typical strategies for marking polar questions presented in (53) may also serve to differentiate content questions. Still, the most typical way to form a content question is to employ an interrogative substitute. Although content questions universally contain an element whose function is to substitute the unknown piece of information in a discourse, this substitute does not necessarily have to be a specific interrogative word (cf. Velupillai 2012: 358). In some languages, interrogative words can also be used as indefinites and/or relatives (cf. Sadock \& Zwicky 1985: 184; Idiatov 2007: 6). Furthermore, as discussed above, interrogative words can occur in echo-questions. In this case, they usually have different morphosyntactic and/or syntactic features, for instance they may occupy different syntactic positions (cf. den Dikken 2003: 84). Den Dikken (2003: 84) observed four types of interrogative words having different features (see 54).

(54) a. regular question words

b. echo-question words

c. indefinite wh-words

d. relative wh-words

This classification provided by den Dikken (2003) concerns the regular interrogative words appearing in single questions, while question words in $(54 b-d)$ occur typically in different clause types. Declarative clauses, for instance, usually contain indefinite interrogative words. Thus, one can assume that content questions contain an element that serves to substitute the unknown part of the information. This element is, however, not obligatorily an interrogative word, but it can function as an interrogative word in a question. As Velupillai (2012: 358) states, in the Wari' language (Chapacuran), for example, a content question does not contain any interrogative word, but it is expressed by positioning a demonstrative sentence initially.

Usually, several dimensions of the interrogative elements are categorized and discussed in the literature. In what follows, the criteria and methods of categorizing interrogatives taken to be relevant in the present study will be discussed. Although almost every known language tends to have a set of interrogative words (or any element used in content questions for substituting a missing/unknown information), the number, meaning and grammatical category of interrogative words may significantly differ across languages (cf. Siemund 2001: 1018). Studies of cross-linguistic diversity of interrogative words usually discuss the semantic 
categories typically fulfilled by interrogative words in languages. Mackenzie (2008: 1132) observed 6 different semantic categories expressed by interrogative words that occur on the basis of a sample of 50 languages. These categories are listed in (55a-f):
(55) a. INDIVIDUALS
b. LOCATION
c. TIME
d. MANNER
e. QUANTITY
f. REASON

In his categorization, Mackenzie (2008: 1133) regards simple interrogative words, i.e. unanalysable forms at the morphosyntactic level, as "true" interrogative categories. A somewhat similar result is provided by Cysouw $(2004,2005)$ on a sample of 67 languages. However, Cysouw (2004; 2005) considers not only the semantic gaps fulfilled by interrogative words but also the forms of the elements. In his studies, Cysouw $(2004 ; 2005)$ differentiates three categories of interrogative words: major, minor and incidental categories. The elements of the major semantic category are interrogative word forms that cannot be analysed within the synchronic structure of the language. In contrast, the minor category consists of synchronically analysable compound lexemes, which are usually derived forms from the elements of the major group. In addition, the elements of the incidental interrogative category "are only unanalysably lexicalised in incidental cases" (Cysouw 2004: 18). The inventory of interrogative words provided by Cysouw $(2004 ; 2005)$ is given in (56-58) below.

(56) Major interrogative categories
a. PERSON
b. THING
c. SELECTION
d. PLACE

(57) Minor interrogative categories
a. QUANTITY
b. TIME
c. MANNER 
(58) Incidental interrogative categories
a. REASON
b. QUALITY
etc.

The typical semantic categories established by Mackenzie (2008) and Cysouw $(2004 ; 2005)$ have a lot in common, nevertheless, they cannot be presumed cross-linguistically. Rather, it seems a language-specific characteristic what meanings are encoded by interrogative forms. Additionally, although Frawley (2002: 235) notes that similar kinds of meaning tend to surface in similar lexical constructions, the distinction made in the systems of lexical forms for filling a particular semantic gap is also a language-specific feature. It cannot be presupposed in a given language which existing semantic category of interrogatives will belong to the major group or to the minor one. A further aspect of the relation between interrogative meanings and interrogative forms is discussed by Dahl (2004) and Mackenzie (2008). There is a correlation concerning the semantics and the morphosyntactic characteristics of interrogative words. Thus, "a language with maximum complexity will display a different form for each category; a language with minimum complexity will use one form for all categories" (Mackenzie 2008: 1133). The system with minimum complexity, where different meanings are expressed by the same lexeme, is called extreme transparancy by Cysouw (2005). Cysouw (2004: 2) presents the extreme example of Asheninca Campa (an Arawak language spoken in Peru), where only one question word form fulfils several information gaps. The minimally complex interrogative word system supposes ambiguous forms among the interrogative words. Their semantic ambiguity may involve grammatical consequences (e.g. distributional differences). At the other endpoint of this scale, languages like English can be found, in which each semantic function has different form. Therefore, these highly complex systems do not contain ambiguous interrogative word forms. Consequently, neither the meaning, nor the surface forms can universally be predicted crosslinguistically. The complexity of the items of the interrogative word set and the complexity of the whole system does, however, correlate with each other.

Another often discussed distinctive parameter of interrogative words is their grammatical categories. The set of the interrogative words in a given language is usually classified as consisting of items that belong to the closed word class of the language with respect to morphological, syntactic, and semantic properties of the items. However, interrogative words usually do not exhibit a homogeneous grammatical category, as they typically "cut across 
other parts-of-speech classes" (Schachter \& Shopen 2007: 33). In many languages, interrogative words may be different grammatically and they may belong to various word classes. Consequently, the grammatical categories or word classes of interrogative words cannot be universally presupposed either (cf. Schachter \& Shopen 2007: 34). However, there is a cross-linguistic tendency regarding the typical parts-of-speech categories of interrogative words (cf. Velupillai 2010: 358). Although, the presence or absence of a given grammatical category varies from language to language, the typical categories for which one can observe interrogative substitutes are pronouns, determiners, adjectives, quantifiers, ordinal numbers, adverbs and verbs (cf. Idiatov \& van der Auwera 2004; König \& Siemund 2007: 302; Velupillai 2012: 359). These parts-of-speech categories fulfil typical syntactic functions across languages. According to König \& Siemund (2007: 302), usually there are interrogative words which "replace the core constituents or arguments of a sentence", they can typically function as subject, object, adverbial, adjectival modifier and predicate, etc. in the clause (cf. König \& Siemund 2007: 302).

However, the most typical criterion concerning content questions is the syntactic position of interrogative words. According to Dryer (2013a), interrogative phrases occur in two typical syntactic positions in the languages (see 59a-b).

(59) a. obligatorily at the beginning of the sentence

b. optionally at the beginning of the sentence

Consequently, there are languages in which interrogative phrases always obligatorily occur sentence-initially, like in English, illustrated in (60a-b).

(60) a. Who saw you? (sentence initial wh-constituent)
b. Whom did you see?

In these types of languages, the initial position of the interrogative phrases may cause changes in the basic word order of the clause, like in (60b) where the word order is OVS instead of the expected SVO. Consequently, the syntactic functions of the interrogative phrases do not play a role in their positions within the clause in these types of languages. Additionally, Dryer (2013a) also considers languages in which the interrogative words are obligatorily fronted, that allows interrogative phrases to occur in positions other than sentence initial under certain 
circumstances. English is a typical fronting language whereas interrogative phrases can also remain in situ, for instance, in English echo-questions (see 61 and compare with 60b).

(61) You saw who? (echo question with in situ wh-constituent)

The other group of languages with respect to the syntactic position of interrogative phrases does not require their interrogative phrases to appear in clause initial position. Instead, the interrogative phrase can either be situated in the immediately preverbal position or it can remain in situ. In Hungarian, for instance, interrogative phrases obligatorily occur in preverbal position regardless of their syntactic function, which position is the typical structural position for the focus ${ }^{24}$ of the clause in the language (cf. É. Kiss 2002: 98; see $62 \mathrm{a}-\mathrm{b}$ ).

(62) Hungarian
a. $K i$ lát-ott
téged?
(wh-constituent in focus position)
who see-PST.3SG.DEF 2SG.ACC
'Who saw you?'
$\mathrm{S}_{\mathrm{Q}}{ }^{25} \mathrm{~V}$
b. Te ki-t
lát-t-ál?
2SG who-ACC see-PST-2SG.INDF
'Whom did you see?'
$\begin{array}{lll}\mathrm{S} & \mathrm{O}_{\mathrm{Q}} & \mathrm{V}\end{array}$

In contrast, the so-called in situ languages allow their interrogative phrases to remain in the same position within the clause in which a non-question word fulfilling the same grammatical function is located. Consequently, in these types of languages the syntactic function of interrogative phrases may determine their position within the clause. Tundra Nenets, for instance, is described as being a typical in situ language (cf. Salminen 1998: 543). Given that Tundra Nenets has an SOV neutral word order, the interrogative phrase functioning as subject appears sentence initially (see 63).

\footnotetext{
24 The term focus covers "an argument accorded prominence within a clause" (cf. Dixon 2010a: 335). The focus is interpreted here as a discourse category, which expresses the new element of the discourse.

${ }^{25}$ The interrogativity of the phrases/clausal constituents are marked by $\mathrm{Q}$ in the disseration.
} 
(63) Tundra Nenets

xib̀a śỉmi śid'e? (wh-constituent in situ)

who 1SG.ACC wake.up.vX.3SG

'Who woke me up?' (Samoylova \& Barmich 2010: 93)

$\mathrm{S}_{\mathrm{Q}} \quad \mathrm{O} \quad \mathrm{V}$

In (64), the interrogative phrase which functions as the direct object follows the subject:

(64) Tundra Nenets

$\begin{array}{llll}\text { pida } & \text { yamge-m? } & \text { xeta? } & \text { (wh-constituent } \text { in } \text { situ) } \\ \text { 3SG } & \text { what-ACC } & \text { say.VX.3SG }\end{array}$

'What did he say?' (Nenyang 2005: 48)

$\mathrm{S} \quad \mathrm{O}_{\mathrm{Q}} \quad \mathrm{V}$

In both clauses above, the word order of the questions corresponds to the basic order of declarative clauses. The appearance of an interrogative phrase does not change the basic word order of the language.

As Dryer (2013a: 3) notes, there are also languages that do not require interrogative phrases to be sentence initial. In these languages, interrogative phrases typically occur at the end of the sentence.

Finally, Dryer (2013a) also describes languages that can hardly be categorized into any of the groups mentioned above. For example, in some languages, placing interrogative phrases in sentence initial position is optional. This means that the non-initial position of an interrogative is not caused by special circumstances (contrary to English echo-questions). In other languages, some interrogative phrases must occur in sentence initial position, while others need not (cf. Dryer 2013a: 5). These languages can be considered as the mix of the two above mentioned types with obligatorily and not obligatorily sentence initial interrogatives.

A somewhat similar classification concerning the position of interrogative words in the clause is provided by König \& Siemund (2007). According to this classification, interrogative words can appear in three typical positions in the clause cross-linguistically (see König \& Siemund 2007: 301-302). These types are given in (65a-c). 
(65) a. obligatorily fronted

b. optionally fronted

c. in situ

This categorization overlaps with he types presented by Dryer (2013a). In obligatorily fronting languages, the interrogative word occurs in the clause initial position obligatorily. This initial placement may change the neutral word order of the clause. In contrast, other languages allow the placing of the interrogative word in clause initial position, but under certain circumstances it can also occur in non-initial positions. Finally, in the so-called in situ languages, interrogative words occur in the position for their constituent type (cf. 2001: 10191020; König \& Siemund 2007: 302).

Greenberg (1966: 82) claims that there is a correlation between the basic word order type of a language and the position of its interrogative words. This correlation is formulated by Greenberg (1966) in Universal 12:

"If a language has dominant order VSO in declarative sentences, it always puts interrogative words or phrases first in interrogative word questions; if it has dominant order SOV in declarative sentences, there is never such an invariant rule." (Greenberg 1966: 82)

Languages with VSO order front their interrogative words into clause initial position, while the sentence initial position for interrogative phrases in SOV languages is not typical. These languages can more likely be categorized as being in situ languages. However, as König \& Siemund (2007: 302) note, a much weaker correlation exists in the case of SOV languages than detectable in VSO languages. Finally, such correlation cannot be detected in languages with SVO basic word order. A similar result is provided by Dryer (1991), with the exception that the correlation in the case of verb initial languages, i.e. VSO and VOS languages, is not exceptionless. On the basis of Greenberg (1966), Dryer (1991) and König \& Siemund (2007), the possible correlation between basic word order and the position of interrogative phrases of languages can be illustrated as in (66a-c).

(66) a. V-initial \& wh-fronted

b. V-final \& wh-in situ

c. SVO \& both 
A content question may contain more than one interrogative word. This subtype of content question is called multiple question. Multiple content questions fall into two groups regarding the position of their interrogative phrases (cf. e.g. Siemund 2001: 1023-1024; see 67a-b).

(67) a. partial fronting

b. multiple fronting

Languages belonging to the category of (67a) allow only one interrogative element in sentence initial position, and the other interrogative phrase remains in situ (cf. Siemund 2001: 1024). English represents this multiple interrogative type (see 68).

(68) Who gave what to whom?

(Siemund 2001: 1024)

In contrast, there are languages in which all multiple interrogative words/phrases occur sentence initially. Amongst other languages, Russian is a typical multiple fronting language (cf. Siemund 2001: 1024; and see 69).

(69) Russian

$\begin{array}{lll}\text { Kto } & \text { kogo } & \text { ljubit? } \\ \text { who } & \text { who.ACC } & \text { love.3SG }\end{array}$

'Who loves whom?' (Siemund 2001: 1024)

For further description of multiple interrogatives see e.g. Cheng (1991); Siemund (2001); Bayer (2006); Dayal (2006); among others.

After formulating the cross-linguistic criteria of content questions typically discussed in the literature, I will now turn to the discussion of the analysable set of Tundra Nenets interrogatives.

\subsection{Defining the analysed constructions in Tundra Nenets}

The aim of this section is to delimit those constructions in Tundra Nenets that will be examined in the present study. This section does not only introduce individual construction 
types in Tundra Nenets that this study will focus on, but also those constructions that will not be discussed in further detail later on. According to the distinction described in $\S 4.1$, I will not concentrate on clause types in Tundra Nenets that are associated with speech acts other than requesting information, therefore declarative and imperative clauses will not be analysed here.

Furthermore, I will examine interrogative clauses which fulfil the criteria explained in $\S 4.2$., thus I will only focus on the interrogatives which contain an interrogative word (phrase) and require a specific answer other than Yes/No illustrated in (70) below.

$\begin{array}{lll}\text { (70) } \begin{array}{ll}\text { xib̆a } \\ \text { wesako-mí }\end{array} & \text { (content question) } \\ \text { who husband-PX.ACC.1SG } & \text { kill-NARR.VX.3SG } \\ \text { 'Who killed my husband?' (Labanauskas 1995: 107) }\end{array}$

Therefore, polar questions (see 71) and alternative interrogatives (see 72) will be excluded from the discussion.

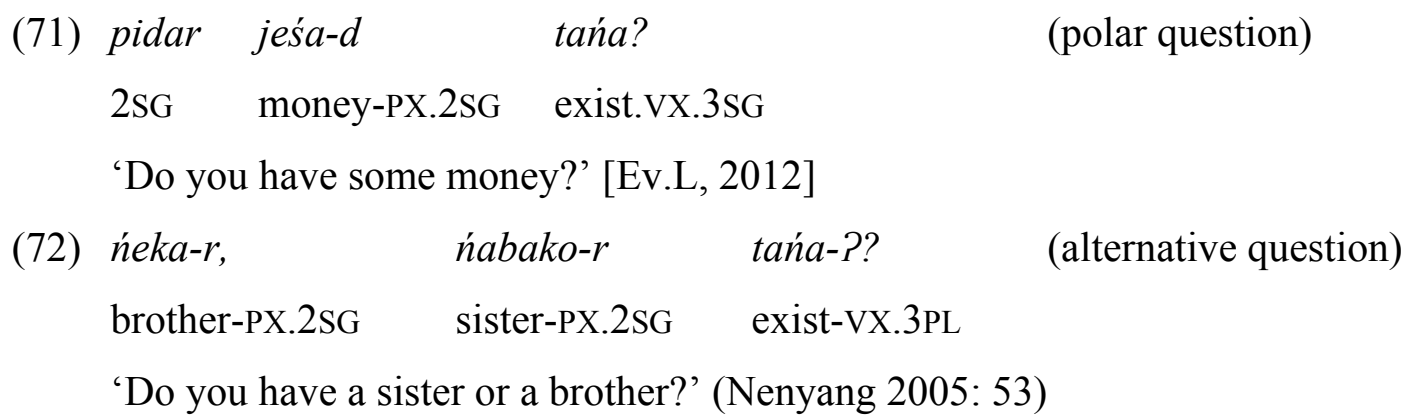

Moreover, as we have seen in $\S 4.1-4.3$, content questions have subtypes which appear only in special contexts. For instance, the echoed content questions are used as a response to a previous utterance for seeking clarification (but not for an unknown answer). Usually, the interrogative word does not occupy its standard position within these questions. Since the grammatical characteristics (e.g. syntactic structure, word order, the position of interrogative words, etc.) of Tundra Nenets standard content interrogatives have not been discussed in detail and we cannot formulate the syntactic rules of the regular use of interrogative words and phrases, these marked types will be excluded from the scope of the investigation. Consequently, the subtype of content questions that expresses surprise or requests for clarification in a given discourse, i.e. the echo questions in Tundra Nenets, represented by example (73b), will not be analysed in the study. 
(73) a. tuku xiba-? mar??

this who-GEN wild.reindeer.bull.vX.3SG

'Whose wild reindeer bull is this?'

b. xiba-? mar? $\quad$

who-GEN wild.reindeer.bull.vX.3SG be-FUT.VX.3SG

'Whose wild reindeer bull could it be [...]?' (Yangasova 2001: 51)

In addition, clauses in which the Tundra Nenets interrogative pro-words appear in a function other than interrogatives, e.g. as relative (74) or as indefinite (75) pro-forms, do not fall within the scope of the present study either.

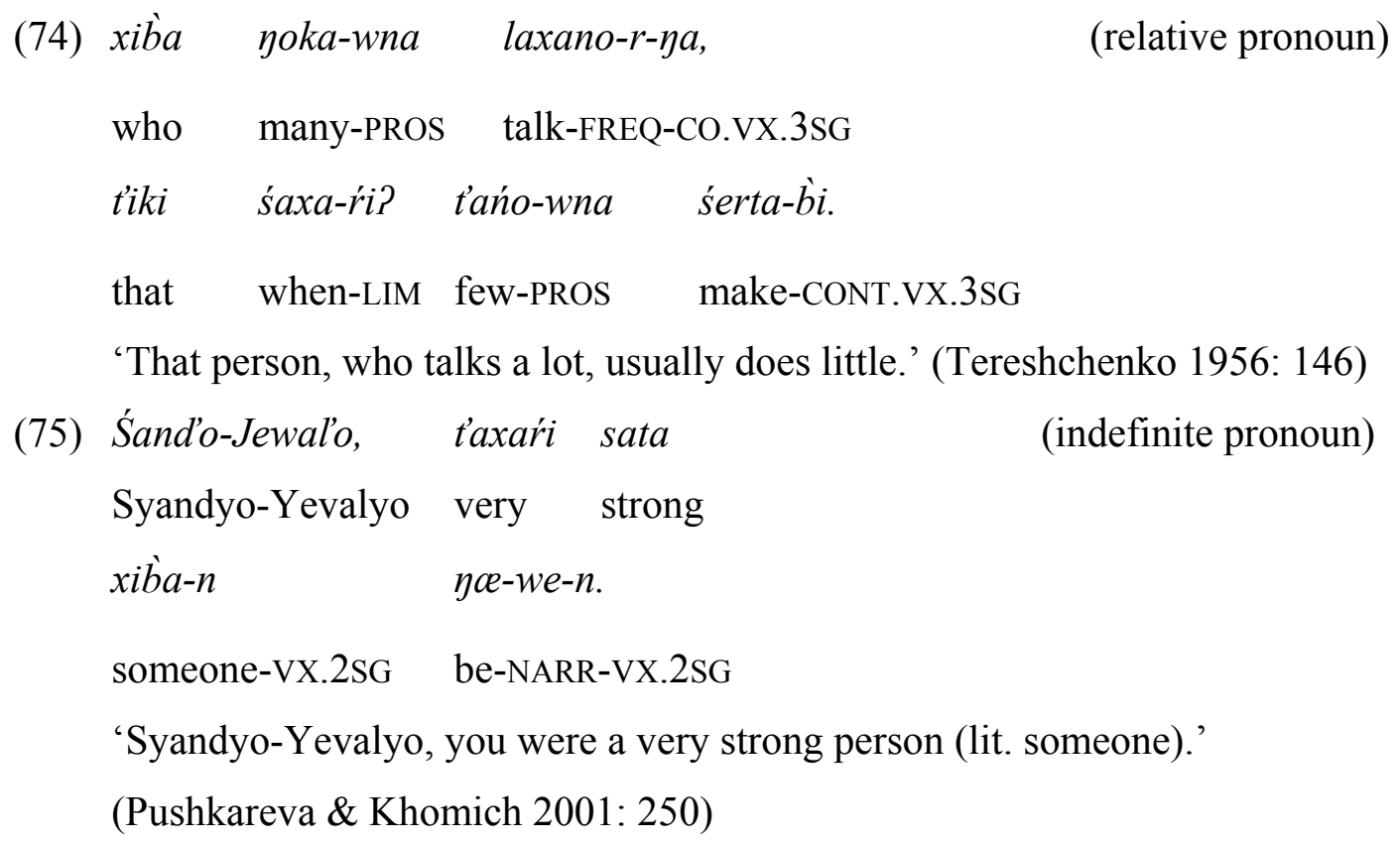

Additionally, interrogative pro-words are found in exclamatives (see 76).

(76) xurka sawa xiba yce-wi! (wh-exclamative)
which good who be-NARR.vX.3SG
'He is succh a good person!' (Tereshchenko 1965: 784; Nikolaeva 2014: 271)

In (76) above the interrogative element is not used in its standard function, i.e. asking for information, therefore, clause-types represented by (76) will not be examined here. 
Furthermore, subordination in Tundra Nenets is typically expressed by non-finite verb forms. In these clauses, the dependent clause may be controlled by its subject via possessive suffixes (as in 77 below) in which cases the adjacency of the "possessor" subject and the "possessed" dependent clause may be obligatory. This can have an effect on the position of the interrogative element in the clause. Therefore, the analysis of complex content questions regardless of whether the matrix clause contain the interrogative word (see 77) or the question is embedded (see 78) - is not included in the present discussion.

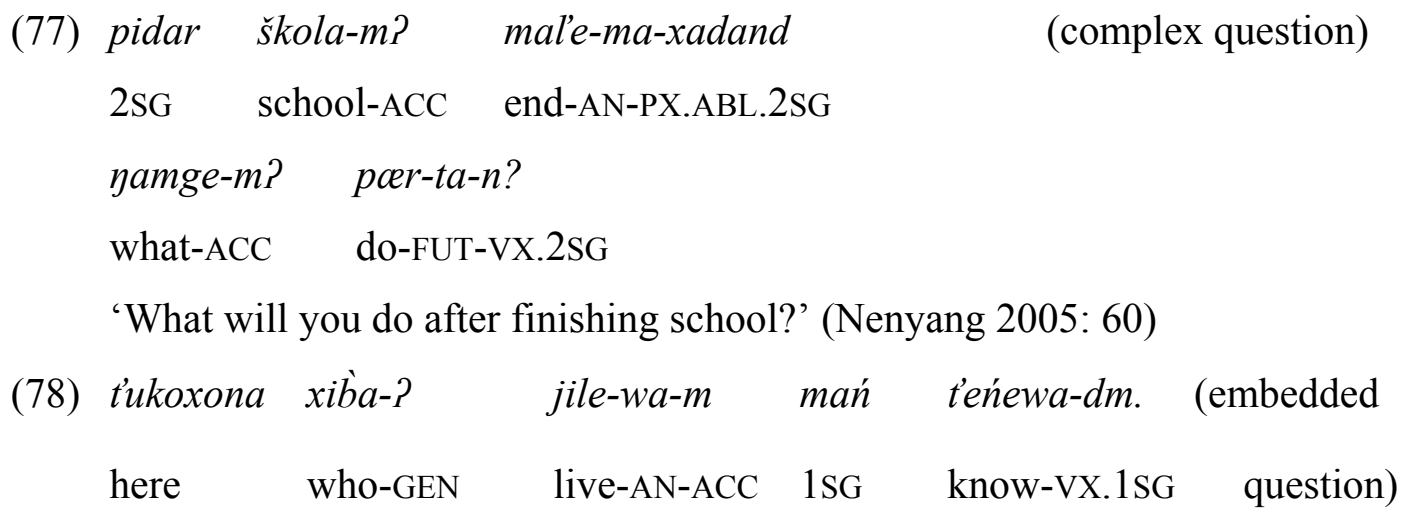

'I know who lives here.' (Nikolaeva 2014: 306)

In addition, the negative structures will also be omitted from the analysis. It is well-known that only one clausal element can also occur in the scope of the negation. In some languages, like in Hungarian, this element can be an interrogative word (see 79).

(79) Hungarian

Nem ki-t, hanem mi-t lát-t-ál?

NEG who-ACC but who-ACC see-PST-2SG.INDF

'Not whom but what did you see?'

Although, a structure illustrated in (79) has not been attested in the Tundra Nenets corpus, the existence of this construction in the language cannot be excluded. In consequence, I exclude content questions in which there is an element either negated with the standard negative auxiliary or with any other negative strategy that is available in Tundra Nenets (see 80-81, respectively). 
(80) xib̀a $\quad$ nuda-śa $\quad$ jil-?? (clausal negation)

who hand-PX.ACC.3SG NEG.AUX-INT.VX.3SG raise-CNG

'Who did not raise his/her hand?' (Nenyang 2005: 146)

(81) t’uku jal'a-? xib̀a jaygu? (existential negation)

this day-GEN who NEG.EX.VX.3SG

'Who is absent today?' (Nenyang 2005: 58)

Moreover, as was already mentioned in $\S 4.3$, different syntactic position may be occupied by the interrogative elements if they appear in a so-called multiple question. Thus, content questions containing more than one interrogative word/phrase, i.e. (see e.g. 82), will not be analysed within the frame of this study.

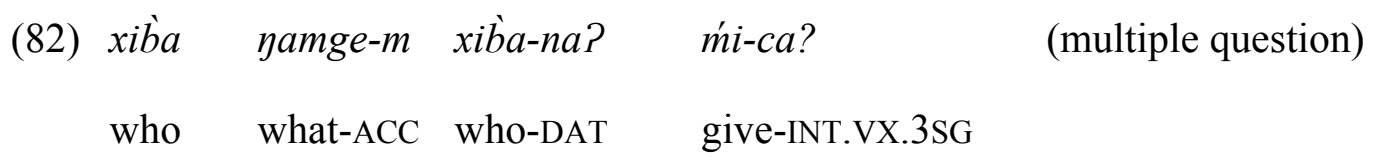

'Who gave what to whom?' (Nikolaeva 2014: 266)

Additionally, several grammars of Tundra Nenets (e.g. Hajdú 1968: 65; Tereshchenko 1973: 92; Salminen 1998: 530) discuss a modal marker of verbs used in questions. The use of this marker is, however, restricted to past tense reference (see 83).

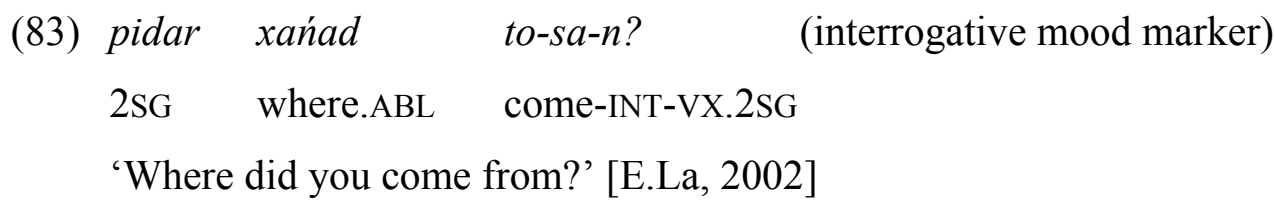

In the present study, I do not deal with this marker in detail but I acknowledge that this affix indicates interrogativity and has past tense reference.

Finally, in Tundra Nenets there is an interrogative verb xa?man 'say what' too. According to Cysouw's (2004: 9) classification of interrogative verb types across languages, this Tundra Nenets verb specifies the semantic category of UTTERANCE (see 84). Since the use of this interrogative verb does not implicate standard content question, this study is not concerned with this element and structure either. 


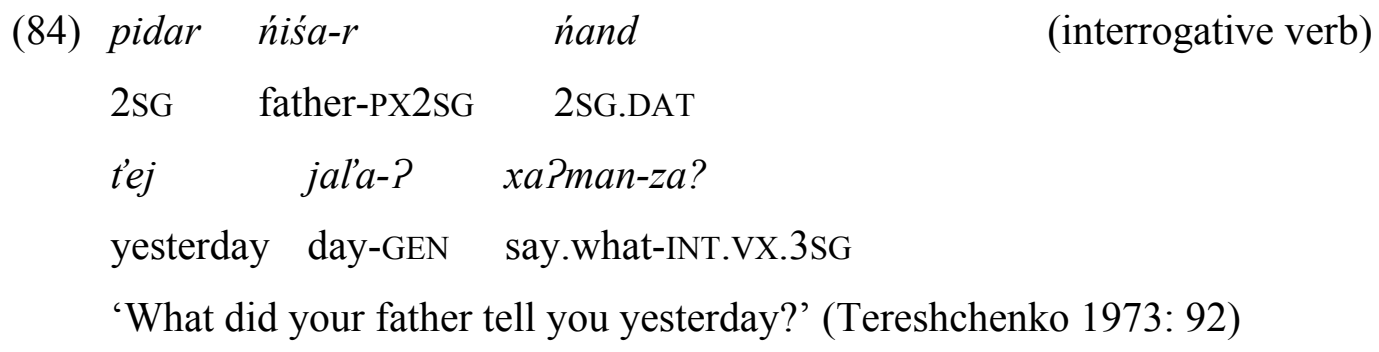

Considering that the present study is the first systematic analysis of content questions in Tundra Nenets, I will only concentrate on the prototypical content question type, which:

(i) does not function as an echo question,

(ii) contains only one interrogative word/phrase and that is not an interrogative verb,

(iii) consits of only one non-negative predicate.

In what follows, I will discuss how content questions and/or interrogative words are interpreted in previous studies on the Tundra Nenets language.

\subsection{Previous research on Tundra Nenets (content) questions}

This section summarizes the results of grammars and studies related to (content) questions in Tundra Nenets.

Four basic clause types are distinguished in Tundra Nenets relative to their conversational use, i.e. to the speech acts they are associated with: declarative, imperative/directive, interrogative and exclamative clauses (cf. Tereshchenko 1973: 87-100; Nikolaeva (2014: $194-223 ; 265-272)$.

Declarative clauses, which are unmarked in Tundra Nenets since the language does not have a special declarative marker, typically express speech acts as claiming, stating, negating (cf. Tereshchenko 1973: 87). They are also typically used for answering interrogative clauses. Within declaratives, the linear order of the clausal elements is usually discussed (see $\$ 2.3$. for a short discussion; cf. Salminen 1998: 543; Dalrymple \& Nikolaeva 2011: 136 and Nikolaeva 2014: 214). As it can be concluded, Tundra Nenets has a relatively free word order. The only constraint is the clause final position of the finite verb. In addition, differences between affirmative and negative counterparts are usually discussed (for a detailed description of Tundra Nenets negatives see e.g. Nikolaeva 2014: 272-282 and from a typological aspect see 
Mus 2015). The Tundra Nenets standard negation is expressed with a negative auxiliary verb which negates a lexical verb. In the negative predicate the negative auxiliary appears as the finite element of the construction, taking the markers of inflectional verbal categories. Furthermore, there are also negative auxiliaries, negative lexical verbs having some other meaning beyond the negation, as well as, there is a negative existential verb. A further aspect of declaratives usually discussed is the type of predicates which may occur in declaratives. Basically, one can distinguish between verbal and nonverbal predicates. Among verbal predicates, intransitive, transitive and ditransitive structures are usually distinguished. A comprehensive syntactic analysis of single clauses including intransitive and transitive structures in Tundra Nenets is provided by Nikolaeva (2014). In addition, a detailed analysis of Dalrymple \& Nikolaeva (2011) specifies transitive constructions in Tundra Nenets. Certain observations concerning the object agreement of verbs provided by the authors will be used in this dissertation. In addition, predicative noun and adjective structures - mainly the declarative ones - are also usually distinguished in the literature (e.g. Tereshchenko 1956; Kuprijanova et al. 1957; Nikolaeva 2014). Moreover other types of typical nonverbal clauses, such as existential, locative, possessive clauses, etc., are described in Nikolaeva (2014: 250264).

Imperatives/directives in Tundra Nenets typically convey requests, commands and orders and are marked through mood affixes attached to the predicate verb (cf. Tereshchenko 1973: 89). Recent grammars (e.g. Salminen 1998: 530; Nikolaeva 2014: 269) consider the hortative and the optative/jussive to be subtypes of imperative clauses as well.

Exclamatives are typically used for expressing strong emphasis and/or emotions in Tundra Nenets and have special raising intonation. These clauses often contain exclamative clitics, particles, interjections, etc. (cf. Tereshchenko 1973: 95-100; Nikolaeva 2014: 270-272). However, the syntactic structure of exclamative clauses do not differ from the three other types. Rather, the other main clause types are all appropriate for expressing exclamation since exclamative clauses are usually expressed through lexical elements. As mentioned in $\S 4.4$., exclamatives may contain interrogative words/phrases as well.

Finally, as Tereshchenko (1973: 90) notes, interrogative clauses are typically associated with the speech act of requesting information. In her grammar, Tereshchenko (1973: 90-95) distinguishes only two types of interrogatives in Tundra Nenets: polar and content questions. Furthermore, Nikolaeva (2014: 267-269) reports on a third type of interrogatives, i.e. the socalled alternative (and deliberative) question. As was already mentioned in $\S 4.2$, Tundra 
Nenets employs the following strategies for expressing polar questions (cf. Miestamo 2011: 8; see $85 a-b)$.

(85) a. interrogative intonation

b. interrogative verb morphology

Tereshchenko (1973: 91) notes that the interrogative intonation is typically a rising intonation if the emphasized, questioned, clausal element occupies the clause final position. In contrast, a falling intonation of the question is detected when the emphasized element is in initial position. In contrast, Nikolaeva (2014: 267) mentions that polar questions in Tundra Nenets are tipically accompained by raising intonation. Since this study is based on the examination of written data, I cannot support these explanations by data. Furthermore, Tundra Nenets can mark its polar questions through an affix attached to the predicate verb, but this marker is used only in the past tense (see 83a above). Several grammars (e.g. Prokofyev 1936; Kupriyanova et al. 1957; Tereshchenko 1973; Nikolaeva 2014) refer to the interrogative affix as an interrogative mood marker used with past tense reference. It is argued in these grammars, that the interrogative suffix is exclusively used in questions. In contrast, Burkova et al. (2010: 339-340) consider this marker to be a modal clitic on grounds of function and semantics. They suggest, inter alia, that the marker can also appear in declaraive clauses. This, however, conflicts with the fact that the affix has interrogative function. In my research, I did not examine the use and occurrence of this affix, therefore I cannot resolve the contradiction in the literature. Following the traditional terminology I will regard this affix as interrogative mood marker with past tense reference. In sum, polar interrogatives in present and future tenses are only expressed by interrogative intonation, while in past tense a modal suffix is attached to the finite verb. Miestamo (2011: 13) notes that Tundra Nenets polar questions are asymmetric structures, in the sense that the difference between the indicative aorist and past tense (see $86 \mathrm{a}-\mathrm{b}$ ) cannot be expressed in the interrogative mood since the interrogative marker has only a past tense reference. Therefore, interrogativity in present and past tense is expressed by declarative forms and interrogative intonation (cf. Miestamo 2011: 13). Examples in $(86 a-c)$ below illustrate this asymmetry in the interrogative paradigm: 
(86) a. $n u$

stand.IND.vX.3SG

'(s)he stands'

b. $n u-s^{\prime}$

stand.IND.VX.3SG-PST

'(s)he stood'

c. $n u-s a$ ?

stand-INT.VX.3SG

'did (s)he stand?' (Miestamo 2011: 13 \& Salminen 1998: 530)

The typical strategies used for distinguishing polar questions are also available for content questions in Tundra Nenets (cf. Tereshchenko 1973: 91). Content questions can be characterized by the following properties:

(87) a. interrogative intonation

b. interrogative verb morphology

c. interrogative words

Tereshchenko (1973: 91) observed the same intonation pattern for content questions as used in polar questions in Tundra Nenets. In addition, the interrogative modal affix referring to past tense can be used in content questions. Accordingly, the most typical difference between polar and content questions in Tundra Nenets is the presence of an interrogative substitute in content questions. A few interrogative word types have already been observed in the literature to typically occur in Tundra Nenets, such as the category of interrogative pronouns, adjectives, quantifiers, determiners, adverbs and verbs (cf. Kupriyanova et al. 1957: 104, 178; Hajdú 1968: 54; Tereshchenko 1973: 91-92; Salminen 1998: 526; Burkova et al. 2010: 56; Nikolaeva 2014: 265). However, there have only been descriptions of the grammatical characteristics of interrogative pronouns. Other interrogative words are only mentioned without analysing the semantic, morphological and/or distributional differences among the elements of the inventory of interrogative words (see e.g. Kupriyanova et al. 1957: 104; Hajdú 1968: 54; Salminen 1998: 526; Burkova et al. 2010: 55-56; Nikolaeva 2014: 265-266). Additionally, Tereshchenko (1956: 190) presents formal differences within certain subdialects of Tundra Nenets; these formal differences will be discussed in Chapter 6. With respect to the semantic categories available for Northern Samoyedic interrogative words, I provided a 
lexico-typologycal classification in Mus (2013). I only concentrated on those interrogative words that are already lexicalized forms (for discussion see Mus 2013). The other aspect of content questions that is usually discussed is the position of interrogative words in the sentence. It is often stated that Tundra Nenets is a so-called in situ language, in which the interrogative word is not situated in a special position within the clause, but remains in the same position in which a non-interrogative word fulfilling the same grammatical function is located (cf. Salminen 1998: 543). However, while Salminen (1998) describes content questions as being in situ, Tereshchenko (1973: 91) notes that the interrogative pro-forms are situated either in the clause initial position or they immediately precede the predicate. This observation is supported by Nikolaeva (2014: 265), who reports on free syntactic position of interrogative words/phrases within content questions. These observations suggest that there are more syntactic positions in which Tundra Nenets interrogative words are licensed. Nikolaeva (2014: 266) claims that these positions are optional.

Finally, there are alternative questions in Tundra Nenets. This type of questions is typically expressed by a doubled predicate construction in which the negative auxiliary follows the finite verb. Both verbs bear the same agreement and TAM markers (see 88; cf. Nikolaeva 2014: 267).
(88)
$\begin{array}{lll}\text { Wera } & \text { to-sa } & n ́ i-s a ? \\ \text { Wera } & \text { come-INT.VX.3SG } & \text { NEG.AUX-INT.VX.3SG }\end{array}$
'Did Wera come or not?' (Nikolaeva 2014: 267)

As Nikolaeva (2014:268) notes, in (88) above the whole utterance stands in disjunction. If the alternatives provided in the question only are only elements of the clause, the second one is situated after the finite verb as in (89):
(89)
noxo- $m$
$x a d a-s a-n$, t’óna-m? arctic.fox-ACC kill-INT-VX.2SG fox-ACC
'Did you kill an arctic fox or a red fox?' (Nikolaeva 2014: 268)

In this case the second alternative is marked by a raising intonation (cf. Nikolaeva 2014: 268).

After this overview of Tundra Nenets grammars about clause types and content questions, several questions arise that have remained without answer so far. The next section summarizes the main questions that will be answered in this study. 


\subsection{Research questions}

As was mentioned previously, this section aims at formulating those research questions that will be discussed in the following chapters (see i-v below).

(i) The first major question that may be asked concerns the semantics of interrogative elements in Tundra Nenets. The question is what potential semantic gaps are/can be filled by an interrogative word in the language.

(ii) The second question addresses certain formal characteristics of these available semantic categories, namely, which semantic category requires a simple, uninflected, or a complex, inflected, form.

(iii) The third question concerning the semantics of interrogative words inquires about possible semantic ambiguities of the given lexical forms, and the grammatical consequences of having these ambiguous forms. The answers to these questions lead us to observe the complexity of the Tundra Nenets interrogative word inventory.

(iv) The fourth question is how the given semantic categories are distinguished grammatically in Tundra Nenets; in other words, what are the typical inflectional, distributional and functional characteristics of the interrogative words.

(v) The final question raised is concerned with all the possible syntactic position of interrogative words, namely, whether the syntactic position correlates with the syntactic functions of interrogative words, or other rules control the syntactic structure of content questions in Tundra Nenets.

In what follows, I will discuss the semantic categories of available interrogative words and their formal relations (see Chapter 5). Afterwards, I will examine the grammatical character of interrogative elements (see Chapter 6). Finally, I will identify their syntactic position and provide a description concerning certain word order peculiarities available in content questions (see Chapter 7). 


\section{The lexico-semantics of interrogative words}

As was mentioned in Chapter 4, Tundra Nenets grammars identify interrogative words as the category that is typically used in interrogative contexts requiring (more) information about a given theme or about a given entity. The present chapter is concerned with the dimension of distinctive semantic features of interrogative words in Tundra Nenets. This dimension also defines the set which can be accepted as an appropriate answer to an interrogative word (cf. Groenendijk \& Stokhof 1993: 2). The central problem to be addressed in the present chapter is the relation among the available semantic categories (lexical meanings) and the morphological form of the interrogative words. Following Cysouw's (2004) classification, those interrogative words will be considered here as elements of the major category that fulfil the following criteria:

(i) lexicalized and only historically analysable forms

(ii) identical (ambiguous) forms

Janhunen $(1977: 15,62,69,75)$ derives the Tundra Nenets interrogative forms from ProtoSamoyedic interrogative stems and analyses them as historically compound forms. Consequently, there are no interrogative words that can be unanalysable in the language. Therefore, the major semantic category consists of lexicalized interrogative words that can only be considered as simple forms within the synchronic structure of the language. In addition to these historically analysable forms, semantic categories expressed by the same lexemes, i.e. ambiguous forms, will be categorized as members of the major semantic group of interrogatives.

Furthermore, morphologically and the syntactically compound forms will be characterized here as elements of the minor semantic group. The formal requirements of this group are illustrated below in (i)-(ii):

(i) morphologically compound forms: an element of the major category is combined with an affix

(ii) syntactically compound forms: an element of the major category is combined with a postposition 
Consequently, the elements of the minor semantic category are interrogatives which are results of certain grammatical operations made on the major interrogative elements. The relation among the elements of the major category and the derived forms, i.e. the elements of the minor category, will be discussed here in order to illustrate the semantic links among the categories. The following sections survey the individual construction types in the Tundra Nenets language.

\subsection{Non-selective interrogative words}

Tundra Nenets distinguishes two interrogative words for eliciting entities, individuals, animals and things in a non-selective situation. These interrogatives are: xiba 'who' and yamge 'what'. By using these interrogative words the speaker asks for an element of an open set of alternatives. ${ }^{26}$ The semantic operation done by non-selective interrogatives is similar to selection/indetification in the sense that it requires a choice from a set. However, nonselective interrogatives carry out this semantic operation on an open set. Therefore, nonselective interrogative words can be characterized by a [-SEL] feature.

According to Lindström (1995) and Ultan (1978) if a language differentiates the interrogative categories of PERSON and THING, then the interrogative words show either a HUMAN/NONHUMAN or an ANIMATE/INANIMATE contrast. The following question-answer pairs illustrate the semantic difference between xiba 'who' and yamge 'what' in Tundra Nenets (see 90-92).

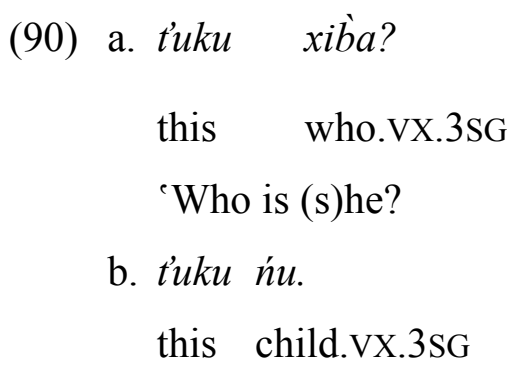

'This is a/the child.' (Okotetto 1998: 11)

\footnotetext{
${ }^{26}$ The selective use of yamge 'what' is also possible in Tundra Nenets. This semantic function will be discussed in $§ 5.1 .4$ below.
} 
(91) a. t'uku yamge?

this what.VX.3SG

'What is this?'

b. t’uku juno.

this horse.VX.3SG

'This is a/the horse.' (Okotetto 1998: 8)

(92) a. tuku yamge?

this what.vX.3sG

'What is this?'

b. t’uku ńo.

this door.VX.3SG

'This is a/the door.' (Okotetto 1998: 11)

The examples above suggest that the interrogative word with the meaning 'who' (xib'a) substitutes a human referent, while the interrogative word for 'what' (yamge) asks about nonhuman animate and non-human inanimate entities, i.e. about animals and things (cf. Kupriyanova et al. 1957: 104; Tereshchenko 1973: 125; Burkova et al. 2010: 56). Consequently, the semantic opposition between the non-selective interrogative words is a HUMAN/NON-HUMAN difference in Tundra Nenets. In other words, they encode a [ \pm HUMAN] feature.

Despite the [ $\left.{ }_{\mathrm{HUMAN}}\right]$ feature distinguishing 'who' from 'what', different uses are also possible in certain contexts. The interrogative word 'who' (xiba) can often be found with animal referents in folklore texts. In these cases, the animate entities are personalized and are thus asked about with 'who' (cf. Kupriyanova et al. 1957: 37; see 93a-b).

(93) a. pidar yańi? $\quad x i \grave{a} a-n$ ?

2SG whether who-VX.2SG

'Who could you be?'

b. noxo-koća-dm?.

arctic.fox-DIM-VX.1SG

'I am a/the small arctic fox.' (Pushkareva et al. 1994: 9) 
Still, the use of the human interrogative word requesting for animals does not imply an ANIMATE/INANIMATE dichotomy between the non-selective interrogative words, because this occurrence is only possible in special pragmatic contexts illustrated above in $(93 a-b)$.

On the other hand, it is possible to utilize the interrogative word of a NON-HUMAN category (yamge 'what') for human referents when a classification, e.g. the profession of a person is asked (see 94).

\author{
(94) a. ńiśa-ḿni gamke? \\ father-PX.1SG what.VX.3SG \\ 'Who is my father (lit. what)?' \\ b. ńiśa-r parayoda \\ father-PX.2SG king.VX.3SG \\ 'Your father is a/the king.' (Pushkareva 2003: 215)
}

To sum it up, the inventory of Tundra Nenets major interrogative words consists of two elements that have a [-SEL] and a [ ${ }_{\text {HUMAN] }}$ semantic feature and are expressed by uninflected free forms.

As was explained at the beginning of this chapter, one may find semantic subcategories within the elements of the major category. The forms of HUMAN and NON-HUMAN interrogative words can freely be suffixed with case markers. These marked forms may result in semantic subcategories belonging to the minor group of interrogatives in Tundra Nenets. Some typical complex forms will be presented in $\S 5.1 .1$ and $§ 5.1 .2$. Additionally, there are also syntactically compound forms whose meanings are defined by postpositions (discussed in §5.1.3). In this categorization, however, solely those complex interrogative forms will be considered as members of the minor interrogative set whose meanings differ from the sum of the meanings of their components.

Finally, certain ambiguities can also be observed in the group of non-selective interrogatives. More precisely, the NON-HUMAN interrogative (yamke 'what') is used for expressing semantic functions other than the NON-HUMAN category. This kind of ambiguity has not been observed in the case of the HUMAN interrogative. The different meanings of yamke 'what' will be discussed in $§ 5.1 .4$ and $§ 5.1 .5$. These interrogative semantic categories encoded by the same lexemes can also be distinguished on the basis of their grammatical 
characteristics. However, the contrastive grammatical features of the homonymous forms will only be discussed in Chapter 6 .

\subsubsection{Possessor}

Within the category of HUMAN and NON-HUMAN interrogatives, the subcategory of POSSESSOR is usually distinguished. In Tundra Nenets, the interrogative words for POSSESSOR are genitive case-marked versions of the HUMAN and NON-HUMAN interrogative words. The genitive marker is attached to the stems without any additional linking elements (see 95-96).

(95) tuku xib̆a-? mar?

this who-GEN tent.VX.3SG

'Whose tent is this?' (Yangasova 2001: 172)

(96) tuku yamge-? xid'a?

this what-GEN dish.VX.3SG

'Whose dish is this?' (Okotetto 1998: 108)

As examples (95-96) above illustrates, the interrogative words encoding the semantic feature of POSSESSOR preserve their original $[{ }$ HUMAN] feature. Since these forms are complex and analysable ones, the semantic category of POSSESSOR belongs to the minor semantic group of interrogatives.

\subsubsection{Comitative and instrument}

In addition to the category of the genitive-marked POSSESSOR, there are also local casemarked forms of non-selective interrogatives that may result in new semantical categories belonging to the minor group of interrogative words. However, some of these forms only result in sub-specified categories of spatial dimensions (such as GOAL, SOURCE or PATH). The local case marked forms of HUMAN/NON-HUMAN interrogatives mostly have spatial reference. The following table provides the inflected forms of non-selective interrogatives. 
Table 10. The semantics of case-marked non-selective interrogatives

\begin{tabular}{|c|c|c|c|c|}
\hline \multirow[b]{2}{*}{ Cases } & \multicolumn{2}{|c|}{ HUMAN } & \multicolumn{2}{|c|}{ NON-HUMAN } \\
\hline & Form & Semantics & Form & Semantics \\
\hline LoC & xibaxana & COMITATIVE & yamgexena & INSTRUMENT \\
\hline DAT & xiban? & GOAL & yamgen? & GOAL \\
\hline ABL & xib̀axad & SOURCE & yamgexed & SOURCE \\
\hline Pros & xib̀awna & PATH & yamgewna & PATH \\
\hline
\end{tabular}

As is illustrated in Table 10, the locative-marked non-selective interrogatives (italicized in the table) end up with meanings other than the supposed spatial meanings. These complex forms do not express spatial position, rather they can be analysed as comitatives and instruments (see 97-98, respectively).

(97) a. pidara xił̀a-xana jil'e-da??

2PL who-LOC live-VX.2PL

'Who do you live with?'

b. mańa? Il'a wesako-xona jil'e-wa?.

1PL Ilya old.man-LOC live-VX.1PL

'We live with Ilya old man.' (Almazova 1961: 18)

(98) a. yamge-xena to-sa-di??

what-LOC come-INT-VX.2DU

'What did you come by?'

b. mańi? mašina-xana to-ńi-ź.

1DU car-LOC come-VX.1DU-PST

'We came by car.' (Vanuyto 2012: 10)

As mentioned above, the other inflected forms do not result in meanings different from spatial sub-specification. Example (99), for instance, examplifies the ablative-marked form of NONHUMAN interrogative that expresses SOURCE.

(99) xid'a-? yamge-xed śerta-ba-da??

dish-PL what-ABL make-CONT-VX.2PL

'What do you make dishes from?' (Okotetto 1998: 137) 
In addition to these local case marked forms, there are the essive case marked forms of the non-selective interrogatives (xibayce and yamgeyce) that express temporary condition of their referent and are typically used for asking about the occupation of a given person. As the question answer pairs in (100-101) show, these forms of 'who' (xibayce) and 'what' (yamgeyce) can be used equivalently for referring the profession of a human entity.

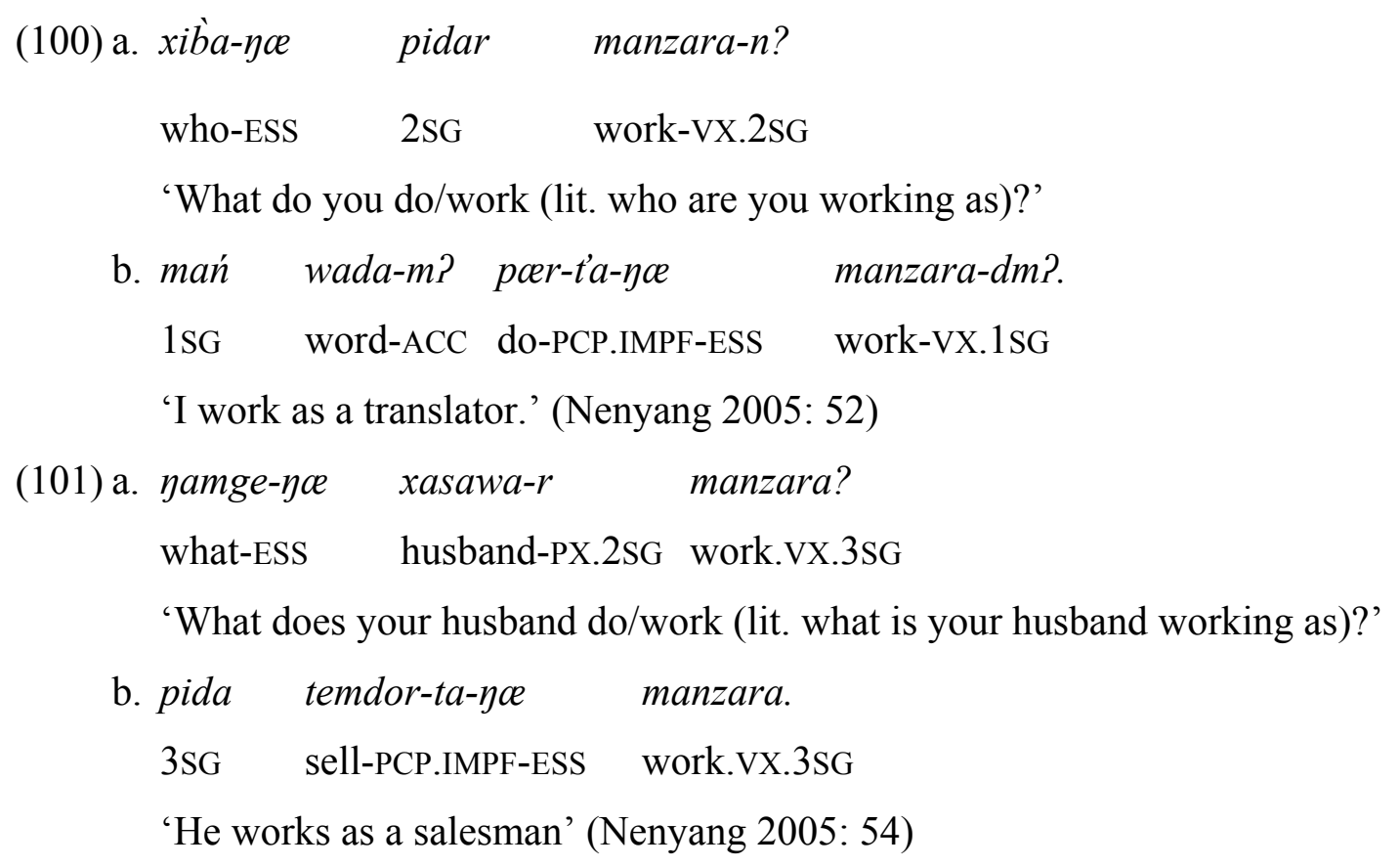

\subsubsection{Beneficiary and goal}

Further spatial dimensions can also be expressed by postpositional phrases in which the complement of the postposition is either the HUMAN (xiba) or the NON-HUMAN (yamge) interrogative word (standing in genitive case). These postpositional phrases result a vast number of new meanings subcategorized by the predicate verb that selects the actual postposition for these constituents (see 102-103).

$$
\begin{array}{rll}
\text { (102) } x i \grave{b a}-? & \text { ńamna } & \text { pad-wi? } \\
\text { who-GEN } & \text { to.PROS } & \text { write-NARR.VX.3SG }
\end{array}
$$

'Who was it written about?' (Okotetto 1998: 95) 


\section{(103) yamge-? ńamna laxana-sa-wa?? \\ what-GEN to.PROS talk-INT-VX.1PL \\ 'What did we talk about?' (Okotetto 1998: 85)}

As the examples above illustrate, the verbs pada- 'write about sy/sg' and laxana- 'talk about sy/sg' require a postpositional phrase as their complement. In the phrases, the postpositions stand in prosecutive cases in both examples. However, these occurrences are not considered to be elements of the minor categories, as these forms are only selected by the verb. In the data, two phrases occur with meanings other than spatial classification. On the one hand, the HUMAN interrogative with the postposition jed? 'for: dat' (xiba? jed? 'for who') refers to BENEFICIARY (see 104a).

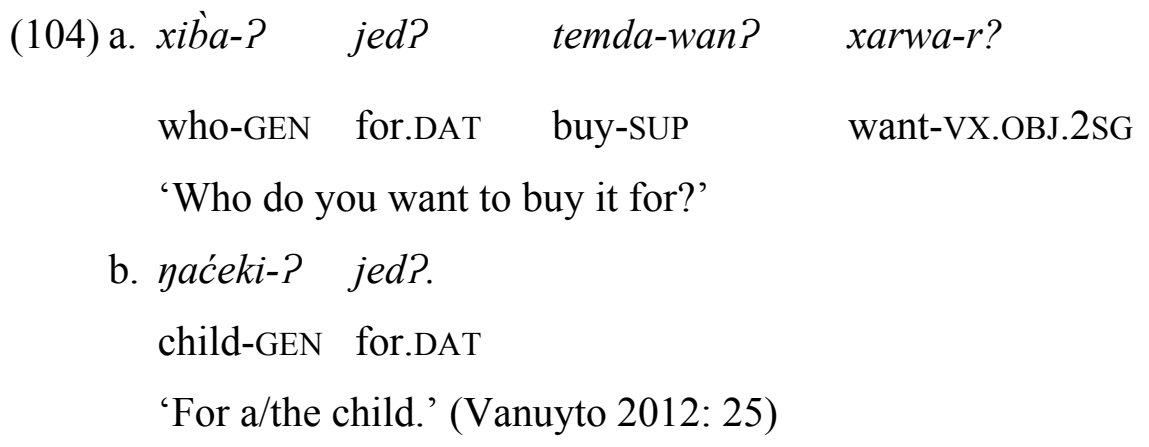

On the other hand, the NON-HUMAN interrogative occuring as the complement of the postposition jePemńa 'for: pros' (yamge? jePemńa) expresses the GOAL subspecification of REASON. This postpositional phrase cannot be used for CAUSE or MOTIVATION (see 105).

(105) yamge-? jePemńa $t i \quad$ tara?
what-GEN for.PROS reindeer be.needed.vX.3SG
'What is the reindeer needed for?' (Okotetto 1998: 110)

\subsubsection{Non-human versus selection/quality}

The non-selective interrogative word specified for the NON-HUMAN category, yamge 'what', can also be used attributively in an interrogative phrase. This attributive use of NON-HUMAN interrogative expresses the semantic operation of either SELECTION or QUALITY (cf. Burkova et al. 2010: 93). If the interrogative word for 'what' is used as a selective interrogative, it 
requires a choice among the elements of a closed set. In other words, it requests the identification of a given element of a closed set (see 106a). ${ }^{27}$

$$
\begin{aligned}
& \text { (106) a. pidar yamge ja-xana jil'e-n? } \\
& \text { 2SG what.qual land-LOC live-VX.2SG } \\
& \text { 'Which country do you live in?' } \\
& \text { b. mań Anglija-xana jil'e-dm? } \\
& \text { 1SG England-LOC live-VX.1SG } \\
& \text { 'I live in England.' (Vanuyto 2012: 16) }
\end{aligned}
$$

In addition, it can also substitute an element referring to a QUALITY of an entity (see 107a).

$$
\begin{aligned}
& \text { (107) a. yamge xal'a t’uku to-xona tańa? } \\
& \text { what.qual fish this lake-LOC exist.VX.3SG } \\
& \text { 'What fish is there in this lake?' } \\
& \text { b. t'uku to-xona pajxa tańa. } \\
& \text { this lake-LOC peled exist.VX.3SG } \\
& \text { 'There are some peled in this lake.' (Vanuyto 2012: 34) }
\end{aligned}
$$

As was discussed in $§ 5.1$, yamge 'what' is used only for non-human referents, bearing a [HUMAN] feature. This semantic feature is preserved in the SELECTIVE/QUALITATIVE use of this interrogative word. Consequently, it is used for selection/qualification either of things (see 106) or animals (see 107).

According to Cysouw (2004: 13) in some languages the lexeme for 'who' is also specified for SELECTIVE function (e.g. in Kobon, a Trans-New Guinean language spoken in NewGuinea, cf. Davies 1981: 8-9). However, a similar attributive use with SELECTIVE specification of the HUMAN interrogative word was not attested in Tundra Nenets.

\footnotetext{
27 In the examples, the non-human interrogative in its selective/qualitative function will be glossed as 'what.qual'.
} 


\subsubsection{Non-human versus reason}

According to Cysouw's observation (2004: 12), the unique pattern, i.e. the uninflected formal representation of the REASON specification is usually an incidental category in the human languages. Mostly, this specification is expressed by a derived form from the interrogative word 'what'. In Tundra Nenets, the lexeme for 'what' (yamge) can be used with the meaning of 'why' without any morphological processes, as in (108).

$$
\begin{aligned}
& \text { (108) Lena, yamge ma-kana xana-ko-? ńińa yamdi-n? } \\
& \text { Lena why tent-LOC sledge-DIM-GEN on.LOC sit-VX.2SG } \\
& \text { 'Lena, why do you sit on a sledge in the tent?' (Okotetto 1998: 63) }
\end{aligned}
$$

The semantic category of REASON can usually be divided into the subcategories of CAUSE (or MOTIVATION) and GOAL. The NON-HUMAN interrogative word used to request information about the REASON of a given event/action is not restricted to either of these subcategories. As example (108) above illustrates, the interrogative word for 'what' can be specified for CAUSE (or MOTIVATION), while example (109) exemplifies its GOAL specification.

$$
\begin{aligned}
& \text { (109) yamge ńeneća-ygana ti } \quad \text { tara? } \\
& \text { why people-LOC reindeer be.needed.vX.3SG } \\
& \text { 'Why (lit. what for) do people need reindeer?' (Okotetto 1998: 152) }
\end{aligned}
$$

In this semantic function, the interrogative word can be regarded as an interrogative adverbial modifier. For the morphological and grammatical distinction of certain semantic representations see $\S 6.1 .3$ and $\S 6.1 .4$.

\subsection{Selective interrogative words}

The semantic operation of interrogative selection is expressed by two different noninflected free forms: xańayi 'which' and xujum? 'which from two' (cf. Kupriyanova et al. 1957: 104; Burkova et al. 2010: 93). The category of selection also belongs to the major semantic group of interrogative words. 
SELECTIVE interrogatives require the hearer to choose a referent from a closed and "contextually determined" set of alternatives (Diessel 2003: 643). Thus, the unique interrogative words have a $[+\mathrm{SEL}]$ fetaure. The interrogative selection expressed by these forms is not specified for a HUMAN/NON-HUMAN dichotomy, they ask for information about humans, animals and things. Additionally, the identification requested by selective interrogatives is not specified for distance distinctions either. The distance of the selectable element is consequently not relevant for this interrogative word. The only semantic difference between these [ $+\mathrm{SEL}]$ interrogative words is the possible amount of the alternatives included in the set of the selectable entities. This set can either be non-restricted or restricted to two elements, so they have a $[ \pm$ RESTR] feature.

\title{
5.2.1. The non-restricted selective interrogative word
}

In the meaning of xańayi 'which', the number of the elements from which one member is needed to be selected is not limited/defined, but these possible elements are referential in the given context (see 110).

\author{
(110)xańayi kńiga-m? tola-bi- $n$ ? \\ which book-ACC read-CONT-VX.2SG \\ 'Which book do you read?' (Barmich \& Nyaruy 2008: 35)
}

Additionally, there is also a possibility to specify the number of the selected elements. For this operation, the plural form of 'which' (xańayi) is used, which takes the plural marker of the nominal domain. As this form is also an inflected form, it is regarded as an element of the minor semantic category (see 111).

\author{
(111)xańayi-? tóre-na-?. \\ which-PL shout-CONT-VX.3PL \\ 'Who (lit. which) are shouting?' (Barmich 2007: 41)
}

According to Tereshchenko (1965: 743) the sub-specification of the non-specified SELECTIVE interrogative is also possible. In this case, the interrogative word takes a selective marker (jum(?); also used in the nominal domain) in order to limit the number of alternatives 
associated in the set of the selectable substitutes. This interrogative word is a synonym of the restricted unique interrogative word. As this form is a derived one, it belongs to the minor category of interrogatives. In the corpus, no grammatical and/or lexical differences are observed between these synonymous forms. The following example illustrates the subspecified form of xańayi 'which':

$$
\begin{aligned}
& \text { (112)xańaje-jum? ńu-wa? ḿi-ta-ygo-bPnana?? } \\
& \text { which-SEL child-PX.1PL give-TR-FUT-GER.PX.1PL } \\
& \text { 'Which of our (two) children would we give to?' (Barmich 2008b: 32) }
\end{aligned}
$$

In example (112) above, the interrogative word takes the selective marker without any affixes. The difference between the uninflected unique form (xujum? 'which from two') and this derived version is not quite clear on the basis of the data, but they might present different dialectal forms.

\subsubsection{The restricted selective interrogative word}

The form of this interrogative word can only historically be analysed into further components so it belongs to the major category (see 113). Similarly to the above mentioned restricted interrogative, this one asks for the selection of a given entity/thing from two possible alternatives.

$$
\begin{aligned}
& \text { (113)xujum? xcewu-wna nul-ta-ygo-bPnan? } \\
& \text { which.from.two side-PROS stop-TR-FUT-GER.PX.1SG } \\
& \text { 'Which of the two sides could I stop at?' (Pushkareva \& Khomich 2001: 310) }
\end{aligned}
$$

To summarize the facts, the category of interrogative selection in Tundra Nenets is expressed either by elements belonging to the major category, or by compund interrogative forms consisting of the minor semantic category. The non-selective meaning was not attested with any of these interrogative words. Consequently, they can only be used in a selective function. 


\subsection{The qualitative interrogative word}

Tundra Nenets distinguishes the interrogative category asking for information about the QUALITY (xurka 'what kind') of its referent (cf. Kupriyanova et al. 1957: 104; Burkova et al. 2010: 93). This interrogative word substitutes any property, e.g. dimension, age, value or color, etc., of its referent and it is not specified for only a single type of QUALTIY. Therefore, it can only be characterized by a simple $[+\mathrm{QUAL}]$ semantic feature. Contrary to the qualitative use of the NON-HUMAN interrogative (yamge; discussed in 5.1.4) the general qualitative interrogative specification does not show a HUMAN/NON-HUMAN dichotomy. Therefore, it can be used for humans, animals and things (see 114-115).

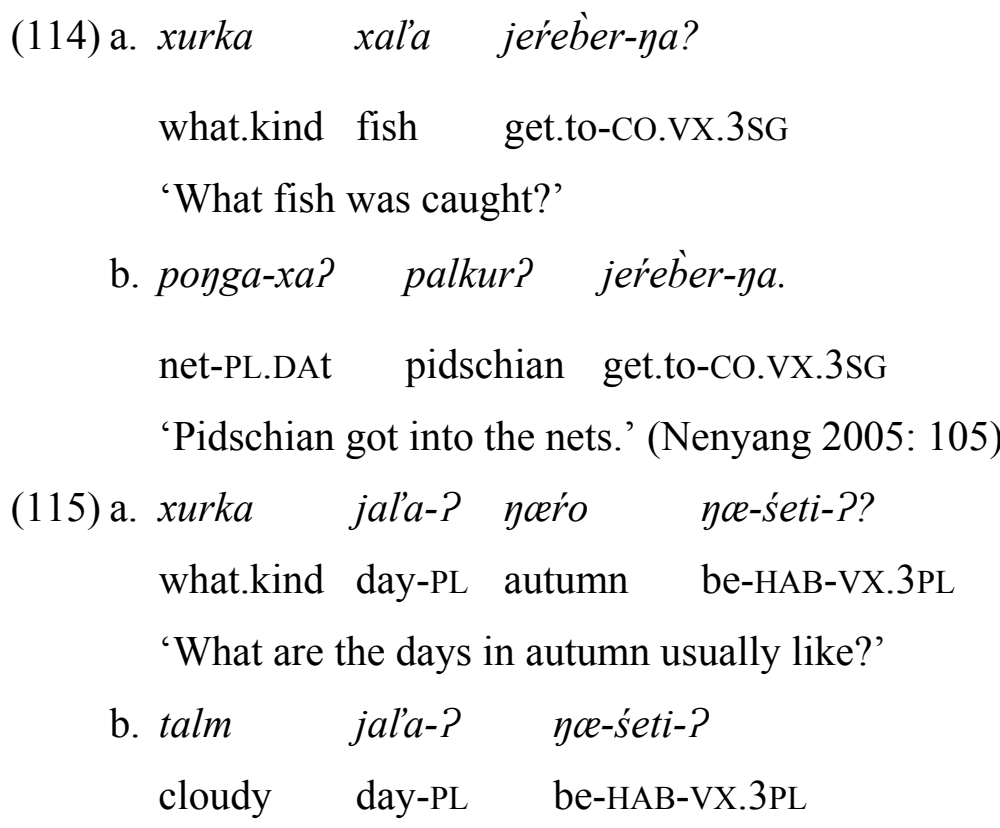

'The days are usually cloudy.' (Nenyang 2005: 109)

As examples in (114-115) illustrate, the QUALITATIVE interrogative word in Tundra Nenets (xurka 'what kind') is usually used in non-selective contexts for requiring an alternative of an opened set of properties. In some contexts, however, the QUALITATIVE interrogative word can also be used for SELECTION, in which case the set of the possible answers is closed. In (116) below, for instance, the answer indicates that the semantic operation required by the interrogative word is carried out on a closed set, i.e. the days of the week. Consequently, the interrogative word in (116) does not ask for information about a given quality of the modified noun (jal'a 'day'). 


$$
\begin{aligned}
& \text { (116) a. t'eda? xurka jal'a? } \\
& \text { now what.kind day.VX.3SG } \\
& \text { 'What day is it today?' } \\
& \text { b. t'uku jal'a-? woskresenije. } \\
& \text { this day-GEN sunday.VX.3SG } \\
& \text { 'Today is sunday.' (Nenyang 2005: 106) }
\end{aligned}
$$

This SELECTIVE use is specified by the context, rather than by the semantic function of the interrogative word. Consequently, the canonical use of xurka 'what kind' is asking for information about any quality of its referent.

\subsection{The interrogative size specification}

In addition to the semantically not specified QUALITATIVE interrogative (xurka 'what kind') presented in $§ 5.3$, there is also an interrogative word (śayar 'how big') encoding a specific qualitative feature, the SIZE, of a given entity in Tundra Nenets (cf. Kupriyanova et al. 1957: 104). It belongs to the major category because it is not an inflected/analysable form at the synchronic stage of the language. This interrogative word is characterized by a [+SIZE] feature, but as exemplified in (117), it does not require the extent of the size.

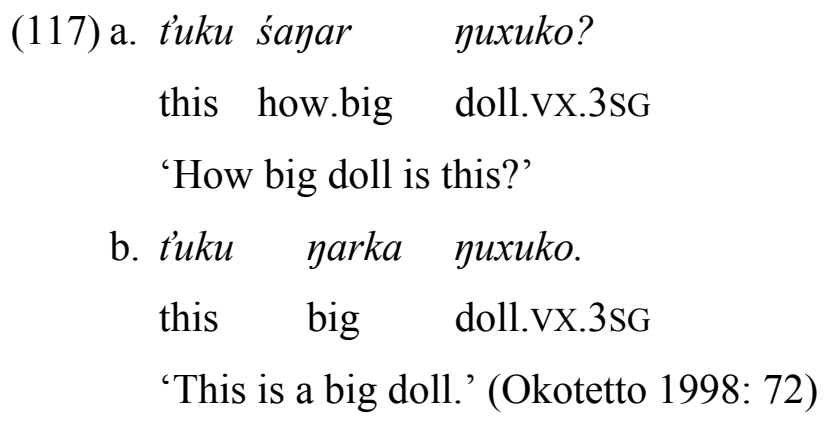

Similarly to the QUALITATIVE interrogative word ( $x u r k a$ 'what kind'), the interrogative word with the meaning 'how big' (śayar) is not restricted to either HUMAN or NON-HUMAN referents. 


\subsection{The quantitative interrogative word}

The category of QUANTITY (śan 'how many') inquiring about the amount or the number of its referent belongs to the major semantic group of Tundra Nenets interrogative words, because the form is not analysable within the synchronic structure of the language. This QUANTITATIVE interrogative word (śan 'how many') substitutes both numerals and existential or universal quantifiers so it has a [+QUANT] feature. In Tundra Nenets there is no count/mass distinction in the nominal paradigm, so the QUANTITATIVE interrogative word is not different with respect to the count/mass dichotomy either. In (118) below, the quantified noun, xal'a 'fish', is countable, while in example (119) the interrogative word quantifies an uncountable noun (moloko 'milk'). In both of these cases, the same interrogative word is used in the same way.

$$
\begin{array}{rlll}
\text { (118) śan xal'a-m? } & \text { tuku } & \text { po-? } & \text { ńa?ma-n? } \\
\text { how.many fish-ACC } & \text { this } & \text { year-GEN } & \text { catch-VX.2SG }
\end{array}
$$

'How much fish did you catch this year?' [VT, 2002]

$\begin{array}{ccccc}\text { (119) śan } & \text { maloka-m } & \text { xorawa-? } & \text { sutka-xana } & \text { tambi-P? } \\ \text { how.many milk-ACC } & \text { cow-PL } & \text { day-LOC } & \text { give-VX.3PL }\end{array}$

'How much milk do the cows lactate a day?' (Nenyang 2005: 94)

There is also a formal variation of the quantitative interrogative word (śayok 'how many') illustrated in (120).

$$
\begin{aligned}
& \text { (120) śayok xal'a-m? tiki po jeremd'e-da? } \\
& \text { how.many fish-ACC that year catch-VX.2PL } \\
& \text { 'How many fish did you catch in that year?' [E.La, 2002] }
\end{aligned}
$$

This variant does not show any differences with respect to its semantics and grammatical characteristics. Additionally, Kupriyanova et al. (1957: 104) and Tereshchenko (1965: 600) mention another QUALITATIVE interrogative, śambir 'how many', however that one is not attested in the corpus and the grammatical descriptions and dictionaries do not provide any examples for the use of this interrogative either. 
5.5.1. The interrogative category of rank

The QUANTITATIVE interrogative (śan 'how many') can be specified for requiring the position or RANK of the answer represented in a sequential order (śańemd'ej; cf. Almazova 1961: 97; Tereshchenko 1965: 601). In this case, the interrogative word takes the ordinal derivative suffix (-md'ej-) normally attached to numerals. The interrogative subcategory of RANK does not appear in the texts, but descriptions and dictionaires exemplify it (see 121).

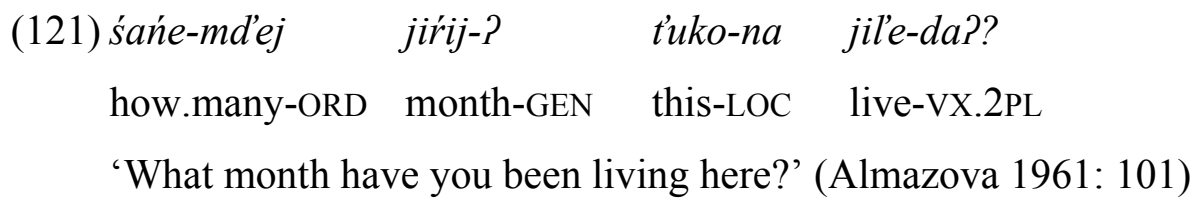

5.5.2. The subspecification of interrogative time category

Although there is a unique form of interrogative TIME specification (see §5.7), the interrogative word for 'how many' (śan) can also appear in a suffixed form (śanxana) for specifying a given interrogative TIME of an event. In this case, the interrogative word takes a locative case marker and it denotes either the TIME POSITION of an event or the TIME RELATION. This form, however, appears only in texts originating from the Ob/Ural subdialect of the Eastern dialectal group (see 122).

(122) Eastern Dialect, Ob/Ural Subdialect

$$
\begin{array}{lll}
\text { labka } & \text { śan-xana } & \text { ńaygar-ya? } \\
\text { store } & \text { how.many-LOC } & \text { open-CO.VX.3SG }
\end{array}
$$

'At what time does the store open?' [E.La, 2002]

The structure of this complex question word form may be a result of the borrowing from Russian language. A similar construction and meaning can also be observed in other dialects, i.e. in Central and Eastern Nenets. However, in these dialects the construction contains a noun with the meaning 'hour' ( $\check{c} a s$ ) that takes the locative case marker and this noun is modified by the QUANTITATIVE interrogative word that does not agree with its head in case. This interrogative phrase (śan časxana) referring to TIME means more likely TIME DURATION, more 
precisely, the SOURCE/STARTING POINT, of the event in time. The following example is from the Yamal subdialect of the Eastern dialectal group:

(123) Eastern Dialect, Yamal Subdialect

śan čas-xana noe-yga?

how.many hour-LOC open-CO.VX.3SG

'At what time does it open?' (Vanuyto 2012: 20)

The two constructions in (122) and (123) above have the same structure, but in the example in (122) from the $\mathrm{Ob} / \mathrm{Ural}$ dialect the head noun is elided from the phrase and the interrogative word can only take the locative case marker (śanxana). This ellipsis seems not to be grammatical in other dialects and subdialects, in which the noun head of the phrase (čas 'hour') is always overt in the structure and it takes the case marker instead of the interrogative word.

The construction illustrated in (123) (śan čas 'how many hours') is available for expressing the whole paradigm of TIME DURATION. In the following example, for instance, it asks for the GOAL/ENDING POINT of an event in TIME (see 124).

$$
\begin{aligned}
& \text { (124) śan čas-? jol'ćand? awtobus jader-ya? } \\
& \text { how.many hour-GEN until.DAT bus walk-CO.VX.3SG } \\
& \text { 'Until when does the bus go?' (Vanuyto 2012: 46) }
\end{aligned}
$$

This function of clarifying the DURATION of an event in TIME is not available for the general TIME interrogative (for the discussion see $§ 5.7$ ).

\subsection{The interrogative place specification}

The interrogative PLACE specification distinguishes four spatial interrogative word forms that consist of a bound interrogative stem (xańa-) combined with the system of local cases. These forms occur with four different locational markers, with locative, dative, ablative and prosecutive cases. The local cases in this interrogative paradigm are morphologically distinct from the corresponding case markers of nouns. Although these forms are morphologically transparent, they are already lexicalized and the interrogative root cannot appear without the 
postposition and the local marker. Table 11 illustrates the sub-categories of the interrogative PLACE specification.

Table 11. The sub-specification of interrogative PLACE category

\begin{tabular}{lcccc}
\hline Categories & Space position & \multicolumn{3}{c}{ Direction } \\
& & GOAL & SOURCE & PATH \\
\hline Oblique cases & LOC & DAT & ABL & PROS \\
\hline Interrogative words & xańana & xańa? & xańad & xańamna \\
\hline
\end{tabular}

Consequently, the PLACE specification constitutes a particular paradigm and has subcategories. Within the set of spatial interrogative words, the interrogative word inflected for locative case (xańana) asks for the space position of a given entity (see 125). While the other three sub-categories substitute directional movements. The form marked by dative (xańa?) requests information about GOAL (see 126); the sub-category of SOURCE is substituted by an ablative-marked spatial interrogative word (xańad; see 127) and the prosecutive case marks the subcategory of PATH (xańamna; see 128).

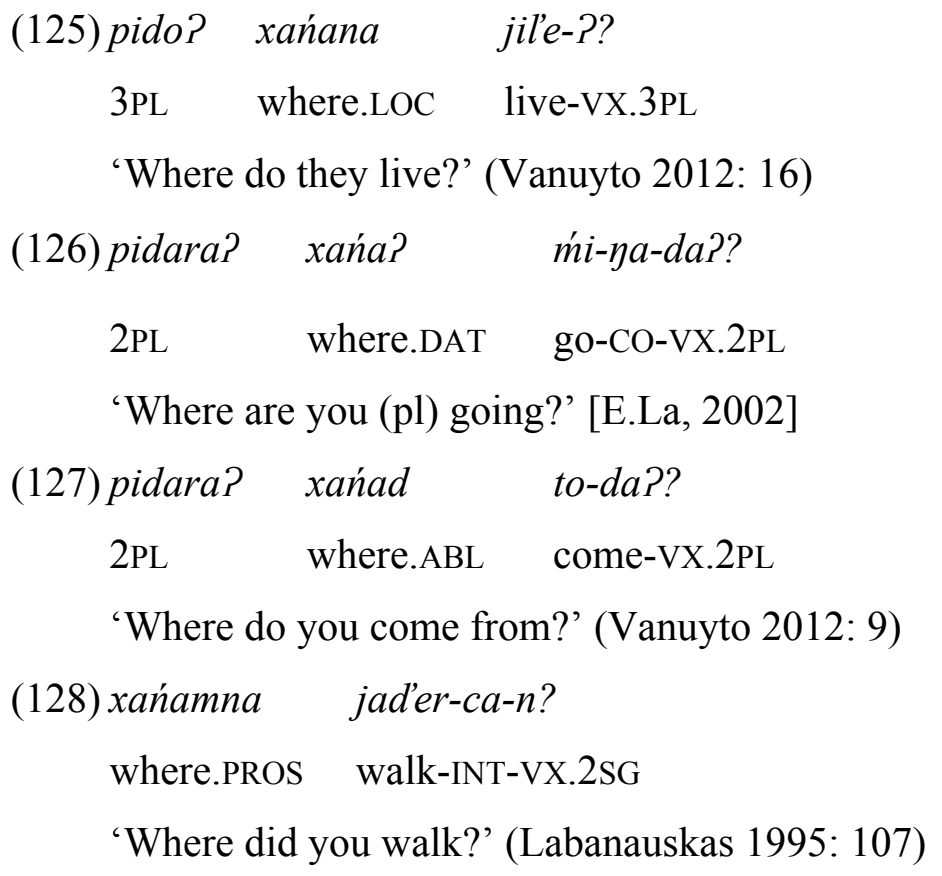

There is also a parallel interrogative PLACE paradigm appearing in the Eastern dialect (discussed in $§ 6.5 .1$ ), in which the bound interrogative stem $(x a-)$ is combined with local case markers without the local postposition (ńa). 


\subsection{The interrogative time specification}

The interrogative word of TIME specification in Tundra Nenets (śaxa? 'when') inquires about temporal relation between the event expressed by the proposition and the speech event. The TIME specification expressed by this unique interrogative form indicates a general temporality of an event. Consequently, it does not inquire either about a specific temporal information (e.g. a part of the day or hour) or about the duration of an event. The following example illustrates the use of the unique TIME interrogative:

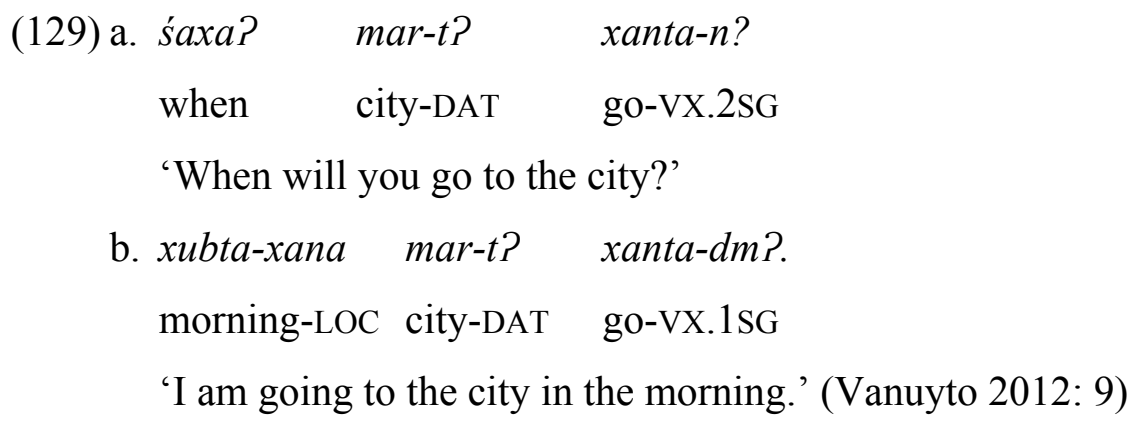

Although this interrogative word is not specified, for instance, for TIME DURATION (like the structure presented in §5.5.2) or FREQUENCY, it also can be used for asking about these subcategories of TIME. The answer in example (130) illustrates that the unique time interrogative may be utilized to a more specific temporal relation, the ENDING POINT, between the event and the speech. I suppose that it is the context that specifies the actual meaning of the TIME interrogative.

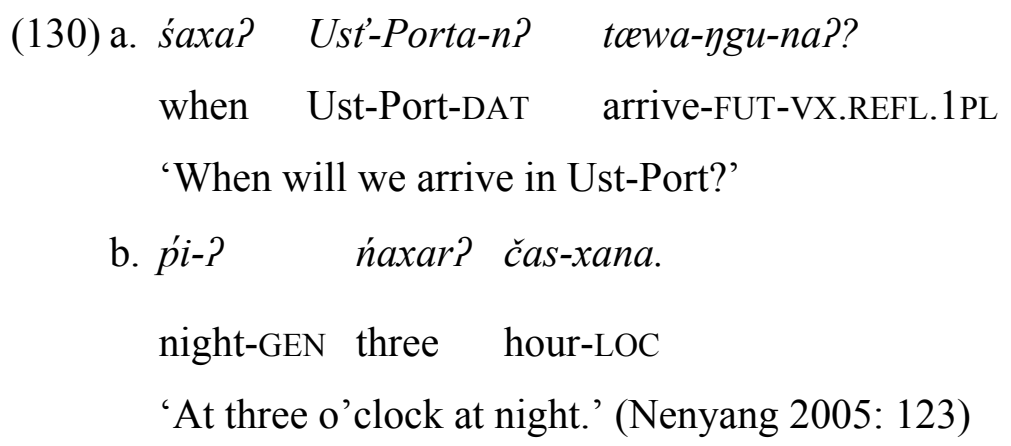




\title{
5.8. The interrogative manner specification
}

The final major interrogative category expressed by a lexicalized interrogative word is specified to the semantic category of MANNER (xanźer? 'how'). This interrogative requests the hearer to define certain MANNER characteristics of a given event/action (see 131).

\author{
(131) a. xanźer? pidara? toxolku-r-ya-da?? \\ how 2PL learn-FREQ-CO-VX.2PL \\ 'How is studying going on?' \\ b. sawa-wna toxolku-r-ya-wa? \\ good-PROS learn-FREQ-CO-VX.1PL \\ 'It is well.' (Nenyang 2005: 58)
}

In the texts, no other use/meaning of the interrogative manner category is attested.

\subsection{Other semantic categories}

The previous sections discussed semantic gaps filled either by simple or by complex interrogative words in Tundra Nenets. A figure illustrating the available semantic categories and links among these categories is provided below (see Figure 5). The semantic categories expressed by unanalysable forms in Tundra Nenets are presented using bolded small capital characters, while the semantic ambiguities are illustrated by bolded words. Finally, the elements of the minor semantic group are indicated in italicized forms. 


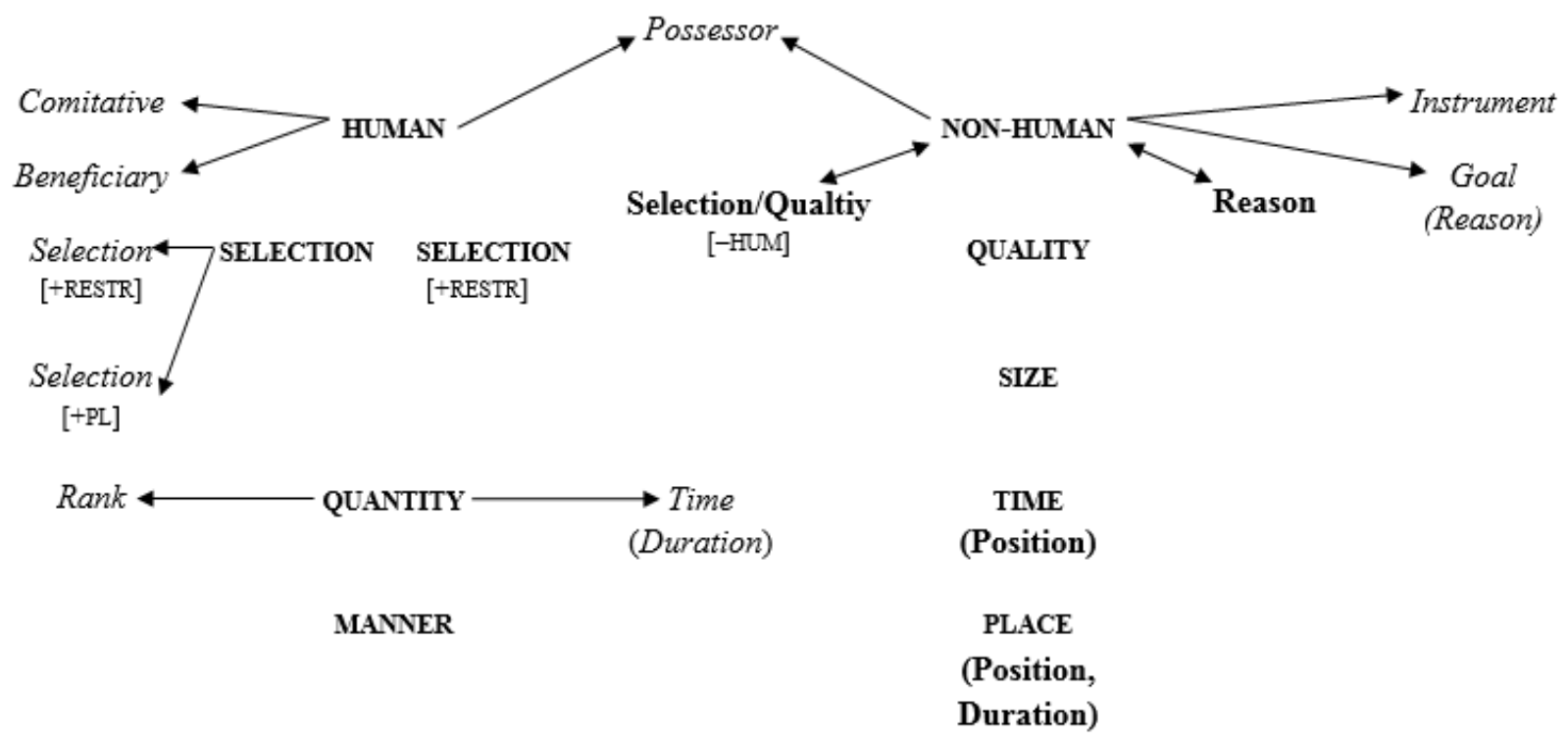

Figure 5. The lexico-typological categories of Tundra Nenets interrogative words

In his typological study, Cysouw (2004) provides at least three additional semantic categories that may be encoded by interrogative words. These are the UTTERANCE ('say what'), the ACTION ('do what') and the EXTENT ('how + [adj]'). From these categories, the UTTERANCE is expressed by an interrogative verb in Tundra Nenets (discussed in Chapter 4). Nevertheless, I do not analyse this interrogative verb in the present study and do not illustrate it in Figure 5 above either. The remaining two categories, ACTION and EXTENT, are not attested in the texts. As Cysouw (2004) notes, the category of EXTENT is usually linked either to the QUANTITATIVE or to the MANNER interrogatives. Nevertheless, I could testify this type of use neither with QUANTITATIVE nor with MANNER interrogatives. Consequently, the question whether Tundra Nenets expresses the interrogative category of EXTENT in some way remains without answer in the present study. In addition, the category of ACTION does not appear in Tundra Nenets either. 


\section{The parts-of-speech categories of interrogative words}

Interrogative words are usually characterized in the literature as being pro-forms. The term pro-form is used for closed word classes that substitute corresponding open word classes (cf. Sasse 1993: 669; Schachter \& Shopen 2007: 24). As Schachter \& Shopen (2007: 3) note, closed word classes in a language often contain a certain (small) number of words whose forms are the same for the members of the speaker community. Interrogative pro-forms (similarly to other pro-forms such as personal, reflexive, etc. pronouns) usually belong to the set of closed classes of words in a given language, but they often "cross-cut the boundaries of several word classes" (Diessel 2003: 635). Consequently, they do not necessarily form a single word class in which the elements share the same grammatical properties. For instance, they may differ in their inflectional characteristics, or in distributional properties, etc. They may also be distinguished on the basis of the syntactic function they fulfil in a clause (cf. Siemund 2001: 1022). In the literature, Tundra Nenets interrogative words are traditionally categorized as pronouns (see e.g. Kupriyanova et al. 1957: 104; Hajdú 1968: 54; Tereshchenko 1973: 91; Salminen 1998: 526; Burkova et al. 2010: 55-56), even though not every element of the set shares the same grammatical properties. For instance, some forms can be inflected for number and case, while others cannot. Therefore, the interrogative words in Tundra Nenets cannot be characterized as elements constituting a homogeneous set. This chapter differentiates between the various interrogative words in Tundra Nenets based on their grammatical characteristics.

The grammatical categorization of interrogative pro-forms, or words in general, raises the problem as to which criteria are relevant for classifying the elements of a given word class. Schachter \& Shopen (2007: 1-2) propose an approach to identify and distinguish parts-ofspeech categories, or word classes in a given language. These criteria are given in (i)-(iii).

(i) morphological (or syntactic) categories

(ii) syntactic function

(iii) distribution

The criterion of morphological/syntactic categories for which a given word may be specified takes into consideration formal differences, such as inflection, declension, etc. As Sasse (1993: 650) writes, one can differentiate between category-establishing and categorychanging morphology. The inventory of category-establishing morphology has "to do with 
the main function of the categories in question" (Sasse 1993: 650). In contrast, categorychanging morphology serves to transfer an element of a given category to another categorial set. In this chapter, only the category-establishing morphology of interrogative words will be discussed. The category-establishing morphology in Tundra Nenets covers the markers of number, possession (and benefactive) and case.

Secondly, the typical core syntactic functions of words (such as subject, object, adverbial, etc.) are closely related to their grammatical characteristics. As already mentioned, case marking also indicates the syntactic function of constituents in Tundra Nenets. This question is consequently linked to the potential morphological characteristics of interrogative words. In addition, the syntactic function of interrogative words also determines their position within the clause. This question will be taken into consideration in Chapter 7.

Finally, the distributional properties of a word cover two aspects of adnominal modification. On the one hand, it identifies structures in which the given word can appear as the modified element. On the other hand, it takes into consideration those cases in which the corresponding word appears as modifier/complement of any other word. Inter alia, the potential modifiers of interrogative pro-forms will also be discussed here. The main question is whether the interrogative word can/may be modified by any element in Tundra Nenets. Additionally, those phrases will also be analysed in which the interrogative words typically appear as complements.

Consequently, the grammatical criteria of Tundra Nenets interrogative words that are of relevance for the present analysis (summarized in (i)-(iii)) are their morphological characteristics, their syntactic functions and their distributions.

Furthermore, as Tereshchenko (1956) observed, certain Tundra Nenets dialects show some formal differences between interrogative words. These differences will also be presented in the corresponding subsections.

This chapter is organized as follows. Each section starts with a dialectal differentiation of the interrogative word forms in question. These formal introductions are considered necessary as the differences among the dialectal forms may mislead the reader. Afterwards, their possible syntactic functions and the corresponding morphological characteristics, e.g. the suffixes they can take, will be discussed. Finally, those phrases and structures will be discussed in which the interrogative words may appear as complements. 


\subsection{The interrogative pronouns}

The interrogative words specified for the HUMAN/NON-HUMAN semantic dichotomy (xiba 'who' and yamge 'what' introduced in $§ 5.1$ ) belong to the category of interrogative pronouns in Tundra Nenets. These are the interrogative words in Tundra Nenets whose grammatical descriptions are provided with the most details by grammars (e.g. Tereshchenko 1956; Kuprijanova et al. 1957; Burkova et al. 2010; etc.).

As Tereshchenko (1956: 182-190) observed, the Eastern and the Western dialectal groups show certain phonological differences in the forms of interrogative pronouns from those found in the Central dialect. These differences are presented in Table 12.

Table 12. The dialectal forms of interrogative pronouns

\begin{tabular}{lcc}
\hline Dialect & HUMAN & NON-HUMAN \\
\hline Western Dialect & $\begin{array}{c}\text { xiwja } \\
\text { xuja }\end{array}$ & amge \\
\hline Central Dialect & $x i \grave{b a}$ & yamge \\
\hline Eastern Dialect & $x i \grave{b a}$ & amge \\
\hline
\end{tabular}

In the Western subdialects, for instance in the Kanin subdialect, a different form of 'who' (xiwja, xuja) is used (see 132).

(132) Western Dialect, Kanin Subdialect xuja ṕir sit jadta-gu?

who 2SG 2SG.ACC meet-FUT.VX.3SG

'Who will meet you?' [AL, 2002]

In addition, the lack of the word initial velar nasal in the Western dialects and the Taimyr subdialect of the Eastern dialectal group discussed in $\$ 2.1$ indicates a different form of 'what' (amge) in the corresponding dialects (see 133).

(133) Eastern Dialect, Taimyr Subdialect

amge xadke-j-??

what happen-REFL.CO-VX.REFL.3SG

'What happened?' (Labanauskas 2001: 110) 
Despite these formal differences, further distinctions, such as grammatical ones, have not been found in the corpus.

As mentioned above, the grammatical characteristics of the interrogative words depend on the function they fulfil in a clause. Both interrogative pronouns can function as all main constituents of the clause, i.e. subject, object, adverbial and predicate. In addition, they can appear as complements in phrases.

Furthermore, the interrogative pronoun with non-human reference (yamge 'what') can also be used in further contexts/functions. For instance, this interrogative can also appear in noun phrases with selective/qualitative semantic function (discussed in §5.1.4), in which case it has the grammatical characteristics of interrogative adjectives. Besides, it can also ask about a reason of a given event (see $\S 5.1 .5$ for the discussion) in which case it is used similarly to interrogative adverbs. These functions are not available to its human counterpart (xib̀ 'who').

In what follows, typical syntactic functions of interrogative pronouns will be discussed.

\subsubsection{Interrogative pronouns as constituents of the main clause}

As mentioned above, all constituents of the main clause can be questioned by interrogative pronouns: They can be subjects, objects, adverbials (either arguments or adjuncts) and predicates in clauses. Table 13 illustrates the distribution of interrogative pronouns with respect to their syntactic functions in the corpus. In the table, S stands for the subject of both intransitive, transitive and nonverbal clauses. O marks the (direct) object of clauses. X serves to indicate adverbials, while Pred abbreviates predicates in nonverbal clauses.

Table 13. The core syntactic functions of interrogative pronouns

\begin{tabular}{ccc}
\hline Syntactic function & HUMAN & NON-HUMAN \\
\hline S & 93 & 54 \\
O & 7 & 121 \\
X & 4 & 48 \\
Pred & 107 & 56 \\
\hline
\end{tabular}

As Table 13 shows, the human interrogative pronoun (xiba 'who') typically appears as a subject and as a predicate, and it is less frequently used as object and as adverbial. In contrast, the non-human interrogative pronoun (yamge 'what') most frequently functions as an object and as an adverbial complement and/or modifier. 
These syntactic functions are associated with different (case) markers. Firstly, the interrogative pronouns functioning as the subject of the clause are in nominative case (see 134-135).

\author{
(134) xib̀a pad-na? \\ who write-CONT.VX.3SG \\ 'Who is writing?' (Nenyang 2005: 14) \\ (135) yamge madar-ya? \\ what bark-CO.VX.3SG \\ 'What is barking?' (Okotetto 1998: 17)
}

As already discussed in $\S 2.3$, number marking in Tundra Nenets distinguishes singular, dual and plural forms. The interrogative pronouns have both dual and plural forms, which are purely agglutinative, so the corresponding markers are attached to the pronominal interrogative words (cf. Tereshchenko 1959: 70, and see Table 14).

Table 14. The interrogative pronouns marked by numbers

\begin{tabular}{|c|c|c|}
\hline Number & HUMAN & NON-HUMAN \\
\hline SG & $x i \grave{b a}$ & yamge \\
\hline DU & xib̀axa? & yamgexe? \\
\hline PL & xib̀a? & yamge? \\
\hline
\end{tabular}

The interrogative pronouns functioning as subjects control agreement on the verb. The verb agrees with the interrogative pronominal subject in person and number. In examples (136)(137), the interrogative pronouns appear in dual forms controlling subject agreement on the verbs:

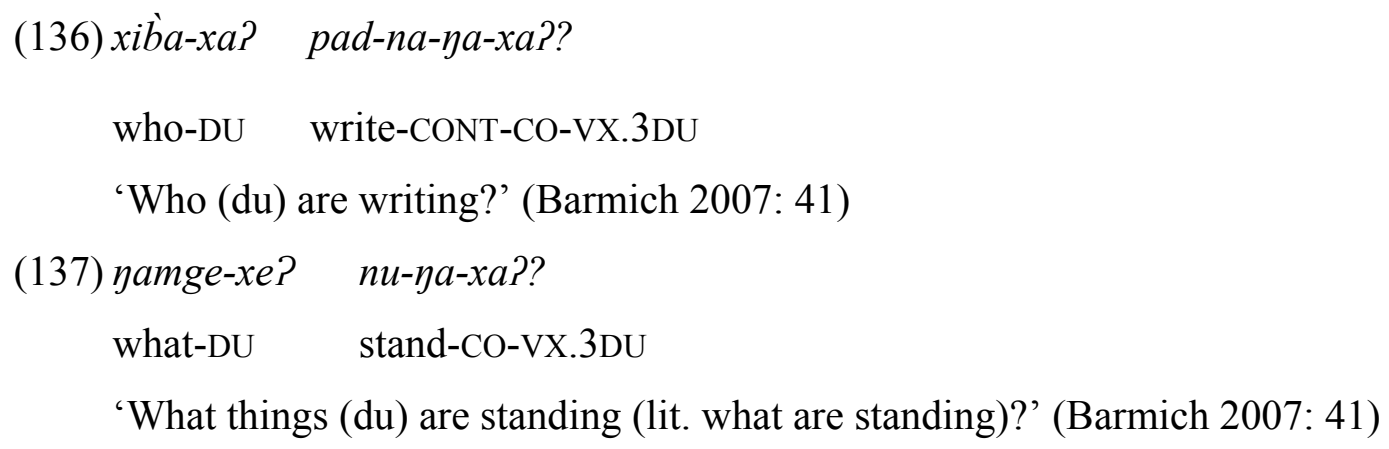


In (138)-(139) the interrogative pronouns are in plural forms, and the predicates agree with the pronominal subjects in person and number.

(138) xib̀-? jor-ya-??

who-PL fish-CO-VX.3PL

'Who (pl) are fishing?' (Barmich 2007: 40)

(139) yamge-? ńawota-r-ya-??

what-PL run-FREQ-CO-VX.3PL

'What things are running (lit. what are running)?' (Barmich 2007: 40)

Secondly, the interrogative pronouns can function as the object of the predicate in transitive clauses. If they function as objects, they take accusative case markers (see 140-141).

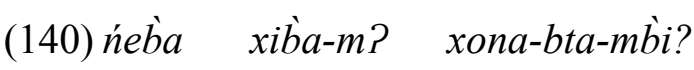

mother who-ACC sleep-TR-CONT.VX.3SG

'Who is made fall asleep by the mother?' (Okotetto 1998: 88)

(141) ńe yamge-m? sedibi?

woman what-ACC sew.VX.3SG

'What does the woman sew?' (Nenyang 2005: 14)

The combination of accusative case and number markers can also appear on the interrogative pronouns. These forms are illustrated in Table 15 (cf. Kuprijanova et al. 1957: 104).

Table 15. The interrogative pronouns marked by accusative case

\begin{tabular}{|c|c|c|}
\hline Number & HUMAN & NON-HUMAN \\
\hline SG & xibam? & yamgem? \\
\hline DU & xib̀axa? & yamgexe? \\
\hline PL & $x i \grave{b i} ?$ & yawo \\
\hline
\end{tabular}

As seen in Table 15, the accusative paradigm of the interrogative pronouns is not complete since the dual forms of interrogative pronouns in nominative and accusative cases are the same. In addition, the plural accusatives of interrogative pronouns are expressed by fusional 
forms. An example illustrating the use of the interrogative pronoun functioning as plural object is provided under (142) below.

\author{
(142) yawo tola-sa-da?? \\ what.PL.ACC read-INT-VX.2PL \\ 'What did you read?' (Barmich 2007: 46)
}

According to Dalrymple \& Nikolaeva (2011: 132), only the topical 3rd person objects control agreement on the verb in Tundra Nenets. Interrogative pronominal objects, being non-topical constituents, never trigger agreement on the predicate (see 140-142 above). Consequently, a transitive verb agrees only with its subject in the presence of interrogative objects.

Thirdly, locative case markers attached to the interrogative pronouns indicate their adverbial functions in the clause. The forms of these oblique case suffixes appearing on interrogative pronouns do not differ from those of nouns. Further suffixes cannot be attached to these forms of interrogative pronouns. Table 16 below shows the case marked forms in singular number (cf. Kupriyanova et al: 1957: 104-105; Tereshchenko 1959: 61).

Table 16. The interrogative pronouns marked by oblique cases

\begin{tabular}{|c|c|c|}
\hline Case & HUMAN & NON-HUMAN \\
\hline DAT & xiban? & yamgen? \\
\hline LOC & xib̀axana & yamgexena \\
\hline $\mathbf{A B L}$ & xib̀axad & yamgexed \\
\hline PROS & xib̀awna & yamgewna \\
\hline
\end{tabular}

The examples in (143-144) below illustrate certain case-marked forms of interrogative pronouns.

$$
\begin{aligned}
& \text { (143)xib̆a-n? laxana-wa?? } \\
& \text { who-DAT talk-VX.1PL } \\
& \text { 'Who are we talking to?' (Okotetto 1998: 89) } \\
& \text { (144) čeda? yamge-n? } n a c ̌ e-n a-\eta g u ? \\
& \text { now what-DAT wait-CONT-FUT.VX.3SG }
\end{aligned}
$$

'Who is (s)he waiting for now?' (Labanauskas 1995: 43) 
The oblique case marked interrogative pronouns can also appear in plural forms. However, this paradigm is not complete either, because locative case markers appear only in singular and plural numbers, whereas the missing dual forms are expressed by the combination of the postposition ńa- 'at' with the corresponding locative cases (cf. Salminen 1998b: 537). In these postpositional constructions the interrogative pronouns, like nouns, are in genitive (see Table 16 and 17$).^{28}$

Table 17. The dual and plural forms of interrogative pronouns marked by oblique cases

\begin{tabular}{|c|c|c|c|c|}
\hline \multirow[b]{2}{*}{ Case $\backslash$ Number } & \multicolumn{2}{|c|}{ HUMAN } & \multicolumn{2}{|c|}{ NON-HUMAN } \\
\hline & DU & PL & DU & PL \\
\hline DAT & xibaxa? ńa? & xib̀axa? & yamgexe? ńa? & yamgexe? \\
\hline LOC & xib̀axa? ńana & xiל̀axa?na & yamgexe? ńana & yamgexe?na \\
\hline $\mathbf{A B L}$ & xib̀axa? ńad & xib̀axat & yamgexe? ńad & yamgexet \\
\hline PROS & xib̆axa? ńamna & xiל̆a?mna & namgexe? ńamna & yawo?mana \\
\hline
\end{tabular}

Example sentences illustrating the combination of locative cases and dual/plural number markers occuring on interrogative pronouns are not attested in the corpus, but tables of these paradigms appear in grammars like Kuprijanova et al. (1957: 104-105) and Tereshchenko's (1959: 61). As already mentioned, the locative case marked forms of the interrogative pronouns (illustrated in 143-144) appear as adverbials (either complements, or adjuncts) in the clause.

To summarize the facts, the interrogative pronouns functioning as subjects appear in nominative case either in transitive or in intransitive clauses. They can also take number markers and always control agreement on the verb. Besides, interrogative pronouns can take accusative case markers if they function as objects. Similarly to the interrogative pronominal subjects, they can appear in dual and plural forms. The interrogative objects never control agreement on the verb which perfectly fits to the object agreement rule formulated by Dalrymple \& Nikolaeva (2011). Finally, locative case markers (also in combination with number markers) indicate their adverbial functions in the clause. These adverbs can be either argumentals or free adjuncts.

A further category for which the interrogative pronouns can be specified is the possessive paradigm. In possessive phrases, the interrogative pronouns appear as the head, i.e. as the

\footnotetext{
${ }^{28}$ For the genitive marked forms of interrogative pronouns see Table 20.
} 
possessed item. ${ }^{29}$ According to the available examples, the interrogative pronominal heads in possessive phrases cannot appear without possessive suffixes contrary to nouns that may also be used without agreement markers, i.e. possessive suffixes (for the discussion see $\S 2.3$ ). Interrogative pronouns take the agreement markers of the possessive paradigm. The available possessive constructions with interrogative pronominal heads in the corpus are illustrated in Table 18 .

Table 18. Possessive constructions with interrogative pronominal heads

\begin{tabular}{lcc}
\hline Possessor & \multicolumn{2}{c}{ Possessed item } \\
& HUMAN & NON-HUMAN \\
\hline- & 5 & 13 \\
pronominal & no data & 1 \\
lexical & no data & 4 \\
\hline
\end{tabular}

On the basis of the available examples given in Table 18, the possessor can be covert in the construction. This possessive phrase type is the most commonly represented in the corpus (see 145-146).

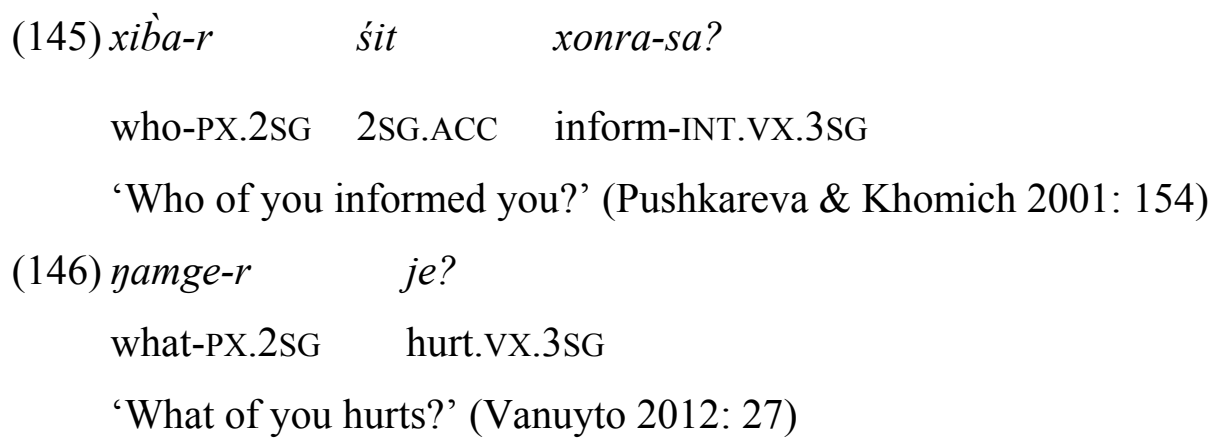

In adition, the possessor (either pronominal or lexical) can be overt, in which case it always precedes the interrogative pronominal head. On the basis of the available examples, possessors expressed by pronouns appear in nominative forms (see 147), while lexical possessors are inflected in genitive case (see 148). In both cases the interrogative heads take possessive suffixes.

\footnotetext{
${ }^{29}$ I differentiate here adnominal possession from predicate possessive structures. In this section, only adnominal possessive structures will be discussed, whereas predicate possession will be examined in §7.1.2 and in §7.3.2.
} 


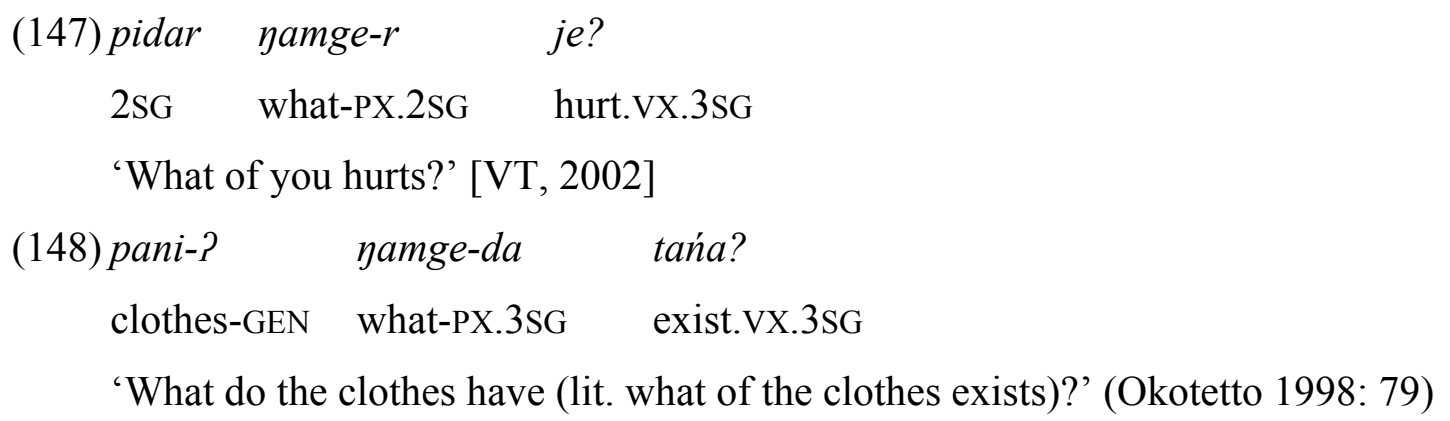

Possessive markers on interrogative pronouns can also combine together with case markers. According to Hajdú (1968: 41-46), the set of possessive markers available for oblique cases differs from those of the nominative in the nominal domain. Similarly to nouns, interrogative pronouns take the oblique forms of possessive markers (see 149).

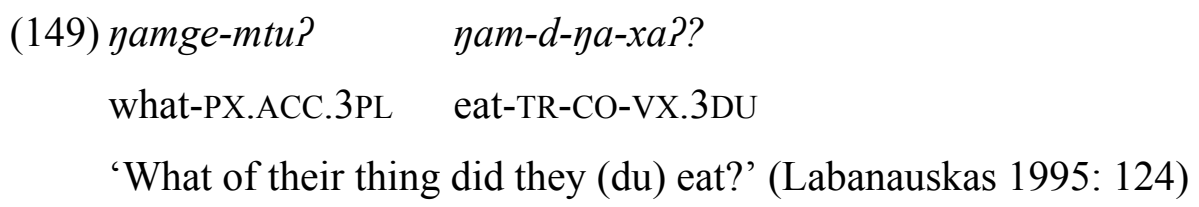

Semantically, these interrogative possessive constructions express inalienable possessions, in which the interrogative pronouns ask about body parts or about relatives, etc. of a person.

These possessive structures (illustrated above in 138-142) are formally identical with the so-called peripheral possessor in the nominal domain (discussed in §2.3) in which the possessive relation is also marked on the head of the phrase instead of only the dependent being marked. As Nikolaeva (2005a: 228) notes, peripheral possessors appear only before determiners in possessive phrases. The insertion of a determiner between an interrogative pronoun and its possessor complement is not observed in the available data.

Moreover, as certain Tundra Nenets grammatical descriptions discuss (e.g. Salminen $1998 \mathrm{~b}$ ), there is also a benefactive paradigm available for nouns in Tundra Nenets. The benefactive suffixes are always followed by possessive markers in the nominal paradigm, expressing that a given entity is made or intended for someone (cf. Salminen 1998b: 539). According to some occurrences in the dictionary of Tereshchenko (1965) interrogative pronouns may also take benefactive suffixes - also called as predestinative by Hajdú (1968: 46) and Nikolaeva (2014: 72) - (see 150). 

(150) yamge-da-r
yadim-da?
what-BEN-PX.2SG
appear-FUT.VX.3SG
'What will appear for you?' (Tereshchenko 1965: 374)

In example (150) above, the benefactive suffix is followed by a possessive marker, which order is typical for the nouns as well. These constructions are not attested in the corpus, but on the basis of the data provided by Tereshchenko (1965) I suppose that interrogative pronouns can take benefactive markers. However, the occurrence of these constructions are semantically limited, therefore they are not represented in the corpus.

Finally, interrogative pronouns may also function as predicates in nonverbal clauses. Like nouns (discussed in \$2.3), interrogative pronouns take verbal agreement markers in every person and number for marking the person and the number of their subject without adding a copular verb. Thus, the agreement between the subject of the clause and the predicative interrogative pronoun is indicated by verbal suffixes (see 151-152).

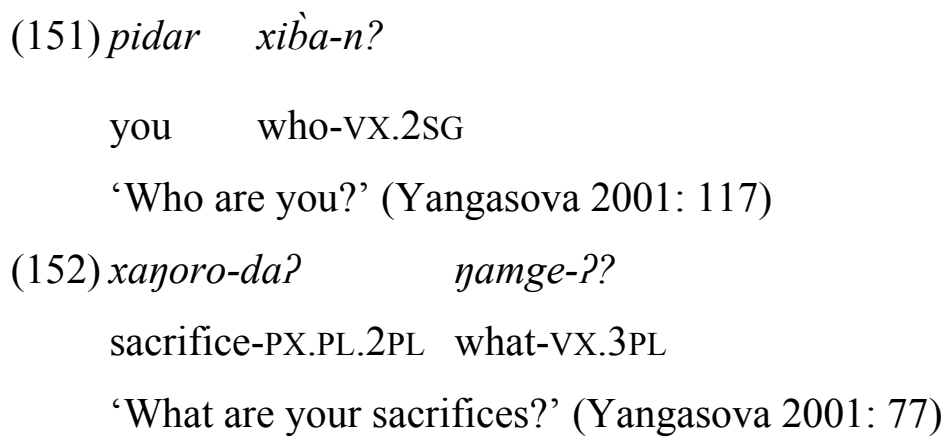

In Tundra Nenets, nouns functioning as predicates can also appear in past tense without a copular verb (cf. Wagner-Nagy \& Viola 2009: 60-61; see §2.3.). Contrary to nouns, however, interrogative pronouns cannot take past tense markers, instead there is a copula appearing in the interrogative predicate construction. The copula is formally the same that is used in noninterrogative clauses. However, this copula does not take the past tense marker in questions, but the so-called interrogative modal marker referring to past tense appears in the sentence. It should be noted that a different interrogative predicate strategy is observed by Nikolaeva (2014: 257), which strategy was, however, not attested in the corpus. For a detailed description see 7.3.1. On the basis of the data, consequently, in interrogative nonverbal clauses the past tense is indicated by the interrogative mood marker instead of the regular past tense marker available in non-interrogative clauses (see 153-154). 
(153) $x i \grave{b} a-n \quad$ yce-sa-n?

who-VX.2SG be-INT-VX.2SG

'Who were you?' (Yangasova 2001: 60)

(154) ńeל̀a-ke?, jerkara-ḿi yamge yo-sa?

mother-DIM clan-PX.1SG what.VX.3SG be-INT.VX.3SG

'Mother, what was my clan?' (Labanauskas 1995: 63)

As illustrated in examples (153-154) above, the person/number suffixes remain on the predicative interrogative pronoun as well.

Additionally, any other verbal suffixes (such as aspect, mood, etc.) can only appear on the copula. Similarly to the previous case, the person/number suffixes are present on the predicative interrogative pronoun as well (see 155-156).

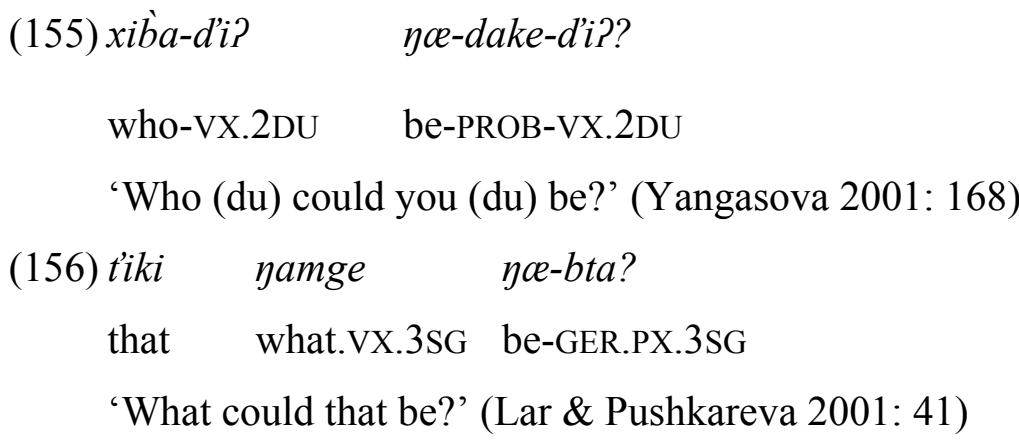

Interrogative pronouns typically occur as predicates in so-called equative and inclusive clauses. These predicate constructions will be examined in $\S 7.3$.

To summarize the main points of this section, we can say that interrogative pronouns can appear as any constituents of the main clause. If they function as subjects, objects or adverbials, they can be specified for case (grammatical and locative) and number (singular, dual and plural). In addition, they can also be marked by possessive markers (attached directly to the interrogative pronouns). In possessive phrases, the interrogative pronouns (either xiba 'who' or yamge 'what') function as the heads (possessed items), while the dependents (possessors) are expressed by pronouns or lexical nouns. However, an overt possessor is not obligatory in these phrases. If the context requires it, the possessive markers on interrogative pronouns can further be combined with grammatical/oblique case markers. Furthermore, the 
so-called benefactive markers can also appear on interrogative pronouns, but these constructions are not attested in the corpus.

Finally, agreement markers are also available for interrogative pronouns, if they function as predicates in nonverbal clauses. This paradigm is, however, restricted to present tense, whereas past tense is expressed by the interrogative modal marker that is attached to a copula instead of the interrogative pronouns.

These categories of interrogative pronouns do not differ formally from those used in the nominal paradigm, so Tundra Nenets does not have a distinct set of categories for the interrogative domain.

In what follows, constructions in which the interrogative pronouns function as complements will be discussed.

\subsubsection{Interrogative pronouns as complements of phrases}

In contrast to the previously discussed constructions, those structures will be presented here in which the interrogative pronouns function as complements of certain phrases. Two kinds of phrases are attested in the corpus. These are possessive phrases ${ }^{30}$ and postpositional phrases illustrated in Table 19.

Table 19. Phrases with interrogative pronominal complements

\begin{tabular}{lcc}
\hline Phrase-type & HUMAN & NON-HUMAN \\
\hline Possessive phrase & 8 & no data \\
Postpositional phrase & 3 & 9 \\
\hline
\end{tabular}

In possessive phrases, the possessor can be substituted by interrogative pronouns (xiba 'who' and yamge 'what'). Although the non-human interrogative possessor (yamge 'what') is not attested in the corpus, I suppose that it also can be used in this function, because it has basically the same grammatical characteristics as the human interrogative pronoun (xiba 'who'). As the concept of possession is more likely associated with human beings, I suppose that the lack of the non-human possessor in the texts has semantic reasons instead of grammatical ones.

\footnotetext{
${ }^{30}$ Similarly to possessive construction discussed in $§ 6.1 .1$, those adnominal possessive constructions will be discussed here in which the interrogative pronouns appear as possessors. For predicate possessive structures see $\S 7.1 .2$ and $\$ 7.3 .2$.
} 
In possessive phrases with interrogative possessors, the head (possessed item) controls case marking on its complement, which means that the interrogative possessor obligatorily has genitive form. A table providing the genitive marked forms of interrogative pronouns is presented under (20) below.

Table 20. The interrogative pronouns marked by genitive case

\begin{tabular}{|c|c|c|}
\hline Number & HUMAN & NON-HUMAN \\
\hline SG & xiba? & yamge? \\
\hline DU & xib̀axa? & yamgexe? \\
\hline PL & $x i \grave{b i} ?$ & yawo? \\
\hline
\end{tabular}

Comparing the data provided in Table 20 with the other inflectional paradigms of the interrogative pronouns (illustrated in Table 14 and 15) it can be observed that the dual paradigms of nominative, accusative and genitive cases of the interrogative pronouns are expressed by the same lexemes (i.e. xibaxa? and yamgexe?). Additionally, the genitive plural form of the human interrogative (xibi? $)$ is identical to the corresponding accusative lexeme.

In possessive phrases with interrogative pronominal possessors the possessive relation is only marked on the dependent (possessor) through genitive case markers. There are no possessive suffixes attached to the possessed items in these constructions. Considering the fact that exactly this information, i.e. the person, the number and/or the identification of the possessor, is missing in the discourse, I do not expect that possessed items would take possessive suffixes in these possessive constructions. The available structures are introduced in $(157-158)$.

(157) xib̀a-? juno jera-bi-da??

who-GEN horse guard-CONT-VX.2PL

'Whose horse do you guard?' (Orlova et al. 1996: 45)

$\begin{array}{rllll}\text { (158) t'uku } & \text { jal'a-? } & \text { xibi? } & \text { manzaja-m? } & \text { toromda-wa?? } \\ \text { this } & \text { day-GEN } & \text { who.PL.GEN } & \text { work-ACC } & \text { make.known-VX.1PL }\end{array}$

'Whose (pl) work did we make known today?' (Okotetto 1998: 86)

In addition, the genitive possessors expressed by interrogative pronouns can also be combined with possessive suffixes (see 159). 

(159) xib̀a-ndo?
ŚO-P
wada-??
who-PX.GEN.3PL song-GEN word-vX.3PL
'Whose lyrics are these (lit. whose of them)?' (Nenyang 2005: 75)

The other phrases in which interrogative pronouns can appear as complements are postpositional phrases. In these phrases, the postpositions control their dependent (which are interrogative pronouns), which appear in genitive forms (see 160-161).

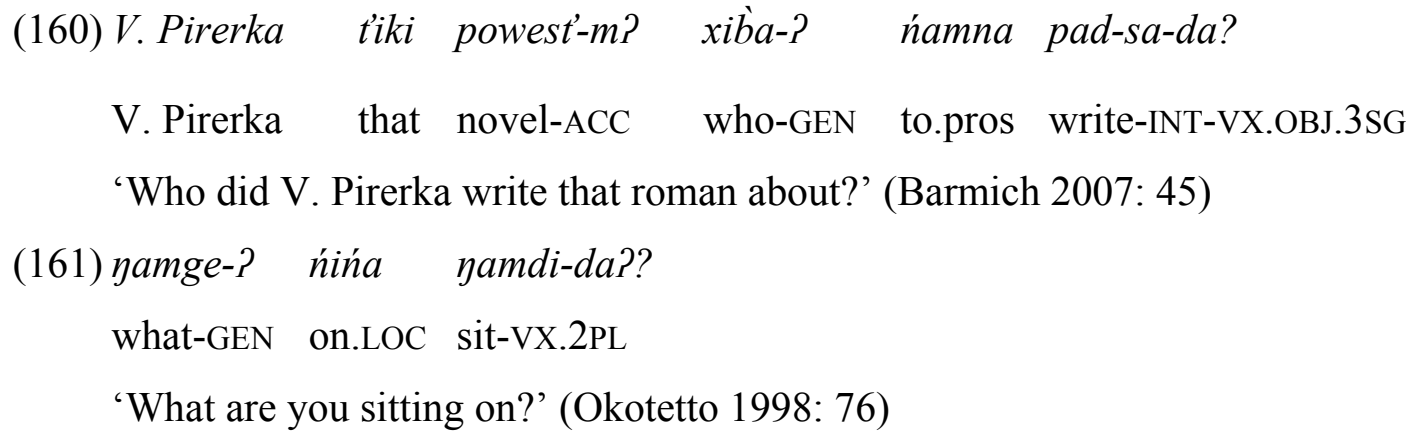

To sum it up, interrogative pronouns may also appear as dependents in possessive and postpositional phrases. In both of these structures, the heads of the phrases (either a possessed item or a postposition) control the case of their interrogative pronominal complements, so the interrogative pronouns appear in genitive forms.

In the following, I will turn to those occurrences of non-human interrogative pronoun in which it is used not only with different meaning, but also with different grammatical characteristics.

\subsubsection{The attributive use of the non-human interrogative pronoun}

As explained in §5.1.4, the non-human interrogative pronoun (yamge 'what') can also be used in selective/qualitative meaning. This different semantic use results in different grammatical category from those presented in $\S 6.1 .1$ and in $\S 6.1 .2$. In its selective/qualitative function, the interrogative pronoun can only be used as a modifier in noun phrases (so it can only form a phrasal constituent with nouns) and it does not occur as the element of the main clause.

In the available phrases, this interrogative modifies only nouns by preceding them. An insertion of any other element between the head and the dependent interrogative is not attested (see 162). 

(162) yamge awtobus tir-t'a yano-? nulaygalwa-n? mi-na?
what.qual bus fly-PCP.IMPF boat-GEN station-DAT go-CO.VX.3SG
'Which/What kind of bus goes to the airport?' (Vanuyto 2012: 52)

Within the phrase, there is no internal number agreement between the noun head and its pronominal dependent (see 163).
(163) tamna
yamg
xobco-ko-?
tańa-??
still
what.qual riddle-DIM-PL exist-VX.3PL
'Which/What kind of riddles are there?' (Okotetto 1998: 133)

Additionally, agreement in case is not available for the elements of the noun phrase either (see 164-165) (either in grammatical or in oblique cases).

$$
\begin{array}{ccl}
\text { (164)pidar } & \text { yamge wada-m? } & \text { toxola-mbi-n? } \\
\text { 2SG } & \text { what.qual word-ACC } & \text { learn-CONT-VX.2SG }
\end{array}
$$

'What language do you learn?' [E.La, 2002]

$$
\begin{array}{cclll}
\text { (165) yamge } & \text { jale-Pmana } & \text { t'ir-t'a } & \text { yano-? } & \text { tir-ya-P? } \\
\text { what.qual } & \text { day-PL.PROS } & \text { fly-PCP.IMPF } & \text { boat-PL } & \text { fly-CO-VX.3PL }
\end{array}
$$

'On which/what days do the airplains fly?' (Vanuyto 2012: 51)

Finally, if the modified noun functions as the predicate of the clause and has agreement marking, this marker appears only on the head noun but not on the dependent interrogative (see 166).

$$
\begin{aligned}
& \text { (166) padar yamge jerkara-n? } \\
& \text { 2SG what.qual surname-VX.2SG } \\
& \text { 'What is your surname?' (Labanauskas 1995: 63) }
\end{aligned}
$$

Consequently, if the non-human interrogative pronoun is used attributively with selective/qualitative semantic function, it immediately precedes the modified head noun and it does not agree with the head in number, case and/or person-number. Its function is similar to that of interrogative adjectives (see the discussion in $§ 6.3$ ). In Tundra Nenets, adjectives can 
typically be used predicatively too. However, the non-human interrogative pronoun used as an adjectival modifier cannot appear as the predicate in attributive clauses.

6.1.4. The adverbial use of the non-human interrogative pronoun

As demonstrated in $§ 5.1 .5$, there is another semantic function available for the non-human interrogative pronoun (yamge 'what'): it can also be used for asking about the reason for an event. In this case, the non-human interrogative pronoun has the grammatical characteristics of adverbials in Tundra Nenets. Consequently, it cannot be inflected at all and cannot be modified by any elements. In the clause, this adverbial is optional, not required by the predicate. The characteristics of this adverbial can only be described on the basis of its position relative to other clause elements. Based on the position it occupies, it belongs to the class of predicational adverbs. ${ }^{31}$ If it is used in a clause, it modifies either a verbal or a nonverbal predicate (see 167-168, respectively).

(167) yamge juśeda-n?

why lie-VX.2SG

'Why are you lying?' (Okotetto 1998: 99)

(168)xasawa ńu-ḿi gamge tarča?

man child-PX.1SG why so.vX.3SG

'Why is my son like this?' (Labanauskas 1995: 72)

Consequently, it typically appears immediately before the predicate. For further positions available to the interrogative adverb yamge 'why' see Chapter 7.

To summarize the facts, the non-human interrogative pronoun (yamge 'what') can also be used either attributively with selective/qualitative reference (yamge 'what kind'), or as an adverbial referring to reason (yamge 'why'). These syntactic functions differ in their grammatical characteristics. A table illustrating the grammatical differences between the

\footnotetext{
${ }^{31}$ Predicational adverbs are adverbs which "relate to the predicate or predicate-plus-other constituents but are not usefully regarded as part of the predicate constituent" (cf. Dixon 2010a: 109). In addition, the so-called sentential adverbs "apply to a complete clause or sentence" (cf. Dixon 2010a: 109). I will also differentiate here the so-called predicate adverbial constructions, in which the adverb can be considered to be the part of the predicate construction.
} 
pronominal, adjectival (attributive) and adverbial uses of the non-human interrogative word is provided below (see Table 21).

Table 21. The differences between the use of yamge

\begin{tabular}{llccc}
\hline \multicolumn{1}{c}{ Grammatical categories } & \multicolumn{3}{c}{ Semantic categories } \\
& & NON-HUMAN & SELECTION/QUALITY & REASON \\
\hline \multirow{4}{*}{ Morphological } & Number & + & - & - \\
categories & Case & + & - & - \\
& Possessive marker & + & - & - \\
& Benefactive marker & + & - & - \\
& Verbal inflection & + & - & - \\
\hline \multirow{3}{*}{ Distribution } & Complement & + & - & - \\
& Modifier & - & + & - \\
\hline \multirow{5}{*}{ Syntactic functions } & + & - & - \\
& Head & + & - & - \\
& Subject & + & - & + \\
& Object & + & - & - \\
\hline
\end{tabular}

As seen in Table 21, the interrogative word yamge used as interrogative pronoun with the meaning 'what' can basically be inflected for number, case, possessive and benefactive paradigms, in which cases it can function as any main constituent of the clause. In addition, it can also be the predicate of the clause by taking person and number agreement markers. Furthermore, it can take a complement in possessive phrases and it can be a complement itself in possessive and postpositional phrases. Unlike the pronominal use, the attributive use with selective/qualitative reference ('what kind') allows for being a modifier of a noun (phrase). In this case, the interrogative word precedes the head and does not agree with it in number, case and/or possession. Unlike interrogative adjectives, the non-human interrogative pronoun used as an attribute cannot function as a predicate on its own. Finally, the non-human interrogative pronoun can also function as an adverbial ('why') without taking any inflectional categories or having any complements, in which case it typically functions as an optional adjunct in the clause. The grammatical characteristics of the interrogative word are the most restricted in this adverbial function. The distribution of these functions of the non-human interrogative pronoun in the corpus is provided in Table 22 below.

Table 22. The distribution of the syntactic functions of yamge

\begin{tabular}{ccc}
\hline NON-HUMAN & SELECTION/QUALITY & REASON \\
\hline 288 & 69 & 51 \\
\hline
\end{tabular}


As Table 22 demonstrates, the most common and frequent function of yamge is the pronominal function with the meaning 'what'. Therefore, I regard its selective and adverbial uses as only being secondary functions.

\subsection{The interrogative determiners}

Interrogatives that require the selection and/or the identification of their specified referent presented in $\$ 5.2$ typically function as determiners in phrases. I reiterate the forms for convenience in Table 23.

Table 23. The interrogative determiners

\begin{tabular}{cccc}
\hline SELECTION & SELECTION FROM TWO & SELECTION OF MORE \\
\hline xańayi & xujum? & xańajejum? & xańayi? \\
\hline${ }^{\mathrm{c}}$ For differences between the two forms of the restricted selective interrogative see $\S 5.2$. &
\end{tabular}

The forms of interrogative determiners illustrated in Table 23 do not show lexical differences in the Tundra Nenets dialectal groups and subdialects.

The interrogative determiners primarily appear as modifiers of nouns (or phrases) by preceding them. Additionally, they can also be used predicatively in nonverbal clauses. The occurrences of those syntactic functions of the interrogative determiners are summarized in Table 24.

Table 24. The core syntactic functions of interrogative determiners

\begin{tabular}{lc}
\hline Syntactic function & SELECTION \\
\hline Modifier & 19 \\
Predicate & 2 \\
\hline
\end{tabular}

As Table 24 shows, these interrogatives are quite rare in the corpus, therefore some of their grammatical characteristics can only be presumed on the basis of the examples available.

In noun phrases, the interrogative determiner precedes the specified noun. Non-singular number marked nouns modified by interrogative determiners are not attested in the data, so the question whether interrogative determiners show agreement in number will not be answered here. According to the data, if an interrogative determiner modifies a noun, it does not show case agreement with the noun head (see 169-170). 

(169) Satako, xańani
xana-ko-m?
yarka yuxuko
xana-ygu?
Satako which
sledge-DIM-ACC
big doll
take-FUT.VX.3SG

'Satako, which sledge will the big doll take?' (Okotetto 1998: 68)

$\begin{array}{rll}\text { (170)xańayi } & \text { ja-xana jile? } \\ \text { which } & \text { land-LOC live.VX.3SG }\end{array}$

'Which country does he live in?' (Barmich 2007: 41)

If the modified element is a personal pronoun, it is covert in the construction and the interrogative determiners take possessive markers which refer to the person and number of the missing personal pronouns (see 171).

\author{
(171) xańaye-ra? tur-ca? \\ which-PX.2PL arrive-INT.VX.3SG \\ 'Which of you arrived?' (Barmich 2007: 41)
}

According to the data available, nominal heads can also be elided from the phrase in which case the interrogative determiners take the inflectional markers of the elided heads. The example provided under (111) in $\$ 5.2 .1$ serves to illustrate this property of interrogative determiners. I repeat this example here for convenience:

\author{
(172) xańayi-P tóre-na-?. \\ which-PL shout-CONT-VX.3PL \\ 'Who (lit. which) are shouting?' (Barmich 2007: 41)
}

The interrogative determiner in (172) appears as the subject of the clause inflected in plural number and there is no noun in the clause. The interrogative determiner controls agreement on the verb, which is in the 3rd plural form. As the relevant structures are underrepresented in the corpus, there is no way to analyse the grammatical characteristics of interrogative determiners in elliptical structures.

Additionally, interrogative determiners can also appear in possessive phrases functioning as possessed items (heads). In this case, the interrogative determiner is marked with possessive suffix which refers to the person and number of the selectable element, of the possessor. Lexical possessors take genitive marker in the construction. In example (173) the 
interrogative determiner functions as the object of the clause, therefore it takes an additional accusative marker.

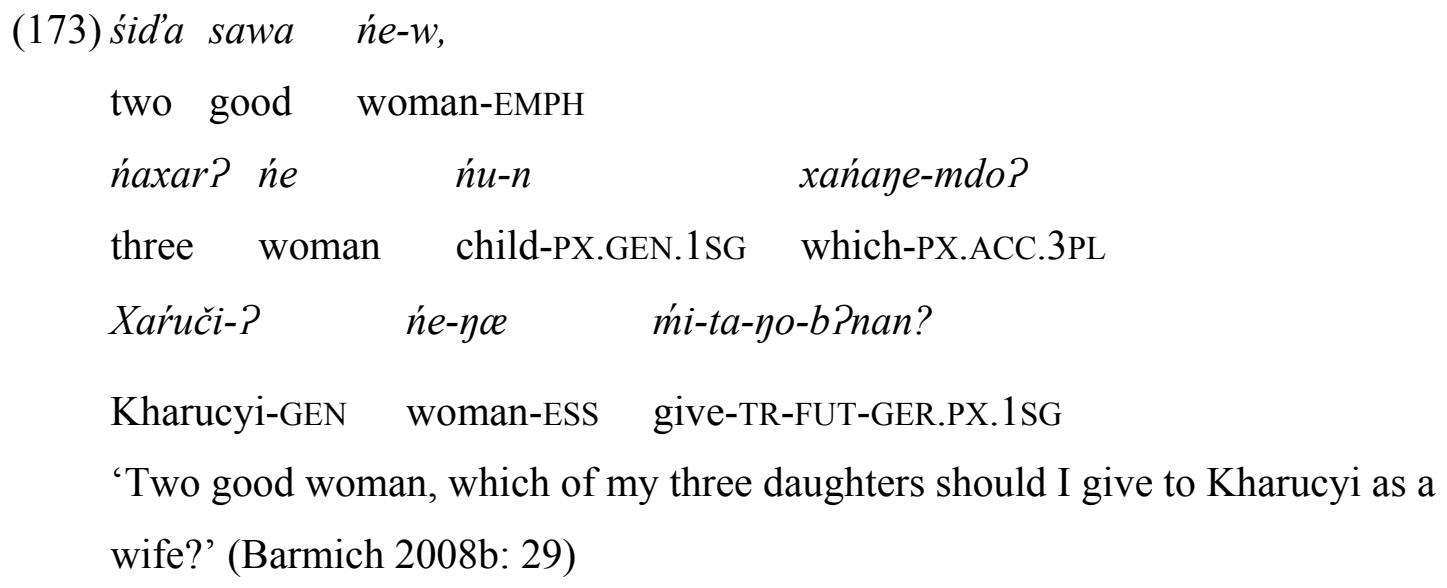

Finally, interrogative determiners can function as predicates of nonverbal clauses in which cases they are inflected for person and number, so they agree with the subject of the clause (see 174).

$\begin{array}{lll}\text { (174) Nad'a, } & \text { papa-ko-r } & \text { xańayi? } \\ \text { Nadya } & \text { brother-DIM-PX.2SG } & \text { which.VX.3SG } \\ \text { 'Nadya, which is your younger brother?' (Okotetto 1998: 116) }\end{array}$

Although there is no available data for illustrating the occurrence of this nonverbal predicate in past tense, I assume that it has exactly the same characteristics as the interrogative pronouns have in the same function, so the past tense is marked by the interrogative modal suffix attached to the overt copular verb that follows the interrogative determiner.

To sum it up, interrogative determiners function either as modifiers in phrases or as predicates in nonverbal clauses. If they modify a noun, they do not agree with it in number and case according to the data extracted from the corpus. The modified noun can be elided from the phrase in which case the interrogative determiners take the number and presumably - the case markers of their modified nouns. If the interrogative determiners modify personal pronouns, the pronouns are not overt in the phrase, therefore possessive suffixes attached to the interrogative determiners mark the person and number of these covert pronouns. In addition, the interrogative determiners can have complements in possessive phrases, in which cases they take the case and number markers. Finally, functioning as 
predicates interrogative determiners take agreement markers in present tense. I also presume that the presence of a copular verb in past tense is obligatory similarly to the interrogative pronominal predicates discussed in $§ 6.1 .1$.

\subsection{Interrogative adjectives}

The interrogative words specified for QUALITY and SIZE dealt with in $§ 5.3$ and in $§ 5.4$ can be categorized as interrogative adjectives in Tundra Nenets (see the forms in Table 25).

Table 25. The interrogative adjectives

\begin{tabular}{cc}
\hline QUALITY & SIZE \\
\hline xurka & śayar \\
\hline
\end{tabular}

For certain Tundra Nenets dialects, there are no additional different forms of interrogative adjectives available. The interrogative adjectives in Tundra Nenets are used either attributively or predicatively. A table illustrating the functional distribution of interrogative adjectives is provided under (26) below.

Table 26. The core syntactic functions of interrogative adjectives

\begin{tabular}{lcc}
\hline Syntactic function & QUALITY & SIZE \\
\hline Modifier & 118 & 1 \\
Predicate & 58 & no data \\
\hline
\end{tabular}

As given in Table (26), the interrogative asking for size of an entity (śayar 'how big') appeared only in one clause. Therefore, it can only be hypothesized that it has exactly the same grammatical characteristics as the interrogative adjectives in Tundra Nenets.

As shown, the basic function of interrogative adjectives is to modify a noun (phrase). In this case, they precede the modified noun. According to the data provided by Tereshchenko (1965: 813), the adjectival interrogative words agree in number with their head nouns. The data of Tereshchenko (1965) come from the Central dialect (see 175).

(175) Central Dialect

xurka-? jun-? tańa-??

what.kind-PL news-PL exist-VX.3PL

'What news are there?' (Tereshchenko 1965: 813) 
As Nikolaeva (2003: 322) notes, the dialects may show differences with respect to the internal agreement of the phrases. She mentions that agreement in number is typically available for the Western dialects. In the corpus, phrases originating from the Western dialect are also represented, in which the interrogative adjectives agree with their noun head in number (see 176).

(176) Western Dialect

$\begin{array}{lllll}\text { tuko-na } & \text { tamna } & \text { xurka-P } & \text { xal'a-? } & \text { tańa-P? } \\ \text { this-LOC } & \text { still } & \text { what.kind-PL } & \text { fish-PL } & \text { exist-VX.3PL }\end{array}$

'What fish is still there?' (Khanzerova et al. 2012: 86)

In contrast, data from the Eastern dialectal group do not show internal agreement in number (see 177).

(177) Eastern Dialect

$\begin{array}{llll}\text { xurka } & p ́ a-P & \text { pedara-xana } & \text { wad'odana-P? } \\ \text { what.kind } & \text { tree-PL } & \text { wood-LOC } & \text { grow-VX.3PL }\end{array}$

'What trees grow in the forest?' (Vanuyto 2012: 64)

This agreement feature seems to be a distinctive porperty among dialects. As most of the available examples do not show agreement in number, this agreement seems to be optional and typically available for the non-Eastern dialects.

Phrases containing interrogative adjectives with internal agreement in case are not attested in the corpus. Examples illustrating the lack of the agreement in case are provided under (178-179) below.

$$
\begin{aligned}
& \text { (178) Xačko xurka ošibka-m? me-wi? } \\
& \text { Xachko what.kind mistake-ACC make-NARR.VX.3SG } \\
& \text { 'What mistake did Xachko make?' (Nenyang 2005: 59) } \\
& \text { (179) xurka xarda-xana jil'e-n? } \\
& \text { what.kind house-LOC live-VX.2SG } \\
& \text { 'What house do you live in?' (Vanuyto 2012: 17) }
\end{aligned}
$$


Moreover, interrogative adjectives do not show agreement in person and number in possessive phrases (see 180).

(180)xurka yawra-ra? tara?

what.kind food-PX.2PL be.needed.VX.3SG

'What food do you need (lit. is needed by you)?' (Khanzerova et al. 2012: 26)

Interrogative adjectives precede the head noun in the phrase, and another adjectival element can also be inserted in between the interrogative pro-form and the head noun. Note, that this structure does not ask about extent (see 181).

(181) Seko xurka sawa śer-m? śerta-sa?
Seko what.kind good thing-ACC make-INT.VX.3SG
'What kind of good thing did Seko make?' (Nenyang 2007: 20)

As mentioned above, interrogative adjectives can also be used predicatively in adjectival clauses (for further discussion about nonverbal predicates see §7.3), in which cases interrogative adjectives take verbal suffixes marking the person and the number of the subjects without overt copular verbs (see 182).

$$
\begin{array}{ccc}
\text { (182) pidari? } & \text { śero-diP } & \text { xurka-P? } \\
\text { 2DU } & \text { thing-PX.PL.2DU } & \text { what.kind-VX.3PL } \\
\text { 'What are your (du) things like?' (Vanuyto 2012: 10) }
\end{array}
$$

Similarly to the interrogative pronominal paradigm, copular verbs appear in past tense that is expressed by the interrogative modal suffix. As example (183) demonstrates, the copula used by interrogative adjectival predicates is the same that appears in the interrogative pronominal predicate constructions (discussed in $\S 6.1 .1$ ).

\footnotetext{
(183) ṕija-ko xurka yo-sa?

stoat-DIM what.kind be-INT.VX.3SG

'What was the stoat like?' (Nenyang 2007: 32)
} 
Additionally, in case of further verbal categories (tense, aspect, mood) the copula is overt and takes the corresponding markers. The agreement markers are presented both on the copula verbs and on the predicative interrogative adjectives (see 184).

$$
\begin{array}{llll}
\text { (184) ja } \quad \text { ta? } \quad \text { xurka } & \text { yce-śeti? } \\
\text { land } \quad \text { summer } & \text { what.kind.vX.3SG } & \text { be-HAB.VX.3SG } \\
\text { 'What does the land look like in summer?' } & \text { (Nenyang 2007: 6) }
\end{array}
$$

To summarize the facts, interrogative adjectives appear as attributes in noun phrases, or as predicates in nonverbal clauses. If they are used as complements of nouns, they optionally agree with the head noun in number, but do not show agreement either in case or in person/number in the possessive paradigm. The ellipsis of the head noun is not attested in the corpus. Like interrogative pronouns, interrogative adjectives can also be predicates of clauses by taking agreement suffixes. In past tense and with other verbal categories (e.g. future tense, mood, aspect) copular verbs appear in the clauses, which follow the adjectival predicates.

\subsection{Interrogative quantifiers}

The interrogative words specified for quantity and rank discussed in $\S 6.4$ have the grammatical characteristics of quantifiers in Tundra Nenets. The lexemes are presented in

\begin{tabular}{|c|c|c|}
\hline \multicolumn{2}{|c|}{ QUANTITY $^{d}$} & RANK \\
\hline śan & śanok & śańemd'ej \\
\hline
\end{tabular}
Table 27. Apparently, there is no variation in the dialectal forms.

Table 27. The interrogative quantifiers

As already mentioned in $§ 6.4$, interrogative quantifier expressing RANK (śańemd'ej) does not appear in the texts, therefore I only discuss the grammatical characteristics of the interrogatives expressing quantity. These interrogatives can either quantify over a noun (phrase) or function as predicates in nonverbal clauses. The syntactic functions and distributions of interrogative quantifiers are illustrated in Table 28. 
Table 28. The core syntactic functions of interrogative quantifiers

\begin{tabular}{lc}
\hline Syntactic function & QUANTITY \\
\hline Quantifier & 83 \\
Predicate & 21 \\
\hline
\end{tabular}

As Stump (1998: 24) notes, a quantifier can control its head noun that appears in an oblique case in the construction, for example in Russian. This grammatical characteristic is not typical of Tundra Nenets quantifiers and interrogative quantifiers as the enumerated nouns are in nominative case. Dual and plural forms of nouns quantified by interrogative quantifiers are not attested either. I expect that the nominal referents of the interrogative quantifiers can only appear in singular number in the phrases (see 185).

$$
\begin{aligned}
& \text { (185) śan yaćeki tańana toxolku? } \\
& \text { how.many child there.LOC learn.VX.3SG } \\
& \text { 'How many children learn there?' (Vanuyto 2012: 33) }
\end{aligned}
$$

Additionally, interrogative quantifiers that precede quantified nouns do not show any agreement in case (see 186-187).

$$
\begin{aligned}
& \text { (186) śayok xal'a-m tiki po jeremd'e-da? } \\
& \text { how.many fish-ACC that year catch-VX.OBJ.3SG } \\
& \text { 'How many fish did he catch that year?' [E.La, 2002] } \\
& \text { (187) pido? śan xal'a-m? xada-wi-P? } \\
& \text { 3PL how.many fish-ACC kill-NARR-VX.3PL } \\
& \text { 'How many fish (PL) did they catch?' (Vanuyto 2012: 34) }
\end{aligned}
$$

Furthermore, interrogative quantifiers do not take any person/number agreement suffixes in possessive phrases (see 188).

$$
\begin{array}{llll}
\text { (188) sowxoz-ra? } & \text { śan } & j a-d a & \text { tańa? } \\
\text { sovkhoz-PX.2PL } & \text { how.many } & \text { land-PX.3SG } & \text { exist.VX.3SG } \\
\text { 'How many lands does your sovkhoz have?' (Nenyang 2005: 99) }
\end{array}
$$

As example (189) below illustrates, the insertion of another element between the quantified noun and the quantifier is possible. 

(189) śan
śunraxa noj?
how.many blue cloth.VX.3SG

'How much blue cloth is it?' (Okotetto 1998: 72)

As was discussed in \$5.5.2, interrogative quantifiers may appear to request (more) information about temporal circumstances of an event, in which cases they take case markers without head nouns. These constructions, whose structures are similar to those of interrogative determiners, seem to be available in the Eastern dialectal group only. Here, interrogative quantifiers can appear in phrases with elided noun heads. In these cases, the quantifiers inflect for the (number and) case of the elided noun head (see 190).

(190) Eastern Dialect

$$
\begin{aligned}
& \text { labka śan-xana pakal-ya? } \\
& \text { store how.many-LOC close-CO.VX.3SG } \\
& \text { 'When does the store close?' [E.La, 2002] }
\end{aligned}
$$

In the corpus, similar constructions are attested, in which the interrogative quantifiers appear in accusative marked forms, while the head nouns are covert in the phrases. These data are also originate from the Eastern dialectal group (see 191).

(191) Eastern Dialect

$$
\begin{array}{lllll}
\text { ṕi-sawej } & \text { jal'a-xana } & \text { labe? } & \text { śan-m? } & \text { miŕe?-na? } \\
\text { night-COM } & \text { day-LOC } & \text { room } & \text { how.many-ACC } & \text { cost-CO.VX.3SG }
\end{array}
$$

'How much does a room cost for a day including night?' (Nenyang 2005: 115)

Consequently, this ellipsis seems to be characteristic only of the Eastern dialectal group.

Finally, just like interrogative adjectives, interrogative quantifiers can also be used as predicates in non-verbal clauses by taking verbal inflectional markers (see 192).

$$
\begin{aligned}
& \text { (192) ńań mir-ta śan? } \\
& \text { bread price-PX.3SG how.many.VX.3SG } \\
& \text { 'How much does the bread cost?' (Vanuyto 2012: 23) }
\end{aligned}
$$


A copular verb is obligatory in the predicate structure if there are additional verbal meanings to be expressed (see 193).
(193) mir-ta
śan
yoe-ygu?
price-PX.3SG how.many.VX.3SG be-FUT.VX.3SG
'How much will it cost?' (Vanuyto 2012: 47)

As is illustrated in example (193) above, the same copula is used with quantifier predicates as the one that appears in the interrogative pronominal, determiner and adjectival predicates. Additionally, this copula is used in the nominal domain as well. Similarly to these predicate constructions, the copular verb follows the nominal part of the predicate and the agreement markers appear on both parts of the complex predicate.

To sum up $§ 6.4$, interrogative quantifiers can appear either as modifiers or as predicates in the clauses. If they modify a noun, they do not control the head noun in number, therefore there are no plural nouns that are modified by interrogative quantifiers. The head nouns and the interrogative modifiers do not show any further agreement in number. However, it seems possible to elide the head nouns from the phrases, in which cases the interrogative quantifiers take the markers of the covert heads ${ }^{32}$. These elliptical structures appear only in data from the Eastern dialectal group. Finally, similarly to the other interrogatives discussed in $\S 6.1-\S 6.3$, interrogative quantifiers taking agreement markers can function as predicates of clauses without a copular verb. Nevertheless, temporal and any other verbal meanings expressed by suffixes can only appear on copulas.

\subsection{Interrogative adverbs}

As discussed in $§ 5.6-\$ 5.8$, there are interrogative words that express place, time and manner specifications of a given event. These interrogatives are categorized as interrogative adverbs based on their grammatical characteristics. The forms of these adverbs are reiterated in Table (29) below.

\footnotetext{
${ }^{32}$ The term covert head is defined on the basis of Dixon (2010: 229) in the following way. A covert head is the component of a phrase which determines the properties of the whole phrase and dictates agreement on other items in the phrase, but does not appear explicitly in the construction.
} 
Table 29. The interrogative adverbs

\begin{tabular}{|c|c|c|c|c|c|}
\hline \multicolumn{4}{|c|}{ Space position/Direction } & \multirow{2}{*}{ TIME } & \multirow{2}{*}{ MANNER } \\
\hline POSITION & GOAL & SOURCE & PATH & & \\
\hline xańana & xańa? & xańad & xańamna & śaxa? & xanźer? \\
\hline
\end{tabular}

These interrogative adverbs in Tundra Nenets have in common the formal characteristics of being uninflectable, therefore, they can only be caracterized in terms of their distribution and syntactic function. All of these interrogative adverbs can appear in clauses as adverbials. In some constructions, additionally, they can be part of the predicate.

If temporal and locative adverbs function as adverbials, they can typically be categorized as sentential ones, whereas manner adverbs appear most typically as predicational adverbial adjuncts in a clause. These interrogative adverbs cannot appear in the same position(s) in clauses with respect to the other clausal elements. The available positions of adverbs will be discussed in detailed in $\S 7.1$ and in $\S 7.2$.

\subsubsection{Sentential interrogative adverbs}

Both sentential interrogatives show further dialectal differences in their forms. The spatial/locational adverbs have four forms according to the locative paradigms: space position, goal, source and path of entities. In the interrogative PLACE specification a parallel paradigm appears in the Eastern dialect. The elements of this dialectal paradigm - similarly to the standard forms presented in $§ 5.6$ - consist of a bound interrogative stem $(x u-)$, which is combined with the system of the locative cases, which results in the same sub-specification of the spatial system. Unlike the standard interrogative forms, the dialectal ones do not contain any additional element (see Table 30 and compare with Table 11).

Table 30. The Eastern dialectal forms of spatial interrogative adverbs

\begin{tabular}{lcccc}
\hline Categories & Space position & \multicolumn{3}{c}{ Direction } \\
& & GOAL & SOURCE & PATH \\
\hline Oblique cases & LOC & DAT & ABL & PROS \\
\hline Interrogative words & xuna & $x u$ ? & xud & xumna \\
\hline
\end{tabular}

The forms of the Eastern dialect are exemplified in (194-197): 
(194) Eastern Dialect

xuna yodal'o-da?

where.LOC travel-PCP.IMPF.VX3SG

'Where is the passenger?' (Labanauskas 1995: 173)

(195) Eastern Dialect

xu? $\quad$ xuna-mbi-n?

where.DAT run-CONT-VX.2SG

'Where are you running to?' (Yangasova 2001: 154)

(196) Eastern Dialect

xud jader-ta-n?

where.ABL walk-CONT-VX.2sG

'Where are you coming from?' (Yangasova 2001: 41)

(197) Eastern Dialect

śińona-? pomna xumna min-d'ake-wa??

foggy-GEN among.PROS where.PROS go-PROB-VX.1PL

'Where are we passing by through the fog?' (Susoy 1990: 90)

In addition, there is also a dialectal form of the temporal interrogative adverb used solely in the Central dialect illustrated in Table 31.

Table 31. The dialectal forms of time interrogative adverb

\begin{tabular}{ll}
\hline Dialect & TIME \\
\hline Western & śaxa? \\
\hline Central & śa?ńa \\
\hline Eastern & śaxa? \\
\hline
\end{tabular}

An example for illustrating this dialectal form appearing in the Central dialect is provided in (198) below.

(198) Central Dialect

lawka śarńa tal-ygu?

store when be.closed-FUT.VX.3SG

'When will the store close?' [VT, 2002] 
The spatial and temporal adverbs typically modify the whole clause, but the local adverb can also appear as the part of the predicate in the so-called locational clauses. In these clauses, the local adverb appears together with a copula as the part of the predicate. The time adverbial can appear in a similar predicate construction, i.e. with a copular verb in which case the time adverbial can also be regarded as the part of the predicate construction. The following distributions can be observed by sentential interrogative adverbs:

Table 32. The core syntactic functions of sentential interrogative adverbs

\begin{tabular}{lcc}
\hline Syntactic function & PLACE & TIME \\
\hline Sentential adverb & 94 & 89 \\
Part of the predicate & 71 & 10 \\
\hline
\end{tabular}

The interrogative adverbs typically appear in the clause as free adjuncts modifying the whole clause (for further discussion regarding the positions and functions available for interrogative adverbs see $\S 7.1$ and $\S 7.2$ ). As mentioned above, interrogative adverbs only have uninflected forms (see 199-200).

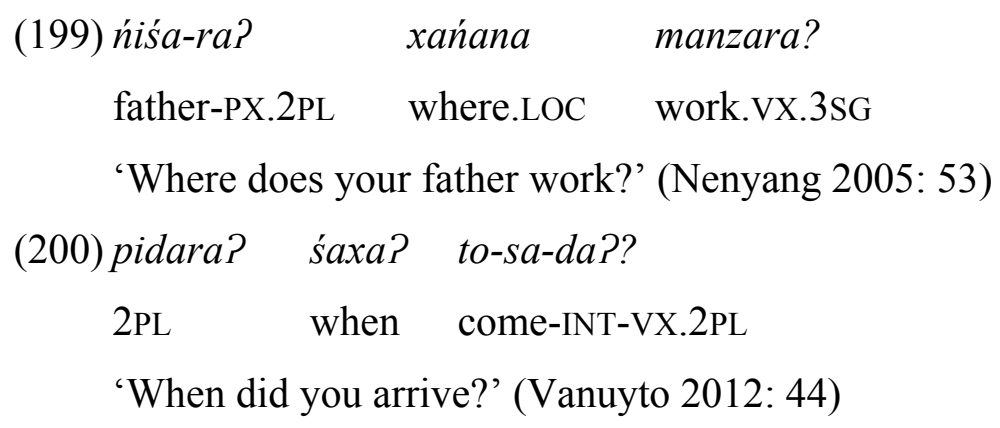

As mentioned above, local interrogatives also appear as the non-verbal parts of locative predicates. The locative expressions indicate the position of their subjects, i.e. the so-called theme elements. The subjects are typically definite in these clauses. The non-verbal parts of these predicates are the spatial interrogatives, but overt copulas situated in the constructions are always obligatory (see 201).

(201) biblioteka xańana ya?
$\begin{aligned} & \text { library where.LOC be.VX.3SG } \\ & \text { 'Where is the library?' (Vanuyto 2012: 42) }\end{aligned}$


Similarly, temporal adverbs can form complex predicate constructions that are formally identical to the locative predicates illustrated above. In these constructions, copulas are always obligatory. The temporal interrogative adverbs do not take any agreement marker either, but they are the predicate of the clause semantically (see 202 and compare with 201).

$$
\begin{aligned}
& \text { (202) tiki śaxa? yce-ygu? } \\
& \text { that when be-FUT.vx.3SG } \\
& \text { 'When will that be?' (Vanuyto 2012: 59) }
\end{aligned}
$$

In these complex predicates, inserting any other element between the adverbials and the copular verbs is not possible.

\subsubsection{The predicational interrogative adverb}

The interrogative adverb exhibiting manner reading appears in clauses as an adverbial, usually modifying the predicate. The form of this interrogative adverb shows differences in the certain dialects of Tundra Nenets (see Table 33).

Table 33. The dialectal forms of manner interrogative adverb

\begin{tabular}{lc}
\hline Dialect & MANNER \\
\hline Western & xuźer? \\
\hline Central & xanźer? \\
\hline & xaćer? \\
& xućer? \\
Eastern & xačer? \\
& xanśer? \\
& xanter? \\
\hline
\end{tabular}

An example illustrating a dialectal form of the manner adverb is provided nunder (203) below:

(203) Eastern Dialect, Taimyr Subdialect

$\begin{array}{lll}\text { čeda? } & \text { xačer? } & \text { jil’e-ygu-ńi?? } \\ \text { now } & \text { how } & \text { live-FUT-VX.1DU }\end{array}$

'How will we (DU) live?' (Labanauskas 1995: 200) 
Although there is a relatively large number of dialectal forms of the manner interrogative, the standard form (xanźer?) occurs in most of the texts. Sometimes the standard form can also be found along with the dialectal forms.

The function available for the manner interrogative is most typically that of being predicational adverb. Moreover, it can also appear as part of complex predicates similar to predicative locative constructions. Table 34 shows the frequency of these functions of manner adverb in the clause.

Table 34. The core syntactic functions of sentential interrogative adverb

\begin{tabular}{lc}
\hline Syntactic function & MANNER \\
\hline Predicational adverb & 149 \\
Part of the predicate & 24 \\
\hline
\end{tabular}

If the manner adverb appears as a predicational adverb, it (typically immediately) precedes the predicate, which is either verbal or nonverbal (see 204-205).

$\begin{array}{rll}\text { (204) yaćeki-P } & \text { xanźer } & \text { toxolku-P? } \\ \text { child-PL } & \text { how } & \text { learn-VX.3PL }\end{array}$

'How do the children learn?' (Vanuyto 2012: 33)

$\begin{array}{rlll}\text { (205) teda } & \text { xanter } & \text { sawa } & \text { yo-ygo-danaki? } \\ \text { now } & \text { how } & \text { good.3SG } & \text { be-FUT-PROB.VX.3SG }\end{array}$

'How will this probably good?' (Pushkareva \& Khomich 2001: 190)

Similarly to sentential adverbials, the manner adverbial can appear in a predicate construction that is formally identical to the locative predicate illustrated above. The copula is always obligatory and the manner adverb does not take any agreement marker. Furthermore, the complex predicate cannot be separated by any elements (see 206).

$\begin{array}{cll}\text { (206) sarmik } & \text { xanźer? } & \text { ya? } \\ \text { wolf } & \text { how } & \text { be.VX.3SG }\end{array}$

'How is the wolf?' (Nenyang 2007: 32)

To summarize the main points of this section, interrogative adverbs in Tundra Nenets do not take any inflectional suffixes and can only function as adverbials in the clause, either sentential or predicational. There is another construction, in which the interrogative adverbs 
appear as part of a complex predicate with a copular verb. They do not take any agreement markers, but they immediately precede the copula. Inserting anything between the verbal and the nonverbal part of the complex predicate is not possible.

In this chapter, I have discussed the grammatical characteristics of interrogative words available in Tundra Nenets. The semantic categories demonstrated in Chapter 5 appear as different parts-of-speech categories in clauses. The relation between the semantics and grammatical categories of Tundra Nenets interrogative words is summarized in Table 35 below.

Table 35. The relation between semantic and parts-of-speech categories of interrogative words

\begin{tabular}{cc}
\hline Semantic categories & Parts-of-speech categories \\
\hline NON-SELECTIVE (HUMAN/NON-HUMAN) & Pronoun \\
NON-HUMAN USED FOR SELECTION/QUALITY & Adjective (restricted) \\
NON-HUMAN USED FOR REASON & Adverb \\
SELECTION & Determiner \\
QUALITY/SELECTION & Adjective \\
QUANTITY & Quantifier \\
TIME & Adverb \\
PLACE & Adverb \\
MANNER & Adverb \\
\hline
\end{tabular}

These grammatical categories have different morphological and/or syntactic characteristics illustrated in Table 36 so they appear in different syntactic functions in the clauses. Question marks have been used to indicate grammatical characters that are not attested in the corpus but are expected. Furthermore, some interrogative words seem to vary in certain Tundra Nenets dialects in which cases both + and - values have been used.

Table 36. The grammatical characteristics of interrogative words

\begin{tabular}{|c|c|c|c|c|c|c|c|c|}
\hline \multicolumn{2}{|c|}{ Grammatical categories } & Pronoun & 'what.qual' & 'why' & Determiner & Adjective & Quantifier & Adverb \\
\hline \multirow{5}{*}{$\begin{array}{l}\text { Morphological } \\
\text { categories }\end{array}$} & Number & + & - & - & + & $+/-$ & - & - \\
\hline & Case & + & - & - & + & $+/-(?)$ & $+/-$ & - \\
\hline & $\begin{array}{l}\text { Possessive } \\
\text { marker }\end{array}$ & + & - & - & + & - & $+(?)$ & - \\
\hline & $\begin{array}{l}\text { Benefactive } \\
\text { marker }\end{array}$ & + & - & - & $+(?)$ & - & $+(?)$ & - \\
\hline & $\begin{array}{l}\text { Agreement } \\
\text { marker }\end{array}$ & + & - & - & + & + & + & - \\
\hline \multirow{3}{*}{ Distribution } & Complement & + & - & - & - & + & + & - \\
\hline & Modifier & - & + & - & + & - & - & - \\
\hline & Head & + & - & - & + & - & $+(?)$ & - \\
\hline \multirow{4}{*}{$\begin{array}{l}\text { Syntactic } \\
\text { functions }\end{array}$} & Subject & + & - & - & $+(?)$ & - & $+(?)$ & - \\
\hline & Object & + & - & - & $+(?)$ & - & $+(?)$ & - \\
\hline & Adverbial & + & - & + & $+(?)$ & - & $+(?)$ & + \\
\hline & Predicate & + & - & - & + & + & + & + \\
\hline
\end{tabular}


As evidenced by Table 36, the use of interrogative pronouns has the least restricted distribution and morphology compared to the other interrogative pro-forms. At the other endpoint of the scale are the interrogative adverbs, which cannot take any inflectional markers at all and can only appear as adverbials and as parts of the predicate. Between these endpoints the interrogative determiners, adjectives and quantifiers are found, whose uses are grammatically more restricted than that of interrogative pronouns, but these interrogatives can be used for more syntactic functions than interrogative adverbs. In what follows, I will discuss the syntactic position of these interrogative words. 


\section{The syntactic position of interrogative phrases}

The previous chapters (Chapter 5 and 6) surveyed the lexico-semantics and the grammatical categories of interrogative words in Tundra Nenets. As was demonstrated in Chapter 6, the set of interrogative words consists of different grammatical categories, such as interrogative pronouns, interrogative determiners, interrogative adjectives, interrogative quantifiers and interrogative adverbs. These different interrogative categories have different grammatical properties, functions and distributions. For instance, while interrogative pronouns can appear as the major constituents of a clause (i.e. as subject, object, several adverbials and predicate) the interrogative adjectives, demonstratives and numerals typically appear in noun phrases preceding the modified noun. The omission of the head noun is not possible in most cases (for some exceptions see $\S 6.2$ and $\S 6.4)$. Unlike interrogative pronouns, these interrogatives cannot fulfil the function of the core arguments ${ }^{33}$ of the predicate on their own. However, they can also function as predicates in certain nonverbal clauses. Moreover, the interrogative adverbs are used to seek information about the location of the situation, its temporal circumstances, or its manner and reason. Additionally, the inflected forms of interrogative pronouns may also function as adverbial complements/adjuncts of the verbal predicate in clauses.

In this chapter, the central problem addressed is the position of the (main) constituents expressed by interrogative words or phrases. I will use the term interrogative phrase here both for interrogative pronouns and for noun/adpositional phrases in which there is an interrogative element functioning as the head or the modifier. This chapter focuses on the differences among word order variations in content questions in order to identify the position of interrogative phrases relative to the position they substitute for.

Before beginning to describe the possible word orders in Tundra Nenets content questions and the different positions of interrogative phrases, I will reiterate and briefly discuss here the typical positions occupied by interrogative phrases cross-linguistically (for a more detailed description see $\S 4.3$ ). As was presented in $\S 4.3$, languages may differ with respect to the position where they situate their interrogative phrases. As Dryer (2013a) claims, two types of languages can be distinguished with respect to this phenomenon (see 207a-b).

\footnotetext{
${ }^{33}$ Core arguments are defined here as clausal elements, which are obligatory in the clause (cf. Dixon 2010a: 228).
} 
(207) a. wh elements obligatorily at the beginning of the sentence

b. wh elements not obligatorily at the beginning of the sentence

Additionally, König \& Siemund (2007: 301-302) provide a three-way distinction illustrated in $(208 \mathrm{a}-\mathrm{c})$ :

(208) a. wh obligatorily fronted

b. wh optionally fronted

c. wh-in situ

Consequently, interrogative phrases can either occur obligatorily in the sentence initial position or they can be situated in sentence initial position, but this position is not obligatory for them. Finally, they can also remain in situ, in the clausal position for their constituent types. As was also discussed in $\S 4.3$, there is a correlation between the basic word order of a language and the position of its interrogative phrases (see e.g. Greenberg 1966; Dryer 1991; König \& Siemund 2007; etc.). This correlation is shown in (209a-c):

(209) a. V-initial \& wh-fronted

b. V-final \& wh-in situ

c. SVO \& both

So languages with VSO basic word order tend to locate their interrogative phrases sentence initially. In SOV languages, the interrogative phrases more likely occur in situ. Finally, there is no such correlation in the case of SVO languages. Since Tundra Nenets is an SOV language, one can presume that interrogative phrases in content questions tend to remain in situ. This is supported by the literature (see Salminen 1998: 543), which assumes in situ interrogative phrases in content questions. In contrast, there are also observations that license more than one available position for interrogative phrases in Tundra Nenets (cf. Tereshchenko 1973: 91; Nikolaeva 2014: 266).

In order to identify the syntactic position of interrogative phrases at the clause level, one has to consider the basic order of constituents in Tundra Nenets declarative clauses. As was already mentioned, Tundra Nenets is an SOV language in which the clause final position of the verb is rigid, therefore, no element can be situated after the verb. As Tundra Nenets has a relatively rich system of nominal case marking, syntactic functions are also indicated by case 
markers. Additionally, the verbal agreement markers identify the subject argument of the clause. The verbal predicate agrees with the subject in person and number. Pronominal subjects, however, are very frequently omitted from the clause. If they are overt, they are focused or emphasized (cf. Nikolaeva 2014: 194). Moreover, the transitive predicate can also take an object agreement marker indicating the number of the direct object, if the agreeing object has a topical role (cf. Dalrymple \& Nikolaeva 2011: 133). Transitive verbs agree only with 3rd person objects. Like pronominal subjects, pronominal objects can also be covert in the clause, in which case the verbal predicate always bears an agreement marker (cf. Nikolaeva 2014: 208).

Structurally, the subject precedes the object in the clause, however, the inversion of these clausal constituents is also possible in some (pragmatically) marked situations. In (210) below, for instance, the subject is preceded by the direct object and the word order is OSV. According to Nikolaeva (2014: 214), the subject can be regarded as a new information, therefore it appears in the immediately preverbal position and follows the object.

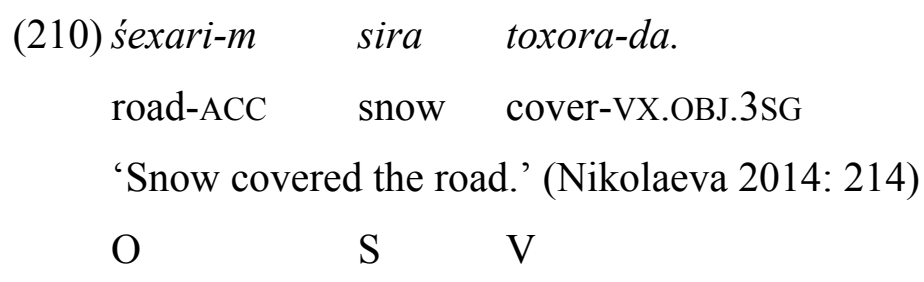

Additionally, there are typical positions for certain adverbials as well. Following usual conventions in distinguishing the positions of adverbials in clauses, one can differentiate two logically possible positions for the adverbials in Tundra Nenets intransitive clauses illustrated in (211).

(211) 1 S 2 V

A third possible position for adverbials in relation to the subject, the object and the verb can be distinguished in Tundra Nenets transitive clauses given in (212) below.

(212) 1 S 20 O 3 V

Thus, certain adverbials may occur sentence initially (in position 1) preceding the subject of the clause. Adverbials may also occupy a medial position either between the subject and the 
object (in position 2), or after the object but before the verbal predicate (in position 3). As intransitive clauses do not contain an object element, only two possible positions (before or after the subject) are available for the adverbials. However, no adverbial seems to be licensed after the predicate verb in Tundra Nenets. Salminen (1998: 543) and Nikolaeva (2011: 136; 2014: 214) provide typical word order patterns for Tundra Nenets clauses, which suppose a correlation among the types of adverbials and their syntactic positions. The word order observed by Salminen (1998: 543) is shown in (213) below.

(213) Time S Location O Manner V

As it was mentioned in $\$ 2.3$, a similar order of constituents is provided by Nikolaeva (2014: 214-217). However, she notes that this order is only a tendency and other orders are also possible without any grammatical/syntactic restrictions (cf. Nikolaeva 2014: 214). The favoured position of clausal elements provided by Nikolaeva (2014: 216) is illustrated in (214).

(214) Time S Location IO DO Manner V

Consequently, sentential adverbials, especially the temporal ones, usually occupy position 1 and precede the subject. Predicational adverbial adjuncts, such as e.g. manner adverbs, mostly appear in a syntactic position after the subject. In some cases, these adverbials tend to occur in the immediately preverbal position. Positions 2 and 3 are usually available for predicational adverbs. Additionally, as Nikolaeva (2011: 136) notes, the orders in which adverbials either precede or follow the object in transitive clauses are optional in the language (see 215). In the word order illustrated by (215), X stands for the adverbial complements and modifiers.

\section{(215) S X O V / S O X V}

Considering these possible orders of the constituents in the clauses and assuming that interrogative phrases appear in situ, their syntactic positions can theoretically be identified. Following certain methods provided by Cable (2010), I examined the questions available in the corpus and tested whether the interrogative phrases occupy the presumed in situ positions. During studying this, I distinguished questions with respect to their predicate types. Thus, I examined intransitive, transitive and nonverbal questions separately. As was already 
mentioned in $\S 3.3,1494$ clauses were selected for examining the interrogative constructions in the language. From the 1494 clauses, there were 987 clauses with intransitive or transitive predicates, of which there were 279 clauses that contained the predicate and an interrogative phrase only. These clauses are not suitable for studying word order variations, therefore I excluded them from the syntactic examination. In the remaining 708 clauses, the interrogative phrases appeared in the presumed in situ position given in (213)-(215) in 478 clauses. This is $67.514 \%$ of the examined constructions, while $32.485 \%$ of the clauses showed differences with respect to the expected positions of the interrogative phrases. As illustrated in Table 37, the intransitive and transitive clauses differ in their deviance from the default in situ type. While in $70.023 \%$ of the intransitive clauses the interrogative phrases appeared in situ, this rate is decreased to $63.218 \%$ in transitive clauses. These results of word order variations in intransitive and transitive questions are summarized in Table 37.

Table 37. The position of interrogative phrases in intransitive and transitive questions

\begin{tabular}{|c|c|c|c|c|c|}
\hline & $\begin{array}{c}\text { Content } \\
\text { questions } \\
\text { containing an } \\
\text { interrogative } \\
\text { phrase }\end{array}$ & $\begin{array}{c}\text { Content } \\
\text { questions } \\
\text { containing an } \\
\text { interrogative } \\
\text { phrase and a } \\
\text { constituent } \\
\text { other than the } \\
\text { predicate } \\
\end{array}$ & $\begin{array}{l}\text { Interrogative } \\
\text { phrase remains } \\
\text { in situ (from } \\
\text { the } 2 \text { nd } \\
\text { column) }\end{array}$ & $\begin{array}{l}\text { The position } \\
\text { of the } \\
\text { interrogative } \\
\text { phrase does } \\
\text { not follow } \\
\text { from the basic } \\
\text { word order }\end{array}$ & $\begin{array}{c}\text { Rate of the } \\
\text { non-in situ } \\
\text { interrogative } \\
\text { phrases }\end{array}$ \\
\hline $\begin{array}{l}\text { Intransitive } \\
\text { clauses }\end{array}$ & 595 & 447 & 313 & 134 & $29.977 \%$ \\
\hline $\begin{array}{c}\text { Transitive } \\
\text { clauses }\end{array}$ & 392 & 261 & 165 & 96 & $36.782 \%$ \\
\hline Total & 987 & 708 & 478 & 230 & $67.514 \%$ \\
\hline
\end{tabular}

Additionally, I have also examined nonverbal clauses containing an interrogative phrase. As these clause types usually contain only two constituents (with the exception of the so-called locative predicates), I focused on the possible order of the predicate and the subject. The attested variations are given in Table 38.

Table 38. The position of interrogative phrases in content questions with nonverbal predicates

\begin{tabular}{ccccc}
\hline & $\begin{array}{c}\text { Content questions } \\
\text { containing an } \\
\text { interrogative } \\
\text { phrase }\end{array}$ & $\begin{array}{c}\text { Interrogative } \\
\text { phrase remains in } \\
\text { situ }\end{array}$ & $\begin{array}{c}\text { The position of } \\
\text { the interrogative } \\
\text { phrase does not } \\
\text { follow from the } \\
\text { basic word order }\end{array}$ & $\begin{array}{c}\text { Rate of the non-in } \\
\text { situ interrogative } \\
\text { phrases }\end{array}$ \\
\hline $\begin{array}{c}\text { Nonverbal } \\
\text { clauses }\end{array}$ & 507 & 491 & 15 & $\mathbf{2 . 9 5 9 \%}$ \\
\hline
\end{tabular}


The ratio of the non-in situ interrogative phrases in nonverbal clauses is quite low in comparison with the two other clause types. I suppose that this data correlates with the rigid verb final characteristics of the language, so elements other than predicates can more frequently appear in non-canonical syntactic positions (see Table 37 for the ratio), whereas predicates typically occupy sentence final positions in the language.

I suggest that there are (at least) the reasons for the word order differences represented in Table 37-38. Firstly, certain interrogative word types may behave differently in the clause. It means that some interrogative phrases may remain in situ, but others may appear in another syntactic position, for instance, sentence initially. Secondly, as Nikolaeva (2014: 213) notes, the order of the clausal constituents other than the predicate is relatively free in Tundra Nenets, so interrogative phrases may also appear in further possible syntactic positions in the language. Thirdly, there are other rules that also influence the word order in questions, e.g. pragmatical rules.

On the basis of the literature concerning the basic word order of a given language (e.g. Siewierska 1993; Dryer 1998; 2007a), there are some typical factors that can influence word orders. One of these aspects taken into account and discussed in the following sections for determining the syntactic positions of the interrogative phrases is the grammatical relation of the clausal elements. Given that interogative phrases occur as adjuncts/arguments of the verb, I will primarily focus on the adjacency of these arguments. Additionally, some syntactic features, such as structural complexity, distribution, etc., of the interrogative phrases will also be considered. I will concentrate on attested orders that are in some way restricted. In addition, semantic roles of interrogative phrases/clausal elements, which may influence the surface representation of a given order, will also be considered. Another common phenomenon that can involve word order change is the pragmatic function, e.g. definiteness, specificity, referentiality, etc., of the clausal elements. Structures in which this factor may influence the surface representation will also be taken into consideration. In addition, the relevancy of other factors, such as discourse roles, e.g. topic, focus, etc., will be discussed. Finally, the frequency of an order may also help to decide whether the given order is the canonical one. Canonical orders are not restricted and determined by any additional, for instance, pragmatic features. However, as Dryer (2007a:74) notes, frequency is not part of the grammar of a given language, therefore it cannot serve as a sole argument in favor of a given order as basic order.

This chapter is organized as follows. In $\S 7.1$, I describe the relative order of constituents in intransitive questions. I will examine the variations in constituent order attested in these 
clause types. The possible reasons of these orders will also be discussed. I will primarily focus on the order of the subject and the sentential/predicational adverbial adjuncts. I will also deal with two subtypes of intransitive clauses: existential predicates and predicational possession. In $§ 7.2$, I discuss the word order possibilities available in transitive clauses. Similarly, I will provide the possible positions of certain interrogative phrases in transitive clauses. Furthermore, I will describe the possible reasons of restricted sequences. The order and adjacency of the object and another clausal elements will primarily be focused on in the section. Finally, certain content interrogatives with nonverbal predicates will be discussed in $\S 7.3$. In this section, the types of nonverbal predicates available in content interrogatives will be examined.

\subsection{Intransitive content questions}

This section identifies the linear order of constituents in intransitive content questions. Intransitive clauses are primarily defined here as clauses with verbal predicates taking a single argument, which is the subject of the clause (cf. Dryer 2007b: 250). These clauses can also contain adverbial(s) fuctioning, for instance, as temporal, locational, etc. modifier(s) of the predicate verb. In addition, I will examine clauses, in which the predicate verb typically requires two arguments, but neither of these arguments is a direct object. These clause types are called semi-transitive clauses by Dryer (2007b: 270), since the intransitive verbal predicate has two arguments semantically and behaves more like a transitive verb. According to Dryer (2007b: 273), verbs expressing motion may typically function as predicates of semitransitive clauses as they usually require a locational expression as one of their arguments.

There are also two further structures typically expressed by intransitive constructions in Tundra Nenets, and these sentence types are existential clauses and predicative possessions, in which the predicate is the existential verb (tańaś 'exist'). In many languages, these structures are expressed by nonverbal predicates (cf. Dryer 2007b: 240-244) but in Tundra Nenets these constructions can rather be regarded as being intransitive clauses. Considering that these clauses show some differences from the default intransitive predicates, I will discuss the word order characteristics of these clause types separately (in $\S 7.1 .1$ and in $\$ 7.1 .2$ respectively).

In the clauses examined, any constituent of the clause (other than the predicate) can be substituted by an interrogative phrase. As already mentioned, the interrogative subject of a clause is expressed not only by an interrogative pronoun, but also by complex phrases 
containing an interrogative word as a modifier. Additionally, adverbials are expressed either by noninflected interrogative adverbs or by case-marked interrogative pronouns/adpositional phrases in Tundra Nenets. Given that the adverbial functions can typically be fulfilled by temporal, locational, manner and reason interrogatives, the relative position of these constituents will primarily be focused on. Additionally, the position of other adverbials functioning as argument-like constituents of intransitive predicates, e.g. locational expressions for indicating the path of motion verbs, or phrases whose case-marking is assigned by the predicate verb (marked by X), will also be taken into consideration. The following Table in (39) illustrates the typical syntactic functions fulfilled by interrogative phrases (indicated by $\mathrm{Q}$ in the Table) in intransitive clauses.

Table 39. The syntactic function of interrogative phrases in intransitive content questions

\begin{tabular}{cccc}
\hline $\begin{array}{c}\text { The function of } \\
\text { interrogative } \\
\text { words/phrases }\end{array}$ & Total № & $\begin{array}{c}\text { Those that contain only the } \\
\text { interrogative phrase and } \\
\text { the predicate }\end{array}$ & $\begin{array}{c}\text { Examined } \\
\text { constructions }\end{array}$ \\
\hline $\mathrm{S}_{\mathrm{Q}}$ & 112 & 51 & 61 \\
Time $_{\mathrm{Q}}$ & 90 & 9 & 92 \\
Location $_{\mathrm{Q}}$ & 120 & 35 & 85 \\
Manner $_{\mathrm{Q}}$ & 82 & 16 & 66 \\
Reason $_{\mathrm{Q}}$ & 33 & 4 & 29 \\
$\mathrm{X}_{\mathrm{Q}}$ & 81 & 22 & 59 \\
Existential clauses & 35 & 11 & 24 \\
Predicative possession & 42 & 11 & $\mathbf{4 4 7}$ \\
\hline Total & $\mathbf{5 9 5}$ & $\mathbf{1 5 9}$ &
\end{tabular}

In the constructions attested, the interrogative constituents occupy preverbal positions, thus no element appear after the verb. As illustrated in Table 39 above, intransitive content questions may contain only one main element expressed by an interrogative phrase in addition to the predicate verb. This constituent can typically be the subject, as in example (216) below, in which the interrogative subject controls agreement in person and number on the predicate verb.

$$
\begin{aligned}
& \text { (216) xib̆a to? } \\
& \text { who come.vX.3sG } \\
& \text { 'Who came?' (Pushkareva et al. 1994: 61) }
\end{aligned}
$$


In addition to interrogative subjects, other clausal elements, such as temporal or spatial adverbials can be expressed by interrogative phrases as well. The clauses in (217-221) contain interrogative constituents other than the subject, whereas the subjects are covert and marked via agreement markers appearing on the verbs.

(217) śaxa? xanta-wa??

when leave-VX.1PL

'When will we leave?' (Vanuyto 2012: 9)

(218)xańana jil'e-n?

where.LOC live-VX.2SG

'Where do you live?' (Vanuyto 2012: 9)

(219) xanźer? jil'e-n?

how live-VX.2SG

'How do you live?' (Vanuyto 2012: 8)

(220) yamge śurb̀er-ya-n?

why run-CO-VX.2SG

'Why are you running?' (Labanauskas 1995: 145)

(221) yamge-xena timbi-da?

what-LOC comb-VX.OBJ.3SG

'What does (s)he comb his/her hair with?' (Okotetto 1998: 145)

These subjectless clauses illustrated in (217-221) above, however, do not provide the possibility of identifying whether the positions of adverbials are 1 or 2 , i.e. the position either before or after the subject. Therefore, these structures are excluded from the analysis.

In the corpus, interrogative subjects may appear either initially or after an adverbial. Typical adverbials that precede interrogative subjects are temporal and locational ones. In addition, adverbials functioning as arguments of the predicate verb may appear before interrogative subjects. Firstly, the order of temporal adverbials and subjects will be dealt with in clauses in which either of these constituents is substituted by an interrogative phrase. Table 40, in which a $\mathrm{Q}$ marks the interrogative clausal elements, illustrates the variation and frequency of the order of these elements. 
Table 40. The order of S and temporal adverbial

\begin{tabular}{ccc}
\hline \multicolumn{2}{c}{ Word order } & № \\
\hline Time & $\mathrm{S}_{\mathrm{Q}}$ & 11 \\
Time $_{\mathrm{Q}}$ & $\mathrm{S}$ & 37 \\
\hline $\mathrm{S}_{\mathrm{Q}}$ & Time & 3 \\
$\mathrm{~S}$ & Time $_{\mathrm{Q}}$ & 32 \\
\hline
\end{tabular}

As is illustrated in Table 40, interrogative subjects are frequently preceded by temporal adverbials $\left(\right.$ Time $\left.\mathrm{S}_{\mathrm{Q}}\right)$, as in (222).

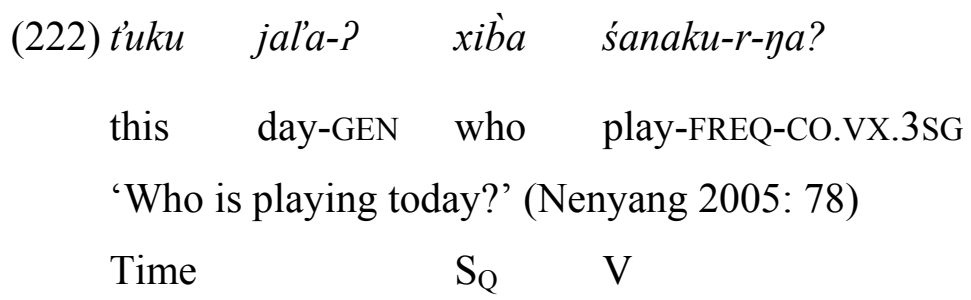

At the same time, temporal adverbials only appear after subjects in some cases, in which cases the subjects are structurally complex like in (223).

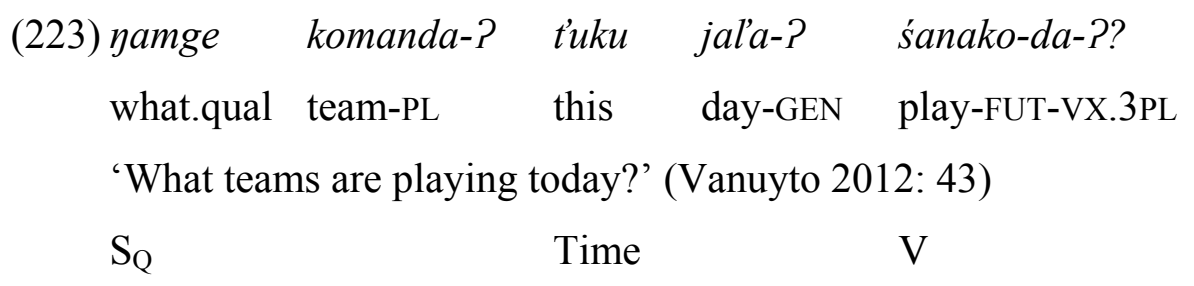

Thus, the canonical order of an interrogative subject and a temporal adverbial is Time $\mathrm{S}_{\mathrm{Q}}$, so temporal adverbials basically precede non-complex interrogative subjects, whereas the complex ones typically appear in clause initial position, precedeing temporal adverbials. In contrast, temporal interrogative phrases may occupy position 1 (before the subject) and position 2 (between the subject and the verb) almost equally. In example (224), the interrogative temporal adverbial appears before the subject, while in (225) it follows the subject.

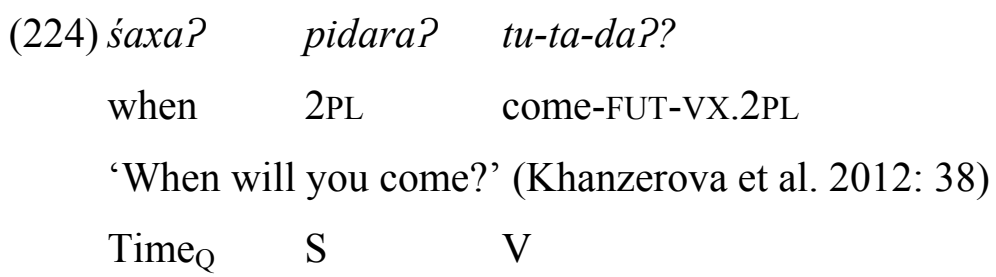




$$
\begin{array}{ccc}
\text { (225) pidara? } & \text { śaxa? } & \text { to-sa-daP? } \\
\text { 2PL } & \text { when } & \text { come-INT-VX.2PL } \\
\text { 'When did you arrive?' (Vanuyto 2012: 44) } \\
\text { S } & \text { Time }_{\mathrm{Q}} & \mathrm{V}
\end{array}
$$

In most of these cases, the orders are optional, as in (224) and (225). Subjects that can either precede or follow the temporal expression, are typically personal pronouns, so they are referential. Temporal interrogatives, however, appear in position 2 (after the subject) only in case of referential subjects as in (226). In the corpus, nonreferential subjects are not followed by interrogative temporal expressions, they always appear after them (see 227).

$$
\begin{array}{cll}
\text { (226) tuku lawka śaxa? noe-yga? } \\
\text { this } & \text { store when open-CO.VX.3SG }
\end{array}
$$

'When does this store open?' (Vanuyto 2012: 22)

$$
\begin{array}{ccllll}
\mathrm{S} & \multicolumn{1}{c}{\text { Time }_{\mathrm{Q}}} & \mathrm{V} & & & \\
\text { (227) śaxa? } & \text { Ust'-Port-? } & \text { jol'ćand? } & \text { tu } & \text { yano } & \text { xanta? } \\
\text { when } & \text { Ust-Port-GEN } & \text { until.DAT } & \text { fire } & \text { boat } & \text { go.VX.3SG }
\end{array}
$$

'When does a steamer set sail for Ust-Port?' (Nenyang 2005: 122)

Time $_{\mathrm{Q}} \mathrm{L}$ S $\mathrm{V}$

To sum it up, temporal adverbials typically precede interrogative subjects, if the subjects are non-complex. In case of complex interrogative subjects, however, the temporal adverbial prefers position 2. These interrogative subjects typically have referents in the previous discourse. In clauses with interrogative temporal adverbials similar orders are attested, i.e. interrogative temporal adverbs typically precede subjects, but if the subjects are referential, they occupy sentence initial positions and precede temporal adverbials.

Another typical adverb that may precede subjects is the locational one. As mentioned above, verbs expressing motion may take locative adverbials as their complements. Therefore, I differentiate here clauses with verbs expressing motion (indicated by an $\mathrm{M}$ indexed on the verb). The attested word order variants are illustrated in Table 41. 
Table 41. The order of S and locational adverbial

\begin{tabular}{cccc}
\hline \multicolumn{3}{c}{ Word order } & № \\
\hline $\mathrm{S}_{\mathrm{Q}}$ & $\mathrm{L}$ & $\mathrm{V}_{\mathrm{M}}$ & 8 \\
$\mathrm{~S}_{\mathrm{Q}}$ & $\mathrm{L}$ & $\mathrm{V}$ & 7 \\
$\mathrm{~S}$ & $\mathrm{~L}_{\mathrm{Q}}$ & $\mathrm{V}_{\mathrm{M}}$ & 35 \\
$\mathrm{~S}$ & $\mathrm{~L}_{\mathrm{Q}}$ & $\mathrm{V}$ & 25 \\
\hline $\mathrm{L}$ & $\mathrm{S}_{\mathrm{Q}}$ & $\mathrm{V}_{\mathrm{M}}$ & 15 \\
$\mathrm{~L}$ & $\mathrm{~S}_{\mathrm{Q}}$ & $\mathrm{V}$ & 6 \\
$\mathrm{~L}_{\mathrm{Q}}$ & $\mathrm{S}$ & $\mathrm{V}_{\mathrm{M}}$ & 12 \\
$\mathrm{~L}_{\mathrm{Q}}$ & $\mathrm{S}$ & $\mathrm{V}$ & 5 \\
\hline
\end{tabular}

On the basis of the frequency of the orders, one can suppose that the canonical order is that in which locational expressions follow subjects. The S L order is attested in 75 clauses, whereas in 38 clauses the subjects appear after locational adverbials.

However, the order of the constituents shows some variation. Firstly, in clauses in which the locational expression is optional and the subject is an interrogative phrase neither order is clearly basic as in (228-229).

\section{(228) t’uko-xana xib̀a padta-wi?}

this-LOC who draw-NARR.VX.3SG

'Who is drawing here?' (Okotetto 1998: 108)

$\begin{array}{lll}\mathrm{L} & \mathrm{S} & \mathrm{V}\end{array}$

(229) xib̀a tuko-na xino?-na?

who this-LOC sing-CO.VX.3SG

'Who is singing here?' (Samoylova \& Barmich 2010: 181)

$\mathrm{S}_{\mathrm{Q}} \quad \mathrm{L} \quad \mathrm{V}$

In contrast, in interrogatives in which the predicates semantically require locational expressions, the preferred orders are rather $\mathrm{L} \mathrm{S}_{\mathrm{Q}}$. Locational adverbials consequently precede interrogative subjects. Considering that in these clauses the locational adverbials are arguments of the verbs, the $\mathrm{S}_{\mathrm{Q}} \mathrm{L}$ order would be expected, in which the adverbials are adjacent to the verbs. We find that the frequency of these constructions does not support this expectation. However, the locational adverbials that occupy the sentence initial position are referential and/or specific as in (230), in which the clause initial locational adverb refers to a specific place. 


$$
\begin{array}{cllll}
\text { (230) t’uku } & \text { obšežitije-xena } & \text { śayok } & \text { ńeneć? } & \text { jil'e? } \\
\text { this } & \text { hostel-LOC } & \text { how.many } & \text { people } & \text { live.VX.3SG }
\end{array}
$$

'How many people live in this hostel?' (Nenyang 2005: 66)
$\mathrm{L}$
$\mathrm{S}_{\mathrm{Q}}$
$\mathrm{VM}$

We can contrast this with (231), where the locational adverb can be interpreted as a nonspecific expression and it follows the interrogative subject.

$$
\begin{array}{rlll}
\text { (231) xiba } & \text { labtej-ko-? } & \text { ḿuńa jil'e? } \\
\text { who } & \text { box-DIM-GEN } & \text { in.LOC } & \text { live.VX.3SG }
\end{array}
$$

'Who lives in a small box?' (Pushkareva et al. 1994: 9)

$\mathrm{S}_{\mathrm{Q}} \quad \mathrm{L} \quad \mathrm{VM}$

From this contrast, we can conclude that the unmarked order can rather be $S_{Q} L$ and the $L S_{Q}$ order is a marked one, which is available for referential and/or specific locational elements.

In clauses with interrogative locational constructions, both orders are possible without any restrictions, as illustrated in (232) and (233). However, their frequency suggest that interrogative locatives typically appear after the subject.

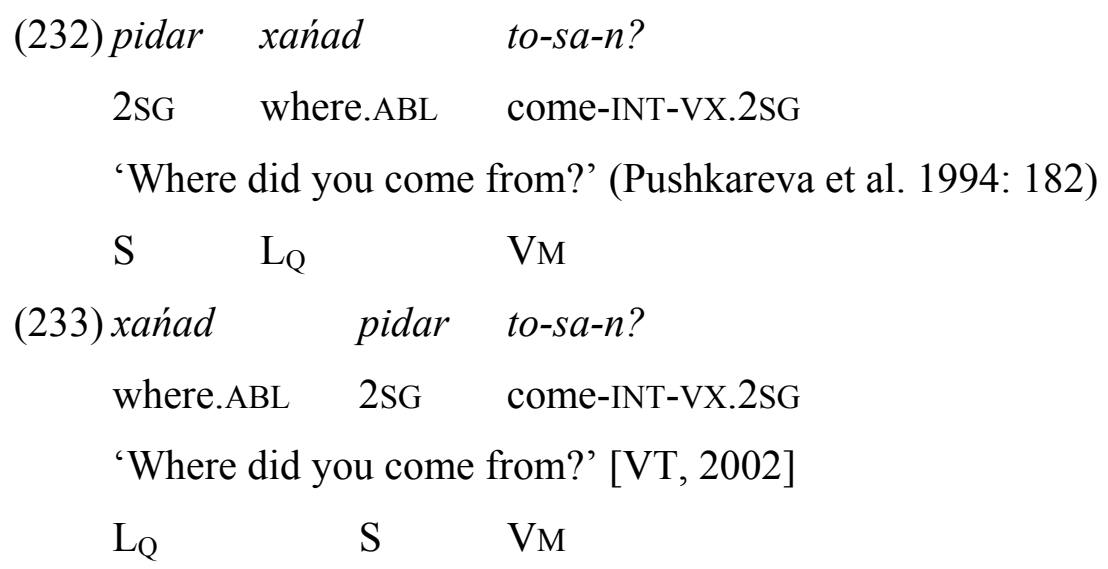

In examples (232) and (233), the interrogative locational expression either follows or precedes the pronominal subject. These expressions do not show any restrictions in their preverbal distributions. Similarly, complex and/or referential locational expressions can appear in position 1 or in position 2 without any further grammatical constraint as in (234) and (235) below. 


\begin{tabular}{cccc} 
(234) pidar & jamge & ja-xana & jil'e-n? \\
2SG & what.qual & land-LOC & live-VX.2SG \\
'Which country do you live in?' (Vanuyto 2012: 16) \\
$\mathrm{S}$ & \multicolumn{2}{c}{ VM } \\
(235) $x$ urka & mar-kana & pidara? & jil'e-da?? \\
what.kind city-LOC & 2PL & live-VX.2PL \\
'Which city do you live in?' (Nenyang 2005: 112) \\
$\mathrm{L}_{\mathrm{Q}}$
\end{tabular}

Like interrogative temporal adverbials, interrogative locational ones may appear either before $\left(\mathrm{L}_{\mathrm{Q}} \mathrm{S}\right)$ or after $\left(\mathrm{S}_{\mathrm{Q}}\right)$ the subject. It seems that these positions are optionally available for them regardless of their function. However, on the basis of the frequency of the two orders, interrogative locational phrases are typically situated after the subject $\left(\mathrm{S} \mathrm{L}_{\mathrm{Q}}\right)$.

Additionally, sequences of temporal and locational adverbials may precede subjects as in (236).

$\begin{array}{cccc}\text { (236) teda? } & \text { kinot'eatra-xa?na } & \text { yamge mi-ya? } \\ \text { now } & \text { cinema-PL.LOC } & \text { what } & \text { go-CO.VX.3SG }\end{array}$

'What is in the cinemas now?' (Nenyang 2005: 72)

Time $\quad \mathrm{L} \quad \mathrm{S}_{\mathrm{Q}} \quad \mathrm{VM}$

The most usual order of adverbial sequences relative to the subject attested in the corpus is the one represented by example (237). In this clause, the temporal adverbial precedes the subject occupying sentence initial position and the locational one follows it.

$\begin{array}{rllll}\text { (237) teda? } & \text { xurka } & \text { ṕirdirma-? } & \text { stadion-xana } & \text { mi-ya-?? } \\ \text { now } & \text { what.kind } & \text { race-PL } & \text { stadium-LOC } & \text { go-CO-VX.3PL }\end{array}$

'What races are there in the stadium now?' (Nenyang 2005: 77)

$\begin{array}{llll}\text { Time } & \mathrm{S}_{\mathrm{Q}} & \mathrm{L} & \mathrm{VM}\end{array}$

In clauses illustrated in (236)-(237) above the order seems to be optional. At the same time, other examples suggest that usually the specific locational expressions precede subjects (see 238). 
(238) 1941-1945 po-xo?na ja-xana-na?

1941-1945 year-PL.LOC land-LOC-PX.OBL.1PL

xurka ja?awkabta-da śer? xadke-sa?

what.kind be.awful-PCP.IMPF thing happen-INT.VX.3SG

'What a horrible thing happened in our country between 1941-1945?'

(Tereshchenko \& Susoy 1995: 93)

Time $\quad \mathrm{L} \quad \mathrm{S}_{\mathrm{Q}}$

Finally, subjects can precede temporal and locational adverbials - as in (239) - despite the fact that both adverbials refer to a specific time and place.

(239) yamge t'uku jal'a-? t'eatra-xana mi-ya?
what this day-GEN theatre-LOC go-CO.VX.3SG

'What is in the theatre today?' (Nenyang 2005: 74)

$\begin{array}{llll}\mathrm{S}_{\mathrm{Q}} & \text { Time } & \mathrm{L} & \mathrm{VM}\end{array}$

We can conclude then that temporal and locational adverbials, being sentential adjuncts, exhibit relatively free variations of order without any apparent grammatical restrictions, although there is a tendency that the temporal one prefers a peripheral position, before the subject. This positional preference is maintained in the case of interrogative and noninterrogative elements. In contrast, the locational adverbial is situated after the subject rather than before it. Note, that the interrogative status of the subject does not cause changes in the word order, either.

Now, let us turn to the discussion of the clausal position of predicational adverbs. Manner and reasonal interrogative adverbs typically function as predicational adjuncts in clauses, therefore, they are frequently adjacent to the verbs. In addition, there are adverbials that are selected by the predicate verb and that may be syntactically obligatory. The attested orders of these constituents and the subject will be discussed here. Firstly, the order of subjects and manner adverbials will be demonstrated. In the corpus, these constituents appear in the orders shown in Table 42. 
Table 42. The position of the subject and the manner adverbial

\begin{tabular}{ccc}
\hline \multicolumn{2}{c}{ Word order } & № \\
\hline $\mathrm{S}_{\mathrm{Q}}$ & Manner & 2 \\
$\mathrm{~S}$ & Manner & 22 \\
\hline Manner $_{\mathrm{Q}}$ & $\mathrm{S}_{\mathrm{Q}}$ & no data \\
Manner $_{\mathrm{Q}}$ & $\mathrm{S}$ & 24 \\
\hline
\end{tabular}

As is evidenced by Table 42, predicational adverbs are quite rare in clauses with interrogative subject. There are only 2 clauses in which an overt manner adverbial appears. In these examples, it follows the interrogative subject, as in (240).

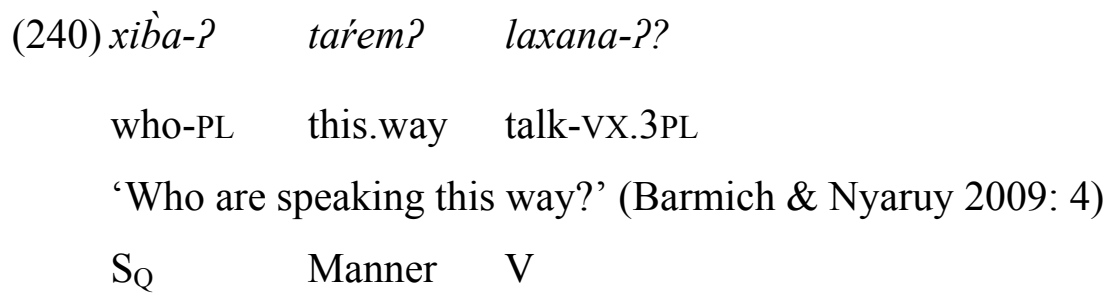

In the case of manner interrogative phrases, however, the manner adverbial optionally appears after the subject (see 241). In this case, it is situated in the position that immediately precedes the verb.

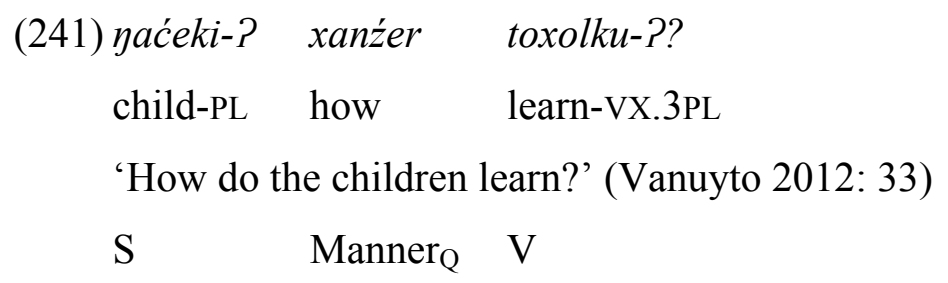

In addition, the manner interrogative phrase is not obligatorily adjacent to the verb but it can also precede the subject (242).

$\begin{array}{cccc}\text { (242) xanźer? } & \text { mań } & \text { tańa? } & \text { xanta-dm?? } \\ \text { how } & \text { 1SG } & \text { there } & \text { go-VX.1SG } \\ \text { 'How do I get there?' (Nenyang } 2005: 113) \\ \text { Manner }_{Q} & \text { S } & \text { L } & \text { V }\end{array}$


In consequence, the manner adverbial seems to appear either before or after the verb. Since there is no clear evidence for the case of these order variations, these two orders are probably optional.

The adjacency to the verb in position 2 (after the subject) is not obligatory for the manner adverbial either (see 243).

$$
\begin{array}{clllll}
\text { (243) tarća } & \text { yaxaP } & \text { ja-nP } & \text { xanźer? } & \text { juno-ći? } & \text { xanta-dm? } \\
\text { so } & \text { far } & \text { land-DAT } & \text { how } & \text { horse-CAR } & \text { go-VX.1SG }
\end{array}
$$

'How can I get to a land far away without a horse?' (Orlova et al. 1996: 50)

$\mathrm{L}$

$$
\text { Manner }_{\mathrm{Q}} \text { Manner } \mathrm{V}
$$

Example (243) illustrates the only positional restriction attested in the corpus. The interrogative manner adverbial immediately precedes the other overt manner adverbial in the clause. There is no example for an alternative order in the corpus.

Like manner adverbials, adjuncts asking about information about the reasons for events may also be situated either before the subject, or after it (see Table 43).

Table 43. The position of the subject and the reason adverbial

\begin{tabular}{ccc}
\hline \multicolumn{2}{c}{ Word order } & № \\
\hline $\mathrm{S}_{\mathrm{Q}}$ & Reason & no data \\
$\mathrm{S}$ & Reason $_{\mathrm{Q}}$ & 7 \\
\hline Reason & $\mathrm{S}_{\mathrm{Q}}$ & no data \\
Reason $_{\mathrm{Q}}$ & $\mathrm{S}$ & 9 \\
\hline
\end{tabular}

Interrogative content questions with interrogative subjects and overt reasonal adjuncts are not attested in the corpus. In the available clauses, the interrogative reason adverbial seems to appear after subject, as in (244).

$\begin{array}{ccccc}\text { (244) pidar } & \text { jaw? } & \text { ńarpoj } & \text { yamge } & \text { juśida-n? } \\ \text { 2SG } & \text { sea } & \text { across } & \text { why } & \text { lie-VX.2SG }\end{array}$

'Why are you lying across the sea?' (Pushkareva \& Khomich 2001: 110)
$\mathrm{S}$
$\mathrm{L}$
Reason $_{\mathrm{Q}} \quad \mathrm{V}$

They can also freely appear in sentence initial positions, as in (245). 


$\begin{array}{cllll}\text { (245) yamge } & \text { ńe } & \text { yaćeki-? } & \text { wesako-xod } & \text { xuni-?? } \\ \text { why } & \text { woman } & \text { child-PL } & \text { old.man-ABL } & \text { run-Vx.3PL }\end{array}$

'Why did the girls run away from the old man?' (Nenyang 2007: 36)

Reason $_{\mathrm{Q}} \mathrm{S} \quad \mathrm{X} \quad \mathrm{V}$

Like interrogative manner adverbials, interrogative phrases fulfilling the function of reason adverbial in position 2 do not have to be adjacent to the verb (see 246).

$\begin{array}{lllll}\text { (246) sira-? } & \text { ńeneća? } & \text { yamge } & \text { pedara-n? } & \text { jamda-yga-?? } \\ \text { winter-GEN } & \text { Nenets } & \text { why } & \text { forest-DAT } & \text { move-FUT-VX.3PL } \\ \text { 'Why do the Nenets move to the forest in winter?' } & \text { (Okotetto 1998: 175) } \\ \text { Time } & \mathrm{S} & \text { Reason }_{\mathrm{Q}} & \mathrm{L} & \mathrm{V}\end{array}$

There is no transparent grammatical evidence for either positions of reason adverbial, therefore, the orders attested are supposed to be optional.

Finally, other adverbials functioning as complements or modifiers may either precede or follow subjects. In Table 44 the orders attested are presented.

Table 44. The order of $\mathrm{S}$ and other adverbials functioning as arguments

\begin{tabular}{|c|c|c|}
\hline \multicolumn{2}{|c|}{ Word order } & № \\
\hline$\overline{\mathrm{S}_{\mathrm{Q}}}$ & $\mathrm{X}$ & 10 \\
\hline $\mathrm{S}$ & $\mathrm{X}_{\mathrm{Q}}$ & 37 \\
\hline $\mathrm{X}$ & $\mathrm{S}_{\mathrm{Q}}$ & 7 \\
\hline $\mathrm{X}_{\mathrm{Q}}$ & $\mathrm{S}$ & 13 \\
\hline
\end{tabular}

As data in Table 44 suggest, there is no significant difference between $\mathrm{S}_{\mathrm{Q}} \mathrm{X}$ and $\mathrm{XS}_{\mathrm{Q}}$ orders. The order, nevertheless, in which the interrogative subject appears initially surfaces a bit more frequently (see 247).

$\begin{array}{lccc}\text { (247) śan } & \text { jeśa } & \text { ńanand } & \text { tara? } \\ \text { how.many } & \text { money } & \text { 2SG.LOC } & \text { be.needed.vX.3SG } \\ \text { 'How much money do you need?' (Nenyang 2005: 93) } \\ \mathrm{S}_{\mathrm{Q}}\end{array}$

It seems that this frequent position of the adverbial complement is not fixed. In example (248) below, the adverbial appears before the subject. 


$\begin{array}{cccc}\text { (248) ńananda? } & \text { xurka } & \text { labe? } & \text { tara? } \\ \text { 2PL.LOC } & \text { what.kind } & \text { room } & \text { be.needed.vX.3SG } \\ \text { 'What room do you need?' (Nenyang 2005: 114) } \\ \mathrm{X} & \mathrm{S}_{\mathrm{Q}} & \mathrm{V}\end{array}$

There is no difference between the constructions in (247) and in (248), therefore, I assume that the two possible orders are optional.

The same variation of constituent order is observed in the case of the unknown adverbials illustrated in (249) and (250) below.

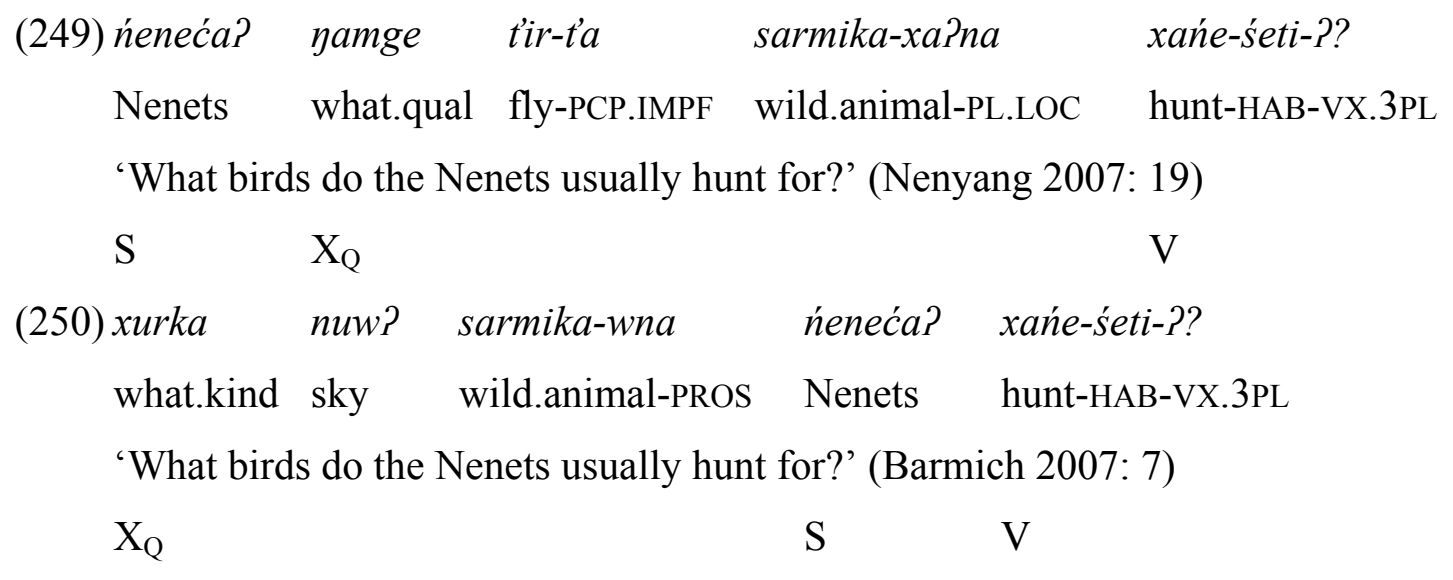

In the examples above, the syntactic functions are fulfilled by similar elements, the subjects are generic lexical expressions, while the unnkown adverbials are complex interrogative phrases. There seems to be no grammatical evidence that one of these orders would be more restricted or marked.

To summarize the main points of this subsection, the position of interrogative phrases in intransitive clauses is relatively free but some tendencies were observed. Firstly, only one possible order can be assumed in the case of interrogatives and verb in which the interrogatives precede the verb (see 251).

$\begin{array}{lll}\text { (251) a. } \mathrm{S}_{\mathrm{Q}} / \text { Time }_{\mathrm{Q}} / \mathrm{L}_{\mathrm{Q}} / \text { Manner }_{\mathrm{Q}} / \text { Reason }_{\mathrm{Q}} / \mathrm{X}_{\mathrm{Q}} & \mathrm{V} & \text { standard order } \\ \text { b. } \mathrm{V} & \mathrm{S}_{\mathrm{Q}} / \operatorname{Time}_{\mathrm{Q}} / \mathrm{L}_{\mathrm{Q}} / \text { Manner }_{\mathrm{Q}} / \operatorname{Reason}_{\mathrm{Q}} / \mathrm{X}_{\mathrm{Q}} & \text { no data }\end{array}$

As was mentioned, this order constraint is the consequence of the rigid verb final characteristic of the language, therefore any (interrogative) element is not assumed after the finite verb. Furthermore, the complex interrogative phrases asking for an information which is 
presumed to be salient both to the speaker and to the hearer tend to occur clause initially. This was found for the interrogative subjects that precede the time adverbial (see 252b).

$\begin{array}{cllll}\text { (252) a. Time } & \mathrm{S}_{\mathrm{Q}} & \mathrm{V} & & \text { standard order } \\ \text { b. } \mathrm{S}_{\mathrm{Q}} & \text { Time } & \mathrm{V} & \text { IF } & \mathrm{S}_{\mathrm{Q}} \text { is complex }\end{array}$

Additionally, non-interrogative constituents interpreted as not new elements of the discourse occur at clause initial position. These constituents either are previously introduced into the discourse or are the part of the common knowledge shared by the speaker and the hearer. Consequently, they function as topics and appear clause initially in these clauses. (253) and (254) illustrate the schemes of those clauses, in which a referential/specific element precede the interrogative constituent involving changes in the standard word order.

$\begin{array}{cllll}\text { (253) a. } \text { Time }_{\mathrm{Q}} & \mathrm{S} & \mathrm{V} & & \text { standard order } \\ \text { b. } \mathrm{S} & \text { Time }_{\mathrm{Q}} & \mathrm{V} & \mathrm{IF} & \mathrm{S} \text { is referential } \\ \text { (254) a. } \mathrm{S} \mathrm{Q}_{\mathrm{Q}} & \mathrm{L} & \mathrm{V}_{\mathrm{M}} & & \text { standard order } \\ \text { b. } \mathrm{L} & \mathrm{S}_{\mathrm{Q}} & \mathrm{V}_{\mathrm{M}} & \text { IF } & \text { L is referential and/or specific }\end{array}$

Moreover, as it has also been demonstrated, there are orders among which there seems to be no grammatical differences. Therefore, these orders are regarded as optional ones (see 255260).

$\begin{array}{clll}\text { (255) a. } \mathrm{L} & \mathrm{S}_{\mathrm{Q}} & \mathrm{V} & \\ \text { b. } \mathrm{S}_{\mathrm{Q}} & \mathrm{L} & \mathrm{V} & \text { optional orders } \\ (256) \text { a. } \mathrm{S} & \mathrm{L}_{\mathrm{Q}} & \mathrm{V} & \\ \text { b. } \mathrm{L}_{\mathrm{Q}} & \mathrm{S} & \mathrm{V} & \text { optional orders } \\ \text { (257) a. } \mathrm{S} & \text { Manner }_{\mathrm{Q}} & \mathrm{V} & \\ \text { b. } \mathrm{Manner} & \mathrm{S} & \mathrm{V} & \text { optional orders } \\ (258) \text { a. } \mathrm{S} & \text { Reason }_{\mathrm{Q}} & \mathrm{V} & \\ \text { b. } \mathrm{Reason} & \mathrm{S} & \mathrm{V} & \text { optional orders } \\ (259) \text { a. } \mathrm{S} & \mathrm{X} & \mathrm{X} & \\ \text { b. } \mathrm{X} & \mathrm{S}_{\mathrm{Q}} & \mathrm{V} & \text { optional orders } \\ \text { (260) a. } \mathrm{S} & \mathrm{X}_{\mathrm{Q}} & \mathrm{V} & \\ \text { b. } \mathrm{X}_{\mathrm{Q}} & \mathrm{S} & \mathrm{V} & \text { optional orders }\end{array}$


In addition, some relative orders are not attested because they do not appear in the texts. However, it cannot be decided whether the attested order is the only possible (see 261).
(261) a. $\mathrm{S}_{\mathrm{Q}}$
Manner $\mathrm{V}$
b. Manner
$\mathrm{S}_{\mathrm{Q}}$
V no data

Finally, there were constructions that do not appear in the texts at all (see 262).

$\begin{array}{cll}\text { (262) a. Reason } & S_{Q} & \text { V no data } \\ \text { b. } S_{Q} & \text { Reason } & V \text { no data }\end{array}$

In what follows, I will discuss the available positions and structures of interrogative phrases in two subtypes of intransitive clauses, in existential constructions and in predicative possessive clauses.

\subsubsection{Existential content questions}

Despite the fact that existential clauses are expressed by nonverbal predicates crosslinguistically (cf. Dryer 2007b: 241), they belong to the intransitive clauses in Tundra Nenets. In the Tundra Nenets structure, the predicate verb is the existential verb (tańaś) which takes at least one argument, the so-called theme element (which is always indefinite) in order to introduce it into the discourse. In the construction, the existential verb may link a theme element together with a location, but the locative phrase is not an obligatory element in the existential clause. In some languages, there is a locative proform, such as the English there (cf. Freeze 2001: 941, Dryer 2007b: 242). As observed by Freeze (2001: 944), the basic word order of a language correlates with the existence of such a (locative) proform in existential clauses. SOV languages do not employ a proform in their existential clauses. As Tundra Nenets is an SOV language, the existence of a proform in existential structures is not expected. In addition, there is also a correlation between the basic word order of languages and the order of the constituents in the existential clauses (cf. Freeze 1992: 556-557, see Table 45, in which $\mathrm{T}$ stands for the theme element, while $\mathrm{L}$ abbreviates the locational constituent of the existential clause.). 
Table 45. The correlation between basic word order and the order in existential clauses

\begin{tabular}{cccc}
\hline Basic word order & \multicolumn{4}{c}{ Existential clauses } \\
\hline SVO & L & cop & T \\
VOS & cop & T & L \\
VSO & cop & T & L \\
SOV & L & T & cop \\
\hline
\end{tabular}

In Tundra Nenets, the LTcop order is expected in the existential clauses. In content interrogative existential clauses, both theme and locational elements can be asked by interrogative phrases. However, it is much more frequent that the theme element, i.e. the subject, is the interrogative one. The attested existential content interrogatives are given in Table 46, in which $Q$ indicates the respective elements expressed by interrogative phrases.

Table 46. The order of existential content questions

\begin{tabular}{cccc}
\hline \multicolumn{3}{c}{ Word order } & № \\
\hline & $\mathrm{T}_{\mathrm{Q}}$ & $\mathrm{V}_{\text {exist }}$ & 11 \\
\hline Time $_{\mathrm{Q}}$ & $\mathrm{T}$ & $\mathrm{V}_{\text {exist }}$ & 1 \\
\hline $\mathrm{L}$ & $\mathrm{T}_{\mathrm{Q}}$ & $\mathrm{V}_{\text {exist }}$ & 15 \\
$\mathrm{~L}_{\mathrm{Q}}$ & $\mathrm{T}$ & $\mathrm{V}_{\text {exist }}$ & 3 \\
\hline $\mathrm{T}_{\mathrm{Q}}$ & $\mathrm{L}$ & $\mathrm{V}_{\text {exist }}$ & 5 \\
$\mathrm{~T}$ & $\mathrm{~L}_{\mathrm{Q}}$ & $\mathrm{V}_{\text {exist }}$ & no data \\
\hline
\end{tabular}

There are 35 occurrences of existential content interrogatives in the corpus. Out of these occurrences, the theme elements are expressed by interrogative phrases in 32 clauses, while only 3 clauses appeared with locative interrogative phrases.

As mentioned above, locative phrases are not obligatory in existential structures, so they can also be left from the questions as in (263).

(263) yamge jedej ser? tańa?
what.qual new thing exist.VX.3SG
'What news are there?' (Nenyang 2005: 39)
$\mathrm{T}_{\mathrm{Q}}$
$\mathrm{V}_{\text {exist }}$

Constituents other than locative expressions can also appear in Tundra Nenets existential clauses. For instance, temporal adverbials can surface instead of locational elements, as in (264). 


$$
\begin{array}{ccc}
\text { (264) śaxa? } & \text { sawajil'e-ńa-? } & \text { tańa-wi-?? } \\
\text { when } & \text { be.rich-PCP.IMPF-PL } & \text { exist-NARR-VX.3PL } \\
\text { 'When did rich men live (lit. exist)?' (Nenyang 2007: 34) } \\
\begin{array}{ccc}
\text { Time }_{\mathrm{Q}} \quad \mathrm{T} & \mathrm{V}_{\text {exist }}
\end{array}
\end{array}
$$

As these examples above illustrate it, the theme element is the subject of the intransitive existential verb and controls agreement on it.

The most frequent construction is, nevertheless, when both the theme and the locative element are overt in the clause. (265) exemplifies a clause in which the theme element is substituted by an interrogative phrase, while in (266) below, the locational part is unknown.

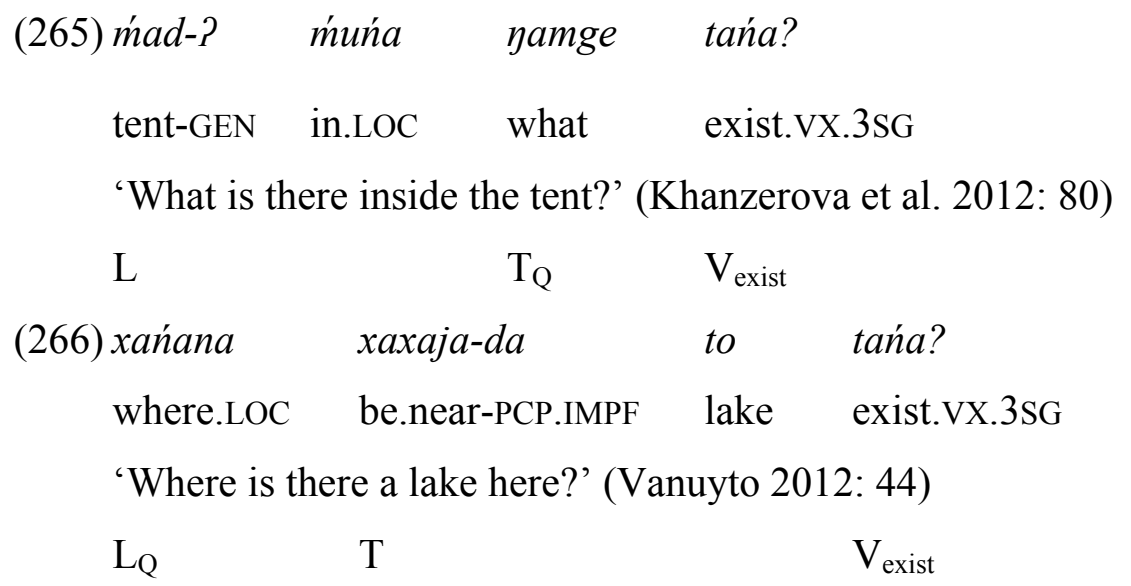

The clauses in (265-266) above illustrate the most frequent attested order in existential content questions in Tundra Nenets, which is LTV. Thus in 18 clauses out of 23 this LTV order is realized, while in 5 clauses the reversed order (TLV) is found in which the theme elements - which precede the locative constituent - are typically complex interrogative phrases, as in (267).

$$
\begin{array}{lccc}
\text { (267) } \begin{array}{ccc}
\text { nurka } \\
\text { nuw? }
\end{array} \text { sarmik-? } & \text { ja-xana-nda? } & \text { tańa-P? } \\
\text { what.kind sky } & \text { wild.animal-PL } & \text { land-LOC-PX.OBL.2PL } & \text { exist-VX.3PL } \\
\text { 'What birds are there in your country?' (Vanuyto 2012: 38) } & \\
\mathrm{T}_{\mathrm{Q}} & \mathrm{L} & \mathrm{V}_{\text {exist }}
\end{array}
$$

We observe then that complex theme elements may precede the locational components and occupy the clause intial position. 
In addition, the non-selective interrogative word referring to human entities also occurs in clause inital position when preceding the locative constituent. In this clause, a possessive marker is attached to the interrogative pronoun (see 268).

\begin{tabular}{|c|c|c|c|}
\hline (268) tamna & $x i \grave{b i-d a ?}$ & ma-kana-nda? & tańa-?? \\
\hline still & who.PL-PX.PL.2PL & tent-LOC-PX.OBL.2PL & exist-VX.3PL \\
\hline 'Who e & se is there in your te & nt?' (Okotetto 1998: 11 & \\
\hline & $\mathrm{T}_{\mathrm{Q}}$ & $\mathrm{L}$ & $\mathrm{V}_{\text {exist }}$ \\
\hline
\end{tabular}

Based on the examples in (267-268), we can observe that complex and referential theme elements can occupy the sentence initial position by changing the basic word order of existential clauses, i.e. by preceding the locational expression.

To summarize our observations, existential clauses may contain interrogative phrases that substitute either the theme or the locational element. The word order of interrogative existential sentences is the same as the corresponding non-interrogative one, that is LTV. Additionally, this order can be reversed (TLV), but it is only typical with complex and/or referential theme elements (see 269-270).

$\begin{array}{rllll}\text { (269) a. } \mathrm{L} & \mathrm{T}_{\mathrm{Q}} & \mathrm{V}_{\text {exist }} & & \text { standard order } \\ \text { b. } \mathrm{T}_{\mathrm{Q}} & \mathrm{L} & \mathrm{V}_{\text {exist }} & \text { IF } & \mathrm{T}_{\mathrm{Q}} \text { is complex } \\ \text { (270) a. } \mathrm{L}_{\mathrm{Q}} & \mathrm{T} & \mathrm{V}_{\text {exist }} & \\ \text { b. } \mathrm{T} & \mathrm{L}_{\mathrm{Q}} & \mathrm{V}_{\text {exist }} & \text { no data }\end{array}$

\subsubsection{Predicative possession expressed by content questions}

Tundra Nenets employs a strategy for expressing predicative possession which is syntactically intransitive. In these clauses, the predicate is the existential verb (tańaś) whose grammatical subject is a possessive phrase. This possessive phrase consists of a possessed item which can be understood as the theme element of the possessive clause. Additionally, the possessed item may be modified by the possessor noun phrase.

As Dryer (2007b: 244) notes, if a language utilizes either an existential or a locative predicative construction for expressing predicate possession, in this case the possessor is conveyed by a locative expression. In Tundra Nenets, however, the pronominal possessor is 
not marked at all, while the lexical possessor is marked either by genitive case or by nominative case in predicate possiessive constructions. Table 47 summarizes the occurrences of predicate possession containing an interrogative phrase. The PD abbreviates the possessed item, i.e. the theme element/subject of the clause, while PR stands for the possessor. Additionally, Q indicates the interrogative expression.

Table 47. Predicative possession expressed by content questions

\begin{tabular}{cccc}
\hline \multicolumn{3}{c}{ Word order } & № \\
\hline & $\mathrm{PD}_{\mathrm{Q}}$ & $\mathrm{V}_{\text {exist }}$ & 1 \\
\hline $\mathrm{PR}$ & $\mathrm{PD}_{\mathrm{Q}}$ & $\mathrm{V}_{\text {exist }}$ & 11 \\
\hline $\mathrm{PD}_{\mathrm{Q}}$ & $\mathrm{PR}$ & $\mathrm{V}_{\text {exist }}$ & 1 \\
\hline & $\mathrm{PD}_{\mathrm{Q}}$ & - & 10 \\
\hline $\mathrm{PR}$ & $\mathrm{PD}_{\mathrm{Q}}$ & - & 19 \\
\hline
\end{tabular}

In the corpus, 42 content questions occur expressing predicative possession. In these clauses, solely the possessed items are substituted by interrogative phrases. As is illustrated in Table 47, the possessors can be elided from the clause, in which cases the possessed items take possessive suffixes that mark the person and number of the possessors as in (271). Grammatically, the possessed item is the subject of the verb that controls agreement on the existential predicate verb.

\begin{tabular}{|c|c|c|}
\hline (271) xurka & xal'a-ra & tańa? \\
\hline what.kind & fish-PX.2PL & exist.VX.3SG \\
\hline 'What fish & you have?' [ & $\mathrm{La}, 2002]$ \\
\hline $\mathrm{PD}_{\mathrm{Q}}$ & & $\mathrm{V}_{\text {exist }}$ \\
\hline
\end{tabular}

If the possessor is overt, it can be a pronominal one, which always stands in nominative case (see 272).

$\begin{array}{llcc}\text { (272) pidara? } & \text { xurka } & \text { manzaja-ra? } & \text { tańa? } \\ \text { 2PL } & \text { what.kind } & \text { work-PX.2PL } & \text { exist.VX.3SG } \\ \text { 'What job do you have?' (Okotetto 1998: } & \text { 152) } \\ \text { PR } & \mathrm{PD}_{\mathrm{Q}} & \mathrm{V}_{\text {exist }}\end{array}$


Unlike pronominal possessors, lexical possessors may surface in genitive form (see 273). In this case, they may also appear without case marking (in nominative) in the constructions (see 274).

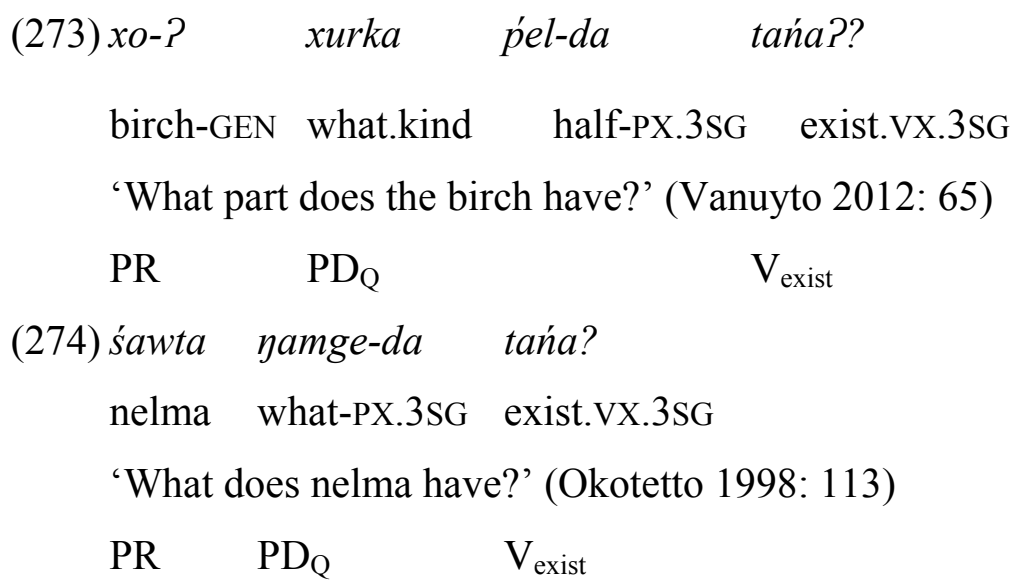

Both of these interrogatives above stand for the possessed item. The relation between the possessors and the possessed items can be categorized as inalienable. In (273) both head marking on the possessed item by possessive suffixes and dependent marking on the possessor appearing in genitive case is involved. In (274) the possessor appears in nominative case so the possessive relation is marked only on the possessed item. There is no clear evidence for a difference between these constituents.

Additionally, the possessed item can appear without possessive markers in which case the possessor obligatorily stays in the genitive case (275).

$\begin{array}{cccc}\text { (275) } \text { mal'ća-? } & \text { tamna } & \text { yamge } & \text { tańa? } \\ \text { malitsa-GEN } & \text { still } & \text { what } & \text { exist.VX.3SG } \\ \text { 'What else does a malitsa have?' (Okotetto 1998: 77) } \\ \text { PR } & \mathrm{PD}_{\mathrm{Q}} & \mathrm{V}_{\text {exist }}\end{array}$

As example (275) illustrates, it is possible to insert an element between the possessor and the possessed item is possible.

The examples in (273-275) above represent the canonical order of the elements in predicational possessive structures, that is PR PD, so the possessors are followed by the possessed items. Given that the possessed items are the grammatical subjects of the cluases, this order corresponds to the order typically surfacing in existential constructions. 
In the corpus, there is only one example in which the possessed item precedes its modifier, the possessor, this is given in (276).

$\begin{array}{cccc}\text { (276) tamna } & \text { yamge-da } & \text { ti } & \text { tańa? } \\ \text { still } & \text { what-PX.3SG } & \text { reindeer } & \text { exist.VX.3SG } \\ \text { 'What else does reindeer have?' (Okotetto 1998: 109) } \\ \mathrm{PD}_{\mathrm{Q}} & \mathrm{PR} & \mathrm{V}_{\text {exist }}\end{array}$

In (276), the possessive relation is only marked on the head (on the possessed item) in the construction. Admitting that there is one exception, the PR PD order is clearly the basic one in possessive constructions.

Finally, structures without an overt existential verb are also attested which suggest that the use of the existential verb that serves to link the two elements of the clause together (the possessor and possessed item) seems to be optional (see 277).

$$
\begin{array}{lll}
\text { (277) pidara? } & \text { xurka } & \text { professija-ra?? } \\
\text { 2PL } & \text { what.kind occupation-PX.2PL } \\
\text { 'What occupation do you have?' (Nenyang 2005: 52) } \\
\mathrm{PR}
\end{array}
$$

In these constructions without an overt existential verb, there is no agreement between the subject and the predicate, as the predicate is covert and the possessed item takes possessive suffixes instead of agreement markers. Similarly to the predicative possession with an overt copula, the possessor can be omitted from the clause as in (278).

$$
\begin{aligned}
& \text { (278) śajok } \quad \text { yaćeke-ra?? } \\
& \text { how.many } \quad \text { child-PX.2PL } \\
& \text { 'How many children do you have?' (Nenyang 2005: 56) }
\end{aligned}
$$

In (278), only the possessed item carries information about the possessor (its person and number) and about the relation (predicate possession) expressed by the construction. The construction does not contain any verbal element.

To sum it up, predicative possession is expressed by existential constructions in Tundra Nenets. The possessive relation itself is marked on the possessed items via possessive suffixes 
and/or on the possessors through genitive case marker. In the attested interrogatives, only the possessed items are substituted by interrogative phrases. A scheme under (279) illustrates the typical elements and their order in questions expressing predicative possession.
(279) a. (PR)
$\mathrm{PD}_{\mathrm{Q}}$
$\left(\mathrm{V}_{\text {exist }}\right)$
b. $\mathrm{PR}_{\mathrm{Q}}$
PD
$\left(\mathrm{V}_{\text {exist }}\right)$
no data

The predicate is an intransitive predicate, i.e. the existential verb, that is controlled by the subject, which is the possessed item. This existential verb can be omitted from the clause, in which case there is no verbal agreement expressed.

The possessor may also be omitted, but if it is overt, it usually precedes the possessed item in the clause but the reverse order is also possible (however it is not typical). Since there is only one example for the reversed order of the possessor and the possessed item, the reason of this structure is unknown. The order variations can be found under (280) below.

$\begin{array}{rlll}\text { (280) a. } \mathrm{PR} & \mathrm{PD}_{\mathrm{Q}} & \left(\mathrm{V}_{\text {exist }}\right) & \text { standard order } \\ \text { b. } \mathrm{PD}_{\mathrm{Q}} & \mathrm{PR} & \left(\mathrm{V}_{\text {exist }}\right) & \text { unknown reason }\end{array}$

In what follows, I will discuss some word order peculiarities in transitive content questions.

\subsection{Transitive content questions}

Transitive clauses are usually described as clause types in which the verbal predicate takes at least - two arguments, the subject and the object (see e.g. Dryer 2007b: 250). In Tundra Nenets transitive clauses, the subject always controls agreement on the predicate verb via agreement suffixes. The markers do not differ from those used in intransitive clauses. In addition, the object always takes an accusative marker and it either controls agreement on the predicate verb or it does not. The objective agreement on the verb marks only the number of the object. According to Dalrymple \& Nikolaeva (2011: 134), agreeing and nonagreeing objects, i.e. objects that trigger agreement on the verb or do not, have different information structural roles. Referential objects always trigger agreement on the predicate verb, while nonreferential objects do not. Consequently, the function of the object agreement on the predicate verb is to indicate the topicality of the direct object (cf. Dalrymple \& Nikolaeva 
2011: 134). If the direct object is overt and agrees with the transitive verb, it has a topical role (cf. Dalrymple \& Nikolaeva 2011: 131-137). If it is covert in the structure, the predicate verb always takes the agreement markers. This is so because topical objects can be omitted. Only the 3 rd person objects trigger agreement on the verb, the 1 st and 2 nd person objects never do so.

In this section, I will examine the order of the combination of predicate verb, subject, object and other adverbial constituents of the main clause expressed by interrogative phrases. The occurrence of interrogative phrases for their constituent types in transitive content questions in the corpus is summarized in Table 48. There are clauses that contain only the object element in addition to the predicate verb. As these structures are not suitable for illustrating word order variations they are excluded from the analysis.

Table 48. The syntactic function of interrogative phrases in transitive content questions

\begin{tabular}{cccc}
\hline $\begin{array}{c}\text { The function of } \\
\text { interrogative } \\
\text { words/phrases }\end{array}$ & Total № & $\begin{array}{c}\text { Those that contain } \\
\text { only the } \\
\text { interrogative phrase } \\
\text { and the predicate }\end{array}$ & $\begin{array}{c}\text { Examined } \\
\text { constructions }\end{array}$ \\
\hline $\mathrm{S}_{\mathrm{Q}}$ & 46 & 7 & 39 \\
$\mathrm{O}_{\mathrm{Q}}$ & 227 & 91 & 104 \\
Time $_{\mathrm{Q}}$ & 11 & 0 & 11 \\
$\mathrm{~L}_{\mathrm{Q}}$ & 31 & 0 & 31 \\
Manner $_{\mathrm{Q}}$ & 43 & 1 & 42 \\
Reason $_{\mathrm{Q}}$ & 18 & 0 & 18 \\
$\mathrm{X}_{\mathrm{Q}}$ & 16 & 0 & 16 \\
\hline Total & $\mathbf{3 9 2}$ & $\mathbf{9 9}$ & $\mathbf{2 6 1}$ \\
\hline
\end{tabular}

First, I will concentrate on the possible order of the core arguments of the transitive predicate, which are the subject, the object and the verb. Given the rigid verb-final property of Tundra Nenets word order, only two logically possible orders can be expected. These are the SOV and the OSV orders. Let us see now the sequences of the subject and the object in content questions in which the subject is the unknown element (see Table 49). 
Table 49. The syntactic position of $\mathrm{S}_{\mathrm{Q}}$ in transitive content questions

\begin{tabular}{cccc}
\hline \multicolumn{3}{c}{ Word order } & № \\
\hline $\mathrm{S}_{\mathrm{Q}}$ & & $\mathrm{V}_{\text {obj }}$ & 7 \\
\hline $\mathrm{S}_{\mathrm{Q}}$ & $\mathrm{O}_{1 \mathrm{st} / 2 \text { nd }}$ & $\mathrm{V}$ & 11 \\
$\mathrm{~S}_{\mathrm{Q}}$ & $\mathrm{O}_{3 \text { rd }}$ & $\mathrm{V}_{\text {subj }}$ & 9 \\
$\mathrm{~S}_{\mathrm{Q}}$ & $\mathrm{O}_{3 \text { rd }}$ & $\mathrm{V}_{\text {obj }}$ & 5 \\
\hline $\mathrm{O}_{2 \text { nd }}$ & $\mathrm{S}_{\mathrm{Q}}$ & $\mathrm{V}$ & 1 \\
$\mathrm{O}_{3 \text { rd }}$ & $\mathrm{S}_{\mathrm{Q}}$ & $\mathrm{V}_{\text {obj }}$ & 13 \\
\hline
\end{tabular}

As illustrated in Table 49, the direct object of the transitive verb does not have to be present in the clause. There are 7 clauses in the corpus in which the direct object is covert and the subject is an interrogative phrase. Like in intransitive clauses, the $\mathrm{S}_{\mathrm{Q}}$ triggers agreement on the predicate verb in transitive clauses as well. Additionally, the transitive predicate has to agree with its covert object in number (see 281).

(281) xib̀a salda-ygu-da?

who pay-FUT-VX.OBJ.3SG

'Who will pay it?' (Vanuyto 2012: 25)

As Table 49 also shows, only $\mathrm{S}_{\mathrm{Q}} \mathrm{OV}$ and $\mathrm{OS}_{\mathrm{Q}} \mathrm{V}$ orders surface in the examined clauses in case of overt objects, thus no element occur after the verb. In the remaining 39 clauses with an overt object, there are 12 clauses with 1st/2nd person objects. As already mentioned, 1st/2nd person objects never trigger agreement on the predicate verb regardless of their information structural role (cf. Dalrymple \& Nikolaeva 2011: 134) This construction is illustrated in (282).

$$
\begin{aligned}
& \text { (282) xib̀a sit jadta-ygu? } \\
& \text { who 2SG.ACC meet-FUT.VX.3SG } \\
& \text { 'Who will meet you?' [E.La, 2002] }
\end{aligned}
$$

There are 27 clauses in which there is a 3rd person object either controlling agreement on the predicate verb as in (283) or not (see 284). 
$\begin{array}{rll}\text { (283) xib̆a } & \text { gol-m? } & \text { me-da? } \\ \text { who } & \text { goal-ACC } \text { make-VX.OBJ.3SG }\end{array}$

'Who scored a/the goal?' (Nenyang 2005: 78)

\begin{tabular}{|c|c|c|}
\hline $\mathrm{S}_{\mathrm{Q}}$ & $\mathrm{O}$ & $\mathrm{V}_{\mathrm{obj}}$ \\
\hline (284) $x i \grave{b a}$ & $t u-m ?$ & ṕata-b̀i? \\
\hline who & fire-ACC & pile-CONT.VX.3SG \\
\hline \multicolumn{3}{|c|}{ 'Who piles fire?' (Okotetto 1998: 132) } \\
\hline $\mathrm{S}_{\mathrm{Q}}$ & $\mathrm{O}$ & $\mathrm{V}_{\text {subj }}$ \\
\hline
\end{tabular}

Given that Tundra Nenets has an SOV order and the interrogative phrases remain in situ, the $\mathrm{S}_{\mathrm{Q}} \mathrm{OV}$ order would be expected. According to the frequency of the clausal elements in a given syntactic position, the canonical order in transitive interrogatives is $\mathrm{S}_{\mathrm{Q}} \mathrm{OV}$ (see 283 and 284). However, in 14 clauses out of the 39 , the order of the core constituents is reversed, they appear in $\mathrm{OS}_{\mathrm{Q}} \mathrm{V}$ order. Considering the word order and the verbal agreement in these clauses, we can state, that there is a clear correlation between object agreement on the verb and the position of the direct object. The reversed non-canonical order $\left(\mathrm{OS}_{\mathrm{Q}} \mathrm{V}\right)$ is realized with agreeing objects. The agreeing 3rd person objects occupy the sentence initial position preceding the $\mathrm{S}_{\mathrm{Q}}$ in 13 cases out of 18 clauses. In these clauses, the direct object has a topical role and it appears sentence initially by changing the basic word order, as in example (285).

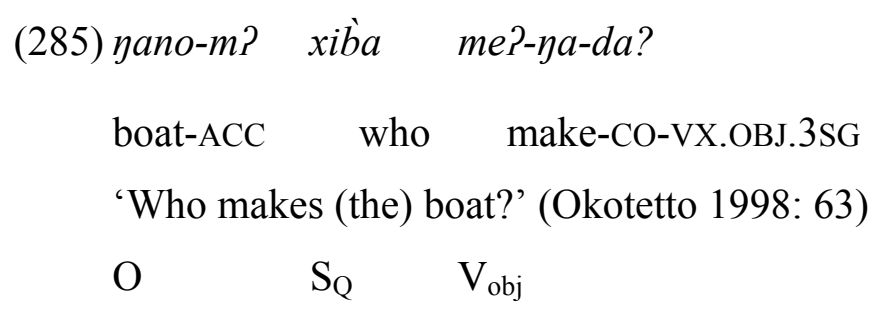

The topical status of the direct object in (285) is supported by the context in (286) in which example (285) appears: 
(286) A: What is this?

$\mathrm{B}$ : This is a boat.

A: Where is the boat used?

$\mathrm{B}$ : The boat is used on the water.

\section{A: yanom? xib̀a me?̉ada?}

'Who makes (the) boat?'

B: The boat is made by (the) people.

(Okotetto 1998: 63)

Given that agreeing objects have a topical role, the $\mathrm{OS}_{\mathrm{Q}} \mathrm{V}$ order can be regarded as a marked one that involves fronting what is known, the topic. However, there are also agreeing objects that appear after the subjects in the clauses (see example in (283) above). There is no clear explanation of why these agreeing objects remain in their standard position, i.e. after the subject. In consequence, it is only a tendency, that the topical object precedes the subject and it occupies the clause initial position.

In addition, as shown by Table 49, there is only one clause in which a non-agreeing object precedes the subject. This clause is illustrated in (287) below.

$$
\begin{aligned}
& \text { (287) Śóna, śit xib̀a xonra-sa? } \\
& \text { Syomya 2SG.ACC who inform-INT.VX.3SG } \\
& \text { 'Syomya, who informed you?' (Pushkareva \& Khomich 2001: 152) } \\
& \begin{array}{llll}
\mathrm{O} & \mathrm{S}_{\mathrm{Q}} & \mathrm{V}
\end{array}
\end{aligned}
$$

In this clause, however, the object is a 2 nd person one which never triggers agreement on the verb, therefore, it cannot be excluded that the object has a topical role in this clause.

To sum it up, the canonical word order of transitive content questions is the one, in which the subjectival interrogative phrase precedes the object $\left(\mathrm{S}_{\mathrm{Q}} \mathrm{OV}\right)$. The reversed order is also possible $\left(\mathrm{OS}_{\mathrm{Q}} \mathrm{V}\right)$ in the case of topical object. $72.2 \%$ of the clauses with agreeing object surface in this marked order.

Now, let us turn to the discussion of transitive clauses with interrogative objects. The first observation is that the interrogative phrases functioning as direct objects, $\mathrm{O}_{\mathrm{Q}}$, never trigger agreement on the verb. This follows from the non-topical status of the interrogative objects. Given that interrogative phrases basically ask for new/unknown information they cannot be 
topics in the clause, therefore - although they always present 3rd person objects - they can only surface as nonagreeing objects. Again, the attested order of $\mathrm{S}$ and $\mathrm{O}_{\mathrm{Q}}$ follows the two logically possible orders, $\mathrm{SO}_{\mathrm{Q}} \mathrm{V}$ and $\mathrm{O}_{\mathrm{Q}} \mathrm{SV}$, illustrated in Table 50 .

Table 50. The syntactic position of $\mathrm{O}_{\mathrm{Q}}$ in transitive content questions

\begin{tabular}{|c|c|c|c|}
\hline \multicolumn{3}{|c|}{ Word order } & № \\
\hline- & $\mathrm{O}_{\mathrm{Q}}$ & $\mathrm{V}$ & 123 \\
\hline $\mathrm{S}$ & $\mathrm{O}_{\mathrm{Q}}$ & $\mathrm{V}$ & 91 \\
\hline $\mathrm{O}_{\mathrm{Q}}$ & $\mathrm{S}$ & $\mathrm{V}$ & 13 \\
\hline
\end{tabular}

As shown in Table 50, there are subjectless questions with interrogative objects. In these clauses, the person/number of the subject is marked on the predicate as in (288).

\author{
(288) yamge-m? yawor-ta-n? \\ what-ACC eat-FUT-VX.2SG \\ 'What will you eat?' (Khanzerova et al. 2012: 30)
}

Based on the different frequency of the clauses with $\mathrm{SO}_{\mathrm{Q}} \mathrm{V}$ and $\mathrm{O}_{\mathrm{Q}} \mathrm{SV}$ order, the canonical order is $\mathrm{SO}_{\mathrm{Q}} \mathrm{V}$, illustrated by (289).

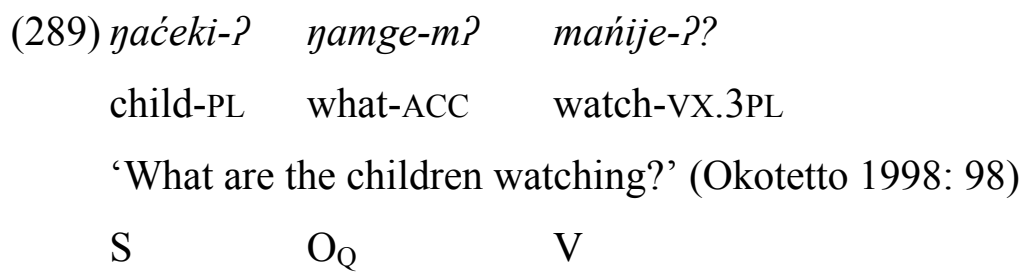

As illustrated in Table 50, there are 13 clauses in which the core arguments of the transitive predicate appear in a reversed, non-canonical order $\left(\mathrm{O}_{\mathrm{Q}} \mathrm{S}\right)$. As an interrogative phrase cannot have topical role, the clause-initial position of the interrogative objects in these clauses cannot be explained by the topic role of the initial object.

Although it is not clear exactly what (discourse) functions are held by these non-canonical orders, certain observations can be made. Firstly, in 9 examples out of the 13 clauses with $\mathrm{O}_{\mathrm{Q}} \mathrm{S}$ order, the object is expressed by a complex interrogative phrase, as in (290). 

(290) xurka
tabad'ar-m? wesako
ńaxara-md'ej
ńa?am-sa?
what.kind task-ACC
old.man three-ORD
get-INT.VX.3SG
'What task did the old man get for the third time?'

(Samoylova \& Barmich 2010: 26)

$\mathrm{O}_{\mathrm{Q}} \mathrm{S} \quad \mathrm{Adv} \quad \mathrm{V}$

In these clauses, the interrogative modifier typically requires the selection/characterization of its noun head, which is referential in the given context. Thus, the clause-initial interrogative objects are contextually determined.

Secondly, another common phenomenon of these clauses is that the subject preceded by the (complex) interrogative phrase is a pronominal one. It is the case in 9 clauses out of the 13 occurrences (see 291).

$\begin{array}{lllll}\text { (291) xurka } & \text { po-? } & \text { ṕel'a-m? } & \text { pidara? } & \text { xarwo-bta-da?? } \\ \text { what.kind } & \text { year-GEN } & \text { half-ACC } & \text { 2PL } & \text { want-TR-VX.2PL } \\ \text { 'What season do you like?' (Okotetto 1998: 98) } & \\ \mathrm{O}_{\mathrm{Q}} & \mathrm{S} & \mathrm{V}\end{array}$

As Nikolaeva (2014) notes, focused or emphasized pronominal subjects are typically overt in the clause. Given that it is the interrogative phrase that functions as the focus, the pronominal subject cannot be focused too. Nevertheless, it may be assumed that the pronominal subject has a contrastive focus reading in these clauses. This assumption can be explained and justified by contexts in which these non-canonical clauses appear. However, the examples do not have any contexts in the sources.

Thirdly, the non-canonical word order can be the result of the contact with Russian, whose interrogative phrases occur obligatorily at the clause-initial position (cf. Dryer 2013a). This is supported by the fact that these non-canonical Tundra Nenets clauses appear in the so-called phrasebooks, in which the Tundra Nenets clauses have presumably been translated from Russian into Tundra Nenets. Thus, the consultants might follow the word order of the Russian constructions while translating (see 292a-b). 
(292) a. Russian

Čem vy zanima-ete-s'?

what.INST 2PL do-VX.2PL-REFL

'What do you (pl) do?' (Nenyang 2005: 93)

$\mathrm{O}_{\mathrm{Q}} \quad \mathrm{S} \quad \mathrm{V}$

b. Tundra Nenets

yamge-m? pidara? poer-ya-da??

what-ACC 2PL do-CO-VX.2PL

'What do you (pl) do?' (Nenyang 2005: 93)

$\mathrm{O}_{\mathrm{Q}} \quad \mathrm{S}=\mathrm{V}$

Nevertheless, any explanations given above would only be verified on the basis of consultations with Tundra Nenets speakers.

To sum up the main points of this section, the order of subject and object in transitive content questions follows the order typically available in non-interrogative clauses. Thus, SOV is the canonical interrogative order attested in the corpus. Consequently, the interrogative words remain in situ. In the case of interrogative subjects, however, topical objects can appear sentence initially preceding the interrogative subject. In these clauses, the order is reversed: $\mathrm{OS}_{\mathrm{Q}} \mathrm{V}$. Another typical non-canonical order is the $\mathrm{O}_{\mathrm{Q}} \mathrm{SV}$, in which case the interrogative object is followed by the subject. In this case the change in the word order may be due to the complexity of interrogative phrase, the (contrastive) focus function of the subject and/or structural borrowing of Russian constructions.

Now, let us turn to the order and position of sentential elements other than subject and object. Adverbials relative to the subject and object show a great positional variety. As was mentioned before, adverbials may occupy three structurally different positions within the transitive clause. These were introduced in the scheme under (212), repeated below as (293).

\section{(293) 1 S 2 O O 3 V}

According to Nikolaeva (2011: 136), positions 2 and 3 are optional in the non-interrogative transitive clauses. As the order of the subject and the adverbial(s) in transitive clauses does not differ from those discussed in intransitive clauses, I will primarily focus on the relative order of object and adverbial(s) in the clauses. In clauses in which the object is expressed by a 
non-interrogative element, I differentiated the agreeing and non-agreeing 3rd person objects in order to mark whether the object has a topical role or does not.

First, let us discuss temporal expressions. As was demonstrated in §7.1, temporal adverbials tend to occur in sentence initial position. However, they can also appear after subjects. The question may be raised as to whether temporal expressions can appear in the position after objects as well. The position of temporal adverbials in the corpus is illustrated in Table 51.

Table 51. The order of $\mathrm{O}$ and temporal adverbial

\begin{tabular}{cccc}
\hline \multicolumn{3}{c}{ Word order } & № \\
\hline Time & $\mathrm{O}_{\mathrm{Q}}$ & $\mathrm{V}$ & 11 \\
Time $_{\mathrm{Q}}$ & $\mathrm{O}_{1 \text { st } / \text { nd }}$ & $\mathrm{V}$ & 2 \\
Time $_{\mathrm{Q}}$ & $\mathrm{O}_{3 \text { rd }}$ & $\mathrm{V}_{\text {subj }}$ & 3 \\
Time $_{\mathrm{Q}}$ & $\mathrm{O}_{3 \text { rd }}$ & $\mathrm{V}_{\text {obj }}$ & 1 \\
\hline $\mathrm{O}_{\mathrm{Q}}$ & Time & $\mathrm{V}$ & 2 \\
$\mathrm{O}_{1 \text { st } / 2 \text { nd }}$ & Time $_{\mathrm{Q}}$ & $\mathrm{V}$ & no data \\
$\mathrm{O}_{3 \text { rd }}$ & Time $_{\mathrm{Q}}$ & $\mathrm{V}_{\text {subj }}$ & 3 \\
$\mathrm{O}_{3 \text { rd }}$ & Time $_{\mathrm{Q}}$ & $\mathrm{V}_{\text {obj }}$ & 2 \\
\hline
\end{tabular}

As shown in Table 51, temporal adjuncts typically appear before objects regardless of their interrogative status. In (294), the interrogative object is preceded by the temporal adverbial (and the subject). Additionally, in (295) the interrogative adverb referring to time appears clause initially by preceding both the subject and the object.

(294) ycerm? jal'a-xana yaćeki-? yamge-m? paer-ćeti-??

north day-LOC child-PL what-ACC do-HAB-VX.3PL

'What do the children usually do on the northern day?' (Nenyang 2007: 6)

Time $\quad \mathrm{S} \quad \mathrm{O}_{\mathrm{Q}} \quad \mathrm{V}$

(295) śaxa? ńeneća? yod'i marla-mba-śeti-??

when Nenets berry.PL.ACC collect-CONT-HAB-VX.3PL

'When do the Nenets usually collect berries?' (Nenyang 2007: 9)

$\begin{array}{llll}\text { Time }_{\mathrm{Q}} & \mathrm{S} & \mathrm{O} & \mathrm{V}\end{array}$

However, - as evidenced by Table 51 - temporal expressions can also appear after objects, in position 3, as in (296-297). 

(296) śan
xal'a-m?
tuku
po-?
ńa?ma-n??
how.many fish-ACC this year-GEN catch-VX.2SG
'How many fish did you catch this year?' [VT, 2002]
$\mathrm{O}_{\mathrm{Q}}$
Time
(297) śi?iw yarka yoesi-m? śaxa? xade-j-d?
seven big village-ACC when reach-PL.OBJ.CO-VX.OBJ.PL.2SG
'When did you arrive in the seven big villages?' (Yangasova 2001: 123)
$\mathrm{O}$
Time $_{\mathrm{Q}} \mathrm{V}$

As shown in Table 51, the topicality of the object does not seem to play a role in the position of the object. In examples in which the object, either expressed by an interrogative phrase or not, precedes the temporal adverbial, however, the object is always a complex phrase. Simple objects seem to appear in the position after the temporal adjunct.

A great variation of word order is also attested concerning the position of locational adjuncts and objects, which is shown in Table 52.

Table 52. The order of $\mathrm{O}$ and locative adverbial

\begin{tabular}{cccc}
\hline \multicolumn{3}{c}{ Word order } & № \\
\hline $\mathrm{L}$ & $\mathrm{O}_{\mathrm{Q}}$ & $\mathrm{V}$ & 14 \\
$\mathrm{~L}_{\mathrm{Q}}$ & $\mathrm{O}_{1 \text { st } / 2 \text { nd }}$ & $\mathrm{V}$ & 2 \\
$\mathrm{~L}_{\mathrm{Q}}$ & $\mathrm{O}_{3 \text { rd }}$ & $\mathrm{V}_{\text {subj }}$ & 4 \\
$\mathrm{~L}_{\mathrm{Q}}$ & $\mathrm{O}_{3 \mathrm{rd}}$ & $\mathrm{V}_{\text {obj }}$ & 6 \\
\hline $\mathrm{O}_{\mathrm{Q}}$ & $\mathrm{L}$ & $\mathrm{V}$ & 7 \\
$\mathrm{O}_{2 \text { nd }}$ & $\mathrm{L}_{\mathrm{Q}}$ & $\mathrm{V}$ & no data \\
$\mathrm{O}_{3 \text { rd }}$ & $\mathrm{L}_{\mathrm{Q}}$ & $\mathrm{V}_{\text {subj }}$ & 6 \\
$\mathrm{O}_{3 \text { rd }}$ & $\mathrm{L}_{\mathrm{Q}}$ & $\mathrm{V}_{\text {obj }}$ & 13 \\
\hline
\end{tabular}

Locational adverbials either precede or follow the objects expressed by interrogative phrases without any grammatical and/or semantic restrictions (see 298-299 respectively).

\begin{tabular}{|c|c|c|c|}
\hline (298) mańa? & uroka-xana & yamge-m? & paer-ca-wa?? \\
\hline $1 \mathrm{PL}$ & lesson-LOC & what-ACC & do-INT-VX.1PL \\
\hline
\end{tabular}

'What have we done in the class?' (Nenyang 2007: 21)
S L
$\mathrm{O}_{\mathrm{Q}}$
$\mathrm{V}$ 
$\begin{array}{rll}\text { (299) yamge-m? } & \text { uroka-xana } & \text { pcer-ca-wa?? } \\ \text { what-ACC } & \text { lesson-LOC } & \text { do-INT-VX.1PL }\end{array}$

'What have we done in the class?' (Nenyang 2007: 18)

$\mathrm{O}_{\mathrm{Q}} \quad \mathrm{L} \quad \mathrm{V}$

It seems that the position of locational expressions is not fixed, therefore they can freely occur in position 2 or in position 3. However, the frequency of the constructions shows that the locational adverbial rather precedes the interrogative object than follows it.

In contrast, there is a tendency of the agreeing objects to appear before the locational expressions expressed by interrogative phrases (see 300).

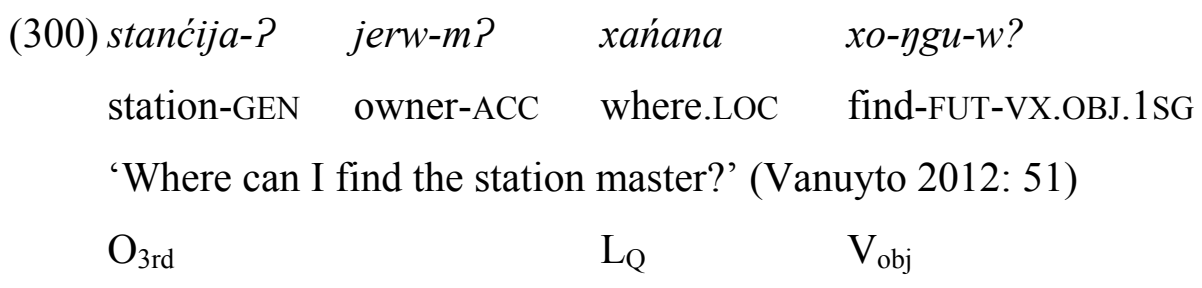

In example (300), the object being a 3rd person topical object is definite and it occupies the position before the interrogative locational adjunct. There are cases where the agreeing objects remain after the interrogative locational element, as in (301):

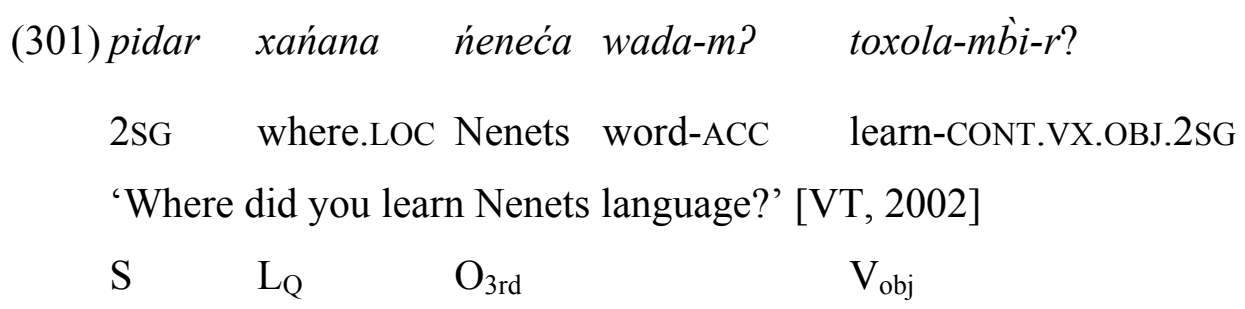

In these clauses, there is, however, no clear evidence of the order realized. It can be that the relative position of the agreeing object and the interrogative locational element is optional. Whereas nonagreeing objects seem to appear either before (see 302) or after the interrogative locational adverbials (see 303) without constraints. 


\begin{tabular}{|c|c|c|}
\hline (302) mar $m a$ & xańana & mar-ygu-wa?? \\
\hline tent-PX.ACC & PL where.LOC & set.up.a.tent-FUT-VX.1PL \\
\hline 'Where wil & ve set up our tent & '[E.La, 2002] \\
\hline $\mathrm{O}_{3 \mathrm{rd}}$ & $\mathrm{L}_{\mathrm{Q}}$ & $\mathrm{V}_{\text {subj }}$ \\
\hline (303) xańa & mar-ma & mar-ygu-wa?? \\
\hline where.LOC & tent-PX.ACC.1PL & set.up.a.tent-FUT-VX.1PL \\
\hline 'Where wil & ve set up our tent & [VT, 2002] \\
\hline $\mathrm{L}_{\mathrm{Q}}$ & $\mathrm{O}_{3 \mathrm{rd}}$ & $\mathrm{V}_{\text {subj }}$ \\
\hline
\end{tabular}

The positions before or after the object are available for sentential, temporal and locational, adverbials. In most of the cases, the orders are not motivated grammatically. However, there are tendencies concerning certain object types that may appear before sentential adjuncts: the complex, agreeing and/or definite objects occupy the position before sentential adverbials more frequently than the position after these adjuncts.

Now, let us turn to the discussion of the position occupied by predicational adverbs. One of the most typical predicational adverbs is the manner adverb. In content interrogatives, they either precede or follow the overt objects as evidenced by Table 53.

Table 53. The order of $\mathrm{O}$ and manner adverbial

\begin{tabular}{|c|c|c|c|}
\hline \multicolumn{2}{|c|}{ Word order } & \multicolumn{2}{|r|}{ № } \\
\hline $\mathrm{O}_{\mathrm{Q}}$ & Manner & $\mathrm{V}$ & 2 \\
\hline $\mathrm{O}_{2 \mathrm{nd}}$ & Manner $_{\mathrm{Q}}$ & $\mathrm{V}$ & 1 \\
\hline $\mathrm{O}_{3 \mathrm{rd}}$ & Manner $_{\mathrm{Q}}$ & $\mathrm{V}_{\text {subj }}$ & 7 \\
\hline $\mathrm{O}_{3 \mathrm{rd}}$ & Manner $_{\mathrm{Q}}$ & $\mathrm{V}_{\mathrm{obj}}$ & 14 \\
\hline Manner & $\mathrm{O}_{\mathrm{Q}}$ & $\mathrm{V}$ & no data \\
\hline Manner $_{Q}$ & $\mathrm{O}_{1 \mathrm{st} / 2 \mathrm{nd}}$ & $\mathrm{V}$ & 6 \\
\hline Manner $_{\mathrm{Q}}$ & $\mathrm{O}_{3 \mathrm{rd}}$ & $\mathrm{V}_{\text {subj }}$ & 8 \\
\hline Manner $_{\mathrm{Q}}$ & $\mathrm{O}_{3 \mathrm{rd}}$ & $\mathrm{V}_{\text {obj }}$ & 6 \\
\hline
\end{tabular}

No manner adverbial preceding an interrogative object is found in the corpus. Furthermore, there are only two clauses in which an overt manner adverbial appears. In both of these clauses it follows the object substituted by an interrogative phrase (see 304). 


\begin{tabular}{|c|c|c|c|c|}
\hline (304) Neko & yamge & manzaja-m? & wenźer? & ṕa-wi? \\
\hline Nyeko & what.qual & work-ACC & badly & start-NARR.VX.3SG \\
\hline \multicolumn{5}{|c|}{ 'What job did Nyeko start badly?' (Nenyang 2007: 18) } \\
\hline $\mathrm{S}$ & $\mathrm{O}_{\mathrm{Q}}$ & & Manner & $\mathrm{V}$ \\
\hline
\end{tabular}

In the case of interrogative adverbial adjuncts, there is a tendency for agreeing objects to occur before manner adverbials, as in (305).

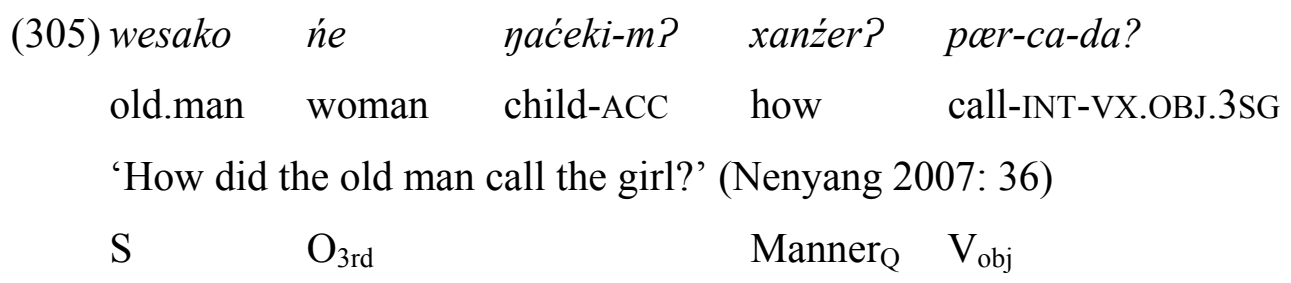

In addition, nonagreeing objects typically occur after manner adverbials like in (306).

$$
\begin{array}{cll}
\text { (306) xanźer } & \text { padar-m? } & \text { pada-ś? } \\
\text { how } & \text { paper-ACC } & \text { write-INT.VX.3SG }
\end{array}
$$

'How did (s)he filled the paper in?' [VT, 2002]

$$
\text { Manner }_{\mathrm{Q}} \mathrm{O}_{3 \mathrm{rd}} \quad \mathrm{V}_{\text {subj }}
$$

However, it is only a tendency. As shown in Table 53, agreeing objects can also be preceded by interrogative manner adjuncts. In addition, manner adverbials can also be situated after nonagreeing objects.

A somewhat similar tendency can be observed in the order of reasonal adverbials, illustrated in Table 54.

Table 54. The order of $\mathrm{O}$ and reason adverbial

\begin{tabular}{cccc}
\hline & Word order & & № \\
\hline $\mathrm{O}_{\mathrm{Q}}$ & Reason & $\mathrm{V}$ & no data \\
$\mathrm{O}_{2 \text { nd }}$ & Reason $_{\mathrm{Q}}$ & $\mathrm{V}$ & no data \\
$\mathrm{O}_{3 \text { rd }}$ & Reason $_{\mathrm{Q}}$ & $\mathrm{V}_{\text {subj }}$ & 1 \\
$\mathrm{O}_{3 \text { rd }}$ & Reason $_{\mathrm{Q}}$ & $\mathrm{V}_{\text {obj }}$ & 10 \\
\hline Reason & $\mathrm{O}_{\mathrm{Q}}$ & $\mathrm{V}$ & no data \\
Reason $_{\mathrm{Q}}$ & $\mathrm{O}_{1 \mathrm{st} / 2 \text { nd }}$ & $\mathrm{V}$ & 2 \\
Reason $_{\mathrm{Q}}$ & $\mathrm{O}_{3 \text { rd }}$ & $\mathrm{V}_{\text {subj }}$ & 3 \\
Reason $_{\mathrm{Q}}$ & $\mathrm{O}_{3 \mathrm{rd}}$ & $\mathrm{V}_{\text {obj }}$ & 2 \\
\hline
\end{tabular}


No content question with an interrogative object and an overt reason adverbial adjunct is attested in the corpus. Therefore, I will discuss here the order variations of interrogative reason adverbs and objects. As shown in Table 54, agreeing objects tend to occur before reason adverbs, as in (307).

$$
\begin{array}{cccc}
\text { (307) jerwa-da } & \text { weńeko-m } & \text { yamge } & \text { yawla-mbi-da? } \\
\text { owner-PX.3SG } & \text { dog-ACC } & \text { why } & \text { feed-CONT-VX.OBJ.3SG }
\end{array}
$$

'Why does the owner feed his dog?' (Okotetto 1998: 108)

$$
\mathrm{S} \quad \mathrm{O}_{3 \mathrm{rd}} \quad \text { Reason }_{\mathrm{Q}} \quad \mathrm{V}_{\mathrm{obj}}
$$

We can contrast this with (308) in which the nonagreeing object follows the predicational adverb.

$$
\begin{array}{lccc}
\text { (308) } \text { yamge ńeneća? } & \text { mud-m? } & \text { me?-ya-?? } \\
\text { why } & \text { Nenets } & \text { sled.caravan-ACC } & \text { keep-CO-VX.3PL } \\
\text { 'Why do the Nenets have sled caravan?' (Okotetto 1998: 157) } \\
\text { Reason }_{\mathrm{Q}} \mathrm{S} & \mathrm{O}_{3 \mathrm{rd}} & \mathrm{V}_{\text {subj }}
\end{array}
$$

As was the case of manner adverbials, the occurrence of the reason adverbial before nonagreeing objects is only a tendency, as it can also precede agreeing objects without any

\begin{tabular}{|c|c|c|c|}
\hline \multicolumn{3}{|c|}{ Word order } & № \\
\hline$X$ & $\mathrm{O}_{\mathrm{Q}}$ & V & 20 \\
\hline $\mathrm{X}_{\mathrm{Q}}$ & $\mathrm{O}_{1 \mathrm{st} / 2 \mathrm{nd}}$ & $\mathrm{V}$ & 6 \\
\hline $\mathrm{X}_{\mathrm{Q}}$ & $\mathrm{O}_{3 \mathrm{rd}}$ & $\mathrm{V}_{\text {subj }}$ & 2 \\
\hline $\mathrm{X}_{\mathrm{Q}}$ & $\mathrm{O}_{3 \mathrm{rd}}$ & $\mathrm{V}_{\mathrm{obj}}$ & 5 \\
\hline $\mathrm{O}_{\mathrm{Q}}$ & $\mathrm{X}$ & $\mathrm{V}$ & 7 \\
\hline $\mathrm{O}_{2 \mathrm{nd}}$ & $\mathrm{X}_{\mathrm{Q}}$ & $\mathrm{V}$ & 1 \\
\hline $\mathrm{O}_{3 \mathrm{rd}}$ & $\mathrm{X}_{\mathrm{Q}}$ & $\mathrm{V}_{\text {subj }}$ & no data \\
\hline $\mathrm{O}_{3 \mathrm{rd}}$ & $\mathrm{X}_{\mathrm{Q}}$ & $\mathrm{V}_{\text {obj }}$ & 2 \\
\hline
\end{tabular}
grammatical restrictions and/or motivations.

Finally, predicational adverbs selected by the verbal predicates may also appear in transitive clauses. Similarly, these adverbials can appear either before the object or after it. However, position 2, the adverbial position before the object, seems to be preferred for these adverbials (see Table 55).

Table 55. The order of $\mathrm{O}$ and other adverbial 
Based on the corpus data, the typical order in which interrogative objects and adverbial complements appear is illustrated in (309).
(309) ńe
yaćeki wesako-xona
yamge-m?
poer-ca?
woman
child old.man-LOC
what-ACC
do-INT.VX.3SG
'What did the girl do with the old man?' (Nenyang 2007: 36)
$\mathrm{S}$
$\mathrm{X}$
$\mathrm{O}_{\mathrm{Q}}$
$\mathrm{V}$

In (309) above, the adverbial precedes the object constituent and the $\mathrm{XO}_{\mathrm{Q}}$ is realised. This order is, however, not fixed, as object interrogatives can also be followed by adverbial complements without any grammatical motivation (see 310 ).
(310)yamge jimbitad-m? garka yuxuko-n? śeri-bt'e-ygu-da?? what.qual shirt-ACC big doll-DAT take.on-TR-FUT-VX.2PL
'Which shirt will you put on the big doll?' (Okotetto 1998: 68)
$\mathrm{O}_{\mathrm{Q}} \mathrm{X} \quad \mathrm{V}$

Similarly, if the adverbial is substituted by an interrogative phrase both orders can freely surface regardless of the topicality of the object (see 311-312).
(311) laxanako yamge-n śidda? toxola-mbi?
story what-DAT 2PL.ACC teach-CONT.VX.3SG

'What did the story teach you about?' (Samoylova \& Barmich 2008: 32)

$\begin{array}{llll}\mathrm{S} & \mathrm{X}_{\mathrm{Q}} & \mathrm{O} & \mathrm{V}\end{array}$

(312) t’uku laxanako śidna? xurka śer-k? toxola-mbì?

this story 1PL.ACC what.kind thing-PL.DAT teach-CONT.VX.3SG

'What did the story teach us about?' (Tereshchenko \& Susoy 1995: 54)
$\mathrm{S}$
$\mathrm{O}$
$\mathrm{X}_{\mathrm{Q}}$
$\mathrm{V}$

To summarize the main points of this section, transitive clauses show great variation concerning their constituent order. Despite this, a syntactic pattern may emerge on the basis of the examples. The complex interrogative objects, for instance typically occupies the clause intial position in the following cases: 


$\begin{array}{cllll}\text { (313) a. } \mathrm{S} & \mathrm{O}_{\mathrm{Q}} & \mathrm{V} & & \text { standard order } \\ \text { b. } \mathrm{O}_{\mathrm{Q}} & \mathrm{S} & \mathrm{V} & \mathrm{IF} & \mathrm{O}_{\mathrm{Q}} \text { is complex } \\ & & & \mathrm{OR} & \mathrm{S} \text { is focused } \\ & & & \mathrm{OR} & \text { Russian influence } \\ \text { (314) a. Time } & \mathrm{O}_{\mathrm{Q}} & \mathrm{V} & & \text { standard order } \\ \text { b. } \mathrm{O}_{\mathrm{Q}} & \text { Time } & \mathrm{V} & \mathrm{IF} & \mathrm{O}_{\mathrm{Q}} \text { is complex }\end{array}$

Furthermore, a clear tendency is shown by the agreeing, topical object, which typically occupies the clause initial position. (315)-(318) illustrate those structures in which the topicality of the object seems to play a role in their structure.

\begin{tabular}{|c|c|}
\hline$(315)$ a. $S_{Q}$ & $\mathrm{O}$ \\
\hline b. $\mathrm{O}_{[+\mathrm{agr}]}$ & $\mathrm{S}_{\mathrm{Q}}$ \\
\hline (316) a. Time $_{Q}$ & $\mathrm{O}$ \\
\hline b. $\mathrm{O}_{[+\mathrm{agr}]}$ & Time $_{Q}$ \\
\hline (317) a. Manner & $\mathrm{O}$ \\
\hline b. $\mathrm{O}_{[+\mathrm{agr}]}$ & Manner $_{\mathrm{Q}}$ \\
\hline$(318)$ a. Reason $_{\mathrm{Q}}$ & $\mathrm{O}$ \\
\hline b. $\mathrm{O}_{[+\mathrm{agr}]}$ & Reason $_{\mathrm{Q}}$ \\
\hline
\end{tabular}

In consequence, topical objects, for instance, typically appear before the subject, as well as, tend to precede clausal adverbials. Finally, there are cases in which neither order appears to be preffered. Therefore, the orders in (319)-(320) are considered here as optional ones.
(319) a. $\mathrm{L}_{\mathrm{Q}} \quad \mathrm{O} \quad \mathrm{V}$
b. $\mathrm{O} \quad \mathrm{L}_{\mathrm{Q}} \quad \mathrm{V}$ optional orders
(320) a. $\mathrm{X}_{\mathrm{Q}} \mathrm{O} \quad \mathrm{V}$
b. $\mathrm{O} \quad \mathrm{X}_{\mathrm{Q}} \quad \mathrm{V}$ optional orders

The third and final type of Tundra Nenets content questions discussed here are those that contain predicates expressed by elements different from verbs: I will now turn to nonverbal clause-types expressed by content questions. 


\subsection{Content questions with nonverbal predicates}

There are several approaches making distinctions between different types of nonverbal predicates (e.g. Freeze 1992; 2001; Payne 1997; Dryer 2007; Stassen 2013a; 2013b; 2013c; 2013d; a.o.). Although each of these approaches present a somewhat different system of nonverbal clause types, they also have a lot in common. According to the studies mentioned above, a cross-linguistic distinction can be made among the three types of nonverbal predicates expressed by nouns, adjectives, or adverbial constructions. Examples in (321-323) illustrate these predicates in English:

(321) My dog is a/the cocker spaniel. (predicate noun) (Dryer 2007: 233)

(322) My dog is sick. (predicate adjective)

(323) A/The dog is in the garden. (predicate adverbial construction) (Dryer 2007b: 242)

On the basis of the literature (e.g. Kupriyanova et al. 1957; Almazova 1961; Hajdú 1968; Wagner-Nagy \& Viola 2009; Nikolaeva 2014; Mus 2015), Tundra Nenets (Northern Samoyedic, Uralic) also employs these predicates (see 324-326).

(324) xasawa-dm?.

(predicate noun)

man-VX.1SG

'I am a/the husband.' (Vanuyto 2012: 10)

(325) mań yarka-dm?.

(predicate adjective)

1sg big-VX.1SG

'I am an/the adult.' (Orlova et al. 1996: 74)

$\begin{array}{clll}\text { (326) texnikuma-wa? } & \text { Dudinka-xana } & \text { ya. } & \text { (predicate adverbial } \\ \text { technical.school-PX.1PL } & \text { Dudinka-LOC } & \text { be.VX.3SG } & \text { construction) } \\ \text { 'Our technical school is in Dudinka.' (Nenyang 2005: 62) } & \end{array}$

Cross-linguistically, a number of subtypes of these major three constructions can be distinguished. I will use here two classifications originating from Dryer (2007b) and Payne (1997). Although, they present a somewhat different system of nonverbal clause types, also 
have a lot in common. A table illustrating the categories and similarities between the two systems is presented under (56).

Table 56. The types of nonverbal predicates/clauses cross-linguistically

\begin{tabular}{ll}
\hline Dryer's (2007b) classification & Payne's (1997) classification \\
\hline Nominal predicates & \\
$\begin{array}{l}\text { Equational clauses } \\
\text { True nominal predicate clauses }\end{array}$ & $\begin{array}{l}\text { Equation } \\
\text { Proper inclusion }\end{array}$ \\
\hline Adjectival predicates & Attributive clauses \\
\hline Locative predicates & Locational clauses \\
\hline Existential clauses & Existential constructions \\
\hline Predicate possession & Possessive clauses \\
\hline Minor types & \\
Genitive predicates & \\
Benefactive predicates & \\
Purpose predicates & \\
Simulative predicates & \\
Predicates denoting origin & \\
Referential expressions & \\
Comitative (or associative) predicates & \\
\hline
\end{tabular}

As Table 56 shows, there are two types of nominal predicates, since a predicate noun phrase can either identify or characterize a subject noun phrase. These clauses contain two noun phrases which are usually linked together by e.g. a copular verb. However, the copula is often not necessary in the clause, or its use is determined by certain grammatical parameters (e.g. the person/number of the subject etc.). A typical example of the predicate noun construction in English is provided under (321) above reiterated here for convenience in (327a-b).
(327) a. My dog is the cocker spaniel.
(equative clause)
b. My dog is a cocker spaniel.
(inclusive clause)

(Dryer 2007b: 233)

In both clauses in (327), the subject noun phrase (my dog) is specific and referential. Therefore, it is only the referentiality of the predicate noun phrase that differentiates the two constructions. The predicate noun phrase in (327a) with a definite article (i.e. the cocker spaniel) results in the identification of the subject noun phrase (i.e. my dog). As in these clauses both phrases are specific and referential, sometimes it is difficult to differentiate them (cf. Payne 1997: 144). Therefore, the subject noun phrase and the predicate noun phrase can 
often be reversed in these types of nonverbal clauses (cf. Dryer 2007b: 223). In contrast, the predicate noun phrase with an indefinite article (i.e. a cocker spaniel; see 327b) more likely denotes a given property of the subject. Therefore, it can be interpreted as being closer to adjectival predicates (cf. Dryer 2007: 233). Dryer (2007) calls the two predicate noun constructions equational and true nominal predicate clauses respectively (cf. Dryer 2007: 234). While Payne (1997) refers to them as equation and proper inclusion in his classification (cf. Payne 1997: 114). The most typical cross-linguistic differences between the two predicate noun phrase types are illustrated in Table 3 (cf. Payne 1997:114; Dryer 2007: 233).

Table 57. The cross-linguistic differences between equative and inclusive constructions

\begin{tabular}{ll}
\hline \multicolumn{1}{c}{ Equation/true equational clauses } & \multicolumn{1}{c}{ Inclusion/true nominal predicates } \\
\hline the predicate is referential & $\begin{array}{l}\text { the predicate is nonreferential } \\
\text { a property of the subject is denoted by the } \\
\text { the subject is identified with the predicate }\end{array}$ \\
the subject and the predicate can be reversed \\
the subject and the predicate cannot be \\
reversed
\end{tabular}

Furthermore, languages in which there is a distinct word class of adjectives differentiate the so-called adjectival/attributive clauses. These clauses have an adjective with predicative function expressing a property of the subject noun phrase as in (328). Languages may differ as to whether they contain a copular verb or not.

(328) My dog is sick. ～(adjectival predicate)

Another common type of nonverbal clauses cross-linguistically conveyed by nonverbal predicates usually contains a locative expression in addition to the subject/theme element. These predicates may express existential and/or locative clauses see (329-330) respectively.

(329) There is a dog in the garden. (existential clause)

(330) a. The dog is in the garden. (locative clauses)

b. A dog is in the garden.

(Dryer 2007b: 242)

As Freeze (1992: 557) notes, although locative and existential clauses contain the same constituents, the theme and the locational elements, they usually present them in different orders with different grammatical characters. While, for instance, in English existential 
clauses illustrated in (329) above the theme element is indefinite, in locative clauses it can be either definite or indefinite (cf. Dryer 2007b: 242, see 330a-b). Additionally, different constituents of the clause function as the predicate. While locational clauses employ the theme element as subject and the locative constituent is the (part of the) predicate, in existential clauses (without a locative proform) the locational expression is in subject position (cf. Freeze 1992: 556). In existential clauses, the theme element is the (part of the) predicate. As the predicate function is fulfilled by different elements in these two clause types, the clauses may also show differences in the order of their constituents. As was already discussed in $§ 7.1 .1$, there is a correlation between the basic word order of a language and the order of the clausal elements in existential/locative clauses (cf. Freeze 1992: 556-557). This correlation regarding the existential construction was introduced in Table (45), repeated here and completed with the correlation regarding the predicate locative clauses as Table (58) below.

Table 58. The correlation between basic word order and order of predicativee locatives and existential clauses

\begin{tabular}{ccccccc}
\hline Basic word order & \multicolumn{3}{c}{ Predicate locative } & \multicolumn{3}{c}{ Existential clause } \\
\hline SVO & T & cop & L & L & cop & T \\
VOS & cop & L & T & cop & T & L \\
VSO & cop & L & T & cop & T & L \\
SOV & T & L & cop & L & T & cop \\
\hline
\end{tabular}

In verb-final languages, like Tundra Nenets, locative clauses employ the theme-locative order as in (331), while the locative-theme order is realized in existential constructions as in (332). There is also a further difference between existential and locative cluases in Tundra Nenets with respect to the verbal part of the predicate construction. While locational clauses use the same copular verb (yaś) that appears in nominal and adjectival clauses, the existential clauses have an existential verb (tańaś) functioning as their verbal predicate.

$\begin{array}{lrr}\text { (331) texnikuma-wa? } & \text { Dud'inka-xana } & \text { ya. } \\ \text { technical.school-PX.1PL } & \text { Dudinka-LOC } & \text { be.VX.3SG } \\ \text { 'Our technical school is in Dudinka.' (Nenyang 2005: 62) } & \\ \text { T } & \text { L V }\end{array}$




(332) t'uku to-xona pajxa
this lake-LOC peled
exist.VX.3SG
'There is peled in this lake.' (Vanuyto 2012: 34)
$\mathrm{L}$

In his categorization, Dryer (2007b) devides existential clauses into subcategories like negative, numeral and quantifier expressions. These subtypes of the existential construction can also show structural differences as compared to simple existential clauses (cf. Dryer 2007b: 246-247). As this section deals with interrogative nonverbal clauses, I will not discuss these subtypes in detail.

There is also a nonverbal clause type that may be expressed by existential constructions in languages. This predicate type is the so-called predicative possession expressing a possessive relation between two elements. In many languages, e.g. in English, this meaning is expressed by a transitive verb with the meaning 'have' as in (333).

(333) I have a dog. （predicative possession)

However, there are also languages that employ the existential construction to express possession and it is the one used in Tundra Nenets (see 334 and compare with 332 above).

(334) mań ńeka-mi, śid'a ńe ńa-ḿi tańa. (predicative
1SG brother-PX.1SG two woman sister-PX.1SG exist.VX.3SG possession)
'I have one brother and two sisters.' (Vanuyto 2012: 13)

As was discussed in $§ 7.1 .1$ and in $§ 7.1 .2$, these clauses have an (existential) intransitive verb functioning as their predicate. Therefore, these constructions will not be discussed here. Unlike existential clauses and predicative possessive structures, locational predicates in Tundra Nenets can be regarded as being nonverbal predicates. Similarly to existential clauses discussed in $\$ 7.1 .1$, these constructions may also contain a so-called theme and a locative element. I will discuss these constructions in $§ 7.3 .5$.

Finally, Dryer (2007b) provides minor types of nonverbal predicate constructions that are not typically common in languages. However, if a language distinguishes one/all of these minor types, they are commonly expressed by nonverbal constructions. These types are, for 
instance, genitive predicates in (335) (cf. Dryer 2007b: 247-249). These subtypes are completely missing from the categorization of Payne (1997).

(335) The dog is mine. $\quad$ (Genitive predicate)

Stassen (2001: 954) considers this type of nonverbal clause as a subtype of predicative possession, in which - contrary to the regular predicative possession - the possessed item has a definite reading.

As already mentioned above, Tundra Nenets also employs constructions in which the predicate is a nonverbal element. These clauses can be expressed by or contain an interrogative phrase. A Table illustrating the attested nonverbal question types is provided below under (59).

Table 59. Types of nonverbal questions in Tundra Nenets

\begin{tabular}{cc}
\hline Nominal predicates & 214 \\
Equative constructions & \\
Inclusive constructions & \\
\hline Predicative possession (with definite possessed item) & 58 \\
Adjectival predicates & 75 \\
Quantifier predicates & 21 \\
Locative predicates & 92 \\
Temporary possession & 13 \\
Temporal predicates & 10 \\
Manner predicates & 24 \\
\hline Total & $\mathbf{5 0 7}$ \\
\hline
\end{tabular}

In the following sections, I will focus on those nonverbal predicate constructions that are expressed by interrogative pro-forms in Tundra Nenets. In this chapter, the internal structure of the predicates and the attested word orders in the content questions will mainly be focused on.

7.3.1. Content questions with nominal predicates: equative and inclusive constructions

In Tundra Nenets, there is no grammatical difference between equative and inclusive constructions. Nominal clauses can have either interpretation so the definiteness of the predicate noun phrase can only be presumed from the context (see 336-337). 


(336) tiki Pira? to.
that Pirya lake.vX.3SG
'That is the lake Pirya.' (Khanzerova et al. 2012: 84)
$\begin{aligned} & \text { (337) tuku ne naćeki. } \\ & \text { this woman child.VX.3SG } \\ & \text { 'This is a/the girl.' (Okotetto 1998: 11) }\end{aligned}$

In example (336) the predicate noun phrase (Pira? to 'lake Pirya'), being a proper name, is referential and specific in the sense that it is inherently unique and referential. Consequently, one can suppose that the clause is equational. We can contrast it with example (337) in which the subject, tuku 'this' is not necessarily identified with only one referent expressed by the predicate (ńe yaćeki 'girl'). This construction can be understood either as an equative construction, 'This is the girl', or as an inclusive one, 'This is a girl'. As is illustrated in these examples, there is no grammatical difference between these two clause types.

In Tundra Nenets, certain interrogative words can fulfil the function of the predicate in equative/inclusive constructions. In the corpus, the interrogative proforms appear only as predicates in equative/inclusive constructions but not as subjects. Table 60 illustrates those constructions that appeared in the texts as the predicates of equative/inclusive constructions.

Table 60. The equative/inclusive content interrogative constructions in Tundra Nenets

\begin{tabular}{ccc}
\hline Predicate NP & № \\
\hline Pronoun $_{\mathrm{Q}}$ & & 163 \\
Determiner $_{\mathrm{Q}}$ & & 2 \\
\hline Adjective $_{\mathrm{Q}}$ & $\mathrm{N}$ & 33 \\
Quantifier $_{\mathrm{Q}}$ & $\mathrm{N}$ & 16 \\
\hline
\end{tabular}

As illustrated in Table 60, the interrogative pronouns and deteminers can function as predicates on their own. However, there are only two representative examples of determiners functioning as predicates in the texts, I suppose that they do not differ in their grammatical features from interrogative pronouns. As was already discussed previously in Chapter 6 , if the interrogative pronouns/determiners function as predicates, they take the agreement markers in every person and number. The use of a copular verb is not allowed in present tense (see 338340). 
(338) pidar xib̀-n?

2SG who-VX.2SG

'Who are you?' (Labanauskas 1995: 150)

(339)pidar ńum-l yamge?

2SG name-PX.2SG what.VX.3SG

'What is your name?' (Okotetto 1998: 143)

$\begin{array}{ccc}\text { (340) } m e-s ́ & \text { jo-na? } & \text { xańayi-P? } \\ \text { take-CVB } & \text { corner-PX.PL.1PL } & \text { which-VX.3PL } \\ \text { 'Which are our places?' (Vanuyto 2012: 52) }\end{array}$

In addition to interrogative pronouns and determiners, other interrogatives can also function as predicates in equative/inclusive clauses (as illustrated in Table 60 above). In these interrogative phrases, the head noun functioning as the predicate is modified by an interrogative proform. On the basis of the data, the head noun takes agreement marker (see 341-344). The example in (344) was also already used in Chapter 5 under (117a).

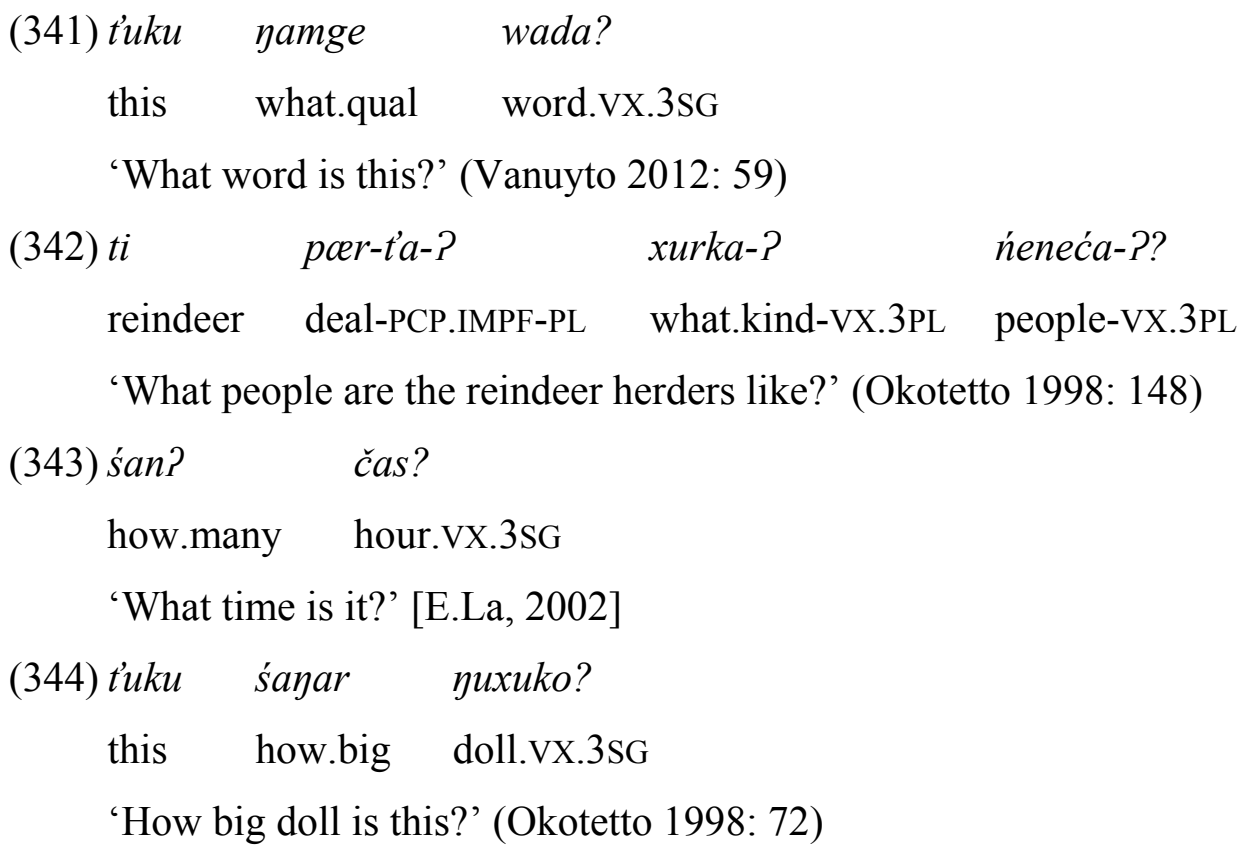

On the basis of example (342) above, it seems that there is an internal agreement between the noun head and its interrogative modifier in person and number when they function together as the predicate of the clause. However, the data are not sufficient to prove this agreement, which can also be a specific dialectal phenomenon. 
Additionally, Nikolaeva (2014: 257) presents a different interrogative predicate structure, in which the interrogative phrases take the past tense marker (-ś $\sim$-ź), and any overt copula verb does not appear in the clause (see 345).

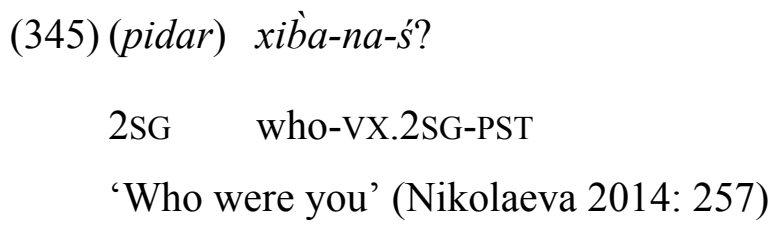

The construction illustrated in (345) is, however, not found in my corpus. Instead, the following structure appears (see 346 and compare with 345):

$$
\begin{array}{ll}
\text { (346) } x i \grave{b a}-n & \text { yce-sa-n? } \\
\text { who-VX.2SG } \quad \text { be-INT-VX.2SG } \\
\text { 'Who were you?' (Pushkareva \& Khomich 2001: 194) }
\end{array}
$$

As examples in (345-346) above illustrate, the subject NP can be omitted from the clause. As can be seen, the so-called interrogative marker $\left(-s^{\prime} a \sim-s a\right)$ refers to past tense instead of the tense marker in the nonverbal interrogative predicate. As already discussed in Chapter 4, this interrogative affix is usually used to mark each type of questions in past tense in Tundra Nenets. So the past tense marker in non-interrogatives and the interrogative marker in questions are in complementary distribution. As Nikolaeva (2014: 97) notes, the interrogative phrase controls the interrogative agreement in past tense through this affix. Consequently, the predicates of the content questions with past tense reference must take interrogative marker instead of past tense marker. The above construction in (345) cannot therefore be expected. According to the literature (cf. Hajdú 1968: 65; Tereshchenko 1973: 92; Salminen 1998: 530; Nikolaeva 2014: 97-98; a.o.), the interrogative suffix is a modal marker, which cannot appear in the predicate interrogative phrase. Therefore, there is a copula (yaś) surfacing in the interrogative predicate construction which takes the mood marker. So the additional difference is that, the copula - which is formally the same that is used in non-interrogative clauses - appear in content questions with past tense reference. In these cases, the agreement suffix appears both on the interrogative word and on the copula. The copula is the same as the one used in the corresponding non-interrogative structures. Further examples are provided under (347) and (348) below: 


$$
\begin{aligned}
& \text { (347) ńeb'a-ke?, jerkara-m'i yamge yo-sa? } \\
& \text { mother-DIM fraternity-PX.1SG what.VX.3SG be-INT.VX.3SG } \\
& \text { 'Mother, what was my fraternity?' (Labanauskas 1995: 63) } \\
& \text { (348) yać-pareyoda xurka néneć yo-sa? } \\
& \text { youth-king what.kind people.vX.3SG be-INT.VX.3SG } \\
& \text { 'What man was the young king like?' (Samoylova \& Barmich 2010: 26) }
\end{aligned}
$$

As illustrated, the person/number suffixes remain on the predicate interrogative pronoun as well. So we can conclude that interrogative phrases can only bear agreement markers. That is, the omission of a copula is allowed solely in present tense. Like by predicate nouns, other verbal suffixes (such as aspect, mood, etc.) appear only on the copula, while the person/number suffixes are present on the predicative interrogative phrase as well (see 349 $350)$.

$$
\begin{aligned}
& \text { (349)pidar xib̀-n yoe-dake-n? } \\
& \text { 2SG who-VX.2SG be-PROB-VX.2SG } \\
& \text { 'Whou could you be?' (Lar \& Pushkareva 2001: 102) } \\
& \text { (350) ńum-t’a yamge yo-bta? } \\
& \text { name-PX.3SG what.3SG be-GER.PX.3SG } \\
& \text { 'What could be his name?' (Pushkareva \& Khomich 2001: 156) }
\end{aligned}
$$

To sum up, in Tundra Nenets, interrogative pronouns/determiners can function as the predicate without an overt copula as they take the so-called subjectival verbal suffixes.

Now let us turn to the order of the elements in content questions. The main question is whether there is a dedicated position for predicate interrogative phrases. In these clauses, the subject-predicate interrogative phrase order is expected. Apart from three exceptions (two of them given in $351-352^{34}$ ) the predicate interrogative phrases occupy sentence final position.

$$
\begin{aligned}
& \text { (351)xib̀a-dì? pidari?? } \\
& \text { who-VX.2DU 2DU } \\
& \text { 'Who are you (DU)?' (Labanauskas 1995: 188) }
\end{aligned}
$$

\footnotetext{
${ }^{34}$ Since two of the three constructions are identical, I will present here those clauses that show structural differences.
} 
(352) xib̀a meńe-na pad-na-na-ra??

who.VX.3SG love-PCP.IMPF write-CONT-PCP.IMPF-PX.2PL

'Who is your favourite writer?' (Nenyang 2005: 69)

In these exceptions, the subjects, that are preceded by the predicates, can be analysed as constituents that are dislocated outside the clause occuring with a clarifying afterthoughts.

Finally, let us see whether content questions make a difference between equative and inclusive constructions. Semantically, the interrogative pronouns (although they do not lose their [ \pm human] feature) express both equative and inclusive constructions and only the context determine their interpretations.

In (353) below, the subject entity (Waśa 'Vasya') is either identified or one of its properties denoted by the human interrogative pronoun (xiba 'who'):

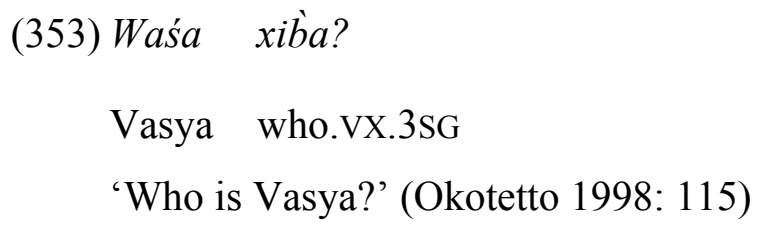

Similarly, the interrogative pronoun with non-human referent (yamge) either identifies its referent with a definite entity or denotes one of its features. This semantic operation can only be known from the context. Consequently, the question in (354a) can either be understood as requesting for identification of the subject with the predicate or as asking about a property of the subject.

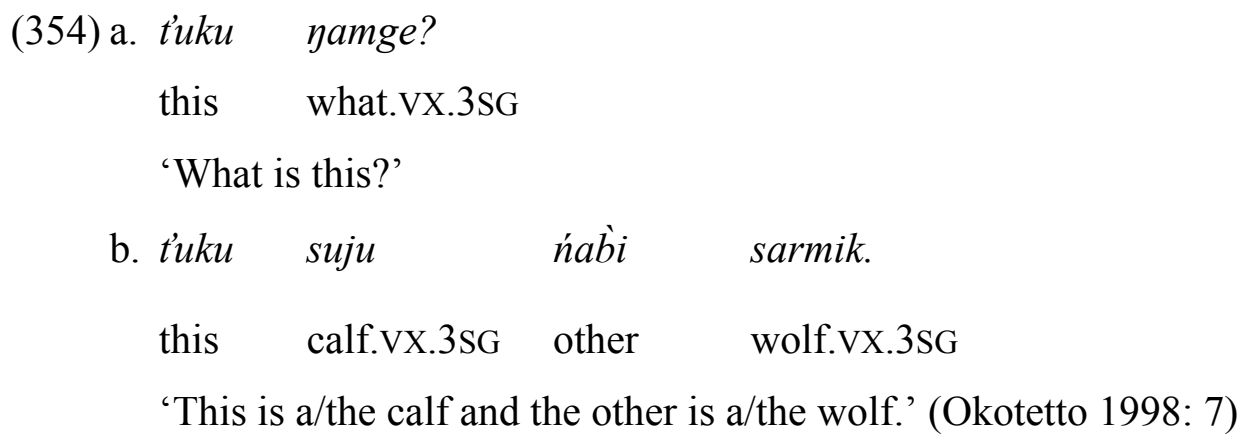

It is only the interrogative determiner substituting an already known element that has a referent in the discourse, therefore, the construction can rather be interpreted as an equative 
construction than an inclusive one (see 355). As this interrogative word is quite rarely used, I will reiterate here an example already used in Chapter 6 under (174).

\author{
(355) Nad'a, papa-ko-r xańayi? \\ Nadya brother-DIM-PX.2SG which.VX.3SG \\ 'Nadya, which is your younger brother?' (Okotetto 1998: 116)
}

7.3.2. Predicative possession with definite possessed item expressed by content questions

There is a predicative possession construction in Tundra Nenets that is similar to the equative/inclusive constructions in a sense: it contains two noun phrases that are identified in the clause. In this construction not only are the two noun phrases identified, but also the possessive relation between them. This type of nonverbal predicate is called a genitive predicate by Dryer (2007b: 248), and it was illustrated in (335) above repeated here under (356).

(356) The dog is mine. $\quad$ (genitive predicate)

In contrast, Stassen (2001: 954) analyses this construction as predicative possession in which the possessed item is definite. The Tundra Nenets content question expressing genitive possession contains two noun phrases, the subject and the predicate. The predicate noun phrase indicates the possession itself. It is definite and (usually) contains the possessor (henceforth PR) and the possessed item (hereinafter PD). According to Stassen (2001: 954), the relation between the PR and the PD is [+Time Stable] and [ \pm Control] (either inalienable or alienable). The definite possessive phrase functioning as the predicate identifies the subject noun phrase. Similarly to the equative constructions, interrogative proforms appear only in the predicate function in the corpus. The attested cluase types in which both the PR and the PD can be substituted by an interrogative expression are illustrated in Table 61 below.

Table 61. Interrogative predicative possession with definite possessed item in Tundra Nenets

\begin{tabular}{cccc}
\hline Subject & \multicolumn{2}{c}{ Predicate } & oo \\
\hline $\mathrm{NP}$ & $\mathrm{PR}_{\mathrm{Q}}$ & $\mathrm{PD}$ & 47 \\
$\mathrm{NP}$ & $\mathrm{PR}$ & $\mathrm{PD}_{\mathrm{Q}}$ & 11 \\
\hline
\end{tabular}


The two structures show certain grammatical differences. If the $\mathrm{PR}$ is asked by an interrogative phrase, the PD takes agreement markers but not possessive suffixes (thus the possessive relation is only marked on the dependent) and the PR expressed by an interrogative phrase stands in genitive as in example (357). The genitive modifier cannot be the predicate alone in Tundra Nenets.

$$
\begin{aligned}
& \text { (357)pidar xib̀a-? ńeb̀a-n? } \\
& \text { 2SG who-GEN mother-VX.2SG } \\
& \text { 'Whose mother are you?' (Okotetto 1998: 118) }
\end{aligned}
$$

As was the case with inclusive/equative constructions, the use of an overt copula is obligatory here if there is any other verbal category to be expressed (see 358).

$$
\begin{aligned}
& \text { (358) tuku-? xib̆a-? yoća yce-daki-P? } \\
& \text { this-PL who-GEN child be-PROB-VX.3PL } \\
& \text { 'Whose child could be (s)he (lit. it)?' (Yangasova 2001: 51) }
\end{aligned}
$$

In example (358), the predicative noun (yoća 'child') does not take agreement marker, although it could be expected on the basis of the data available (see e.g. the predicative noun in 357). The agreement between the subject and the predicative noun is thus marked only on the copular verb. It is assumed in examining the available constructions that the agreement marker appears both in the predicate phrase and in the copular verb.

In the other attested construction, the PD is substituted by an interrogative phrase that does not take a verbal agreement marker but a possessive suffix appears on it, and there is no agreement marker in the construction (see 359).

$$
\begin{aligned}
& \text { (359) t'uku yamge-da? } \\
& \text { this what-PX.3SG } \\
& \text { 'What of his is this?' (Okotetto 1998: 105) }
\end{aligned}
$$

This construction is similar to the predicate possession discussed in $\S 7.1 .1$, but here two noun phrases are involved in the construction. As the possessive relation is marked on the predicative noun via possessive suffixes (yamgeda 'what of his'), an agreement marker 
cannot be attached to it. The agreement, therefore, is not marked overtly in present tense, indicative mood in these structures. Similarly to the nominal predicates, however, the copula appears in the clause taking tense, aspect, modal markers, as in (360).

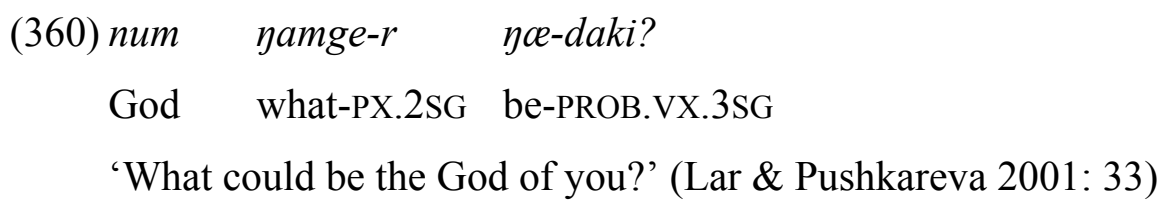

In this case, the copular verb takes agreement marker and possessive suffix appears in the predicative noun.

\subsubsection{Content questions with adjectival predicates}

Semantically, clauses with adjectival predicates can typically be described as attributive clauses (cf. Payne 1997: 112). In these clauses, the adjectival predicate denotes a given property of the subject noun phrase. These constructions are close to the previously introduced inclusive clauses. The main distinction is that in adjectival clauses the predicate is an adjective. The attested attributive questions are shown in Table 62.

Table 62. Attributive content interrogative constructions in Tundra Nenets

\begin{tabular}{ccc}
\hline Subject & Predicate & № \\
\hline $\mathrm{NP}$ & $\mathrm{Adj}_{\mathrm{Q}}$ & 58 \\
$\mathrm{NP}_{\mathrm{Q}}$ & $\mathrm{Adj}$ & 17 \\
\hline
\end{tabular}

As illustrated in Table 62, both the subject noun phrase and the predicative noun can be substituted by interrogative phrases in adjectival predicate constructions. If an interrogative adjective functions as the predicate of the clause, the agreement between the subject and the predicate adjective takes place through agreement suffixes attached to the predicate adjective (without any verbalizer). Consequently, there is no overt copula in the clause in present tense (see 361).

$\begin{array}{cccc}\text { (361) tuku } & \text { jal'a-? } & \text { num? } & \text { xurka? } \\ \text { this } & \text { day-GEN } & \text { weather } & \text { what.kind.VX.3SG }\end{array}$

'What is the weather like today?' (Nenyang 2005: 129) 
The omission of a copula is allowed solely for the types of constructions illustrated in (361). If any additional verbal category (aspect, mood, etc.) needs to be expressed, a copula appears in the construction taking the agreement marker and the additional verbal markers. The predicate adjective also bears the agreement marker. The copula appearing with adjectival predicate is the same as the one used in equative/inclusive constructions (see 362).

$$
\begin{array}{clll}
\text { (362) ńe-koća-? } & \text { ńu-da } & \text { xurka-? } & \text { yce-sa-?? } \\
\text { woman-DIM-GEN } & \text { child-PX.PL.3SG } & \text { what.kind-VX.3PL } & \text { be-INT-VX.3PL }
\end{array}
$$

'What were the children of the woman like?' (Nenyang 2007: 38)

As example (362) above illustrates, past tense is not expressed by the past tense marker, but the interrogative modal marker referring to past is attached to the copula. The adjectival interrogative predicate takes solely the agreement marker, which is also present on the copular verb.

If the interrogative construction functions as the subject in the clause, then it controls agreement on the predicative adjective, similarly to intransitive and transitive clauses. This construction does not need any verbal element either (see 363).

$$
\begin{aligned}
& \text { (363) xiba-ra? } \quad \text { yarka? } \\
& \text { who-PX.2PL big.vX.3SG } \\
& \text { 'Who of you is big?' (Orlova et al. 1996: 74) }
\end{aligned}
$$

In attributive interrogatives, the adjectival predicate is preceded by the subject and the construction is predicate final.

\subsubsection{Content questions with quantifier predicates}

In Tundra Nenets, interrogative quantifiers can also function as the predicate of a clause in constructions asking about the amount of the subject. In the corpus, there were 21 clauses in which the interrogative quantifier appeared as the predicate. The quantifier predicate construction is similar to attributive clauses in the sense that the interrogative quantifier functions as the predicate on its own, bearing agreement markers in present tense, indicative $\operatorname{mood}($ see 364). 


$\begin{array}{ccc}\text { (364) tir-ma-wa? } & \text { xun-ta } & \text { śan? } \\ \text { fly-AN-PX.1PL } & \text { length-PX.3SG } & \text { how.many.VX.3SG } \\ \text { 'How long does our flight take?' (Vanuyto 2012: 51) }\end{array}$

In non-present tenses and/or with other verbal categories, however, the use of a copula is necessary. The copula is the same form as the one used in the types examplified above (see $365)$.

\begin{tabular}{|c|c|c|}
\hline (365) mir-ta & śan & yж-ทgu? \\
\hline price-PX.3sG & how.many.vX.3SG & be-FUT.VX.3SG \\
\hline
\end{tabular}

\subsubsection{Locative predicates expressed by content questions}

Unlike existential clauses expressed by intransitive predicate constructions, locative ones can structurally be regarded as being nonverbal predicates in Tundra Nenets. In the locative predicate, there is a nonverbal locational element functioning as the predicate. These constructions are used to provide the spatial location of a given entity. As was already discussed, they contain the same elements (theme and locational ones) that the existentials do. However, they show some grammatical differences with respect to existential constructions cross-linguistically. In Tundra Nenets, there are some special characteristics of locative clauses discussed in the following points:

(i) Locative clauses employ a copula used with nominal/adjectival predicates as well, so they do not involve the existential verb like existential clauses do.

(ii) There is another copular verb exclusively used with human theme elements (meś) which means that Tundra Nenets employs two different copulas for expressing locational predicates. One is used with inanimate theme elements (yaś) and the other is with animate (human and animal) entities.

(iii) The encoding strategy of the locational predicate construction differs from that of nominal/adjectival constructions in the sense that the locative part of the predicate does not take agreement suffixes and it usually does not appear without a copula: agreement and any other verbal suffixes are attached to the copula. 
(iv) Agreement takes place between the copula and the theme element, that is, the grammatical subject of the clause.

(v) Locational clauses have a reversed order of the clausal elements as compared to existential clauses. In locational predicates, the theme-locational-copula order is the most frequent order. This order corresponds to the correlation observed by Freeze (1992: 556).

In locational clauses, both the theme and the locative element can be substituted by an interrogative phrase. The attested constructions and orders are represented in Table 63.

Table 63. Locative predicates in Tundra Nenets content questions

\begin{tabular}{|c|c|c|c|}
\hline & Word order & & № \\
\hline & $\mathrm{L}_{\mathrm{Q}}$ & cop & 5 \\
\hline Time & $\mathrm{L}_{\mathrm{Q}}$ & cop & 2 \\
\hline Reason $_{\mathrm{Q}}$ & $\mathrm{L}$ & cop & 3 \\
\hline $\mathrm{T}$ & $\overline{\mathrm{L}_{\mathrm{Q}}}$ & cop & 58 \\
\hline $\mathrm{T}$ & $\mathrm{L}_{\mathrm{Q}}$ & & 11 \\
\hline $\mathrm{T}_{\mathrm{Q}}$ & $\mathrm{L}$ & cop & 4 \\
\hline $\mathrm{L}_{\mathrm{Q}}$ & $\mathrm{T}$ & cop & 5 \\
\hline $\mathrm{L}$ & $\mathrm{T}_{\mathrm{Q}}$ & cop & 4 \\
\hline
\end{tabular}

As illustrated in Table 63, the theme element is not an obligatory part of the question. Therefore, it can also be omitted as in (366).

$$
\begin{aligned}
& \text { (366) xańana } \quad \text { a? } \\
& \begin{array}{l}
\text { where.LOC } \quad \text { be.vX.3SG } \\
\text { 'Where is it?' (Pushkareva \& Khomich 2001: 102) }
\end{array}
\end{aligned}
$$

As was already mentioned, the different theme elements select for a different copular verb. If the theme element is inanimate, like in (366) above, then the copula used in nominal/adjectival predicate construction (yaś) appears. In the case of an animate theme element, however, another copula (meś) surfaces in the structure (see 367).

$$
\begin{aligned}
& \text { (367) xańana me-sa-n? } \\
& \text { where.LOC be-INT-VX.2SG } \\
& \text { 'Where were you?' (Labanauskas 1995: 63) }
\end{aligned}
$$


Both clauses have a covert theme element, but the copulas refer to their person/number and to their animacy.

In addition, adverbial elements, such as temporal or reason adverbials, can also appear in locational predicates. In example (368), the theme element is overt (the agreement suffix refers to its person and number, while the copula type to its animacy), and there is an additional temporal adverbial in the construction.

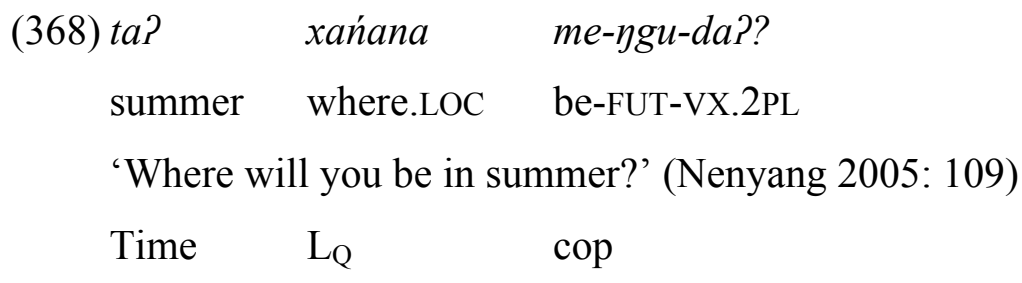

As illustrated in Table 63, the theme element is most typically overt. In the attested 82 constructions with an overt theme element, the expected theme-locational order is realized. The following examples in (369) and (370) represent the canonical word order either with an interrogative theme element, or with an interrogative locational one respectively.

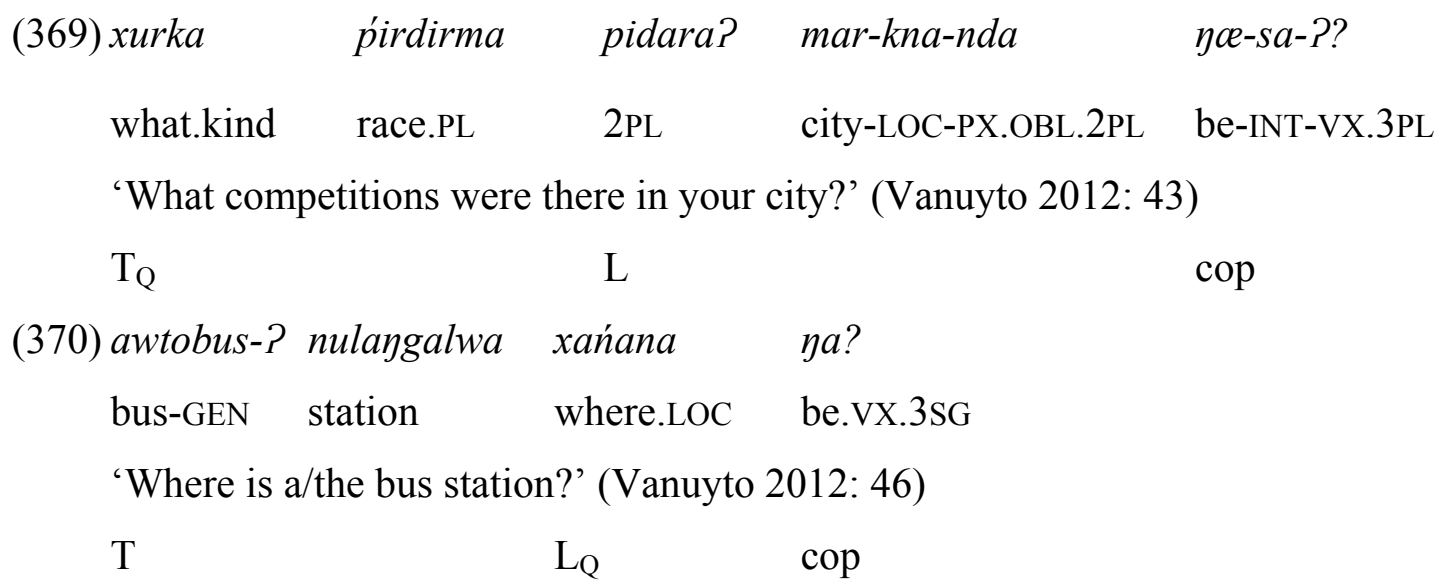

Example (370) illustrates that theme elements in locative clauses can be either definite or indefinite. The interrogative phrase appears adjacent to the copular verb, while the reversed word order results in the clause initial position of the locative interrogative, as in (371). 


$\begin{array}{ccccc}\text { (371)xańana } & \text { śamanxat } & \text { yarka } & \text { stadion } & \text { ya? } \\ \text { where.LOC } & \text { COMP } & \text { big } & \text { stadium } & \text { be.vX.3SG }\end{array}$

'Where is the biggest stadium?' (Nenyang 2005: 78)

$\mathrm{L}_{\mathrm{Q}} \mathrm{T}$ cop

This order appears solely with a definite theme element that is situated closer to the copula. However, there is no clear grammatical reason for the word order change in these constructions.

In the case of an interrogative theme element, the clause initial locative element has a referential reading, as in (372) below.

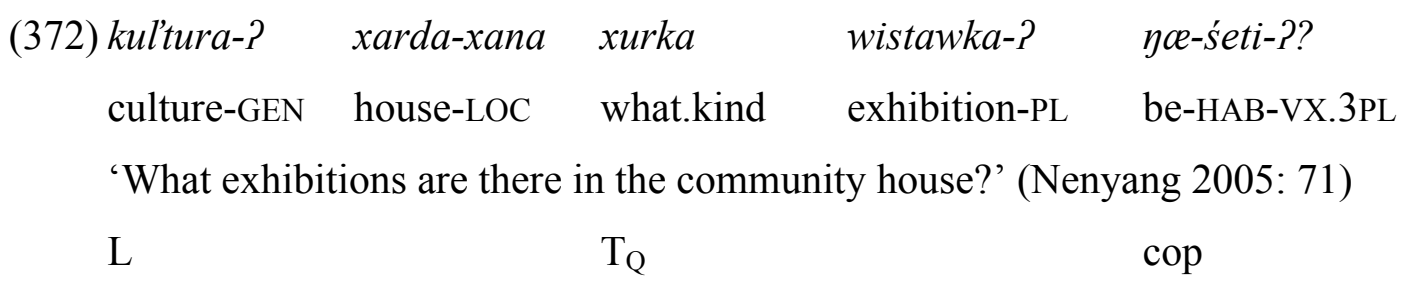

The referentiality of the locational element explains its clause initial position: as it is a known element from the previous discourse, it has a topical role.

Finally, the copula can be omitted in some cases. These constructions appear with an interrogative locational constituent (see 373).

\author{
(373)jaxa xańana? \\ river where.LOC \\ 'Where is the river?' (Okotetto 1998: 82)
}

As the adverbial element cannot take an agreement marker, there is no finite element in this construction. These constructions are relatively rare and only appear in phrasebooks which represent new texts. As they are not typical for Tundra Nenets, they may be regarded as the result of the contact with Russian. In Russian, the copular verb is not overt in locational clauses in present tense, as can be seen in (374). 
(374) Russian

Gde reka?

where river

'Where is the river?'

Therefore, it can be expected that in these examples without a copula the Russian structure is borrowed.

\subsubsection{Temporary possession expressed by content questions}

In Tundra Nenets, there is also a possessive construction that can have a temporary possessive reading. In the corpus, there were 13 clauses altogether that express a [-Time Stable] and $[+\mathrm{Control}]$ relationship between the possessor and the possessed item. In these constructions, the possessor element is not marked by genitive case (contrary to predicational possession), but it is inflected in locative case as in (375) below.

$$
\begin{aligned}
& \text { (375) brigada-xana-nda? śan neneća-la?? } \\
& \text { team-LOC-PX.OBL.2PL how.many people-PX.2PL } \\
& \text { 'How many people do you have in your team?' (Vanuyto 2012: 35) }
\end{aligned}
$$

In addition, the possessed item takes possessive markers. This construction is similar to predicational possession in the sense that it expresses a possessive relation. Unlike in predicate possession, however, there is no overt verbal element taking agreement suffixes in temporary possessive structures. Grammatically, this structure cannot be regarded as a finite structure. Additionally, locational clauses have a very similar structure, as the possessor appears in locative case functioning as a locational adverbial.

\subsubsection{Content questions with temporal predicates}

In Tundra Nenets, there are clauses that have the same grammatical structure as locational predicates do. These clauses have an additional adverbial other than the locational one, functioning as the predicate. One type is the temporal expression that is part of the predicate at least semantically (see 376 ). 


$$
\begin{aligned}
& \text { (376) tiki śaxa? yoe-ygu? } \\
& \text { that when be-FUT.VX.3SG } \\
& \text { 'When will that be?' (Vanuyto 2012: 59) } \\
& \mathrm{T} \quad \text { Time }_{\mathrm{Q}} \text { cop }
\end{aligned}
$$

Similarly to locational clauses, these constructions also contain a theme element (either definite or indefinite) and a temporal expression that appears instead of the locational one. There is also a copular element that is similar to that of locational predicates. This clause type is quite rare, it is attested only 10 times in the corpus and always with future tense reference. The copula is always overt and takes agreement and tense markers. As the copula in future tense is obligatory, it cannot be concluded whether the construction appears without a copula in the present tense or it is always obligatory in the construction.

\subsubsection{Content questions with manner predicates}

Similarly to temporal predicates, clauses can contain a theme element (either definite or indefinite) and a manner expression used together with a copula (see 377).

$$
\begin{array}{lll}
\text { (377) } s c e w-m i & \text { xačer? } & \text { ya? } \\
\text { eye-PX.1SG } & \text { how } \quad \text { be.VX.3SG } \\
\text { 'How is my eye?' (Labanauskas 1995: 184) } \\
\text { T }
\end{array}
$$

Example (377) above clearly illustrates that the construction requires a copula that takes agreement markers. While the manner adverbial determines the predication semantically, gramatically it behaves as an adverbial modifier. In the case of any other verbal suffixes, it is only the copula that can take these markers (see 378).

$\begin{array}{cll}\text { (378) ńu-da } & \text { xanźer? } & \text { yce-sa-P? } \\ \text { child-PX.PL.3SG } & \text { how } & \text { be-INT-VX.3PL } \\ \text { 'How were his/her children?' (Nenyang 2007: 38) } \\ \text { T } \\ \text { Manner }\end{array}$


To summarize the main points of this section, nonverbal clauses can be formed with interrogative phrases. The so-called equative/inclusive, adjectival and quantifier predicates have the same characteristics. As was discussed, these interrogative constructions can take agreement markers without an overt copula. Nevertheless, the copula must be overt in past tense (that is expressed by the interrogative modal marker) and in the presence of additional verbal suffixes. The copular verb used in content questions is the same used in declarative nominal clauses. As was also discussed, the predicate construction occupies the clause final position in most of the cases. There are only a few instances in which the interrogative predicate is followed by the subject noun phrase. A similar predicate construction is available in nonverbal clauses expressing predicative possession in which the possessed item is definite. In these clauses, the predicate usually contains a possessor in the genitive form, which functions as the modifier of the predicate noun. The predicates indicating temporary possession do not contain an agreement marker. Finally, the locative, temporal and manner predicates are expressed with a construction usually containing a copular verb. This copula takes verbal markers, while the adverbial parts of the predicate cannot be inflected at all. The copula used in this constructions is the same as with nominal predicates. 


\section{Conclusions}

This study aimed at giving an analysis of Tundra Nenets content interrogatives. As there is no detailed description of interrogatives in Tundra Nenets, the present analysis has included lexico-semantic and the morphological features, as well as, the syntactic positions of interrogative pro-forms in Tundra Nenets.

In Chapter 2, the general characteristics of Tundra Nenets have been introduced: its genetic affiliation, the traditional areas of habitation, dialectal divisions and differences, the current demographic situation, literacy and wiritng system of Tundra Nenets. Afterwards a brief typological description has been provided which demonstrated that head-final syntagmatic relations are typically available in Tundra Nenets. Consequently, clauses are verb-final constructions in which auxiliaries follow the main verbs, postpositions are used instead of prepositions, possessors precede possessed items, and adjectival modifiers precede the modified nouns. In Chapter 3, the primary data and the corpus have been presented. The corpus represents the written standard of Tundra Nenets consisting of two types of texts namely recorded and imagined texts. The corpus contains more than 617,000 tokens originating from narratives and conversations. Chapter 4 has discussed the (content) questions from a typological perspective and has defined them as interrogative clauses that (i) require a specific answer other than 'Yes/No' and (ii) contain an interrogative phrase (cf. Dryer 2013a). In Chapter 5, the lexico-semantics of Tundra Nenets interrogative pro-forms, in particular their distinctive features, have been discussed. Two groups have been differentiated on the basis of the relation between interrogative forms and interrogative meanings: the major and the minor group. The major group contains lexicalised interrogative pro-forms which can only be analysed historically. In contrast, the minor group consists of interrogative pro-forms derived from the elements of the major group, so they are morphologically compound forms. It has also been demonstrated that some Tundra Nenets interrogative pro-forms display different meanings in different contexts. The central problem addressed in Chapter 6 is the parts-of-speech categories of these interrogative pro-forms. Within the frame of a grammatical analysis, interrogative words have been classified according to their morphological characteristics, their distribution and their syntactic function. In the morphological analysis, the inflectional features of interrogative pro-forms have only been considered. This analysis has shown that there are interrogative pronouns, determiners, adjectives, quantifiers and adverbs in Tundra Nenets, whose grammatical characteristics do not differ basically from the corresponding non-interrogative parts-of-speech categories. 
Finally, Chapter 7 identified the position of interrogative words in intransitive, transitive and nonverbal questions. 595 intransitive, 392 transitive and 507 nonverbal clauses of the corpus have been examined. On the basis of the data, the interrogative words typically occur in situ. The interrogative words occur in non-in situ position in $16.399 \%$ of the cases. Nevertheless, there is a remarkable difference in the ratio of non-in situ interrogative words if one examines the clause-types separately. $97.041 \%$ of the nonverbal clauses, for instance, appear in the expected order, while this ratio is $70.023 \%$ in intransitive questions and is $63.218 \%$ in transitive constructions. I have argued that the unexpected non-in situ structures can be due to three possible reasons. Firstly, the interrogative word may appear sentence initially rather than in its standard position. In these types of clauses, the interrogative word is usually complex and asks for an information, which is presumed to be salient both to the speaker and to the hearer. It can be interpreted as asking about an information which originates from a set of known or presupposed elements. Accordingly, the interrogative word is linked to the previous part of the discourse. This logical linkage has syntactic consequences on the sentences. Secondly, the different word order is the result of the special discourse role of one of the non-interrogative elements. In this case, the position of this non-interrogative element does not correspond to its usual syntactic function, for instance, the object appears sentence initially by preceding the interrogative subject. Finally, there are clauses in which the effect of the Russian language can be detected. As it has been shown, the change in word order is due to structural borrowing in these cases.

As pointed out, the Tundra Nenets dialects exhibit differences in formal and functional characteristics of certain interrogative words. On the one hand, differences were observed between the forms of the interrogative pronouns in the Central and Eastern dialects. Additionally, the forms of interrogative adverbs exhibiting place, time and manner readings also vary in the Tundra Nenets dialects. On the other hand, certain structures employ different grammatical characteristic in some dialects:

(i) the nouns seem to be ellipted from the phrase in the Ob/Ural of the Eastern dialectal group, in which case the case, person/number, etc. suffixes are attached to the interrogative modifier/adjective (see $\$ 5.2$ ).

(ii) in the Central and Western dialects, the noun and its interrogative modifier/complement show agreement in number. While this pattern is not attested in the Eastern dialect (see $\S 6.3$ ). 
(iii) there is also an internal agreement within the nonverbal predicate between the interrogative modifier and the predicate head in verbal person/number marking. This agreement is, however, observed in the Yamal subdialect in the Eastern dialectal group only (see. §7.3.1). 


\section{List of references}

Aikio, Ante 2002. New and old Samoyed etymologies. Finnisch-Ugrische Forschungen 57. 9-57.

Aikio, Ante 2006. New and Old Samoyed Etymologies (Part II). Finnisch-Ugrische Forschungen 59: 9-34.

Almazova A. V. (Алмазова, А. В.) 1961. Samouchitel nenetskogo yazyka (Самоучитель ненецкого языка) [Teach yourself Nenets]. Leningrad: Uchpedgiz

Andrews, Avery D. 2007. Relative clauses. In Timothy Shopen (ed.), Language Typology and Syntactic Description. vol. 2, Complex Constructions. 2nd edn., 206-236. Cambridge: Cambridge University Press.

Atkins, Sue \& Clear, Jeremy \& Ostler, Nicholas 1992. Corpus Design Criteria. Journal of Literary and Linguistic Computing. 7(1). 1-16.

Award, Jan 2001. Parts of speech. In Martin Haspelmath \& Ekkehard König \& Wulf Oesterreicher \& Wolfgang Raible (eds.), Language typology and language universals: An international handbook. vol. 1, 726-735. (Handbücher zur Sprach- und Kommunikationswissenschaft) Berlin: De Gruyter Mouton.

Barmich, Maria Ya. (Бармич, Мария Я.) 2007. Nenetskiy yazyk. Uchebnoe posobie dlya 8 klassa obshcheobrazovatelnikh uchrezhdeniy (Ненецкий язык. Учебное пособие для 8 класса общеобразовательных учреждений) [Nenets language. Textbook for 8th grade, public education]. Sankt-Peterburg: Prosveshchenie.

Barmich, Maria Ya. (Бармич, Мария Я.) 2008a. Nenetskiye skazki kn. 1. (Ненецкие сказки, кн. 1.) [Nenets tales vol. 1]. Sankt-Peterburg: Drofa.

Barmich, Maria Ya. (Бармич, Мария Я.) 2008b. Nenetskiye skazki kn. 2. (Ненецкие сказки, кн. 2.) [Nenets tales vol. 2]. Sankt-Peterburg: Drofa.

Barmich, Maria Ya. \& Nyaruy, Valentina N. (Бармич, Мария Я. \& Няруй, Валентина Н.) 2007. Nenetskiy yazyk. Uchebnoe posobie dlya 5 klassa obshcheobrazovatelnikh uchrezhdeniy (Ненецкий язык. Учебное пособие для 5 класса общеобразовательных учреждений) [Nenets language. Textbook for 5th grade, public education]. SanktPeterburg: Prosveshchenie.

Barmich, Maria Ya. \& Nyaruy, Valentina N. (Бармич, Мария Я. \& Няруй, Валентина Н.) 2008. Nenetskiy yazyk. Uchebnoe posobie dlya 6 klassa obshcheobrazovatelnikh uchrezhdeniy (Ненецкий язык. Учебное пособие для 6 класса общеобразовательных учреждений) [Nenets language. Textbook for 6th grade, public education]. SanktPeterburg: Prosveshchenie.

Barmich, Maria Ya. \& Nyaruy, Valentina N. (Бармич, Мария Я. \& Няруй, Валентина Н.) 2009. Nenetskiy yazyk. 7 klass. Uchebnoe posobie dlya obshcheobrazovatelnikh uchrezhdenikh uchrezh deniy (Ненецкий язык. 7 класс. Учебное пособие для общеобразовательных учреж дений) [Nenets language. Textbook for 7th grade, public education].Sankt-Peterburg: Prosveshchenie.

Bayer, Josef 2006. Wh-in-Situ In Martin Everaert \& Henk van Riemsdijk (eds.), The Blackwell Companion to Syntax. vol. 5, 376-438. Oxford: Blackwell.

Bergmann, Markus \& Lublinskaya, Marina \& Sherstinova, Tatiana 2002. The Russian-Nenets Audio Phrasebook. http://www.speech.nw.ru/Nenets/intro-eng.html (Accessed 2015-0601).

Biber, Douglas \& Conrad, Susan 2009. Register, Genre and Style. (Cambridge Textbooks in Linguistics). Cambridge: Cambridge University Press.

Burkova, Svetlana I. \& Koshkareva, Natalia B. \& Laptander, Roza I. \& Yangasova, N. M. (Буркова, Светлана И. \& Кошкарева, Наталья Б. \& Лаптандер, Роза И. \& Янгасова, 
H.M.) 2010. Dialektologicheskiy slovar nenetskogo yazyka (Диалектологический словарь ненецкого языка) [Dialectological dictionary of the Nenets language]. Ekaterinburg: Rossiyskaya Akademiya Nauk.

Cable, Seth 2010. The Grammar of Q: Q-Particles, Wh-Movement and Pied-Piping. Oxford: Oxford University Press.

Castrén, Matthias A. 1854. Grammatik der samojedischen Sprachen. Bearb. und hrsg. von A. Schiefner. St. Petersburg: Kaiserliche Akademie der Wissenschaften.

Cheng, Lisa 1991. On the typology of wh- questions. MIT. (Doctoral dissertation.)

Cysouw, Michael 2004. Interrogative words: an exercise in lexical typology. (Handout presented at the seminar Bantu Grammar: description and theory 3, session on question formation in Bantu, ZAS Berlin, 13 February 2004.)

Cysouw, Michael. 2005. The typology of content interrogatives. (Handout presented at the seminar 6th meeting of the Association for Linguistic Typology, Padang, Indonesia, 24 July 2005.) http://www.staff.unimarburg.de/ cysouw/presentations/index_files/cysouwALTINTER_handout.pdf (Accessed 2015-06-01).

Dahl, Östen 2004. The Growth and Maintenance of Linguistic Complexity. Amsterdam: Benjamins.

Dalrymple, Mary \& Nikolaeva, Irina 2011. Objects and Information Structure (Cambridge Studies in Linguistics 131). Cambridge: Cambridge University Press.

Davies, John 1981. Kobon (Lingua Descriptive Studies 3). Amsterdam: North-Holland Publishing Company.

Dayal, Veneeta 2006. Multiple-Wh-Questions. Martin Everaert \& Henk van Riemsdijk (eds.), The Blackwell Companion to Syntax. vol. 3, 275-326. Oxford: Blackwell.

Décsy Gyula 1966. Yurak chrestomathy (Uralic and Altaic Series 50). Bloomington: Indiana University Press

den Dikken, Marcel 2003. On the morphosyntax of wh-movement. In Cedric Boeckx \& Kleanthes K. Grohmann (eds.), Multiple wh-fronting, 77-98. Amsterdam: John Benjamins.

Diessel, Holger 2003. The relationship between demonstratives and interrogatives. Studies in Language 27(3). 635-655.

Dimitriadis, Alexis \& Musgrave, Simon 2009. Designing linguistic databases: A primer for linguists. In Martin Everaert \& Simon Musgrave \& Alexis Dimitriadis (eds.), The use of datbases in cross-linguistic studies. 13-75. Berlin: De Gruyter Mouton.

Dixon, Robert M. W. 2010a. Basic linguistic theory. vol. 1, Methodology. Oxford: Oxford University Press.

Dixon, Robert M. W. 2010b. Basic linguistic theory. vol.2, Grammatical Topics. Oxford: Oxford University Press.

Dixon, Robert M. W. 2012. Basic linguistic theory. vol. 3, Further Grammatical Topics. Oxford: Oxford University Press.

Dryer, Matthew S. 1991. SVO Languages and the OV/VO Typology. Journal of Linguistics 27(2). 443-482.

Dryer, Matthew S. 1998. Aspects of word order in the languages of Europe. In Anna Siewierska (ed.), Constituent Order in the Languages of Europe. 283-319. Berlin: De Gruyter Mouton.

Dryer, Matthew S. 2005. Polar Questions. In Martin Haspelmath \& Matthew S. Dryer \& David Gil \& Bernard Comrie (eds.), The World Atlas of Language Structures. 470-473. Oxford: Oxford University Press.

Dryer, Matthew S. 2007a. Word order. In Timothy Shopen (ed.), Language Typology and Syntactic Description. vol. 1, Clause Structure. 2nd edn., 61-131. Cambridge: Cambridge University Press. 
Dryer, Matthew S. 2007b. Clause types. In Timothy Shopen (ed.), Language Typology and Syntactic Description. vol. 1, Clause Structure. 2nd edn., 224-275. Cambridge: Cambridge University Press.

Dryer, Matthew S. 2013a. Position of Interrogative Phrases in Content Questions. In Matthew S. Dryer \& Martin Haspelmath (eds.), The World Atlas of Language Structures Online. Chapter 93. Munich: Max Planck Digital Library. http://wals.info/chapter/93 (Accessed 2015-06-01).

Dryer, Matthew S. 2013b. Polar Questions. In Dryer, Matthew S. \& Haspelmath, Martin (eds.) The World Atlas of Language Structures Online. Chapter 116. Munich: Max Planck Digital Library. http://wals.info/chapter/116 (Accessed 2015-06-01).

Dudeck, Stephan 2013. Challenging the State Educational System in Western Siberia: Taiga School by the Tiuitiakha River. In Erich Kasten \& Tjeerd de Graaf (eds.), Sustaining Indigenous Knowledge: Learning Tools and Community Initiatives for Preserving Endangered Languages and Local Cultural Heritage. 129-157. Fürstenberg/Havel: Kulturstiftung Sibirien.

Encyclopaedia Britannica. 1768-2014. Uralic languages. http://www.britannica.com/EBchecked/topic/619069/Uralic-languages/74940/OtherFinnic-languages (Accessed 2015-06-01).

É. Kiss Katalin 2002. The Syntax of Hungarian (Cambridge Syntax Guides). Cambridge: Cambridge University Press.

Foley, William A. 2007. A typology of information packaging in the clause. In Timothy Shopen (ed.), Language Typology and Syntactic Description. vol. 1, Clause Structure. 2nd edn., 362-446. Cambridge: Cambridge University Press.

Frawley, William 2002. Fundamental Issues in Lexical Semantics. In Alan D. Cruse \& Franz Hundsnurscher \& Michael Job \& Peter R. Lutzeier (eds.), Lexicology. An International Handbook on the Nature and Structure of Words and Vocabulaires, vol. 1, 228-236. Berlin: De Gruyter Mouton.

Freeze, Ray 1992. Existentials and other locatives. Language 68(3). 553-595.

Freeze, Ray 2001. Existential constructions. In Martin Haspelmath \& Ekkehard König \& Wulf Oesterreicher \& Wolfgang Raible (eds.), Language typology and language universals. 941-953. Berlin: De Gruyter Walter.

Greenberg, Joseph H. 1966. Some universals of grammar with particular reference to the order of meaningful elements. In Joseph H. Greenberg (ed.), Universals of Language, 2nd edn., 73-113. Cambridge: MIT Press.

Grinevald, Colette \& Bert, Michel 2011. Speakers and communities. In Peter K. Austin \& Julia Sallabank (eds.), The Cambridge Handbook of Endangered Languages. 45-65. Cambridge: Cambridge University Press.

Groenendijk, Jeroen \& Stokhof, Martin 1993. Interrogatives and Adverbs of Quantification. In Katalin Bimbó \& András Máté (eds.), Proceedings of the Fourth Symposium on Logic and Language. 1-29. Budapest: Aron Publishers.

Haan, Judith 2001. Speaking of questions: an exploration of Dutch question intonation. Utrecht: LOT.

Hajdú Péter 1966. Bevezetés az uráli nyelvtudományba; a magyar nyelv finnugor alapjai [Introduction to Uralic linguistics; The Finno-Ugric Basis of the Hungarian Language]. Budapest: Tankönyvkiadó.

Hajdú Péter 1968. Chrestomathia Samoiedica. Budapest: Tankönyvkiadó.

Haspelmath, Martin 2001. Word Classes and Parts of Speech. In Paul B. Baltes \& Neil J. Smelser (eds.), International Encyclopedia of the Social and Behavioral Sciences. 1653816545. Amsterdam: Pergamon 
Helimski, Eugen (Хелимский, Евгений) 1982. Drevneyshie vengersko-samodiyskie yazykovye paralleli. (Древнейшие венгерско-самодийские языковые параллели) [The oldest Hungarian-Samoyed language parallels]. Moskva (Doctoral dissertation.)

Helimski, Eugen 2001. Samoyedic studies: a state-of-the-art report. Finnisch-Ugrische Forschungen 56. 175-216.

Helimski, Eugen 2005. Geneologische und areale Verhältnisse der samojedischen Sprachen miteinander. (Handout from the lecture held at the University of Vienna.) http://www.unihamburg.de/onTEAM/grafik/1264671657/TABLE_-

_SAM_Genealogische_und_areale_Verhaeltnisse.pdf (Accessed 2015-06-01).

Himmelmann, Nikolaus P. 1998. Documentary and Descriptive Linguistics. Linguistics 36. 161-195.

Huddleston, Rodney 1994. The Contrast between Interrogatives and Questions. Journal of Linguistics 30(2). 411-439.

Hundt, Marianne 2008. Text corpora. In Anke Lüdeling \& Merja Kytö (eds.), Corpus Linguistics. An International Handbook, vol. 1, 168-187. (Handbooks of Linguistics and Communication Science). Berlin: De Gruyter Walter.

Idiatov, Dmitry \& van der Auwera, Johan 2004. On interrogative pro-verbs. In Ileana Comorovski \& Manfred Krifka (eds.), Proceedings of the Workshop on the Syntax, Semantics and Pragmatics of Questions, ESSLLI 16, August 9-13, 2004, Nancy, France, 17-23. Nancy: The European Association for Logic, Language and Information.

Idiatov, Dmitry 2007. A typology of non-selective interrogative pronominals. Antwerp: University of Antwerp (Doctoral dissertation.)

Jalava, Lotta 2012. Tempuksen ilmaiseminen tundranenetsin moduksissa [The expression of tense in Tundra Nenets moods]. In Tiina Hyytiäinen \& Lotta Jalava \& Janne Saarikivi \& Erika Sandman (eds.), Per Urales ad Orientem. 131-144. (Mémoires de la Société FinnoOugrienne 264). Helsinki: Suomalais-Ugrilainen Seura.

Janhunen, Juha 1977. Samojedischer Wortschatz. Gemeinsamojedische Etymologien (Castrenianumin toimitteita 17). Helsinki: Suomalais-Ugrilainen Seura.

Janhunen, Juha 1998. Samoyedic. In Daniel Abondolo (ed.), The Uralic Languages. 457-479. (Routledge Language Family Descriptions). London: Routledge.

Karttunen, Lauri 1977. Syntax and Semantics of Questions. Linguistics and Philosophy, 1: 3 44.

Kasten, Erich \& de Graaf, Tjeerd (eds.) 2013. Sustaining Indigenous Knowledge: Learning Tools and Community Initiatives for Preserving Endangered Languages and Local Cultural Heritage. Fürstenberg/Havel: Kulturstiftung Sibirien.

Kavitskaya, Darya \& Staroverov, Peter 2008. Opacity in Tundra Nenets. In Natasha Abner \& Jason Bishop (eds.), WCCFL 27: Proceedings of the 27th West Coast Conference on Formal Linguistics.

Khanina, Olesya 2007. Intransitive split in Tundra Nenets, or how much semantics can hide behind syntactic alignment? In Soeren Wichmann \& Mark Donohue (eds.), The Typology of Semantic Alignment Systems. 162-196. Oxford: Oxford University Press.

Khanzerova, Irina \& Haapalainen, Annikki \& Torikka-Gelensher, Ritva (Ханзерова, Ирина \& Хаапалайнен, Анникки \& Торикка-Геленшер, Ритва) 2012. Pogovorim / Lakhanava" / Sagastallat samtgilli / Puhutaan suomea (Поговорим / Лаханахава" / Sagastallat samtgilli / Puhutaan suomea) [Let's talk]. Narjan-Mar: ANO-Informatsionnoissledovatelskiy tsentr.

Køhler, Thomas \& Wessendorf, Kathrin (eds.) 2002. Towards a New Millennium: Ten Years of the Indigenous Movement in Russia. Moscow/Copenhagen: RAIPON - IWGIA. 
König, Ekkehard \& Siemund, Peter 2007. Speech act distinctions in grammar. In Timothy Shopen (ed.), Language Typology and Syntactic Description. vol. 1, Clause Structure. 2nd edn., 276-324. Cambridge: Cambridge University Press.

Körtvély, Erika 2005. Verb conjugation in Tundra Nenets (Studia Uralo-Altaica 46). Szeged: SzTE Finnugor Tanszék.

Kupriyanova Z. N. \& Khomich, Lyudmila V. \& Scherbakova, A. M. (Куприянова, 3. H. \& Хомич, Людмила В. \& Щербакова, А. М.) 1957. Nenetskiy yazyk. Uchebnoe posobie dlya pedagogicheskikh uchilishch (Ненецкий язык. Учебное пособие для педагогических училищ) [Nenets language. Textbook for teacher training colleges]. Leningrad: Prosveshchenie.

Labanauskas, Kazys I. (Лабанаускас, Казис И.) 1995. Nenetskiy folklor: Mifi, skazki, istoricheskie predaniya (Ненецкий фольклор: Мифы, сказки, исторические предания) [Nenets folklore: myths, fairy tales, historical legends].Krasnoyarsk: Krasnoyarskoe knizhnoe izdatelstvo.

Labanauskas, Kazys I. (Лабанаускас, Казис И.) 2001. Yamidikhy” lakhanaku”- Skazy sedoy stariny: Nenetskaya folklornaya kherstomatiya (Ямидхы“ лаханаку“ - Сказы седой старины: Ненецкая фольклорная хрестоматия) [Yamidikhy” lakhanaku” - Ancient tales: Nenets folklore anthology]. Moskva: Izdatelstvo Russkaya literatura.

Laptander, Roza 2013. Model for the Tundra School in Yamal: a New Education System for Children from Nomadic and Semi-nomadic Nenets Families. In Erich Kasten \& Tjeerd de Graaf (eds.), Sustaining Indigenous Knowledge: Learning Tools and Community Initiatives for Preserving Endangered Languages and Local Cultural Heritage. 181-194. Fürstenberg/Havel: Kulturstiftung Sibirien.

Lar, Leonid A. \& Pushkareva, Elena T. (Лар, Леонид А. \& Пушкарёва, Елена Т.) 2001. Mifi i predaniya nentsev Yamala (Мифы и предания ненцев Ямала) [Yamal Nenets myths and legends]. Tyumen: Izdatelstvo Instituta problem osvoeniya Severa SO RAN.

Lehtisalo, Toivo 1947. Juraksamojedische Volksdichtung (Suomalais-Ugrilaisen Seuran toimituksia 90). Helsinki: Suomalais-Ugrilainen Seura.

Lehtisalo, Toivo 1956. Juraksamojedisches Wörterbuch (Lexica Societatis Fenno-Ugricae 13). Helsinki: Suomalais-Ugrilainen Seura.

Lehtisalo, Toivo (ed). 1960. Samojedische Sprachmaterialien (Gesammelt von M. A. Castrén und T. Lehtisalo) (Suomalais-Ugrilaisen Seuran toimituksia 122). Helsinki, SuomalaisUgrilainen Seura.

Liarskaya, Elena V. 2009. Settlement Nenets on the Yamal Peninsula: Who Are They? Electronic Journal of Folklore $41 . \quad 33-46$. http://www.folklore.ee/folklore/vol41/liarskaya.pdf (Accessed 2015-06-01).

Liarskaya, Elena V. 2010. Women and the Tundra: Is There a Gender Shift on Yamal? Anthropology of East Europe Review 28(2). 51-84.

Lindström, Eva 1995. Animacy in interrogative pronouns. In: Inger Moen \& Hanne Gram Simonsen \& Helge Lødrup (eds.), Papers from the 15th Scandinavian Conference of Linguistics, 307-15. Oslo: University of Oslo.

Mackanzie, J. Lachlan 2008. Content interrogatives in a sample of 50 languages. Lingua 119. 1131-1163.

Miestamo, Matti 2005. Standard Negation. The Negation of Declarative Verbal Main Clauses in a Typological Perspective (Empirical Approaches to Language Typology 31). Berlin: De Gruyter Mouton.

Miestamo, Matti 2007. Symmetric and asymmetric encoding of functional domains with remarks on typological markedness. In Matti Miestamo \& Bernhard Wälchli (eds.), New challenges in typology: Broadening the horizons and redefining the foundations (Trends in Linguistics. Studies and Monographs 189). 293-314. Berlin: De Gruyter Mouton. 
Miestamo, Matti 2011. Polar interrogatives in Uralic languages. A typological perspective. Linguistica Uralica 47(1). 1-21.

Miestamo, Matti \& Tamm, Anne \& Wagner-Nagy, Beáta (in Press) Negation in Uralic Languages. Amsterdam: Benjamins.

Mikola Tibor 1988. Geschichte der samojedischen Sprachen. In Denis Sinor (ed.), The Uralic languages: description, history and foreign influences (Handbuch der Orientalistik 8: Handbook of Uralic studies 1). 219-263. Leiden: E. J. Brill.

Mikola Tibor 2004. Studien zur Geschichte der samojedischen Sprachen (Aus dem Nachlass herausgegeben von Beáta Wagner-Nagy) (Studia Uralo-Altaica 45). Szeged: SzTE Finnugor Tanszék.

Mus Nikolett 2013. The Typology of the Northern Samoyedic Question Words. FinnischUgrische Mitteilungen. 37. 175-195.

Mus Nikolett 2015. Negation in Nenets. In Miestamo, Matti \& Tamm, Anne \& Wagner-Nagy, Beáta Negation in Uralic Languages. Amsterdam: Benjamins. 75-102.

Nenyang, Mikhail А. (Ненанг, Михаил А.) 2005. Russko-nenetskiy razgovornik (Руссконенецкий разговорник) [Russian-Nenets Phrasebook]. Sankt-Peterburg: Drofa.

Nenyang, Mikhail A. (Ненянг, Михаил А.) 2007. Na urokakh nenetskogo yazyka (На уроках ненецкого языка) [For Nenets language class].Sankt-Peterburg: Prosveshchenie.

Nikolaeva, Irina 2001. The Hungarian external possessor in a European perspective. In Cornelius Hasselblatt \& Rogier Blokland (eds.), Finno-Ugrians and Indo-Europeans: Linguistic and literary contacts. Proceedings of the Symposium at the University of Groningen, November 22-24, 2001. 272-285. (Studia Fenno-Ugrica Groningana 2). Maastricht: Shaker.

Nikolaeva, Irina 2003. The Structure of the Tundra Nenets Noun Phrase. In Marianne BakróNagy \& Károly Rédei (eds.), Ünnepi kötet Honti László tiszteletére. 315-327.

Nikolaeva, Irina 2005a. Modifier-Head Person Concord. In Geert Booij \& Emiliano Guevara \& Angela Ralli \& Salvatore Sgroi \& Sergio Scalise (eds.), Morphology and Linguistics Typology. On-line Proceedings of the Fourth Mediterranean Morphology Meeting (MMM4) Catania, 21-23 September 2003. Universitá degli Studi di Bologna. 221-234. http://morbo.lingue.unibo.it/mmm/mmm-proc/MMM4/MMM4-Proceedings-full.pdf (Accessed 2015-06-01).

Nikolaeva, Irina 2005b. Agreement and linguistic construal. In Jocelyn Fernandez-Vest (ed.), Uralic languages today. A linguistic and cognitive approach. 533-546. (Bibliothèque de l'Ecole des Hautes Etudes 340). Paris: Librairie Honoré Champion.

Nikolaeva, Irina 2012. Periphrasis in Tundra Nenets. In Marina Chumakina \& Greville Corbett (eds.), Periphrasis: the role of syntax and morphology in the paradigms (Proceedings of the British Academy 180). Oxford: British Academy and Oxford University Press.

Nikolaeva, Irina 2014. A Grammar of Tundra Nenets. Berlin: Mouton de Gruyter.

Noonan, Michael 2007. Complementation. In Timothy Shopen (ed.), Language Typology and Syntactic Description. vol. 2, Complex Constructions. 2nd edn., 52-150. Cambridge: Cambridge University Press.

Okotetto, Elena N. (Окотэтто, Елена Н.) 1998. Nenetskiy yazyk v detskom sadu (Ненецкий язык в детском саду) [Nenets language for pre-schools]. Sankt-Peterburg: Prosveshchenie.

Orlova Tatiana, N. \& Barmich, Maria Ya. \& Borisenko, A. V. (Орлова, Татьяна Н. \& Бармич, Мария Я. \& Борисенко, А. В.) 1996. Kovyor-tirtya ngano: lutsa' wadako”. Kover-samolet: russkie narodnye skazki (Ковёр-тиртя нано: луца' вадако". Коверсамолет: русскиэ народныэ сказки) [Flying carpet: Russian folk tales].Sankt-Peterburg: Alfavit. 
Pakendorf, Brigitte 2010. Contact and Siberian Languages. In Raymond Hickey (ed.), The Handbook of Language Contact. 714-737. Malden/ Mass: Wiley-Blackwell.

Pallas Peter S. (Паллас Петер C.) 1787. Sravnitelnie slovari vsekh yazykov i narechiy, sobrannie desnitseyu vsevysochayshey osobi. Chast pervaya. (Сравнительные словари всех языков и наречий, собранные десницею всевысочайшей особы. Часть перьвая) [Comparative dictionaires of all languages and dialects compiled with the encouragement of the empress. vol. 1].Sankt-Peterburg.

Pallas Peter S. (Паллас Петер С.) 1789. Sravnitelnie slovari vsekh yazykov i narechiy, sobrannie desnitseyu vsevysochayshey osobi. Chast vtoraya. (Сравнительные словари всех языков и наречий, собранные десницею всевысочайшей особы. Часть вторая) [Comparative dictionaires of all languages and dialects compiled with the encouragement of the empress. vol. 2]. Sankt-Peterburg.

Payne,Thomas E. 1997. Describing morphosyntax. Cambridge: Cambridge University Press.

Popova, Ya. N. (Попова, Я. Н.) 1978. Foneticheskie osobennosti lesnogo narechiya nenetskogo yazyka (Фонетические особенности лесного наречия ненецкого языка) [The phonetic features of the forest dialect of Nenets language]. Moskva: Nauka.

Prokofyev, Georgy N. (Прокофьев, Георгий Н.) 1936. Samouchitel nenetskogo yazyka (Самоучитель ненэцкого языка) [Teach yourself Nenets]. Moskva/Leningrad: Uchpedgiz.

Pushkareva, Elena Т. (Пушкарёва, Елена Т.) 2003. Istoricheskaya tipologiya i etnicheskaya spetsifika nenetskikh mifov-skazok (Историческая типология и этническая специфика ненецких мифов-сказок) [Historical typology and ethnic specificity of Nenets mythstales]. Moskva: Mysl.

Pushkareva, Elena T. \& Lapsuy, Anastasia T. \& Yangasova, N. M. \& Bogdanov, I. A. (Пушкарёва, Елена Т. \& Лапсуй, Анастасия Т. \& Янгасова, Н. М. \& Богданов, И. А.) 1994. Malenkiy slushatel: khrestomatiya dlya detskikh doshkolnykh uchpezhdeniy (Маленький слушатель: хрестоматия для детских дошкольных учреждений) [A small listener: chrestomathy for pre-schools].Sankt-Peterburg: Prosveshchenie.

Pushkareva, Elena T. \& Khomich, Lyudmila (Пушкарёва, Елена T. \& Хомич Людмила В.) 2001. Folklor nentsev (Фольклор ненцев) [Nenets folklore]. Novosibirsk: Nauka.

Rozhin, А. I. (Рожин, А. И.) 1954. Nenetsa' vada (Ненэця' вада) [Nenets word]. Leningrad: Pedagogicheskoe Izdatelstvo.

Sadock, Jerrold M. \& Zwicky, Arnold M. 1985. Speech act distinctions in syntax. In Timothy Shopen (ed.), Language Typology and Syntactic Description. vol. 1, Clause structure. 155196. Cambridge: Cambridge University Press.

Salminen, Tapani 1993. On identifying basic vowel distinctions in Tundra Nenets. FinnischUgrische Forschungen 51. 177-187.

Salminen, Tapani 1998. Nenets. In Daniel Abondolo (ed.), The Uralic Languages. 516-547. London: Routledge.

Sammallahti, Pekka 1974. Material from Forest Nenets (Castrenianumin toimitteita, 2). Helsinki: Suomalais-Ugrilainen Seura.

Samoylova, Elena N. \& Barmich Maria Ya. (Самойлова Елена Н. \& Бармич, Мария Я.) 2008. Chitaem sami (Читаем сами) [Read it yourself].Sankt-Peterburg: Prosveshchenie.

Samoylova, Elena N. \& Barmich Maria Yа. (Самойлова Елена Н. \& Бармич, Мария Я.) 2010. Rodnoe slovo (Родное слово) [Indigenous word]. Sankt-Peterburg: Prosveshchenie.

Sasse, Hans-Jürgen 1993. Syntactic Categories and Subcategories. In Joachim Jacobs \& Arnim von Stechow \& Wolfgang Sternefeld \& Theo Vennemann (eds.), Syntax: Ein internationales Hanbuch zeitgenössischer Forschung. vol. 1, 646-685. Berlin: De Gruyter Mouton. 
Schachter, Paul \& Shopen, Timothy 2007. Parts-of-speech systems. In Timothy Shopen (ed.), Language Typology and Syntactic Description. vol. 1, Clause Structure. 2nd edn., 1-60. Cambridge: Cambridge University Press.

Schneider, Edgar W. 2002. Investigating Variation and Change in Written Documents. In J. K. Chambers \& Peter Trudgill \& Natalie Schilling-Estes (eds.), The Handbook of Language Variation and Change. 67-96. Oxford: Blackwell Publishing.

Siemund, Peter 2001. Interrogative constructions. In Martin Haspelmath \& Ekkehard König \& Wulf Oesterreicher \& Wolfgang Raible (eds.), Language typology and language universals. 1010-1028. Berlin: De Gruyter Walter.

Siewierska, Anna 1993. On the interplay of factors in the determination of word order. In Joachim Jacobs \& Arnim Von Stechow \& Wolfgang Sternefeld (eds.), Syntax: An International Handbook of Contemporary Research. 826-846, Berlin: De Gruyter Walter.

Stammler, Florian 2005. Reindeer Nomads Meet the Market: Culture, Property and Globalisation at the End of the Land (Halle Studies in the Anthropology of Eurasia 6). Muenster: Litverlag.

Stassen, Leon. 2001. Predicative Possession. In Martin Haspelmath \& Ekkehard König \& Wulf Oesterreicher \& Wolfgang Raible (eds.), Language typology and language universals. 954-960. Berlin: De Gruyter Walter.

Stassen, Leon 2013a. Predicative Possession. In Matthew S. Dryer \& Martin Haspelmath (eds.), The World Atlas of Language Structures Online. Chapter 117. Leipzig: Max Planck Institute for Evolutionary Anthropology. http://wals.info/chapter/117 (Accessed 2015-06$01)$.

Stassen, Leon 2013b. Predicative Adjectives. In Matthew S. Dryer \& Martin Haspelmath (eds.), The World Atlas of Language Structures Online. Chapter 118. Leipzig: Max Planck Institute for Evolutionary Anthropology. http://wals.info/chapter/118 (Accessed 2015-0601).)

Stassen, Leon 2013c. Nominal and Locational Predication. In Matthew S. Dryer \& Martin Haspelmath (eds.), The World Atlas of Language Structures Online. Chapter 119. Leipzig: Max Planck Institute for Evolutionary Anthropology. http://wals.info/chapter/119 (Accessed 2015-06-01).

Stassen, Leon 2013d. Zero Copula for Predicate Nominals. In Matthew S. Dryer \& Martin Haspelmath (eds.), The World Atlas of Language Structures Online. Chapter 120. Leipzig: Max Planck Institute for Evolutionary Anthropology. http://wals.info/chapter/120 (Accessed 2015-06-01).

Staroverov, Peter 2006. Vowel deletion and stress in Tundra Nenets In Beáta Gyuris (ed.), Proceedings of the first Central European Student Conference in Linguistics. http://www.nytud.hu/cescl/proceedings.html (Accessed 2015-06-01).

Stump, Gregory T. 1998. Inflection. In Andrew Spencer \& Arnold M. Zwicky (eds.), The Handbook of Morphology. 13-43. Oxford: Blackwell.

Susoy, Elena G. (Сусой, Елена Г) 1990. Nenetskaya literatura (Ненецкая лтература) [Nenets literature]. Leningrad: Prosveshchenie.

Tereshchenko, Natalia М. (Терещенко, Наталия М.) 1947. Ocherk grammatiki nenetskogo (yurako-samoedskogo) yazyka (Очерк грамматики ненецкого (юрако-самоедского) языка) [Nenets (Yurak Samoyed) grammatical sketch]. Leningrad: Gosudarstvennoe uchebno-pedagogicheskoe izdatelstvo.

Tereshchenko, Natalia М. (Терещенко, Наталия М.) 1956. Materiali i issledovaniya po yazyku nentsev (Материали и исследования по языку ненцев) [Materials and studies on Nenets language]. Moskva/Leningrad: Izdatelstvo Akademii Nauk. 
Tereshchenko, Natalia M. (Терещенко, Наталия М.) 1965. Nenetsko-russkiy slovar (Ненецко-русский словарь) [Nenets-Russian dictionary]. Moskva: Sovetskaya Enciklopediya.

Tereshchenko, Natalia M. (Терещенко, Наталия М.) 1973. Sintaksis samodiyskikh yazykov (Синтаксис самодийских языков) [The syntax of Samoyedic languages]. Leningrad: Nauka.

Tereshchenko, Natalia M. (Терещенко, Наталия М.) 1993. Nenetskiy yazyk (Ненецкий язык) [The Nenets language]. In Ю. С. Елисеев \& К. Е. Майтинская (От. ред.), Языки мира: Уральские языки. 326-343. Moskva: Nauka.

Tereshchenko, Natalia M. \& Susoy, Elena G. (Терещенко, Наталия M. \& Сусой, Елена Г.) 1995. Nenetskiy yazyk (Ненецкий язык) [The Nenets language]. Sankt-Peterburg: Prosveshchenie.

The Leipzig Glossing Rules. http://www.eva.mpg.de/lingua/pdf/LGR08.02.05.pdf (Accessed 2015-06-01).

Toulouze, Eva 1999. The Development of a Written Culture by the Indigenous Peoples of Western Siberia. Arctic Studies 2 (Pro Ethnologia 7). 53-85.

Ultan, Russell 1978. Some general characteristics of interrogative systems. In Joseph H. Greenberg (ed.), Universals of Human Language. vol. 4, Syntax. 211-48. Stanford: Stanford University Press.

Vanuyto Galina, I. (Вануйто, Галина И.) 2012. Russko-nenetskiy razgovornik (Руссконенецкий разговорник) [Russian-Nenets phrasebook]. Moskva: Ventana-Graf.

Velupillai, Viveka 2012. An introduction to linguistic typology. Amsterdam: John Benjamins.

Verbov, Grigoriy D. (Вербов, Григорий Д.) 1973. Dialekt lesnikh nentsev (Диалект лесных ненцев) [The Forest Nenets dialect]. (Samodiyskiy sbornik) Novosibirsk.

Volzhanina, Elena A. 2007. The Forest Nenets: Habitat and population size in the 20th century, and the present demographic situation. Archaeology, Ethnology and Anthropology of Eurasia 30(2). 143-154.

Volzhanina, Elena A. 2013. The nomadic way of life and the preservation of the native language among Nenetses of the Yamal at the turn of the 21st century. Finnisch-Ugrische Mitteilungen 37. 195-240.

Wagner-Nagy, Beáta 2011. On the Typology of Negation in Ob-Ugric and Samoyedic Languages (Mémoires de la Société Finno-Ougrienne 262). Helsinki: SuomalaisUgrilainen Seura.

Wagner-Nagy, Beáta \& Viola, Márta Sarolta 2009. Typology of affirmative and negative nonverbal predicates in the Ugric and Samoyedic languages. Finnisch Ugrische Forschungen 60. 117-159.

Yangasova, N. M. (Янгасова, Н. М.) 2001. Nenetskie" skazki i epicheskie pesni syudbabts", yarabts" (Ненэцкие" сказки и эпические песни сюдбабц", ярабц") [Nenets tales and epic songs syudbabts", yarabts"]. Tomsk: Izdatelstvo Tomskogo Universiteta.

Ziker, John P. 2010. Changing Gender Roles and Economies in Taimyr. Anthropology of East Europe Review 28(2). 102-119. 